\title{
Herramientas alternativas para el procesamiento y análisis de señales microsísmicas
}

\author{
Geof. Soledad Rocio Lagos \\ Director: Dr. Danilo Rubén Velis
}

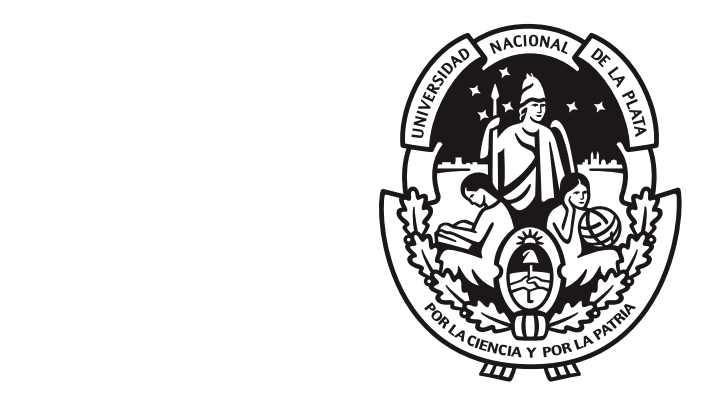

Facultad de Ciencias Astronómicas y Geofísicas Universidad Nacional de La Plata

Tesis presentada para optar por el grado de

Doctora en Geofísica

Abril 2019 



\title{
Herramientas alternativas para el procesamiento y análisis de señales microsísmicas
}

\author{
Tesis presentada en cumplimiento de los requisitos \\ para obtener el grado de \\ Doctora en Geofísica \\ por \\ Soledad Rocio Lagos \\ en la \\ Facultad de Ciencias Astronómicas y Geofísicas \\ Universidad Nacional de La Plata
}

Director: Danilo Rubén Velis

Jurado: Dra. Patricia Gauzellino, Universidad Nacional de La Plata

Dra. Silvina Nacif, Universidad Nacional de San Juan

Dr. Mauricio Sacchi, University of Alberta

Facultad de Ciencias Astronómicas y Geofísicas

Universidad Nacional de La Plata

Paseo del Bosque s/n

La Plata (1900)

Argentina

Abril 2019 



\section{Agradecimientos}

A los que me acompañan cada día, quienes sin saberlo ni quererlo fueron el motor de este proceso.

Al jurado de esta Tesis, por el tiempo dedicado a la lectura de este trabajo y por cada uno de sus comentarios y sugerencias.

A mis compañeros y amigos de Geofísica Aplicada, que llenaron este camino de buenos momentos.

A la Facultad de Ciencias Astronómicas y Geofísicas de la Universidad Nacional de La Plata.

Al Consejo Nacional de Investigaciones Científicas y Técnicas.

A la educación pública argentina. 



\section{Resumen}

El procesamiento de las señales microsísmicas registradas durante procesos de fracturación hidráulica tiene como principales objetivos contribuir a aumentar la eficiencia de éstos en términos de producción de hidrocarburos y su control frente a los posibles riesgos asociados. En ese contexto, resulta necesario contar con estrategias de procesamiento de señales confiables y eficientes que permitan llevar a cabo o supervisar estas tareas. En esta Tesis se presenta un conjunto de métodos para el tratamiento de la información microsísmica, especialmente en escenarios de monitoreo de pozo, que representa la geometría de adquisición empleada en la mayoría de los casos. En primer lugar, se presentan herramientas de preacondicionamiento de las señales que consisten en la orientación de los sensores de pozo aprovechando la energía de las mismas, y en la calibración del modelo de velocidades a partir de la información de pozo disponible asumiendo medios anisótropos. Luego, se presentan modificaciones realizadas a herramientas preexistentes para la detección de eventos microsísmicos y la determinación de tiempos de arribo. En particular, se detallan las adaptaciones propuestas con el fin de identificar automáticamente las distintas fases asociadas a un evento y realizar estimaciones confiables de la dirección de procedencia de la energía. Por otra parte, se describe el enfoque adoptado para llevar a cabo la estimación de las coordenadas espacio-temporales de los eventos microsísmicos registrados. Por último, se presenta un método para la estimación de magnitudes momento de eventos microsísmicos por medio del ajuste de modelos a los espectros de amplitud de los stacks de todas las fases disponibles. Varios de los métodos mencionados son planteados como problemas de optimización que, dado su carácter no lineal y la complejidad de las ecuaciones que los caracterizan, se resuelven por medio de los algoritmos de optimización globales Very Fast Simulated Annealing y Particle Swarm Optimization. Todas las herramientas presentadas fueron adaptadas o diseñadas e implementadas computacionalmente mediante códigos en lenguaje Fortran. Además, han sido utilizadas en datos de campo registrados durante procesos de fracturación hidráulica llevados a cabo en la República Argentina y constituyen métodos útiles para el procesamiento de datos microsísmicos de pozo o la supervisión y evaluación de resultados de terceros. 



\section{Índice general}

1. Introducción 1

1.1. Reservorios de hidrocarburos convencionales y no convencionales . . . . 1

1.2. Fracturación hidráulica . . . . . . . . . . . . . . . 6

1.3. Monitoreo microsísmico . . . . . . . . . . . . . . . . . . 8

1.4. Motivación y objetivos . . . . . . . . . . . . . . . . . . . . . . . . . . . . . .

1.5. Organización de la Tesis . . . . . . . . . . . . . . . . 11

2. Algoritmos de optimización $\quad \mathbf{1 5}$

2.1. Introducción . . . . . . . . . . . . . . . . . . . 15

2.2. Simulated annealing $(\mathrm{SA}) \ldots \ldots \ldots \ldots$

2.2.1. Very fast simulated annealing (VFSA) . . . . . . . . . . . 19

2.3. Particle swarm optimization (PSO) . . . . . . . . . . . . . . . . . . 20

2.3.1. Calibración del algoritmo PSO . . . . . . . . . . . . . . . . 22

2.4. Conclusiones . . . . . . . . . . . . . . . . . . . 26

$\begin{array}{llr}\text { 3. Pre-procesamiento } & 29\end{array}$

3.1. Introducción . . . . . . . . . . . . . . . . . . . . 29

3.2. Orientación de sensores de pozo . . . . . . . . . . . . . . . . . . 31

3.2.1. Metodología . . . . . . . . . . . . . . . 32

3.2.2. Ejemplo sintético . . . . . . . . . . . . . . . 35

3.2.3. Ejemplo con datos de campo . . . . . . . . . . . . . . . . . 36

3.3. Calibración de modelos de velocidades . . . . . . . . . . . . . . . 44

3.3.1. Fundamentos teóricos . . . . . . . . . . . . . . . . 45

3.3.2. Planteo del problema inverso . . . . . . . . . . . . . . . 46

3.3.3. Ejemplo con datos de la Formación Vaca Muerta . . . . . . . . 48

3.4. Conclusiones . . . . . . . . . . . . . . . . . . . 53

4. Detección de eventos, picado de tiempos de arribo y estimación de backazimuths

4.1. Introducción . . . . . . . . . . . . . . . . . . . . . 55

4.2. Detección de eventos microsísmicos . . . . . . . . . . . . 56

4.2.1. Detección de eventos por medio del picado automático de fases . 57

4.2.2. Detección de eventos con identificación automática de ondas P y S 58

4.3. Picado de tiempos de arribo . . . . . . . . . . . . . . . . . 65 
4.3.1. Picado de tiempos de arribo por métodos STA/LTA . . . . . . . 65

4.3.2. Detección y picado de tiempos de arribo por reconocimiento de

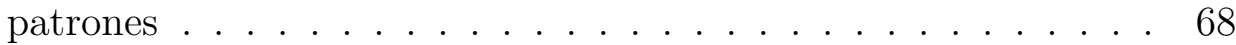

4.4. Análisis de polarización . . . . . . . . . . . . . . . . . . . 71

4.4.1. Estimación de la dirección de polarización por análisis de hodograma . . . . . . . . . . . . . . . . . 71

4.4.2. Estimación de la dirección de polarización por diagonalización de la matriz de varianza-covarianza de los datos . . . . . . . . . 73

4.4.3. Estimación de la dirección de polarización basada en la energía . 73

4.4.4. Estimación del backazimuth a partir de la onda S . . . . . . . . 74

4.4.5. Estimación simultánea de backazimuths y tiempos de arribo . . 76

4.4.6. Incertidumbres en la estimación del backazimuth . . . . . . . . . 81

4.5. Conclusiones . . . . . . . . . . . . . . . . . 86

5. Localización de eventos microsísmicos $\quad 87$

5.1. Introducción . . . . . . . . . . . . . . . . . . . 87

5.2. Secuencia automática de procesamiento en datos sintéticos . . . . . . 88

5.2.1. Métodos involucrados . . . . . . . . . . . . . . . . . 89

5.2.2. Resultados ..................... . . 94

5.3. Localización con datos de campo . . . . . . . . . . . . . . . 100

5.3.1. Tiempos de arribo . . . . . . . . . . . . . . . 100

5.3.2. Función de costo . . . . . . . . . . . . . . . . . . 102

5.3.3. Resultados . . . . . . . . . . . . . . . . . . . 107

5.3.4. Incertidumbres en la localización . . . . . . . . . . . . 112

5.4. Conclusiones . . . . . . . . . . . . . . . . . . . . 119

6. Estimación de magnitudes momento 121

6.1. Introducción . . . . . . . . . . . . . . . . . . . . . 121

6.2. Fundamentos teóricos . . . . . . . . . . . . . . . . . . . 122

6.2.1. Desplazamientos en campo lejano, momento sísmico y magnitud momento . . . . . . . . . . . . . . . . 122

6.2.2. Modelado del espectro de amplitud . . . . . . . . . . . . . 125

6.2.3. Combinación de la información: Stack . . . . . . . . . . . 125

6.2.4. Problema de optimización . . . . . . . . . . . . . 126

6.3. Ejemplos . . . . . . . . . . . . . . . . . 127

6.3.1. Ejemplo pseudo-sintético . . . . . . . . . . . . . . 127

6.3.2. Ejemplo con datos de campo . . . . . . . . . . . . . . . . . . . 130

6.4. Estimación de magnitudes momento en datos de campo . . . . . . . . . 134

6.4.1. Estimación conjunta de $\Omega_{0}^{P}, \Omega_{0}^{S}$ y $f_{c} \ldots \ldots \ldots$. . . . . . . 134

6.4.2. Resultados . . . . . . . . . . . . . . . . . . . . . . . . . . . . . . . . . . . . .

6.5. Discusión . . . . . . . . . . . . . . . 136

6.6. Conclusiones . . . . . . . . . . . . . . . . . . 138 
7. Conclusiones $\quad 139$

7.1. Contribuciones científicas . . . . . . . . . . . . . . . . . . . 142

7.2. Contribuciones tecnológicas y desarrollos . . . . . . . . . . . . . 143

$\begin{array}{ll}\text { A. Trazado de rayos } & 145\end{array}$

$\begin{array}{ll}\text { B. Simulación de registros sintéticos } & 151\end{array}$

$\begin{array}{ll}\text { Bibliografía } & 155\end{array}$ 



\section{Capítulo 1}

\section{Introducción}

\subsection{Reservorios de hidrocarburos convencionales y no convencionales}

La utilización de derivados del petróleo por parte del ser humano es tan antigua como el surgimiento de la civilización (Downey, 2009; Maugeri, 2006). En la antigua Mesopotamia, alrededor del 4000 a.C., el petróleo era utilizado para impermeabilizar botes o como adhesivo para las construcciones. En China, alrededor del 1000 a.C., ya se empleaba para generar luz y calor, mientras que en el 600 d.C. se empleaba como arma en el "fuego griego" del imperio bizantino. Incluso se han encontrado herramientas paleolíticas en Siria con trazas de bitumen que prueban que los hidrocarburos ya eran empleados por el hombre de Neandertal (Boëda et al., 2008). A lo largo de la historia, se utilizaron los hidrocarburos disponibles en superficie o cercanos a ella, que en general alcanzaron profundidades someras gracias a filtraciones desde rocas profundas.

La explotación de hidrocarburos como la conocemos hoy, caracterizada por la extracción de petróleo y gas mediante la perforación de pozos, tuvo su inicio a mediados del Siglo XIX. Esta actividad se desarrolló en torno a los denominados sistemas petroleros convencionales. El advenimiento de este concepto y la caracterización de sus componentes tuvo lugar principalmente durante las primeras décadas de esta era (Bjørlykke, 2010; Selley, 1998). En sus inicios, la exploración petrolera consistía en la búsqueda de hidrocarburos expuestos en superficie y la perforación de pozos en las inmediaciones de estas filtraciones. Con el tiempo se observó que las acumulaciones de petróleo y gas se asociaban comúnmente a estructuras geológicas de similares características, principalmente vinculadas a domos salinos o anticlinales. El mapeo geológico y la delimitación de este tipo de estructuras se transformó en la regla básica de la prospección.

En Argentina, mientras comenzaba la explotación de hidrocarburos por parte de las potencias globales, hubo diversos intentos para iniciar la producción entre mediados y fines del Siglo XIX a partir de evidencias superficiales de la presencia del mismo. Las dificultades logísticas, la falta de recursos humanos capacitados y la no existencia de un mercado local hacia el cual volcar la producción fueron algunas de las razones 
que truncaron esos primeros intentos (Gadano, 2006). Finalmente, la explotación de petróleo en nuestro país, precursora de la actividad actual, comenzó en el año 1907 con el hallazgo de hidrocarburos en un pozo exploratorio de $539 \mathrm{~m}$ de profundidad en Comodoro Rivadavia.

Para que la producción de petróleo y gas convencionales sea posible y económicamente rentable, deben darse un conjunto de elementos y procesos que determinan la existencia de un sistema petrolero. En primer lugar, una roca madre, en general de tipo sedimentario, en la que en algún momento de la historia geológica tuvo lugar la acumulación de grandes cantidades de materia orgánica en condiciones que impidan su degradación, es decir, en ambientes de depositación tranquilos y anóxicos. Esta roca debe ser luego sometida a condiciones de presión y temperatura tales que permitan la maduración de la materia orgánica, proceso que consiste en su transformación en hidrocarburos. Esto es alcanzado gracias al soterramiento de la roca, que tiene lugar al depositarse nuevas rocas por encima de la roca madre. La migración consiste en la expulsión de parte del hidrocarburo maduro de la roca madre y su movimiento hasta una roca reservorio caracterizada por una importante porosidad que pueda albergar al fluido y una permeabilidad que permita su movimiento para la producción. La conservación del hidrocarburo en la roca reservorio depende de la presencia de una roca sello, impermeable, que detenga la migración y permita la acumulación. Es necesaria, además, una disposición geométrica de las rocas reservorio y sello que garanticen la preservación del hidrocarburo en una porción limitada del espacio hasta el día de hoy, lo que se conoce como trampa. Por último, pero no menos importante, la depositación de las distintas rocas que participan en la conformación de los elementos del sistema petrolero y la ocurrencia de los diferentes procesos deben seguir un orden cronológico. En otras palabras, la sincronización o el timing de los distintos elementos y procesos es fundamental para la existencia de un sistema petrolero.

La extracción de hidrocarburos convencionales se realiza generalmente mediante pozos verticales. Se aprovecha la presión natural del reservorio y la alta permeabilidad de las rocas del mismo para que el recurso fluya hacia el pozo y luego hacia la superficie. Hay distintos mecanismos que permiten el desplazamiento natural del fluido, como la invasión del reservorio por parte del agua de formación o la expansión del gas presente en el reservorio. En aquellos reservorios en los que los mecanismos naturales no son suficientes, o en aquellos que alcanzaron la madurez productiva, suelen utilizarse estrategias de bombeo artificial y realizarse la estimulación por medio de la inyección de fluidos (Selley, 1998; Bjørlykke, 2010).

La creciente demanda energética global y las diferentes proyecciones a futuro siguen poniendo a los combustibles fósiles en el primer lugar del consumo energético global (Chengzao, 2017). De acuerdo a la Agencia Internacional de Energía de los Estados Unidos (EIA, 2017) se proyecta que, a pesar de que el consumo de energías renovables presentaría el mayor crecimiento (2.3\%/año en promedio), el $77 \%$ del consumo energético global en el año 2040 será cubierto por el uso de combustibles fósiles, apenas un $6 \%$ menos que en la actualidad, como se muestra en la Figura 1.1, en la que el consumo neto global de energía es fraccionado en las distintas fuentes de 

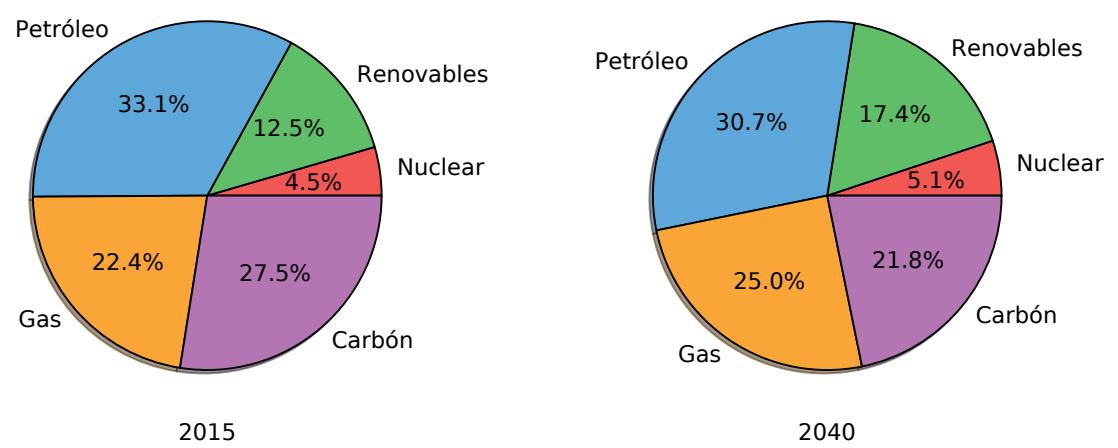

Figura 1.1. Porcentajes del consumo energético global correspondiente a cada fuente de energía observados para el año 2015 y proyectados para el año 2040 (EIA, 2017).

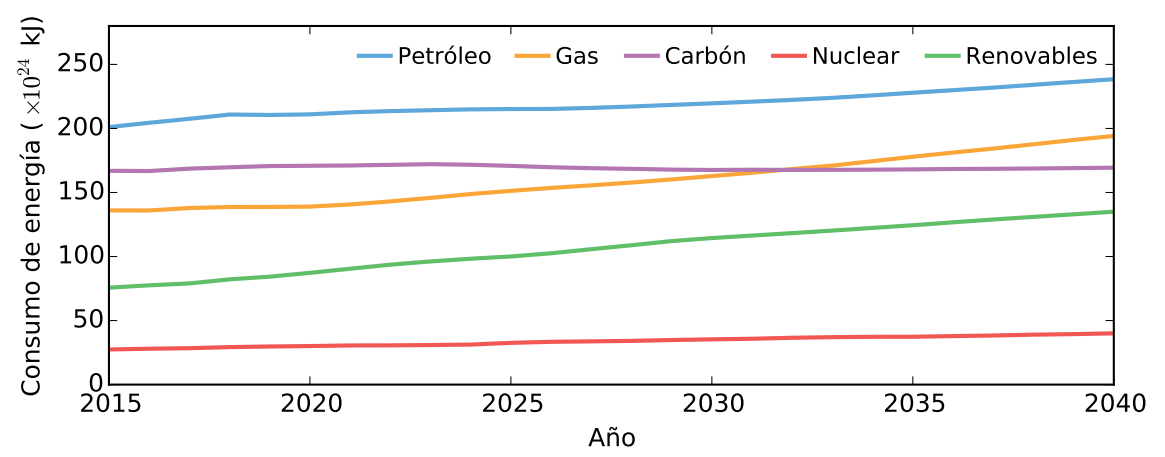

Figura 1.2. Proyección hasta el año 2040 del consumo de energía por fuente (EIA, 2017).

obtención de la misma. La proyección del consumo de energía por fuente calculada a partir del año 2015 puede verse en la Figura 1.2. En lo que respecta a combustibles fósiles, se espera que el gas natural presente el mayor crecimiento, con un promedio de $1.4 \%$ /año. Esta demanda global de hidrocarburos da lugar a la necesidad de desarrollar tecnologías que permitan encontrar nuevas reservas o acceder a reservorios complejos, maximizar la recuperación de hidrocarburos en los reservorios en producción y atender las emisiones de $\mathrm{CO}_{2}$ (van der Baan et al., 2013).

El escenario energético hoy conduce a desviar la mirada a reservorios previamente no rentables por los altos costos que implica su producción, los reservorios no convencionales (Bentley, 2002; Jiang et al., 2016). Los sistemas petroleros asociados a reservorios no convencionales se caracterizan por la imposibilidad de los hidrocarburos de fluir. Es decir, las reservas de hidrocarburo se encuentran, en la mayoría de los casos, en la misma roca madre en la que se dieron las condiciones para su generación, sin que tenga lugar la migración. Entre las distintas características de los reservorios no convencionales que 
hacen altamente compleja su explotación, la más sobresaliente es la baja permeabilidad de las rocas.

Los reservorios no convencionales pueden ser clasificados en distintos tipos en función de su litología y su contenido de hidrocarburos, entre otras propiedades. Si bien no hay un consenso absoluto sobre esta clasificación (Jiang et al., 2016; Zee Maa, 2016), son de particular interés los hidrocarburos no convencionales denominados shale oil y shale gas, es decir, petróleo y gas embebidos en esquistos (arcillas sometidas a altas presiones). La permeabilidad de estas rocas es tan baja que su medición es muy difícil, pero diferentes estudios la han estimado en el rango de 1 a $100 \mathrm{nD}$. Ejemplos de shales son las formaciones Barnett, Fayetteville y Woodford en América del Norte (Warpinski et al., 2009), y la formación Vaca Muerta en Argentina. Otro tipo de reservorio de interés lo constituyen las llamadas tight sands, en general dadas por depósitos sedimentarios lenticulares con permeabilidades bajas pero superiores a los shales, de 0.1 a $1.0 \mu \mathrm{D}$ (Warpinski et al., 2009). Algunos autores ubican a estas formaciones dentro de los reservorios convencionales, pues en su mayoría se trata de rocas reservorio sin capacidad generadora (Sondergeld et al., 2010). Sin embargo, su producción no es posible si no es mediante la aplicación de tecnologías no convencionales. Las formaciones Clinton de la cuenca apalachiana, Cotton Valley al norte de la cuenca del Golfo de México y Mulichinco en la cuenca Neuquina son ejemplos de reservorios tight (Hongjun et al., 2016; Alonso et al., 2017).

De acuerdo a las estimaciones de la Agencia Internacional de Energía de los Estados Unidos (EIA, 2013), Argentina se ubica en el segundo lugar en cuanto a recursos técnicamente recuperables ${ }^{1}$ de shale gas y en cuarto lugar en shale oil a nivel global. Las Tablas 1.1 y 1.2 cuantifican dichos recursos de shale oil y shale gas, respectivamente, para los cinco primeros países en cada caso. Los reservorios convencionales, que son "fácilmente" explotables, constituyen, en realidad, una fracción menor de los reservorios existentes (Holditch, 2013). En el caso argentino, los $802 \mathrm{Tcf}^{2}$ de gas no convencional representan el $96.4 \%$ del total del potencial gasífero del país, cuyas reservas convencionales son de 30.2 Tcf. Por su parte, las reservas convencionales de petróleo en Argentina son de $4.4 \mathrm{Mbbl}^{3}$ (14.0\% del total) frente a los $27 \mathrm{Mbbl}$ no convencionales, correspondientes al $86 \%$ del total (Secretaría de Energía, 2018).

Pese a la mayor disponibilidad de reservorios no convencionales, superar la dificultad que implican las bajas permeabilidades que los caracterizan requiere de la aplicación de tecnologías más complejas para la recuperación del hidrocarburo (Warpinski et al., 2009). La perforación de múltiples pozos horizontales, en general distribuídos de la forma más regular posible, en combinación con una adecuada estimulación hidráulica de las rocas es la práctica actualmente aceptada, establecida y exitosa para la explotación de reservorios no convencionales (Waters et al., 2009; Warpinski et al., 2014). Esto permite

\footnotetext{
${ }^{1}$ Se denomina recursos técnicamente recuperables a aquellos que podrían ser producidos con la tecnología, prácticas e información geológica actuales. A medida que la tecnología avanza, y se mejoran las prácticas industriales y el entendimiento general sobre el reservorio, es de esperar que se expandan (EIA, 2013).

${ }^{2}$ Tcf: trillones de pies cúbicos

${ }^{3} \mathrm{Mbbl}$ : millones de barriles.
} 


\begin{tabular}{cccc}
\hline Posición & País & $\begin{array}{c}\text { RTR shale oil } \\
\text { en Mbbl }\end{array}$ & $\begin{array}{c}\text { RTR shale oil } \\
\text { relativo al total }\end{array}$ \\
\hline 1 & Rusia & 75800 & $22.0 \%$ \\
2 & USA & 58100 & $16.8 \%$ \\
3 & China & 32200 & $9.3 \%$ \\
4 & Argentina & 27000 & $7.8 \%$ \\
5 & Libia & 26100 & $7.6 \%$ \\
\hline
\end{tabular}

Tabla 1.1. Países con los mayores recursos técnicamente recuperables de shale oil de acuerdo a EIA (2013). El total para todos los países considerados es de $345000 \mathrm{Mbbl}$.

\begin{tabular}{cccc}
\hline Posición & País & $\begin{array}{c}\text { RTR shale gas } \\
\text { en Tcf }\end{array}$ & $\begin{array}{c}\text { RTR shale gas } \\
\text { relativo al total }\end{array}$ \\
\hline 1 & China & 1115 & $15.3 \%$ \\
2 & Argentina & 802 & $11.0 \%$ \\
3 & Algeria & 707 & $9.7 \%$ \\
4 & USA & 665 & $9.1 \%$ \\
5 & Canadá & 573 & $7.9 \%$ \\
\hline
\end{tabular}

Tabla 1.2. Países con los mayores recursos técnicamente recuperables de shale gas de acuerdo a EIA (2013). El total para todos los países considerados es de 7299 Tcf. 
aumentar la superficie conductora en contacto con la matriz rica en hidrocarburos para facilitar su eliminación de la roca madre y su movimiento hacia los pozos (Warpinski et al., 2009).

\subsection{Fracturación hidráulica}

La fracturación hidráulica se ha utilizado por décadas para mejorar la producción de pozos hidrocarburíferos. Fue implementada por primera vez en el año 1947 en Kansas, Estados Unidos, y desde entonces ha evolucionado en respuesta a los esfuerzos realizados para su desarrollo y optimización hasta transformarse en un procedimiento rutinario para poner un pozo en producción (Fairhurst, 2016; Maxwell, 2014). En Argentina, los procesos de estimulación hidráulica se han llevado a cabo a la par del desarrollo de los mismos a nivel global. Dichos procesos se han utilizado para recuperación secundaria en pozos convencionales desde fines de la década del '50, cuando se practicó por primera vez en Neuquén (Bercovich y Rebossio, 2015).

El objetivo de la fracturación hidráulica es generar un sistema altamente conductivo que permita el flujo de gas y/o petróleo desde la roca reservorio hacia el pozo, a partir de la reactivación de fracturas preexistentes o la generación de fracturas nuevas (Fairhurst, 2016). Este proceso consiste en la inyección de fluidos a altas presiones en las formaciones geológicas de interés hasta lograr superar las tensiones naturales de las rocas y así fracturarlas (Maxwell, 2014). Los fluidos de fractura están conformados por una base, por lo general de agua (ocasionalmente también puede ser petróleo o ácido), a la que se adicionan químicos que modifiquen alguna/s de sus características, como por ejemplo su viscosidad o su capacidad de retirarse fácilmente de los canales creados una vez terminada la estimulación (Speight, 2016). Junto a este fluido se inyectan materiales apuntalantes sólidos, conocidos como proppants para que, una vez generada la fractura, ésta permanezca abierta y, en consecuencia, permita el movimiento de fluidos. Dichos agentes de sostén suelen ser arenas o granos de cerámica especialmente creados con este fin. Son de pequeño tamaño, generalmente entre $105 \mu \mathrm{m}$ y $2.38 \mathrm{~mm}$ (Speight, 2016) y suelen utilizarse diferentes tamaños para un mismo proceso de fractura: mientras las partículas de mayor tamaño tienen el fin de maximizar la conductividad en la zona cercana al pozo, las partículas más pequeñas buscan alcanzar los extremos de las fracturas (Liang et al., 2015). Los materiales más pequeños suelen inyectarse al inicio del procedimiento. El diseño de un proceso de fractura hidráulica requiere un enfoque integrado que considere la mayor cantidad de información posible en relación a las propiedades del reservorio (Zee Maa, 2016). Las variables más importantes que definen el tipo de procedimiento a realizar incluyen la porosidad, permeabilidad y litología de la formación, su contenido orgánico, los fluidos presentes en la misma, las propiedades mecánicas de las rocas y la distribución general de esfuerzos en la zona. En base al análisis de toda esta información por medio del estudio de coronas, imágenes y perfiles de pozo, datos sísmicos, etc., no solo deben definirse la óptima posición y orientación del pozo y la distancia entre fracturas, sino que debe prestarse especial atención al tipo de fluidos de inyección y sus agregados, pues estos tienen una gran influencia en 

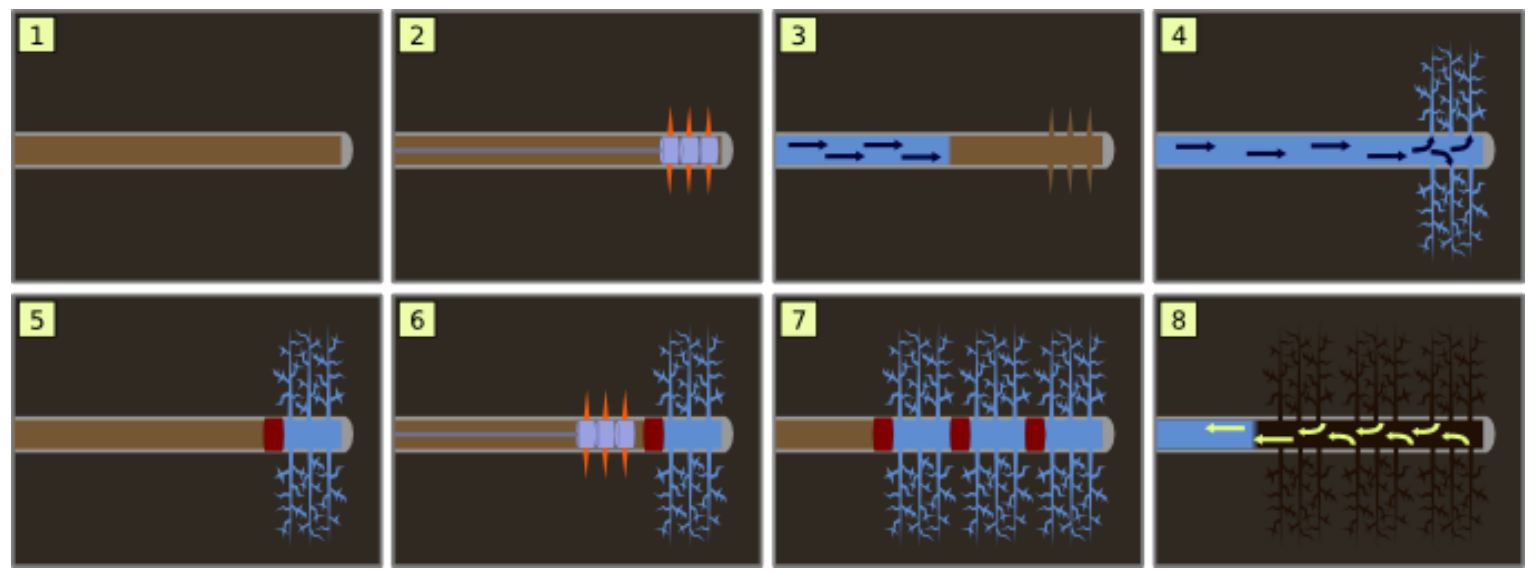

Figura 1.3. Una vez perforado el pozo, introducido el casing (una cañería de acero) y realizada la cementación para aislar las formaciones aledañas del pozo (1), se realiza la perforación de las paredes del pozo para ponerlo en contacto con la formación en la posición donde se desea fracturar (2). Se inyecta el fluido de fractura con los agentes de sostén correspondientes (3) y se bombea a altas presiones fracturando la roca (4). Para aislar la etapa realizada de las siguientes se coloca un tapón (5) y el procedimiento se repite $(6,7)$ hasta finalizar el total de las etapas planificadas. Finalmente, se retiran los tapones y se inicia la producción, a partir del flujo del hidrocarburo por la red de fracturas generadas (8).

la eficiencia del procedimiento (Mata et al., 2016). Habitualmente, los procesos de fracturación hidráulica son llevados a cabo en etapas, cada una de las cuales tiene una duración de horas. Se aísla una porción del pozo horizontal y se perforan las paredes del pozo para ponerlo en contacto con la formación y a partir de allí iniciar la estimulación. Estas perforaciones suelen crearse por medio de la detonación de cargas explosivas en posiciones predefinidas, en el intervalo del pozo a estimular. La definición de la cantidad de etapas a realizar y de la separación entre ellas es también de gran importancia. Una selección subóptima de estos parámetros puede dar lugar a regiones de estimulación nula y por lo tanto no productivas (Mayerhofer et al., 2006). En la Figura 1.3 se muestran, a modo ilustrativo, los diferentes pasos del proceso de estimulación hidráulica. Los fluidos y proppants a utilizar, las tasas y presiones de bombeo, y los cambios de cada una de estas variables a lo largo de cada etapa del procedimiento son definidas con antelación y volcadas en el plan de fractura o frac plan, que debe ser conocido y seguido por todos los miembros de la operación.

El desarrollo de una fractura puede ser planificado, como ya se mencionó, a partir del estudio integral de las diversas propiedades que caracterizan al reservorio y a su entorno. Sin embargo, el comportamiento real de las rocas ante la estimulación hidráulica no puede predecirse con total certeza, ni ser directamente observado, pues se trata de rocas que, en el caso de Vaca Muerta, por ejemplo, rondan los $3000 \mathrm{~m}$ de profundidad. Comprender la ubicación y la geometría de las fracturas y determinar el volumen efectivamente estimulado son claves para evaluar la eficiencia del procedimiento y 
contribuir a la optimización de los diseños de fractura (Wu et al., 2016; Le Calvez et al., 2007; Cipolla et al., 2011). Más aún, supervisar el desarrollo de la fractura en tiempo real es de gran utilidad para detectar posibles riesgos vinculados a la reactivación de fallas, al aumento indeseable de la presión en el pozo o a la filtración de fluidos en formaciones aledañas, y mitigarlos modificando el plan de fractura (Maxwell, 2014; Kendall et al., 2011). Existen diversas herramientas para evaluar la eficiencia del proceso de estimulación hidráulica. Por ejemplo, inclinómetros dispuestos en pozos o en superficie son capaces de detectar pequeños campos de deformación que dependen de la geometría de la fractura generada (acimut, inclinación, dimensiones), como explican Zhou et al. (2015). Sensores de temperatura, que en general utilizan fibra óptica, pueden dar información sobre la eficacia en la aislación de las diferentes etapas, la cantidad de fluidos que ingresa por las distintas perforaciones del pozo, las posiciones de los puntos de inicio de las fracturas, etc. (Holley et al., 2010). Las observaciones de los cambios en la presión y las tasas de producción suelen ser utilizados por ingenieros para inferir propiedades de la fractura (Gulrajani y Nolte, 2000), mientras que relevamientos sísmicos time-lapse tienen el potencial de detectar cambios en la formación vinculados, por ejemplo, a fracturas abiertas rellenas de fluido. No obstante, la herramienta más utilizada y ampliamente aceptada para evaluar los procesos de fractura hidráulica tanto en tiempo real como en post-procesamiento, capaz de proveer de la más detallada información sobre las fracturas generadas, es el monitoreo microsísmico (Maxwell, 2014; Warpinski, 2013; Wu et al., 2016).

\subsection{Monitoreo microsísmico}

En términos generales, el monitoreo microsísmico consiste en la registración pasiva, detección, análisis e interpretación de señales originadas en la liberación de energía que ocurre al producirse la deformación frágil de las rocas, en lo que llamamos eventos microsísmicos. Los eventos microsísmicos son terremotos muy pequeños, de magnitudes generalmente negativas (van der Baan et al., 2013) que se producen en torno a las fracturas generadas durante la estimulación hidráulica. El monitoreo microsímico surgió originalmente como una herramienta para observar la microsisimidad asociada a operaciones mineras. Los cambios en las tensiones de las rocas en torno a las excavaciones subterráneas pueden causar grandes rupturas en las mismas, de manera que la detección temprana de pequeñas rupturas puede alertar sobre un posible colapso de las rocas. Esta aplicación del monitoreo microsísmico se implementó por primera vez en 1908, en Alemania, pero rápidamente se propagó a diversos países en los que los riesgos de seguridad vinculados a la actividad minera eran importantes. En ese entonces, el método se basaba en la observación, mediante un único receptor, de la tasa de ocurrencia de eventos, que aumenta rápidamente antes del colapso de las rocas (Grechka y Heigl, 2017). Luego del desarrollo inicial de la técnica, su uso se extendió a diversas áreas. Un ejemplo de ello es el monitoreo de la microsismicidad inducida por la creación de embalses. Simpson (1976) lista una serie de ejemplos en los que se ha observado un aumento en la microsismicidad generado por cambios en las tensiones y/o 
en la presión poral de las rocas en torno al gran volumen de agua. Por otra parte, la microsísmica ha sido utilizada para monitorear procesos de inyección de fluidos no solo en reservorios no convencionales. Desde la década del ' 70 se han llevado a cabo fracturas hidráulicas en formaciones asociadas a sistemas geotermales con el fin de transformarlas en reservorios de energía geotérmica (Jupe et al., 1992; Häring et al., 2008), en los que se utilizó el monitoreo microsísmico como una herramienta para la comprensión de la respuesta de las rocas a la estimulación (Dyer et al., 2008). Estas tareas contribuyeron ampliamente y durante décadas al desarrollo de la microsísmica, tanto desde el punto de vista tecnológico, vinculado al desarrollo de herramientas adecuadas, como en relación a la optimización de las geometrías de adquisición (Grechka y Heigl, 2017). De la misma manera, la microsísmica ha contribuido al monitoreo de la sismicidad inducida por la inyección de fluidos de desechos, entre ellos fluidos radioactivos (Stow y Haase, 1986), y contribuye al desarrollo de proyectos de inyección de $\mathrm{CO}_{2}$ (Sherlock y Dodds, 2003; Zhou et al., 2009), dos aplicaciones que actualmente son de gran interés desde el punto de vista medioambiental. En la industria hidrocarburífera, la microsísmica es utilizada también para monitorear la deformación inelástica asociada con la inyección de vapor, agua o gas para la recuperación secundaria en pozos convencionales, pero su aplicación más extendida actualmente en esta área radica en los procesos de fracturación hidráulica (Maxwell et al., 2010b).

Como ya se mencionó, los eventos microsísmicos pueden definirse como terremotos de muy baja magnitud. De este modo, el análisis de la información que brindan los registros microsísmicos es análogo al utilizado por la sismología global, en una escala reducida al reservorio y sus alrededores (Warpinski, 2013). Para ello, entonces, es necesario contar con sensores de alta sensibilidad. En general se utiliza un arreglo de múltiples sensores dispuestos en superficie o en pozos a una profundidad cercana a la de la zona de fractura (Wu et al., 2016). Los arreglos dispuestos en pozos suelen contar con 8 a 12 sensores 3C separados entre ellos unas pocas decenas de metros. La ventaja de esta disposición radica en la mejor relación señal-ruido que puede alcanzarse, pues se minimiza la atenuación y el ruido de fondo propio de las operaciones de campo (Maxwell et al., 2010b). Sin embargo la disponibilidad de pozos aledaños al de fractura que puedan utilizarse para el monitoreo, es decir, que no estén en producción al momento de la inyección, es una limitación para la utilización de este tipo de arreglos (Chambers et al., 2010). Por su parte, en los arreglos de superficie se utilizan miles de sensores verticales, usualmente dispuestos de manera lineal, en forma de estrella con centro en el pozo de tratamiento (Duncan y Eisner, 2010). Los mayores niveles de ruido observados con estos receptores pueden ser mitigados por el gran número y la disposición de los mismos. En la Figura 1.4 se muestra, a modo de ejemplo, un registro microsísmico obtenido mediante un arreglo de 10 receptores $3 \mathrm{C}$ dispuesto en un pozo monitor aproximadamente vertical. En la figura se pueden observar algunas señales procedentes de eventos microsísmicos inducidos.

Los registros microsísmicos obtenidos contienen abundante y variada información tanto sobre los resultados del proceso de inyección hidráulica como del reservorio. Los objetivos primarios y más elementales del procesamiento microsísmico son la 


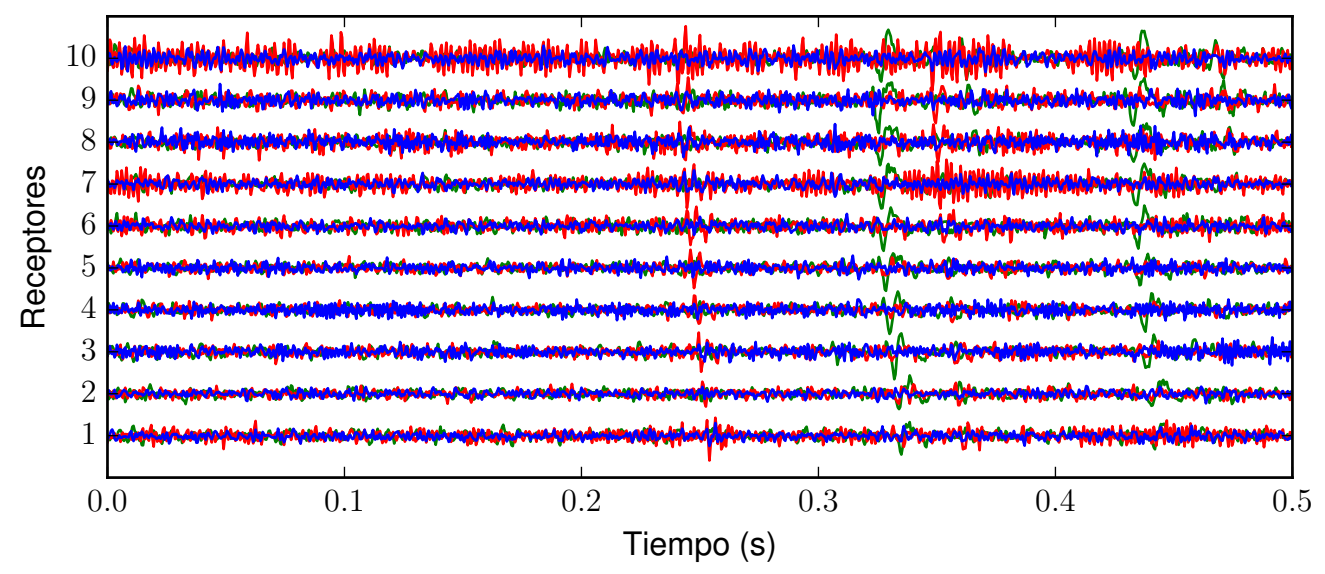

Figura 1.4. Ejemplo de un registro microsísmico obtenido durante un proceso de fracturación hidráulica. En azul, rojo y verde se indican las componentes $x, y$ y $z$ del registro, respectivamente.

identificación de eventos dentro del gran volumen de datos dado por los registros y la localización de los mismos, dada por sus coordenadas espacio-temporales (Maxwell, 2014). Dichas tareas son llevadas a cabo mediante la implementación de diferentes estrategias. Algunas de ellas tienen un enfoque similar a la migración Kirchhoff de la sísmica de reflexión. En este caso la posición de un evento queda definida a partir del punto del espacio que maximiza alguna medida de semblanza de los arribos de las distintas fases de un evento, sin necesidad de una determinación precisa de sus tiempos (Rentsch et al., 2007; Drew et al., 2013). Otro enfoque posible, el considerado en esta Tesis, se basa en el picado de los tiempos de arribo de los eventos (Eisner et al., 2009a; Lagos et al., 2014; Lagos y Velis, 2018) y la inversión de los mismos para la determinación de las coordenadas espacio-temporales de un evento microsímico. Estos dos objetivos primarios constituyen el punto inicial para la evaluación de la eficiencia del procedimiento de inyección realizado y para la caracterización exhaustiva de las fracturas generadas (Cipolla et al., 2012). A partir de ellos es posible interpretar, por ejemplo, la evolución de la fractura en tiempo y espacio, la geometría de la misma y su complejidad. Asimismo, son el punto de partida para el procesamiento más avanzado de la información, que incluye (pero no se limita a) el cálculo del volumen estimulado en el procedimiento, que provee una estimación de la máxima extensión de la fractura hidráulica, y la determinación de parámetros de la fuente como su magnitud momento y el mecanismo focal asociado. Por otra parte, si la detección y localización de eventos microsísmicos es llevada a cabo en tiempo real es posible, por ejemplo, advertir la necesidad de re-estimular o de modificar el plan de fractura o la posición de las etapas siguientes. Más aún, la observación in situ del crecimiento de la región afectada por la inyección a medida que ésta tiene lugar permite controlar el crecimiento vertical de la fractura e identificar posibles riesgos vinculados a la reactivación de fallas preexistentes, información de gran importancia para la seguridad de la operación. El procesamiento en tiempo real constituye en sí mismo un desafío, pues implica la implementación de 
algoritmos computacionalmente eficientes capaces de procesar grandes volúmenes de datos en forma rápida y precisa.

\subsection{Motivación y objetivos}

En el contexto descripto, la necesidad de disponer de software confiable y eficiente acompaña el incremento actual de las operaciones vinculadas a reservorios no convencionales en la República Argentina y da lugar a los objetivos generales de esta Tesis. En los próximos capítulos se vuelca el trabajo realizado con el propósito de generar algoritmos computacionales especializados para el procesamiento y análisis de señales microsísmicas. Con estas tareas como punto de partida se busca contribuir, a mediano y largo plazo, al desarrollo de este tipo de tecnologías en la República Argentina, que actualmente son ofrecidas únicamente por compañías operadoras extranjeras. Esto permitirá mejorar el control y la eficiencia de los complejos y costosos procesos de estimulación hidráulica destinados al monitoreo y/o desarrollo de reservorios no convencionales de hidrocarburos. Cabe mencionar que las herramientas generadas y sus aplicaciones no se limitan exclusivamente al monitoreo de fracturas hidráulicas en reservorios no convencionales, sino que podrían ser utilizadas para el monitoreo de cualquier actividad con microsismicidad asociada. En particular, el monitoreo microsísmico tiene un gran potencial de utilidad en actividades que hoy constituyen grandes desafíos desde el punto de vista medioambiental, como la observación de la inyección de líquidos de desecho de múltiples actividades industriales y el almacenamiento geológico de $\mathrm{CO}_{2}$, principal gas de invernadero contribuyente al calentamiento global.

\subsection{Organización de la Tesis}

Los contenidos de esta Tesis se organizan en siete capítulos en los cuales se describen las herramientas desarrolladas para el procesamiento de registros microsísmicos. En el Capítulo 2 se describen los dos algoritmos de optimización globales utilizados a lo largo de esta Tesis. En el Capítulo 3 se proponen métodos para la realización del pre-procesamiento de los datos microsísmicos. En los Capítulos 4, 5 y 6 se detallan las herramientas propuestas para el procesamiento propiamente dicho y finalmente las conclusiones de este trabajo se enumeran en el Capítulo 7. Adicionalmente se incluyen dos apéndices en los que se muestran herramientas adicionales necesarias para el desarrollo del trabajo. En el Apéndice A se brindan detalles sobre el trazado de rayos considerado necesario para el cálculo de tiempos de arribo requerido por las herramientas de calibración de modelos de velocidades y de localización de eventos. En el apéndice B, por su parte, se describe la metodología empleada para la generación de registros sintéticos, que fueron utilizados para el testeo de los diversos algoritmos desarrollados. 


\section{Capítulo 2: Algoritmos de optimización}

Se introducen los conceptos básicos asociados a la resolución del problema inverso mostrando la necesidad de considerar algoritmos de optimización globales para los problemas de interés. Se brinda una descripción detallada de los dos algoritmos utilizados en esta Tesis para la resolución de problemas de optimización, a saber: Very fast simulated annealing (VFSA) y Particle swarm optimization (PSO). En el caso particular del PSO, se muestra una calibración realizada sobre los parámetros que caracterizan al método orientada a hallar los óptimos para la aplicación del mismo a la localización de eventos microsísmicos.

\section{Capítulo 3: Pre-procesamiento}

En el Capítulo 3 se describen los pasos que deben ser llevados a cabo previos al procesamiento de datos microsísmicos. En ese marco, se presenta una herramienta para la orientación de sensores de pozo, necesaria para caracterizar la geometría de adquisición de los datos. La herramienta se basa en el cálculo de la energía de las ondas $\mathrm{P}$ provenientes de fuentes de posiciones conocidas, en las componentes horizontales registradas por medio de los sensores a orientar. Se hace uso, además, de la información asociada a la inclinación y el acimut del pozo en el que se disponen los sensores. El método y su sensibilidad al ruido característico de la registración son testeados por medio de ejemplos sintéticos y datos de campo adquiridos durante procesos de fracturación hidráulica. Por otro lado, se presenta la calibración de modelos de velocidades considerando medios estratificados con anisotropía VTI. La calibración es llevada a cabo a partir de modelos de velocidades iniciales obtenidos por medio de perfiles sónicos de pozo y arribos de señales provenientes de fuentes cuyas posiciones son conocidas. Para ello se introduce una técnica que utiliza VFSA para ajustar diversos parámetros asociados al modelo de velocidades: velocidades de ondas $\mathrm{P}$ y S, parámetros de anisotropía de Thomsen $(\varepsilon, \delta$ y $\gamma)$ así como las profundidades de las interfases entre estratos. Para reducir la ambigüedad propia del problema planteado, se considera una restricción adicional basada en la litología del medio en cuestión. Por medio de la localización de las fuentes de posición conocida se muestra la importancia de realizar la calibración y de considerar la anisotropía del medio en los modelos de velocidades a utilizar.

\section{Capítulo 4: Detección de eventos, picado de tiempos de arribo y estimación de backazimuths}

En este capítulo se trabaja con los primeros pasos en el procesamiento de eventos microsísmicos: la detección de los mismos, el picado o determinación de sus tiempos de arribo y la estimación de la dirección de procedencia de las señales o backazimuth. El primero de estos pasos está orientado a definir qué porciones de registro, en el gran volumen de datos que se almacena, contiene información de interés. Para ello se hace uso de la estrategia multitraza propuesta por Sabbione y Velis (2013), que fue adaptada al procesamiento de registros en formato SEG-Y. Se introduce, además, una 
modificación propuesta sobre esta herramienta para la identificación automática de las fases $\mathrm{P}$ y $\mathrm{S}$ asociadas a un evento microsísmico y la declaración de un evento como tal cuando ambas son detectables en el registro. En segundo lugar, se describen dos herramientas empleadas para el picado de tiempos de arribo. La primera de ellas está dada por la estrategia multitraza ya mencionada y la segunda se basa en la propuesta de Velis et al. (2015) que hace uso de un reconocimiento de patrones en el registro para la identificación de eventos. Por otro lado, se describen las técnicas de análisis de polarización que fueron implementadas durante el desarrollo de esta Tesis, basadas en el ajuste lineal de hodogramas, la diagonalización de la matriz de varianza-covarianza de los registros en torno a un arribo y la energía de la señal. En particular, se describe una modificación propuesta a la estrategia propuesta por Velis et al. (2015) mediante la cual se realiza la estimación simultánea de backazimuths y tiempos de arribo de las ondas $\mathrm{P}$ y S. Por último, se evalúan las incertidumbres asociadas a la estimación del backazimuth y se introduce una estrategia basada en la desviación absoluta de las observaciones respecto de la mediana del conjunto (DAM) que permite eliminar valores atípicos en las observaciones y así reducir las incertidumbres asociadas.

\section{Capítulo 5: Localización de eventos microsísmicos}

Se describe el enfoque considerado en esta tesis para la localización de eventos microsísmicos, caracterizado por la utilización de los tiempos de arribo de las ondas P y S asociadas a cada uno de ellos. La localización se plantea como un problema de optimización que, por su carácter no lineal y la complejidad de la función de costo involucrada, se resuelve mediante VFSA y PSO. En primer lugar, se muestra el trabajo realizado considerando registros sintéticos, que fue llevado a cabo entre los primeros pasos del desarrollo de este doctorado. Se propone un flujo de procesamiento automatizado que concatena todos los pasos requeridos para el procesamiento de los registros de eventos microsísmicos y que finaliza con la estimación de las coordenadas espaciales de éstos. La efectividad en la obtención de una solución de los algoritmos de optimización mencionados es evaluada, así como su eficiencia computacional que además es comparada con la del clásico Grid Search o búsqueda exhaustiva. Posteriormente, la disponibilidad de datos de campo dio lugar a la adaptación de todas las herramientas de procesamiento disponibles y a la necesidad de considerar modelos de velocidades más complejos para la localización de eventos y de modificar la función de costo del problema de optimización asociado. Se muestran los cambios propuestos y ejemplos de localizaciones de eventos reales, a cuyos registros le fueron aplicados todos los pasos mencionados en los capítulos previos. Por último, se discuten las incertidumbres en la localización de eventos microsísmicos asociadas a diversos factores y se calculan las elipses de error asociadas a un conjunto de eventos.

\section{Capítulo 6: Estimación de magnitudes momento}

En este capítulo se explican los fundamentos teóricos en los que se basa la estimación de magnitudes momento de eventos microsísmicos. Ésta se plantea como un problema de 
optimización en el que se ajusta un modelo al espectro de amplitud del stack de los datos. El problema, que se resuelve por medio de VFSA, es estudiado mediante la utilización de registros pseudo-sintéticos a través de distintas pruebas que tienen por objetivo evaluar el comportamiento del método frente al ajuste de distintos conjuntos de parámetros del modelo (incógnitas del problema). Luego, se muestran las modificaciones realizadas a esta herramienta con el fin de aplicarla de manera automática en grandes cantidades de eventos microsísmicos. Por último, se discuten los alcances de la estrategia y las limitaciones observadas en el trabajo con datos de campo asociadas a las aproximaciones que implica su aplicación.

\section{Capítulo 7: Conclusiones}

En el Capítulo 7 se enumeran las conclusiones generales de esta Tesis y se señalan las más importantes a las que se arriba en cada capítulo. Por otra parte, se detallan las contribuciones científicas realizadas durante el desarrollo de este trabajo, que fueron presentadas mediante diversas publicaciones en eventos científicos nacionales e internacionales y en revistas de circulación internacional con referato. Se describen, además, las contribuciones tecnológicas del trabajo, asociadas a la transferencia de herramientas al sector productivo y los códigos desarrollados para la implementación de todas las herramientas que se describen a lo largo de la Tesis. 


\section{Capítulo 2}

\section{Algoritmos de optimización}

\subsection{Introducción}

Los diferentes fenómenos que tienen lugar en el subsuelo o las propiedades del mismo, que son de interés para la Geofísica, pueden ser observados en superficie por medio de diferentes técnicas. El sistema de interés, dado por dichos fenómenos o propiedades, puede ser aproximado con mayor o menor grado de complejidad por un conjunto de parámetros que definen un modelo del mismo. Establecer un conjunto de relaciones físico-matemáticas que permitan predecir las observaciones a partir del modelo, constituye el planteo del problema directo (Sen y Stoffa, 2013; Tarantola, 2005). En otras palabras, si $\mathbf{d}=\left(d_{1}, d_{2}, \ldots, d_{N}\right)$ son los datos geofísicos u observaciones y $\mathbf{m}=\left(m_{1}, m_{2}, \ldots, m_{M}\right)$ los parámetros del modelo, el problema directo consiste en definir una función $f$ que satisfaga

$$
\hat{\mathbf{d}}=f(\mathbf{m})
$$

donde $\hat{\mathbf{d}}$ son predicciones de las observaciones. Resolver el problema inverso consiste en encontrar los parámetros del modelo, m, tales que las predicciones obtenidas de acuerdo a la ecuación 2.1, $\mathbf{d}$, coincidan con las observaciones $\mathbf{d}$. Esta coincidencia se da dentro de una cierta tolerancia, dado que la incertidumbre propia de las observaciones y las aproximaciones realizadas en el modelo no permiten que sea exacta. Los parámetros del modelo $\mathbf{m}$ pueden adoptar valores dentro de ciertos rangos que dependen de cada problema. El conjunto de todas las posibles soluciones al problema inverso se denomina espacio de búsqueda.

La complejidad de la función $f$, que en la mayoría de los problemas geofísicos es no lineal, dificulta la obtención de los parámetros $\mathbf{m}$ a partir de su inversión matemática directa. La resolución del problema inverso, entonces, se lleva a cabo mediante la optimización de una función que mide la discrepancia entre las observaciones y las predicciones obtenidas a partir de cada juego de parámetros. A lo largo de esta Tesis, a esta función se la denomina de forma indistinta función de costo o función objetivo. Existen numerosos métodos de optimización que pueden utilizarse para hallar el modelo que mejor represente a las observaciones. La elección del método a utilizar en cada 
caso debe contemplar aspectos tales como la cantidad de parámetros a determinar, la complejidad del modelo directo, las dimensiones del espacio de búsqueda y el tiempo disponible para realizar el cálculo.

Dependiendo del problema a resolver, la función objetivo puede presentar múltiples extremos locales. En esta situación, los métodos de optimización tradicionales basados en gradientes o en linealizaciones de la función objetivo, capaces de hallar el mínimo de una función de forma local, no son una buena opción salvo que se disponga de aproximaciones iniciales adecuadas, que en general no es el caso. Una posibilidad para hallar el óptimo global de una función de costo es recorrer el espacio de búsqueda de manera exhaustiva evaluando la función de costo a intervalos regulares buscando el punto del espacio en el que su valor es mínimo (Grid Search). Mientras más variabilidad presente la función de costo, más fina debe ser la discretización. Sumado a esto, la cantidad de modelos a evaluar crece exponencialmente con las dimensiones de $\mathbf{m}$ por lo que, a pesar de ser un método efectivo para hallar el mínimo global de una función, no es eficiente para la mayoría de los problemas geofísicos (Sen y Stoffa, 2013). Otra posibilidad consiste en recorrer el espacio de búsqueda de manera aleatoria en lo que se conoce como métodos Monte Carlo o de búsqueda aleatoria (random search). De acuerdo a este enfoque y de manera iterativa, se toma una muestra del espacio de búsqueda de forma aleatoria, se evalúa la función de costo en la misma y se la compara con la iteración anterior. En cada paso se conserva el modelo con el mejor resultado logrado hasta el momento hasta completar un máximo de iteraciones predefinido o alcanzar algún criterio de convergencia. Sin embargo, dependiendo de la complejidad de la función de costo y el tamaño del espacio de búsqueda, esta forma de realizar el muestreo puede ser altamente costosa desde el punto de vista computacional (Sen y Stoffa, 2013). Como alternativa se han planteado diversas estrategias para recorrer el espacio de búsqueda con la suficiente aleatoriedad que permita al algoritmo tener capacidad de exploración sin concentrarse de forma prematura en mínimos locales y, al mismo tiempo, con capacidad de dirigir gradualmente la búsqueda hacia los modelos óptimos.

Dentro del gran universo de algoritmos de optimización global de naturaleza estocástica existente, el algoritmo Very Fast Simulated Annealing (VFSA) (Ingber, 1989) ha demostrado una gran eficiencia en la resolución de problemas geofísicos inversos (Velis, 1998). Por su parte, el método de optimización denominado Particle Swarm Optimization (PSO) forma parte de los algoritmos poblacionales cuya popularidad en aplicaciones geofísicas ha ido en aumento en los últimos años (Shaw y Srivasta, 2007; Sen y Stoffa, 2013).

Los dos algoritmos mencionados anteriormente son utilizados a lo largo de esta Tesis para la resolución de diferentes problemas vinculados al monitoreo microsísmico. El algoritmo VFSA se utiliza para resolver los problemas de inversión vinculados a la calibración de modelos de velocidades (Pérez et al., 2019), la detección de eventos microsísmicos (Velis et al., 2015), la estimación de parámetros de fuente (que conducen al cálculo de magnitudes momento) (Lagos y Velis, 2017b,a) y para la localización de eventos microsísmicos (Lagos y Velis, 2018; Lagos et al., 2014). Por su parte, el 
algoritmo PSO fue implementado computacionalmente para la localización de eventos microsísmicos (Lagos y Velis, 2018; Lagos et al., 2014). Por tratarse ésta de una aplicación del método que no había sido realizada con anterioridad, fue necesario llevar a cabo una calibración del mismo que permitió hallar los parámetros óptimos del algoritmo para el problema en cuestión. En el presente capítulo se describen los dos algoritmos mencionados y se pormenoriza la calibración realizada para el PSO.

\subsection{Simulated annealing (SA)}

El algoritmo Simulated Annealing (SA) surge de estudiar cómo se comporta un sistema dado por un gran número de partículas a medida que desciende su temperatura. El estado del sistema, dado por un grupo de partículas interactuando a una temperatura finita, puede describirse mediante la posición de las mismas. En la resolución de un problema de optimización por medio de Simulated Annealing, la posición de las partículas del sistema representa al conjunto de parámetros del modelo que se desea determinar, la energía del sistema está dada por la función de costo y, por lo tanto, encontrar el mínimo de la función de costo se corresponde con encontrar los estados del sistema con mínima energía (Velis, 1998).

El algoritmo parte de considerar que el sistema se encuentra inicialmente a alta temperatura y que luego comienza a enfriarse. En cada paso se modifica la configuración del sistema de partículas de forma aleatoria, buscando que la energía disminuya en cada iteración. Sin embargo, a veces se admite un aumento en la función de costo (un aumento de energía) entre dos iteraciones consecutivas, lo que permite escapar de eventuales mínimos locales. La probabilidad de aceptar un aumento de la función de costo disminuye al decrecer la temperatura. Cuando el sistema se encuentra a alta temperatura pueden tener lugar grandes cambios entre dos configuraciones consecutivas. Al disminuir la temperatura, disminuye la magnitud de los "saltos" que pueden ocurrir en la configuración del sistema. El proceso termina cuando se alcanza un máximo de iteraciones permitidas o cuando ya no se observan cambios apreciables de la función de costo. En el segundo caso, se asume que el sistema de partículas se ha enfriado lo suficiente como para que ya no se produzcan cambios significativos en su configuración. Se dice, entonces, que el sistema ha cristalizado.

Llamamos "estado" $x$ a la configuración del sistema y $E(x)$ a su energía. Si $T$ es la temperatura de equilibrio termal del sistema con energía $E(x)$, la probabilidad de que el sistema se encuentre en el estado $x$ está dada por la relación

$$
\Pi_{T}(x)=\frac{1}{Z(T)} e^{\frac{-E(x)}{\kappa T}},
$$

conocida como distribución de Boltzman o Gibbs. En la ecuación $2.2 \kappa$ es la constante de Boltzman y $Z(T)$ la función de partición

$$
Z(T)=\sum_{\omega \in X} e^{\frac{-E(\omega)}{\kappa T}}
$$


donde $X$ es el conjunto de todos los posibles estados. En cada iteración se modifica el estado en una cantidad $\Delta x$ y se calcula la nueva energía y su correspondiente incremento $\Delta E=E(x+\Delta x)-E(x)$. De acuerdo al criterio de Metrópolis, la probabilidad de que la nueva configuración sea aceptada queda dada por la ecuación

$$
h=\frac{\Pi_{T}(x+\Delta x)}{\Pi_{T}(x)}=e^{-\frac{\Delta E}{\kappa T}} .
$$

El estado $x^{\prime}=x+\Delta x$ es aceptado si $h$ es mayor a un número aleatorio $r$ que es obtenido a partir de una función de densidad de probabilidad uniforme $U[0,1]$, y es descartado en el caso contrario. Notar que si el nuevo estado implica una disminución de la energía $(\Delta E<0)$, se tiene que $h>1$ y por lo tanto la nueva configuración es aceptada.

La implementación del algoritmo requiere de la definición de tres funciones importantes:

1. La función generadora $g(\Delta x)$ representa la función de densidad de probabilidad para la generación de nuevas configuraciones en el espacio de búsqueda. Esta función depende de la temperatura como se ilustra en la Figura 2.1: a medida que el proceso avanza y la temperatura desciende, disminuye la probabilidad de generar grandes perturbaciones en el estado del sistema, mientras que aumenta la probabilidad de que los nuevos estados se asemejen a estados previos.

2. La función de aceptación $h(\Delta E)$ es la función de densidad de probabilidad para aceptar la nueva configuración que genera un cambio $\Delta E$ en la función de costo $E$. La probabilidad de aceptar nuevas configuraciones que generen incrementos en la función de costo decrece con la temperatura.

3. El esquema de enfriamiento es la función que determina la temperatura $T_{k}$ en la $k$-ésima iteración del proceso.

En cada iteración, el nuevo estado es generado a partir de $g(\Delta x)$. Se evalúa el correspondiente cambio en la función de costo, se acepta o descarta el nuevo estado como se describió y finalmente se reduce la temperatura de acuerdo al esquema de enfriamiento. La Figura 2.3 (izquierda) muestra un diagrama de flujo que ilustra el funcionamiento del algoritmo.

En el diseño canónico del algoritmo Simulated Annealing, la función generadora está dada por una función densidad de probabilidad Gaussiana $M$-dimensional ( $M$ es la cantidad de parámetros del modelo)

$$
g(\Delta x)=(2 \pi T)^{-M / 2} e^{-\frac{\Delta x^{2}}{2 T}}
$$

donde $\Delta x=x-x_{0}$ es la perturbación aplicada a la configuración previa, $x_{0}$. Por su parte la función de aceptación tiene la forma

$$
h(\Delta E)=\frac{1}{1+e^{\frac{\Delta E}{T}}} \simeq e^{-\frac{\Delta E}{T}},
$$




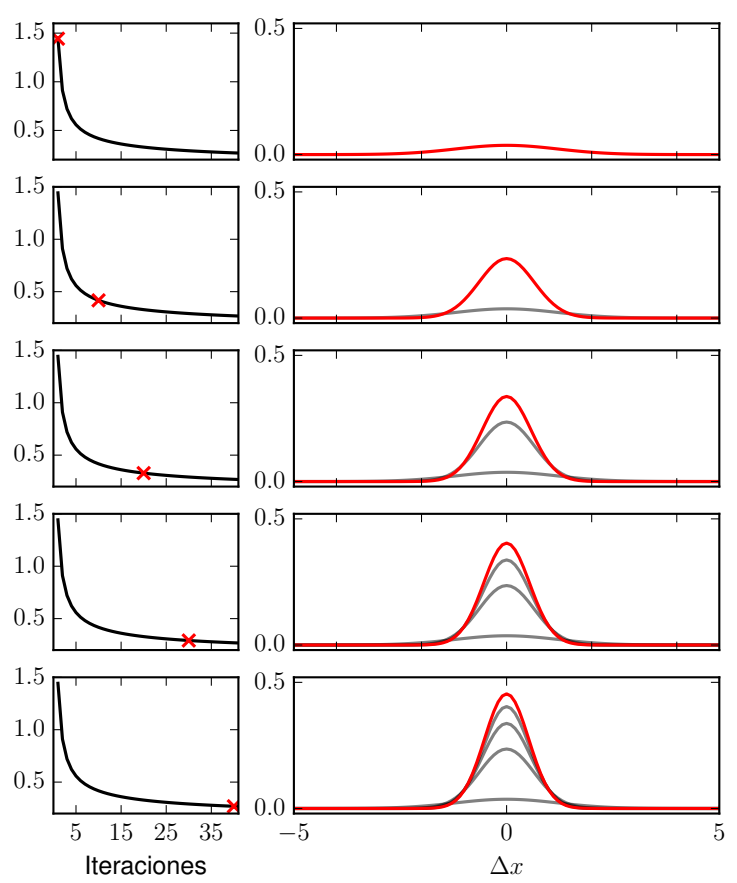

Figura 2.1. Izquierda: temperatura en función de las iteraciones. Derecha: cada curva roja corresponde a la función generadora para la temperatura indicada con una cruz (izquierda).

donde se ha supuesto $\kappa=1$ (constante de Boltzman). Por último, es necesario que la temperatura disminuya con la lentitud suficiente para alcanzar el equilibrio térmico antes de que ocurra una cristalización prematura del sistema, lo que implica que el método quede atrapado en un mínimo local. Para ello, la temperatura debe decrecer a una tasa no mayor que

$$
T_{k}=\frac{T_{0}}{\ln (1+k)}
$$

donde $T_{0}$ es una constante.

\subsubsection{Very fast simulated annealing (VFSA)}

Existen diferentes formas de llevar a cabo la implementación del algoritmo SA, cuyas diferencias radican en la elección de las funciones de generación y en el esquema de enfriamiento considerado. Tal es el caso del Fast annealing, que permite un esquema de enfriamiento más rápido en virtud de la función densidad de probabilidad de Cauchy que utiliza como función generadora (Szu y Hartley, 1987). Esta función es mayor para grandes perturbaciones que la función generadora gaussiana de la ecuación 2.5, lo que le otorga al método una mayor capacidad de explorar el espacio (evitando la convergencia prematura a mínimos locales), y una convergencia más rápida. Por su parte, el algoritmo Very fast simulated annealing (VFSA) usa una función generadora 
con colas aún más largas que las de la distribución de Cauchy, que permite utilizar un esquema de enfriamiento más rápido acelerando aún más la convergencia a un mínimo global. En el VFSA se muestrean rangos finitos, lo que permite establecer límites en el espacio de búsqueda. Además, la función generadora $g(\Delta x)$ se puede expandir o contraer adaptativamente de acuerdo a la sensibilidad de la función de costo respecto de cada uno de los parámetros. Por último, en el algoritmo SA, y especialmente en el VFSA, es posible incorporar restricciones, ya sean del modelo o de contorno. Las primeras pueden estar dadas por relaciones explícitas o implícitas entre los parámetros del modelo, mientras que las últimas son naturalmente implementadas en la definición de los rangos de búsqueda. En este trabajo se utiliza este último algoritmo, de manera que cuando se haga referencia al algoritmo Simulated Annealing (SA), se estará hablando, en realidad, de Very Fast Simulated Annealing (VFSA).

\subsection{Particle swarm optimization (PSO)}

El método Particle Swarm Optimization (PSO) es una estrategia de optimización inspirada en el comportamiento social observado en algunas especies de aves en relación al intercambio de conocimiento en la búsqueda de la mejor fuente de alimento (Kennedy y Eberhart, 1995). La evolución en las posiciones de cada individuo involucra tanto su conocimiento individual como el comportamiento del conjunto en la búsqueda de la solución óptima (mejor fuente de alimento). Cada individuo $i$ de un conjunto de $N$ partículas es representado por su posición dentro de un espacio $M$-dimensional dada por $\mathbf{m}_{i}=\left(m_{i}^{1}, m_{i}^{2}, \ldots, m_{i}^{M}\right)$, conservando memoria de su mejor posición previa $\mathbf{m}_{i}^{l}$, de su velocidad $\mathbf{v}_{i}$ y de la mejor posición alcanzada por algún miembro del grupo hasta el momento, $\mathbf{m}^{g}$. Una posición es mejor a otra cuando el conjunto de parámetros $\mathbf{m}_{i}$ que la definen conduce a un menor valor de la función de costo que caracteriza al problema. El proceso inicia con el conjunto de parámetros $\mathbf{m}_{i}^{0}$ distribuido aleatoriamente dentro del espacio de búsqueda $\Omega$ con velocidad inicial nula $\left(\mathbf{v}_{i}=0\right)$ para las $N$ partículas. Con el paso de las iteraciones las posiciones se actualizan buscando converger a la "mejor fuente de alimento", que corresponde al mínimo global de la función de costo. En cada iteración, la posición de cada individuo se actualiza a partir de su posición previa, utilizando la información de su "memoria" como se describe más abajo. El proceso se detiene cuando se logra alcanzar un valor deseado de la función de costo o bien cuando se alcanza el máximo de iteraciones permitidas. La Figura 2.2 ilustra este proceso: en 8 iteraciones un conjunto de 50 partículas de posiciones inicialmente aleatorias se desplaza por el espacio de búsqueda evitando los mínimos locales de la función de costo y convergiendo al mínimo global.

Numerosas modificaciones han sido aplicadas al método desde su origen, con el fin de aumentar su eficiencia. Esto ha dado lugar a diferentes versiones que involucran distintos parámetros (Poli et al., 2007). En la implementación que se utiliza en la presente Tesis se consideran las siguientes expresiones para determinar la posición de 

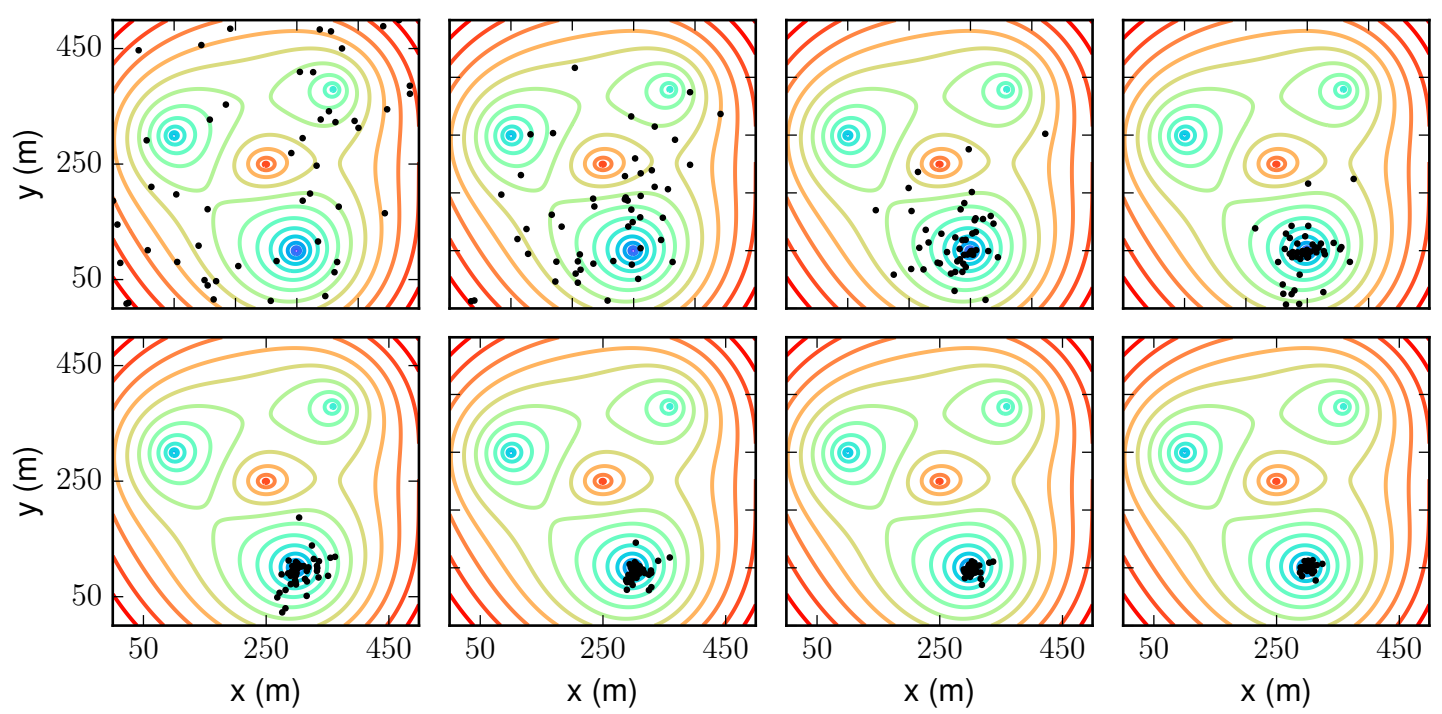

Figura 2.2. Ejemplo de funcionamiento del PSO. El conjunto de partículas de distribución inicial aleatoria converge al mínimo global de una función de costo con múltiples mínimos locales.

la $i$-ésima partícula en la iteración $k$ :

$$
\begin{aligned}
& \mathbf{v}_{i}^{k}=a\left[\mathbf{v}_{i}^{k-1}+b r\left(\mathbf{m}_{i}^{l}-\mathbf{m}_{i}^{k-1}\right)+c r\left(\mathbf{m}^{g}-\mathbf{m}_{i}^{k-1}\right)\right], \\
& \mathbf{m}_{i}^{k}=\mathbf{m}_{i}^{k-1}+\mathbf{v}_{i}^{k} .
\end{aligned}
$$

Las constantes $b$ y $c$ representan las tasas de aprendizaje que determinan la influencia de las componentes cognitiva y social, respectivamente, en el comportamiento individual. La cognición individual es representada por el segundo término de la velocidad, la componente asociada a la mejor posición individual previa. Por su parte, el tercer término de la velocidad representa la influencia social en el comportamiento de la partícula, dada por la mejor posición que ha logrado la población. Es decir, con $b$ y $c$ es posible pesar las dos componentes dependiendo del problema que se esté tratando. La constante $a$ es un factor de constricción para reducir la magnitud de las velocidades, que pueden llegar a ser muy grandes dependiendo de las dimensiones del espacio de búsqueda. Este factor fue introducido por Shi y Eberhart (1998), quienes lo denominaron factor de inercia. Por último, $r$ representa un número aleatorio de una distribución uniforme en $[0,1]$. Es importante destacar que la magnitud de estos parámetros juega un rol fundamental en la capacidad de exploración del método, ya que determinan la posibilidad de cada individuo de moverse a otras partes del espacio o de concentrarse en su vecindad. Una mayor capacidad de exploración o diversificación le otorga al método un carácter global, permitiendo el alcance del óptimo absoluto. Por otra parte, la posibilidad de intensificar la búsqueda en regiones prometedoras del espacio permite alcanzar soluciones precisas y con rapidez, pero que no necesariamente 
corresponderán al óptimo absoluto. Los valores óptimos de los coeficientes $a, b$ y $c$, que le otorguen al algoritmo los dos comportamientos simultáneamente y le permitan al mismo alcanzar un mínimo global con una precisión aceptable y en un tiempo de procesamiento razonable dependen del problema con el que se trabaje.

El método presenta un cierto grado de inestabilidad intrínseco, que se ha propuesto mitigar con la inclusión de diversas restricciones. Una de ellas es el ya mencionado factor de inercia, que suele pensarse como una "viscosidad" que puede ir aumentando con el paso de las iteraciones. La tasa de cambio de $a$ es otro factor altamente influyente en la velocidad de convergencia del método. En esta Tesis se considera que $a$ es una constante, mientras que para evitar que el método diverja a resultados que escapan del espacio de búsqueda original, se consideraron las siguientes restricciones:

- $v_{\max }$ : Las magnitudes de las velocidades no pueden superar un cierto valor máximo. Esa magnitud depende de las dimensiones del espacio de búsqueda. Cuando ocurre que $\left|\mathbf{v}_{i}\right|>v_{\max }$, se redefine la velocidad respetando la dirección que apunta a una mejor posición dependiente de las mejores posiciones previas del individuo y el grupo:

$$
\mathbf{v}_{i}=v_{\max } \frac{\mathbf{v}_{i}}{\left|\mathbf{v}_{i}\right|}
$$

- A partir de la idea propuesta por Clerc (2006), que el autor denomina Suicide and generation, cuando al modificar la posición del individuo éste escapa del espacio de búsqueda se lo elimina y se crea otro con una posición idéntica a la mejor alcanzada hasta el momento y velocidad $\mathbf{v}=0$.

La Figura 2.3 (derecha) corresponde al diagrama de flujo del algoritmo PSO utilizado en esta Tesis.

\subsubsection{Calibración del algoritmo PSO}

El algoritmo fue implementado inicialmente con los parámetros $a, b$ y $c$ utilizados por Shaw y Srivasta (2007). Sin embargo, los resultados de Lagos et al. (2014) mostraron que dicho conjunto de parámetros no son óptimos para la localización de eventos microsísmicos. En consecuencia, dada la necesidad de aumentar la eficiencia computacional del algoritmo, resultó necesario restringir los posibles valores de los parámetros $a, b$ y $c$ a un rango adecuado para el problema con el que se trabaja.

El problema de interés consiste en la determinación de las coordenadas de las fuentes microsísmicas que se originan durante los procesos de fracturación hidráulica. Por medio de un conjunto de sensores dispuestos en general en un pozo cercano a la zona de inyección (algunos cientos de metros) se registran las señales asociadas a tales eventos. Los tiempos de arribo de estas señales, en conjunto con las velocidades de propagación de las ondas en el medio, permiten estimar las posiciones de los eventos por medio de la minimización de la siguiente función de costo:

$$
J\left(x_{f}, y_{f}, z_{f}\right)=\left[\frac{1}{N} \sum_{i=1}^{N_{c}}\left(\Delta t_{i}-\Delta t_{i}^{o b s}\right)^{2}\right]^{1 / 2}
$$



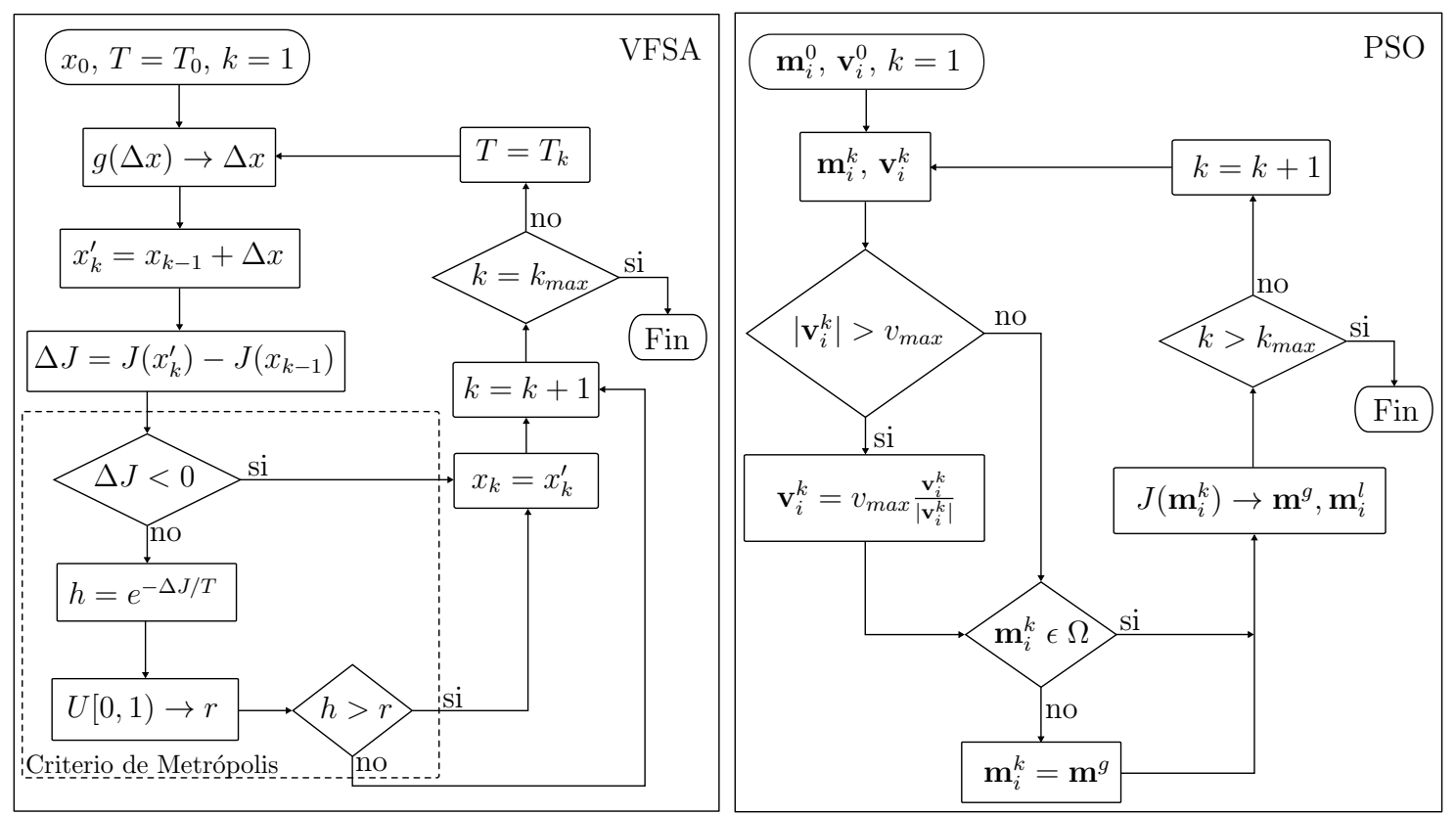

Figura 2.3. Diagramas de flujo de los métodos de optimización utilizados. $J$ corresponde a la función de costo del problema.

donde $N$ es el número de trazas, $\Delta t_{i}$ y $\Delta t_{i}^{o b s}$ son las diferencias entre los tiempos de arribo de las ondas S y P modelados y observados, respectivamente. El problema será descripto con mayor detalle en el Capítulo 5 de esta Tesis.

Con el fin de estimar para qué juego de constantes $a, b$ y $c$ el algoritmo muestra más eficiencia dado el problema a resolver, se procedió a ejecutar el programa ingresando cada vez un conjunto diferente de parámetros de aprendizaje y constricción. Para esto se consideraron tiempos de arribo de eventos microsísmicos sintéticos, generados de manera teórica considerando una geometría de adquisición dada por un pozo vertical y una nube de eventos a unos cientos de metros, en un medio homogéneo e isótropo. El programa fue ejecutado, además, con diferentes semillas para la generación de números pseudoaleatorios y utilizando diferentes datos de entrada. Es decir:

- Se consideraron 30 instancias diferentes. Cada instancia corresponde a un evento microsísmico sintético con sus correspondientes tiempos de arribo.

- Se consideraron 100 semillas para la ejecución del programa con cada una de las instancias.

- Se evaluaron valores de $a$ en el intervalo $(0.1,1.0)$, y valores de $b$ y $c$ en $(0.0,3.0)$, en todos los casos con un paso de 0.1. Estos rangos se eligieron en función de los valores recomendados por la bibliografía consultada.

Se tienen, entonces, 3000 salidas del programa para cada una de las 9610 ternas $(a, b, c)$. Para interpretar y visualizar este gran volumen de información se realizaron los siguientes pasos: 


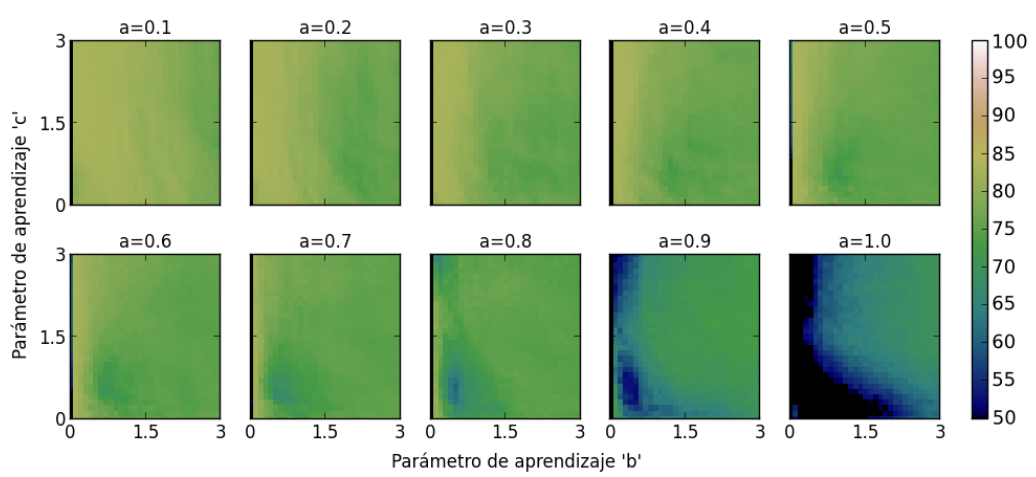

Figura 2.4. Porcentaje de éxito alcanzado para las distintas ternas $(a, b, c)$. La escala solo contempla los juegos de parámetros con más del $50 \%$ de éxito.

- Se calculó el porcentaje de éxito del método para cada una de las ternas. Se considera que una salida es "exitosa" cuando se encontró una solución sin llegar al máximo de iteraciones permitidas, es decir, cuando se alcanzó el valor esperado de la función de costo.

- Se comparó la eficiencia del método para cada terna de parámetros en función de la cantidad de iteraciones necesarias para la convergencia, dado que éstas se vinculan directamente con la cantidad total de evaluaciones de la función objetivo. Para esto se determinó la mediana de las 3000 pruebas correspondientes a cada juego de parámetros.

- Se calculó un coeficiente de eficiencia que vincule los dos puntos anteriores. Los mejores juegos de parámetros son aquellos para los cuales el porcentaje de éxito es alto y la cantidad de evaluaciones requeridas para converger es baja. De esta manera, la cantidad

$$
C_{e}=\left(1-\frac{\text { cantidad de iteraciones }}{\text { cantidad máxima de iteraciones }}\right) \times \frac{\text { porcentaje de éxito }}{100},
$$

que toma valores en el intervalo $(0,1)$, permite evaluar el comportamiento del método contemplando ambos criterios. Cuanto menor sea la cantidad de evaluaciones necesarias y mayor sea el porcentaje de éxito, mayor será $C_{e}$.

Los resultados de las pruebas realizadas se visualizan en las Figuras 2.4, 2.5 y 2.6. La Figura 2.4 muestra el porcentaje de éxito en función de $b$ y $c$, para cada uno de los 10 posibles valores de $a$. Se puede observar que para valores de $a$ de hasta 0.7 , se tienen similares resultados para todas las ternas de parámetros, pero son levemente mejores hacia los menores valores de $b$, excepto cuando $b \approx 0$. El valor de $c$ no influye significativamente en los resultados, salvo para los mayores valores de $a$.

De manera similar, en la Figura 2.5 se muestra el número de iteraciones necesarias para converger (la mediana de las 3000 pruebas para cada terna). Nuevamente se 


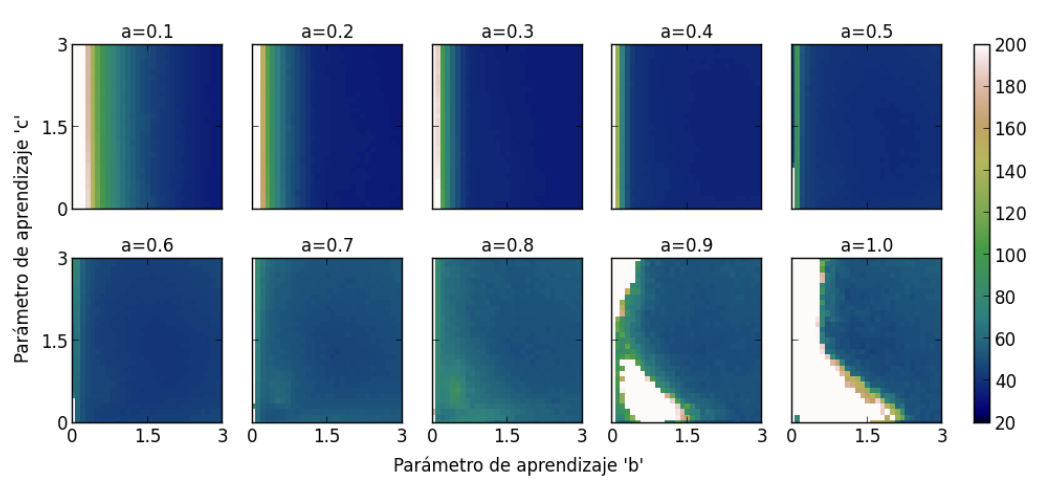

Figura 2.5. Mediana de la cantidad de iteraciones necesarias para converger, obtenida a partir de las 3000 pruebas para cada terna $(a, b, c)$. Los juegos de parámetros que requirieron más de 200 iteraciones están fuera de la escala.

observa que el algoritmo tiene buenos resultados para $a \leq 0.7$. Se observa, además, que la cantidad de iteraciones requeridas para converger aumenta hacia los menores valores de $b$ y que el intervalo de valores de este parámetro que requiere mayor cantidad de iteraciones es más grande para los $a$ pequeños. Nuevamente, $c$ no muestra una influencia significativa en los resultados, salvo para valores grandes de $a$.

Tal como se explicó anteriormente, con el fin de evaluar la eficiencia del algoritmo contemplando simultáneamente los dos análisis realizados, se calculó el coeficiente de eficiencia $C_{e}$ para cada terna (Figura 2.6). En esta figura, la escala de colores ha sido elegida de forma tal que sature para aquellas ternas para las cuales el coeficiente $C_{e}$ es menor a 0.7. Como era de esperar de acuerdo a los resultados anteriores la eficiencia es baja para $a \geq 0.8$, mejoran para valores de $b$ pequeños, pero decrece nuevamente al acercarse a $b=0$. Analizando la eficiencia considerando el porcentaje de éxito y la cantidad de iteraciones simultáneamente se pueden distinguir valores de $c$ para los cuales el algoritmo no tiene un buen rendimiento, incluso para $a \leq 0.7$. Como en ningún caso la eficiencia superó el $80 \%$, en la Figura 2.7 se ha modificado la escala de colores de la Figura 2.6 al rango $(0.7,0.8)$ para destacar esta observación. Allí se pueden distinguir con mayor claridad cuáles son las ternas para las cuales el algoritmo alcanzó una mayor eficiencia, que corresponden a valores de $a$ en el intervalo $(0.3,0.5)$, de $b$ en $(0.4,1.0)$ y de $c$ en $(1.5,3)$ (zonas en amarillo claro y blanco, donde $C_{e} \geq 0.78$ aproximadamente).

Como se observa en las diferentes figuras, el parámetro $c$ no tiene una gran influencia en los resultados, en tanto $a \leq 0.7$. Al mismo tiempo, mientras $b \neq 0$, el algoritmo muestra un alto porcentaje de éxito. Recordando que $b$ y $c$ determinan la influencia que tienen el comportamiento individual y colectivo respectivamente, estos resultados muestran que mientras a un individuo se le permita desplazarse considerando su propio conocimiento, el método converge sin importar el conocimiento grupal. Sin embargo no se debe perder de vista el hecho de que se está trabajando con el problema microsísmico simplificado, en el que el medio es homogéneo e isótropo y por lo tanto la función de 


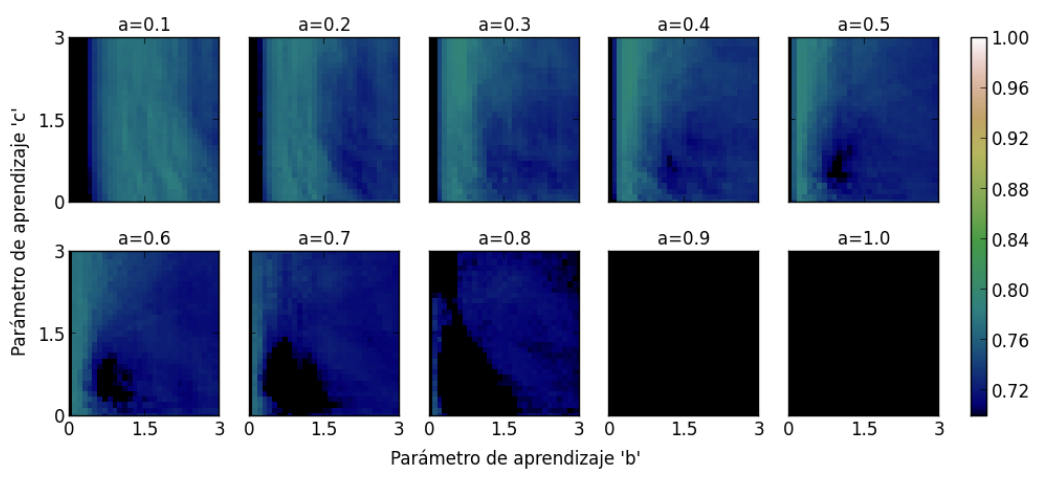

Figura 2.6. "Coeficiente de eficiencia" para las distintas ternas $(a, b, c)$. La escala de colores corresponde a $C_{e} \geq 0.7$.

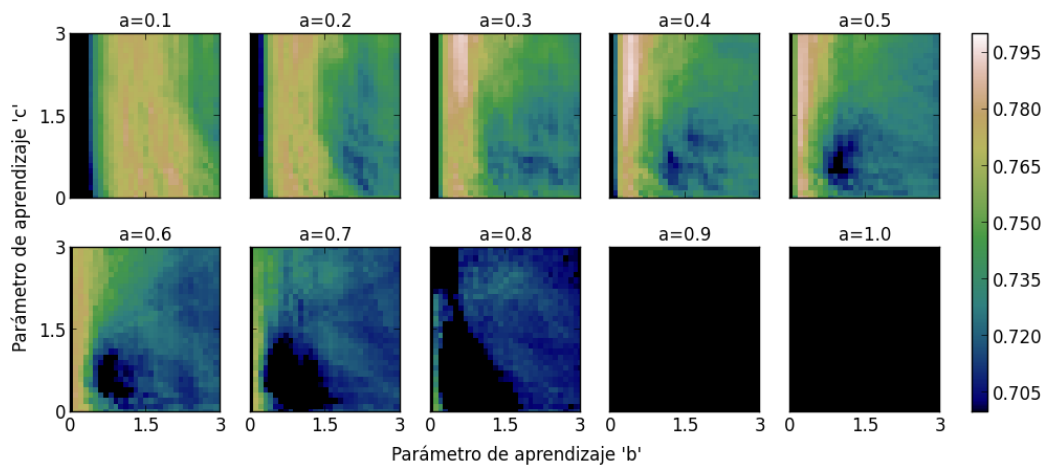

Figura 2.7. "Coeficiente de eficiencia" para las distintas ternas $(a, b, c)$. Notar que la escala de colores corresponde a $0.7 \leq C_{e} \leq 0.8$.

costo no tiene una mayor complejidad. Por esta razón, la baja influencia del parámetro $c$ podría no asociarse al algoritmo en sí, sino al problema en cuestión.

\subsection{Conclusiones}

La complejidad característica de los problemas de inversión en Geofísica motiva la utilización de algoritmos de optimización globales. Se presentaron los algoritmos Very Fast Simulated Annealing y Particle Swarm Optimization que son utilizados para la resolución de distintos problemas a lo largo de esta Tesis. En el caso del primer algoritmo, se ha utilizado una versión del mismo implementada por el Dr. Danilo Velis y modificada por el Dr. Daniel Pérez. En el segundo caso, el algoritmo fue implementado computacionalmente para esta Tesis. El conjunto de parámetros que gobiernan la eficiencia del algoritmo depende del problema en el cual es aplicado. Por lo tanto, fue necesario realizar una calibración de los mismos para su utilización en la localización de eventos microsísmicos. Del análisis de los resultados se puede concluir que los parámetros para los cuales el algoritmo muestra la mayor eficiencia para este problema 
en particular corresponden a las ternas $(a, b, c)$ en los intervalos $(0.3,0.5),(0.4,1.0) \mathrm{y}$ $(1.5,3)$, respectivamente. Es claro que no se trata de intervalos demasiado acotados, lo que habla de un comportamiento versátil del método. En el Capítulo 5 de esta Tesis se muestra la aplicación del algoritmo PSO con los parámetros estimados a partir de esta calibración para la localización de eventos microsísmicos reales, que tuvieron lugar en medios complejos. Allí se observa que, efectivamente, la utilización de los parámetros calibrados mejoran la eficiencia del método respecto de los resultados de Lagos et al. (2014), siendo adecuados para el problema a resolver. Los parámetros utilizados para el algoritmo en esta Tesis son $a=0.4, b=0.8$ y $c=2.0$. 



\section{Capítulo 3}

\section{Pre-procesamiento}

\subsection{Introducción}

Uno de los principales resultados que se buscan alcanzar mediante el procesamiento de señales microsísmicas es la determinación de las coordenadas espacio-temporales de las fuentes microsísmicas o localización. Ésta permite realizar interpretaciones primarias en relación al procedimiento de estimulación hidráulica, y es el punto de partida para un procesamiento más avanzado que permita caracterizar con mayor detalle las fuentes originadas durante la estimulación (Maxwell, 2014). El éxito de esta tarea depende en gran medida de las condiciones de la información a partir de la cual se realiza el procesamiento. La detección de un evento y el picado de sus tiempos de arribo en los registros microsísmicos, por ejemplo, está limitada por la relación señal-ruido del mismo (Akram y Eaton, 2016). Por su parte, la determinación de las coordenadas espaciales de las fuentes requiere que los sensores estén debidamente vinculados al sistema de referencia geográfico y que el modelo de velocidades considerado sea representativo del medio por el cual se propagan las señales (Grigoli et al., 2012; Bardainne y Gaucher, 2010). De esta manera, los pasos principales del pre-procesamiento, que constituyen el punto de partida del procesamiento microsísmico, están dados por: (1) la definición de la geometría de adquisición, (2) la construcción y calibración de un modelo de velocidades adecuado y (3) el acondicionamiento de los datos, en general llevado a cabo mediante la aplicación de filtros digitales.

Para definir la geometría de adquisición son necesarias la caracterización de los pozos mediante la determinación precisa de sus coordenadas, la realización de un perfil de desviación, que permite conocer con precisión la inclinación y el acimut del pozo en función de la profundidad, y la determinación de las posiciones y orientaciones de los sensores. En general, luego de que los sensores son introducidos en el pozo de monitoreo, sus posiciones son conocidas a partir de las profundidades medidas desde la boca del pozo. Esta información, sumada a la que brindan los perfiles de desviación, es utilizada para calcular las coordenadas espaciales de los geófonos. La inclinación de los mismos respecto de la dirección vertical coincide con la desviación local del pozo. No obstante, puesto que los sensores rotan al ser introducidos al pozo, su orientación es 
desconocida y debe ser determinada. Esto permite vincular las tres componentes de los sensores con el sistema de coordenadas geográfico.

La construcción de un modelo de velocidades comienza, en general, a partir de la información de perfiles sónicos del pozo de monitoreo. Esto da lugar a un modelo unidimensional de velocidades que contempla las estratificaciones del modelo asumiendo homogeneidad en cada una de las capas. Con este modelo como punto de partida, la calibración del modelo de velocidades típicamente considera el registro de una o varias fuentes de posición conocida, en general punzados, y consiste en modificar el modelo inicial para hallar aquel que mejor explique los tiempos de arribo observados y sea a su vez representativo de la litología de la zona. El modelo calibrado puede buscarse en forma manual o como la solución a un problema de inversión. La calibración del modelo de velocidades suele repetirse para cada una de las etapas de la fracturación para considerar posibles variaciones de las velocidades entre las distintas regiones del medio. Una pobre estimación del modelo de velocidades en un monitoreo microsísmico se traduce en importantes errores en la localización de los eventos. Mediante un ejemplo sintético, Maxwell et al. (2010a) muestran que errores del orden del $5 \%$ en las velocidades dan lugar a errores de decenas de metros en las posiciones estimadas de los eventos microsísmicos. La calibración del modelo de velocidades resulta, entonces, esencial para un correcto procesamiento e interpretación de las señales microsísmicas. La calibración del modelo de velocidades es un problema ambiguo: distintos modelos de velocidad pueden explicar los tiempos de arribo observados (Maxwell, 2009), de manera que toda la información que pueda considerarse para el mismo es de gran utilidad.

Las señales microsísmicas se originan en eventos de pequeña magnitud, por lo cual presentan bajas relaciones señal-ruido que dificultan su procesamiento. Existe una gran diversidad de estrategias de supresión o reducción de ruido que permiten mejorar la calidad de la señal (Sabbione et al., 2015; Velis et al., 2015; Vera Rodriguez et al., 2012). El ejemplo más común y la forma más simple de acondicionamiento de la señal es el filtrado por frecuencias (Maxwell, 2014). Éste permite remover el ruido que se encuentra por fuera del ancho de banda de la señal, manteniendo aquel que comparte su espectro con la señal. El filtrado de las señales microsísmicas, en realidad, no suele realizarse una única vez y para todo el procesamiento, sino que depende de qué paso del mismo se desee aplicar a los datos. En el caso de la detección, por ejemplo, remover tanto ruido como sea posible permitiría incrementar la relación señal-ruido y hacer visibles eventos previamente enmascarados. Sin embargo, para el picado de tiempos de arribo, se debe prestar especial atención a que los filtros utilizados sean causales para no modificar tales tiempos. Por otra parte, la estimación de la dirección de la cual proviene la energía (backazimuth) y el cálculo de parámetros de la fuente requieren que las amplitudes de las señales sean conservadas. Es decir, el filtro a utilizar debe ser definido en función de qué etapa del procesamiento se desea realizar a continuación y en todos los casos es aconsejable conservar los registros originales.

En el presente capítulo se presenta un método para estimar los ángulos de orientación de los sensores basado en el cálculo de la energía de la señal (Lagos y Velis, 2019). Esta estrategia considera las componentes horizontales del registro de una fuente 
de posición conocida, que en general puede ser un punzado. Teniendo en cuenta la inclinación y el acimut del pozo, mediante este enfoque se busca el ángulo que, luego de aplicar las rotaciones pertinentes, conduce a maximizar la energía en la dirección fuente-receptor (y a minimizarla en la dirección transversal). El método es testeado en registros sintéticos y en datos de campo adquiridos en monitoreos microsísmicos de fracturas hidráulicas llevadas a cabo en la Formación Vaca Muerta. Además, se evalúa estadísticamente la sensibilidad del método al ruido propio de la registración y a los errores esperables del picado de tiempos de arribo. Los resultados muestran que, a pesar de la simplicidad de la implementación del criterio basado en la energía, el método propuesto es una herramienta robusta que permite obtener estimaciones confiables del ángulo de orientación con una mínima supervisión del usuario (Lagos y Velis, 2019). Por otra parte, se describe el procedimiento de calibración de modelos de velocidades como solución de un problema de inversión que, además, contemple la anisotropía del medio, suponiendo que ésta es de tipo VTI (Isotropía Transversal de eje Vertical) (Pérez et al., 2019). La calibración se realiza partiendo de un modelo inicial construido a partir de perfiles sónicos de pozo y se resuelve utilizando el algoritmo Very Fast Simulated Annealing (VFSA). Por medio de un ejemplo que considera datos de campo de la Formación Vaca Muerta, se muestra la eficiencia de la estrategia y la importancia de considerar las propiedades anisotrópicas del medio.

\subsection{Orientación de sensores de pozo}

Conocer con precisión la posición y orientación de los sensores multicomponente que se utilizan en el monitoreo microsísmico es imprescindible para llevar a cabo cualquier procesamiento de las señales registradas (Le Calvez et al., 2013). Determinar la orientación de los sensores no es un problema exclusivo del monitoreo microsísmico. Los sismómetros que se disponen en el fondo oceánico, por ejemplo, también deben ser orientados luego de ser posicionados, tarea que puede ser llevada a cabo a partir de registros de pistolas de agua (air guns) o de terremotos catalogados, entre otras estrategias (Anderson et al., 1987; Li y Yuan, 1999; Stachnik et al., 2012). Otra situación típica está dada por los sensores utilizados por la sismología global o sensores magnetotelúricos que han sido orientados de acuerdo a la dirección del polo geomagnético, en áreas que presentan importantes anomalías geomagnéticas (Grigoli et al., 2012). Las técnicas estándar utilizan por lo general algún tipo de análisis de polarización de la onda $\mathrm{P}$ para determinar la orientación relativa entre el sistema de coordenadas local, correspondiente al sensor, y el sistema de coordenadas geográfico (Bulant et al., 2007; Huo et al., 2016; Greenhalgh y Mason, 1995; Li y Yuan, 1999), dado que no suelen haber sensores de referencia disponibles y es necesario determinar valores absolutos. Estas estrategias son altamente sensibles a la determinación de los tiempos de arribo y a la longitud temporal de la ventana utilizada para el cálculo. Por lo tanto, la precisión de los resultados depende fuertemente de la relación señal-ruido. En el caso del monitoreo microsísmico, por lo general, se considera un conjunto de punzados para llevar a cabo el procedimiento, aunque también pueden utilizarse drop 
balls o señales generadas con camiones vibradores, dependiendo de la geometría de adquisición y del plan de fractura. Con el fin de lograr coherencia entre las estimaciones realizadas con los registros de diferentes fuentes de posición conocida, este proceso suele implementarse de forma iterativa mediante la actualización del picado de los tiempos de arribo y las longitudes de las ventanas hasta que los ángulos de orientación obtenidos con distintas fuentes presenten desvíos aceptables. Esta tarea requiere una importante interacción del usuario con la interfaz del software utilizado.

Otras estrategias consideran la forma de onda completa para realizar el cálculo. Aunque se trata de herramientas más robustas, dependen de la existencia de un sensor de referencia de orientación conocida. Las orientaciones absolutas, entonces, son obtenidas a partir de soluciones relativas (Grigoli et al., 2012; Krieger y Grigoli, 2015). Si los ángulos de orientación de los sensores son determinados de esta manera, la acumulación de errores debe ser tenida en cuenta. En el trabajo realizado por Ekström y Busby (2008), se utilizan sismogramas sintéticos que se cross-correlacionan con los registros para obtener la orientación de los sensores. Los sismogramas sintéticos son generados a partir de los parámetros de fuente de terremotos catalogados, los cuales no están disponibles en los escenarios de monitoreo microsísmico. Zeng y McMechan (2006), por su parte, combinan una solución analítica propuesta por DiSiena et al. (1984), basada en la maximización de la potencia de la señal, con una estrategia basada en una cross-correlación, y obtienen la orientación de los sensores por medio de un ajuste por mínimos cuadrados a partir de un gran número de fuentes de posición conocida.

A continuación se muestra la implementación de una estrategia sencilla pero efectiva para el cálculo de los ángulos de orientación de sensores de pozo utilizando un criterio basado en la energía de la señal. La estrategia propuesta no requiere que el pozo sea vertical, pero requiere la información de la inclinación y acimut del pozo en las posiciones de los sensores. Se muestra que diferentes longitudes de ventana o errores en la determinación de tiempos de arribo no tienen un gran efecto en los resultados si la ventana en cuestión contiene suficiente información de la onda P. Mediante un ejemplo sintético y dos juegos de datos de campo se muestra que a pesar de su simplicidad, se trata de una estrategia robusta y en la cual la intervención requerida por parte del usuario es mínima.

\subsubsection{Metodología}

En la Figura 3.1 se ilustran los sistemas de coordenadas asociados a un sensor individual dentro de un pozo desviado. El plano y los ejes del sensor (rojo) corresponden al sistema de coordenadas local, dado por las tres componentes del sensor. El eje $z$ del sensor coincide con la dirección local del pozo, desviado de la dirección vertical $v$ un ángulo $i$. El plano horizontal está definido por la dirección $x^{\prime}$, dada por el acimut $\alpha$ del pozo (medido desde el Norte en sentido horario), y su dirección perpendicular $y^{\prime}$. El ángulo $\Omega$ es el ángulo de orientación y se mide sobre el plano del sensor entre las direcciones $y$ e $y^{\prime}$. Los ángulos $i, \alpha$ y $\Omega$ definen las rotaciones que vinculan los sistemas de coordenadas geográfico y local. En consecuencia, de acuerdo a Becquey y Dubesset 


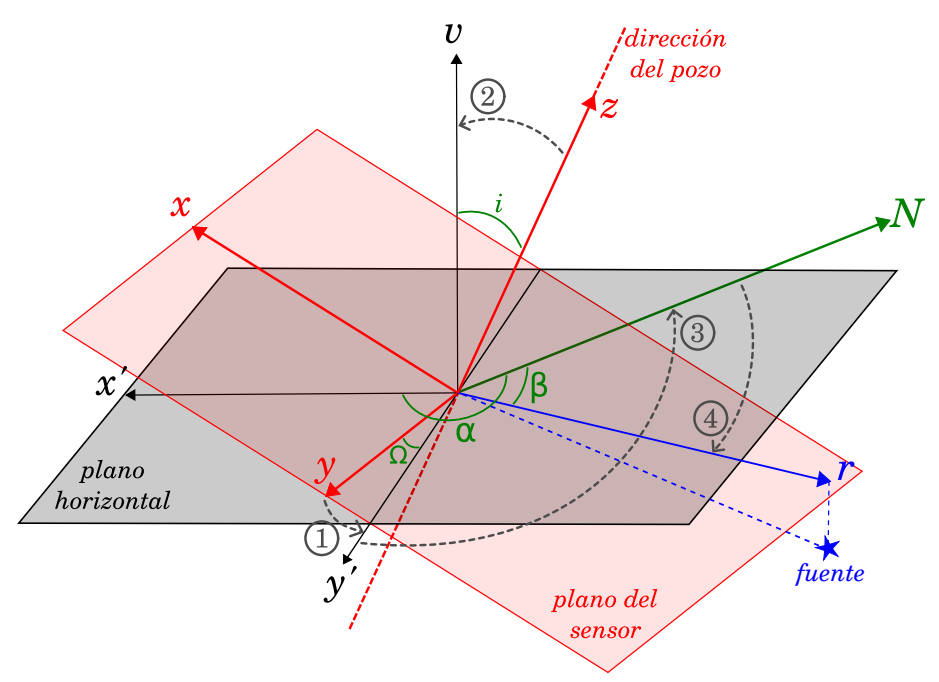

Figura 3.1. Sistemas de coordenadas geográfico y local (asociado al sensor) y los correspondientes ángulos de rotación entre ambos.

(1990) las coordenadas geográficas $\left(x_{g}, y_{g}, v\right)$ (relativas al Este y Norte geográfico y a la dirección vertical, respectivamente) de cualquier punto del espacio se pueden obtener a partir de sus coordenadas $(x, y, z)$ del sistema de coordenadas local mediante

$$
\left[\begin{array}{c}
x_{g} \\
y_{g} \\
v
\end{array}\right]=\left[\begin{array}{ccc}
\sin \alpha & -\cos \alpha & 0 \\
\cos \alpha & \sin \alpha & 0 \\
0 & 0 & 1
\end{array}\right]\left[\begin{array}{ccc}
\cos i & 0 & -\sin i \\
0 & 1 & 0 \\
\sin i & 0 & \cos i
\end{array}\right]\left[\begin{array}{ccc}
\cos \Omega & \sin \Omega & 0 \\
-\sin \Omega & \cos \Omega & 0 \\
0 & 0 & 1
\end{array}\right]\left[\begin{array}{l}
x \\
y \\
z
\end{array}\right] .
$$

Las tres matrices de rotación de la ecuación 3.1 representan, de derecha a izquierda, rotaciones antihorarias en torno a los ejes $z, y^{\prime}$ y $v$, respectivamente. Estas rotaciones se indican como 1, 2 y 3 en las flechas punteadas de la Figura 3.1.

Además, las coordenadas geográficas $\left(x_{g}, y_{g}, v\right)$ obtenidas pueden ser transformadas al sistema radial-transversal-vertical: la dirección radial corresponde a la dirección horizontal entre las posiciones de la fuente y del receptor (indicada como $r$ en la Figura 3.1), mientras que la dirección transversal es perpendicular a la primera, también en el plano horizontal. Si $\beta$ es el acimut de la dirección fuente-receptor (medido en sentido horario desde el Norte), luego:

$$
\left[\begin{array}{l}
r \\
t \\
v
\end{array}\right]=\left[\begin{array}{ccc}
\sin \beta & \cos \beta & 0 \\
-\cos \beta & \sin \beta & 0 \\
0 & 0 & 1
\end{array}\right]\left[\begin{array}{c}
x_{g} \\
y_{g} \\
v
\end{array}\right]
$$

que corresponde a una rotación en sentido horario en torno al eje $v$, indicada como 4 en la Figura 3.1.

Si se aplican todas las rotaciones anteriores a los registros que contienen los arribos correspondientes a las fuentes de posición conocida, la componente radial no debería contener energía de onda S, sino solo energía correspondiente a la onda P. Separar las 


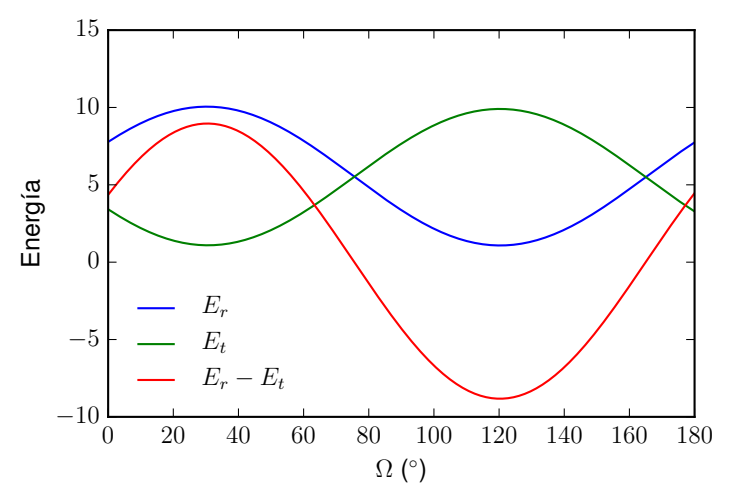

Figura 3.2. Función objetivo $J$ y energías de las componentes radial y transversal para un ejemplo sintético.

energías de las ondas $\mathrm{P}$ y $\mathrm{S}$ por medio de estas rotaciones es útil, por ejemplo, para facilitar el picado de tiempos de arribo y en consecuencia contar con mejor información de entrada para la calibración de modelos de velocidades y/o para la localización. Los ángulos $i, \alpha$ y $\beta$, por lo general, son conocidos. Por lo tanto, este enfoque puede ser utilizado para hallar los ángulos de orientación de los sensores. Para cada receptor, se consideran las ecuaciones descriptas y se lleva a cabo una búsqueda exhaustiva del ángulo $\Omega$ para el cual la energía en la componente radial es máxima y en la componente transversal es mínima, en una ventana temporal que contiene a la onda $\mathrm{P}$. Matemáticamente, el problema consiste en la maximización de la función

$$
J(\Omega)=E_{r}(\Omega)-E_{t}(\Omega)
$$

donde

$$
E_{r}(\Omega)=\sum_{i=\tau_{0}}^{\tau_{0}+\Delta T} r_{i}(\Omega)^{2}, \quad \text { y } \quad E_{t}(\Omega)=\sum_{i=\tau_{0}}^{\tau_{0}+\Delta T} t_{i}(\Omega)^{2}
$$

representan las energías de las componentes radial y transversal, respectivamente. Las $i$-ésimas muestras de las componentes radial y tangencial, $r_{i}$ y $t_{i}$, se obtienen a partir de aplicar las rotaciones de las ecuaciones 3.1 y 3.2 a las muestras $\left(x_{i}, y_{i}, z_{i}\right)$ del registro original (que corresponden al sistema de coordenadas local). El tiempo de arribo de la onda $\mathrm{P}, \tau_{0}$, se determina manualmente mientras que la longitud de la ventana temporal, $\Delta T$, es elegida de antemano. La Figura 3.2 ilustra el comportamiento de la función objetivo (ecuación 3.3) para un ejemplo sintético en el que se aplicó la metodología a un registro que fue generado asumiendo un ángulo de orientación de $32^{\circ}$. El máximo de la función $J$ se ubica en la posición esperada, en coincidencia con el máximo de la energía en la componente radial y el mínimo de la energía en la componente transversal.

Existen dos posibles valores de $\Omega$ que optimizan la ecuación 3.3, que representan un cambio de polaridad en las trazas. Esta ambigüedad puede ser resuelta, por ejemplo, a partir de considerar la información correspondiente a la componente vertical de los registros, que en conjunto con la posición conocida de la fuente, permite determinar 
unívocamente la polaridad de cada traza. Otra posibilidad es calcular la suma de todas las amplitudes de la componente radial en una ventana que contenga el primer movimiento correspondiente a la onda P, como explican Zeng y McMechan (2006). Si se sabe con certeza que las fuentes son de tipo explosivas, por ejemplo, el resultado de dicha suma debería ser negativo. Por lo tanto, la determinación de la polaridad correcta de las trazas podría considerarse como un paso adicional en la estimación de los ángulos de orientación de los sensores si se define cuidadosamente la ventana temporal que contenga únicamente el primer movimiento asociado a la onda P. En el desarrollo de la estrategia presentada para la orientación de sensores, fue evaluada la posibilidad de incluir la determinación automática de la polaridad. Sin embargo, las pruebas realizadas mostraron que las estrategias mencionadas para llevarlo a cabo requieren una muy alta precisión en la definición de la ventana temporal que contenga solo el primer movimiento asociado a la onda $\mathrm{P}$ (determinación del tiempo de arribo y de la longitud de la ventana), lo que no resultaba práctico. Por lo tanto, se optó por seleccionar manualmente la polaridad luego de la estimación del ángulo de orientación dado que, en el caso general en un monitoreo microsísmico de un proceso de fracturación hidráulica, el número de fuentes de posición conocida disponibles es pequeño.

Por otra parte, es posible que existan diferencias significativas entre la polarización de la onda $\mathrm{P}$ observada y la dirección fuente-receptor debidas a variaciones laterales en las velocidades, con lo cual la dirección radial no puede ser directamente estimada de los registros como se ha planteado hasta ahora (Van Dok et al., 2016). No obstante, en tales casos, la dirección radial puede pensarse como aquella de la cual debería proceder la energía dadas las posiciones de fuente y receptor y un modelo de velocidades 3D. En otras palabras, si el modelo de velocidades presenta variaciones laterales, la dirección radial puede ser determinada por medio de un trazado de rayos $3 \mathrm{D}$ en lugar de ser calculada directamente de la dirección que une fuente y receptor.

\subsubsection{Ejemplo sintético}

El siguiente ejemplo sintético tiene por objetivo evaluar qué tan sensible a la presencia de ruido es la estrategia propuesta. Con este fin, se propone una fuente ficticia que se modela como una explosión (tensor momento sísmico diagonal) en un medio homogéneo. El campo de ondas resultante es registrado en un arreglo de 8 sensores dispuestos en un pozo aproximadamente vertical. A los registros sintéticos generados se les agrega ruido gaussiano de banda limitada, con diferentes relaciones señal-ruido. La relación señal-ruido es calculada como el cociente entre la máxima amplitud absoluta de la señal y la desviación estándar del ruido, $\sigma$, con el fin de evitar eventuales grandes amplitudes del ruido al ser obtenidas de la distribución gaussiana. Para este ejemplo se generaron 100 registros (realizaciones) para cada relación señalruido (entre 3 y 5). La Figura 3.3 (izquierda) muestra tres registros individuales para cada una de las tres relaciones señal-ruido consideradas. Se aplicaron las rotaciones correspondientes para simular la inclinación y el acimut del pozo y un ángulo de orientación de los sensores. Los ángulos de orientación simulados para cada receptor se indican con círculos rojos en la Figura 3.3. Los ángulos de orientación para cada 

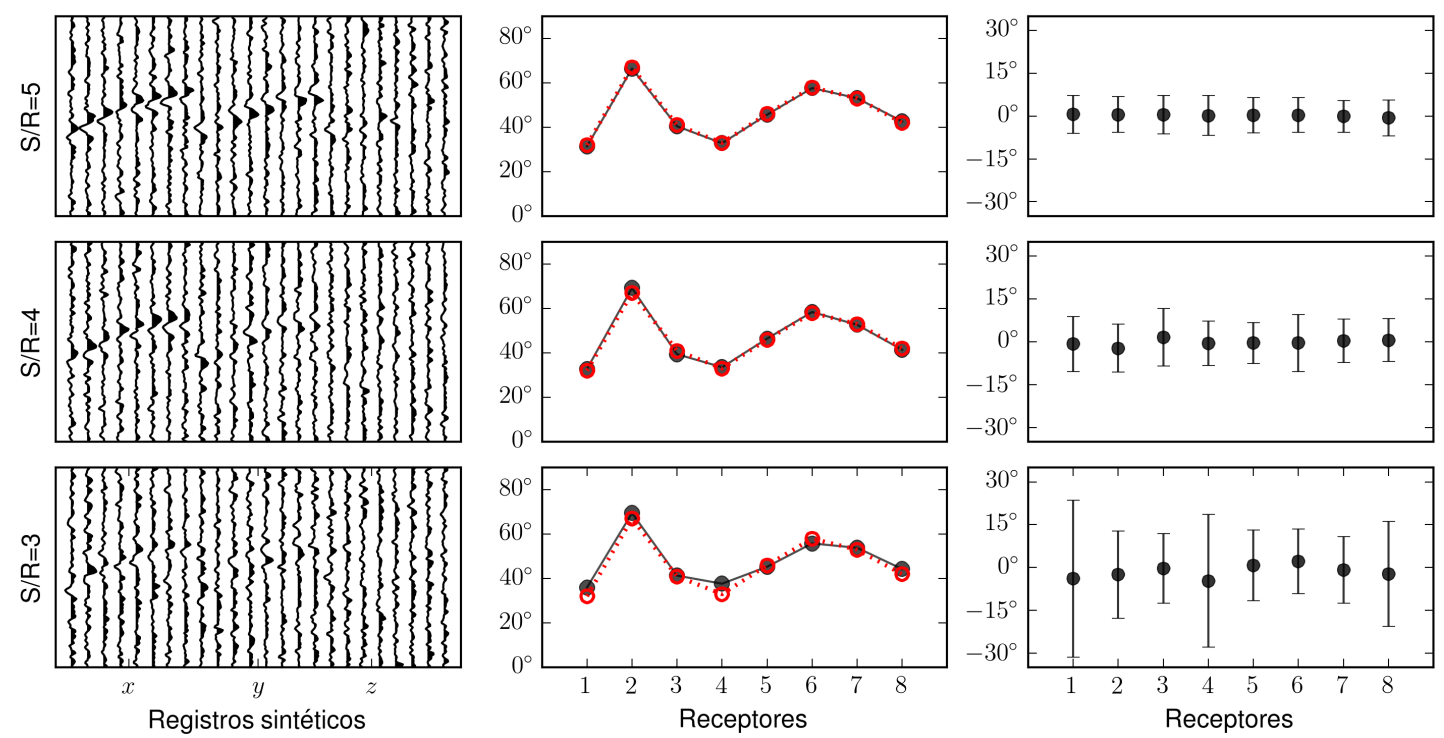

Figura 3.3. Izquierda: registros sintéticos para relaciones señal-ruido de 3 a 5. Centro: ángulos de orientación simulados (rojo) y valores medios de los ángulos de orientación estimados (negro). Derecha: errores medios y desvíos.

una de las 100 realizaciones para cada relación señal-ruido fueron calculados como se describió en la sección anterior. Los tiempos de arribo y las ventanas temporales consideradas son las mismas para todos los registros. En la Figura 3.3 se muestran los resultados de estos tests. La columna central muestra los ángulos de orientación para cada sensor (puntos negros) en comparación con los simulados (círculos rojos) y sus desvíos estándar. La columna derecha, por su parte, muestra los errores medios y los desvíos estándar. Como es de esperar, los desvíos crecen al disminuir la relación señal-ruido. Sin embargo, solo son significativos para niveles de ruido no muy frecuentes para registros de punzados, que por lo general son eventos fuertes en comparación al ruido ambiente en los escenarios considerados. Se realizaron pruebas para relaciones señal-ruido más altas que no se muestran en la figura pues las desviaciones para estos casos se vuelven despreciables.

\subsubsection{Ejemplo con datos de campo}

La herramienta propuesta fue testeada utilizando dos conjuntos de registros de punzados realizados en dos procedimientos de estimulación hidráulica en la Formación Vaca Muerta. El juego de datos que llamamos "Set 1" está compuesto por tres punzados de cada una de 7 etapas (21 en total) registrados en un arreglo de 7 sensores dispuestos en un pozo aproximadamente vertical. La Figura 3.4 (arriba) muestra un registro típico para los punzados de este juego de datos. En el caso del segundo juego de datos, "Set 2 ", se dispone de 3 punzados en total. En este caso, los registros se obtuvieron con un arreglo de 10 receptores, también ubicados en un pozo aproximadamente vertical. 

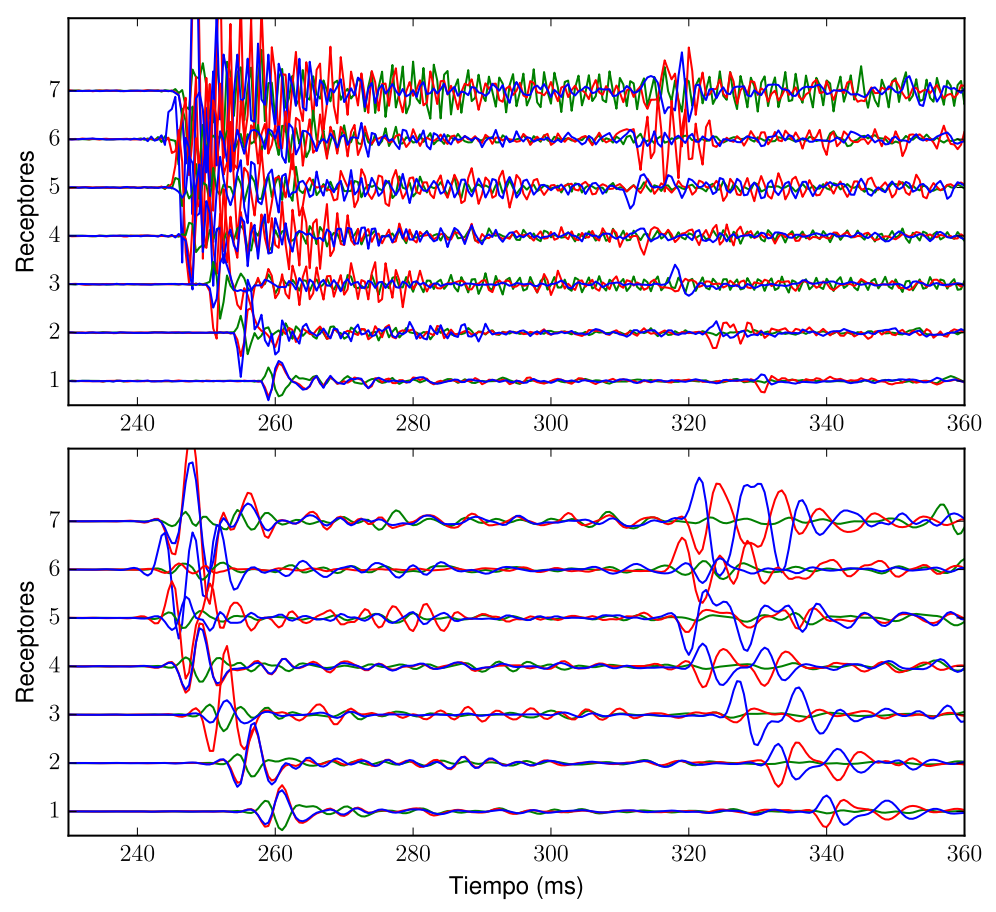

Figura 3.4. Registro correspondiente a un punzado del "Set 1". Arriba: registro original; Abajo: registro luego de aplicar un filtro pasabanda (30$300 \mathrm{~Hz}$ ). Los colores azul, rojo y verde indican las componentes $x, y$ y $z$ (en el sistema local) del registro, respectivamente.

En ambos casos se cuenta con la información de inclinación y acimut de los pozos correspondientes y se asumieron modelos de velocidad sin variaciones laterales.

La Figura 3.5 muestra los ángulos de orientación de los sensores obtenidos para el "Set 1". Los resultados para cada uno de los 21 punzados se indican con círculos, mientras que los triángulos representan los respectivos valores medios. Los resultados que se muestran en la Figura 3.5a se obtuvieron a partir de los registros originales sin ningún tipo de filtrado, mientras que para los resultados de la Figura 3.5b, un filtro pasabanda $(30-300 \mathrm{~Hz})$ fue aplicado previamente a los datos. En la Figura 3.4 se muestra el registro de un punzado original (arriba) y luego de la aplicación del filtro mencionado (abajo). Las Figuras 3.5c y 3.5d muestran las diferencias entre los ángulos individuales y los respectivos valores medios. Por su parte, la Figura 3.7 muestra los resultados para el "Set 2". Los tiempos de arribo fueron determinados de forma manual, y se consideró una longitud fija de $20 \mathrm{~ms}$ para todas las ventanas temporales. La ambigüedad en la polaridad de las trazas se resolvió de forma manual con el fin de poder prescindir de una gran precisión en la determinación de los tiempos de arribo y en la selección de las ventanas temporales utilizadas, como se explicó anteriormente. 

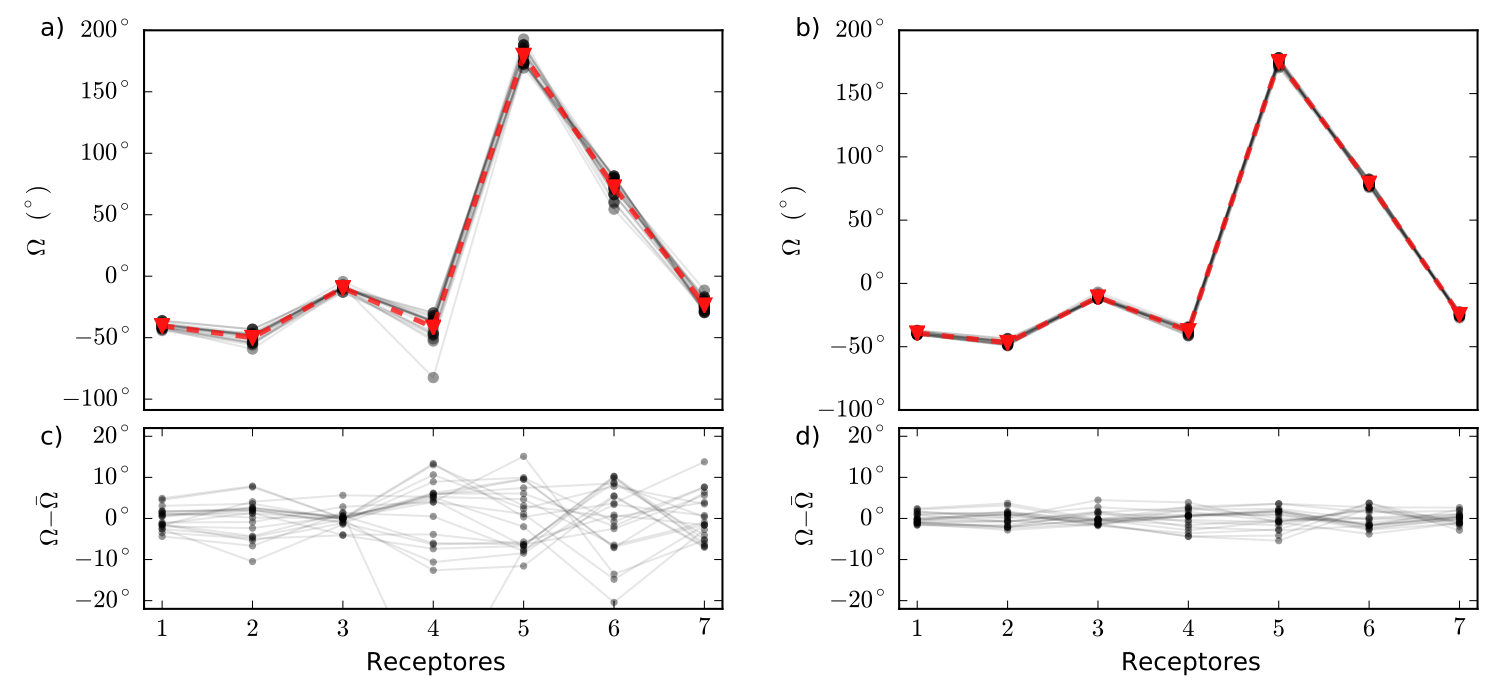

Figura 3.5. Ángulos de orientación estimados para cada receptor a partir de los punzados (gris) del "Set 1" de datos de campo y valores medios (rojo) para (a) los datos originales y (b) los datos filtrados. (c) y (d) Diferencia entre los resultados obtenidos para cada punzado y los valores medios para los casos (a) y (b), respectivamente.

Los resultados muestran que se alcanza una gran consistencia entre los ángulos de orientación obtenidos para cada sensor, independientemente del punzado considerado para el cálculo. En el caso de los datos sin filtrar del "Set 1" (Figure 3.5a), a pesar de que el ruido presente en los datos introduce dispersión a las soluciones, el filtro aplicado permitió mejorar significativamente la consistencia de los resultados sin introducir errores en los valores medios, como se muestra en la Figura 3.6. Las diferencias entre los ángulos de orientación individuales y medios se mantienen menores a los $8^{\circ}$ para el "Set 1" filtrado, y menores a $0.5^{\circ}$ para el "Set 2 ".

Con el fin de evaluar la robustez de la estrategia propuesta, se realizaron pruebas adicionales considerando diferentes condiciones que podrían alterar los resultados:

- Errores gaussianos en el picado de tiempos de arribo, con $\sigma=2 \mathrm{~ms}$. Estos errores doblan los desvíos esperados para el picado de tiempos de arribo de eventos microsísmicos (Eisner et al., 2010).

- Errores sistemáticos (sesgos) obtenidos de una distribución uniforme en el intervalo $[-3,3]$ ms. Estos errores suelen ser introducidos involuntariamente por quien realiza el picado manual o bien por un algoritmo automático que no determine con precisión el primer quiebre sino cruces por cero o máximos.

- Ventanas temporales de longitud variable entre $5 \mathrm{~ms}$ y $40 \mathrm{~ms}$. Estas variaciones se introducen para simular los cambios en las ventanas que una estrategia tradicional de análisis de polarización requiere. El rango se eligió teniendo en cuenta que 


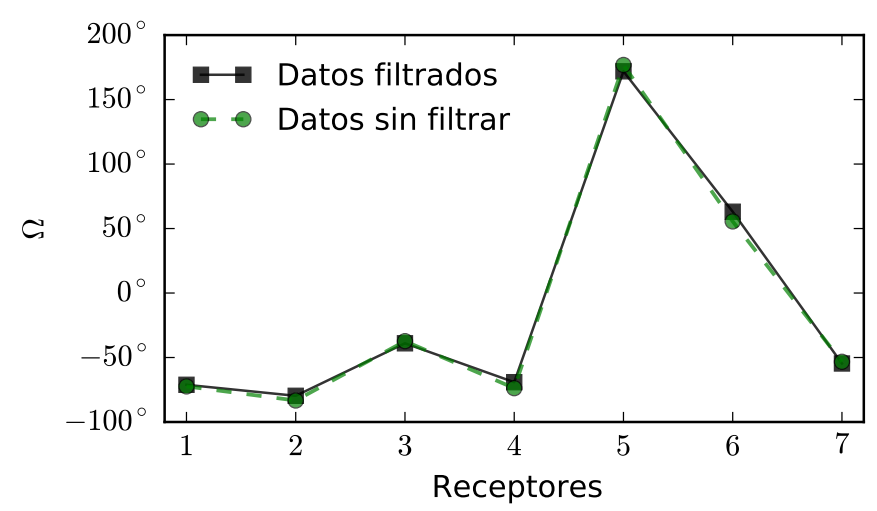

Figura 3.6. Ángulos de orientación medios para los datos originales y filtrados del "Set 1".
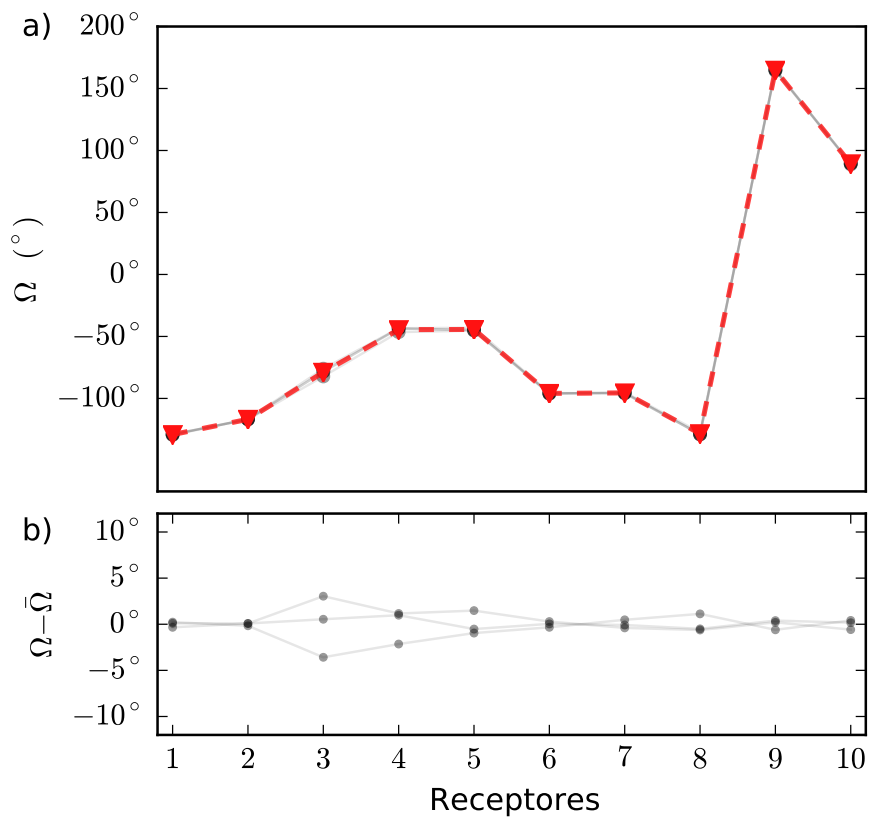

Figura 3.7. (a) Ángulos de orientación calculados para cada receptor a partir de los punzados (gris) del "Set 2" de datos de campo y los correspondientes valores medios (rojo). (b) Diferencias entre los resultados obtenidos para cada punzado y los respectivos valores medios. 


\begin{tabular}{ccccc}
\hline Receptor & $\bar{\Omega}$ & $\sigma_{\Omega}$ & Mínimo & Máximo \\
\hline 1 & $-71.1^{\circ}$ & $1.2^{\circ}$ & $-73.5^{\circ}$ & $-68.3^{\circ}$ \\
2 & $-79.8^{\circ}$ & $1.8^{\circ}$ & $-83.3^{\circ}$ & $-74.0^{\circ}$ \\
3 & $-38.7^{\circ}$ & $1.8^{\circ}$ & $-42.8^{\circ}$ & $-33.0^{\circ}$ \\
4 & $-68.6^{\circ}$ & $2.7^{\circ}$ & $-74.5^{\circ}$ & $-60.8^{\circ}$ \\
5 & $172.2^{\circ}$ & $2.8^{\circ}$ & $163.2^{\circ}$ & $176.0^{\circ}$ \\
6 & $63.3^{\circ}$ & $2.4^{\circ}$ & $59.0^{\circ}$ & $68.2^{\circ}$ \\
7 & $-54.6^{\circ}$ & $1.3^{\circ}$ & $-58.3^{\circ}$ & $-51.3^{\circ}$ \\
\hline
\end{tabular}

Tabla 3.1. Ángulos de orientación medios $\bar{\Omega}$ para cada receptor, desvíos estándar $\sigma_{\Omega}$ y valores máximos y mínimos obtenidos luego de las 1000 realizaciones para los 21 punzados del "Set 1 " de datos de campo.

ventanas más cortas podrían no contener información de la onda $\mathrm{P}$ en absoluto, y ventanas más largas podrían contener además otras fases.

Se llevaron a cabo 1000 realizaciones independientes teniendo en cuenta los errores listados, para cada uno de los 21 punzados del "Set 1" (un total de 21000 pruebas). La Tabla 3.1 resume los resultados obtenidos. En estos resultados, se destacan los pequeños desvíos estándar alcanzados a pesar de las diferentes fuentes de error consideradas, que incluyen errores significativos en el picado de tiempos de arribo y una gran variedad de longitudes de las ventanas.

En la Figura 3.8 se muestra una de cada 200 realizaciones. Siempre que la onda P o parte de ella esté contenida en la ventana considerada, y que esta ventana no contenga ninguna otra fase, la estrategia basada en el cálculo de la energía por componentes conduce a resultados estables.

Por último, una forma de evaluar el éxito de los resultados obtenidos para los ángulos de orientación, es visualizar los registros originales en contraste con los obtenidos luego de aplicar las rotaciones descriptas por las ecuaciones 3.1 y 3.2. Con ese objetivo, la Figura 3.9 muestra las componentes horizontales del registro correspondiente a un punzado del "Set 1" antes y luego de la rotación al sistema radial-transversal-vertical. Puede observarse cómo las energías de las ondas $\mathrm{P}$ y S, originalmente distribuidas en ambas componentes, luego de la rotación resultan claramente separadas en las componentes radial y transversal, respectivamente. De la misma manera, la Figura 3.10 muestra el registro de un punzado del "Set 2" antes y después de aplicar la rotación. 


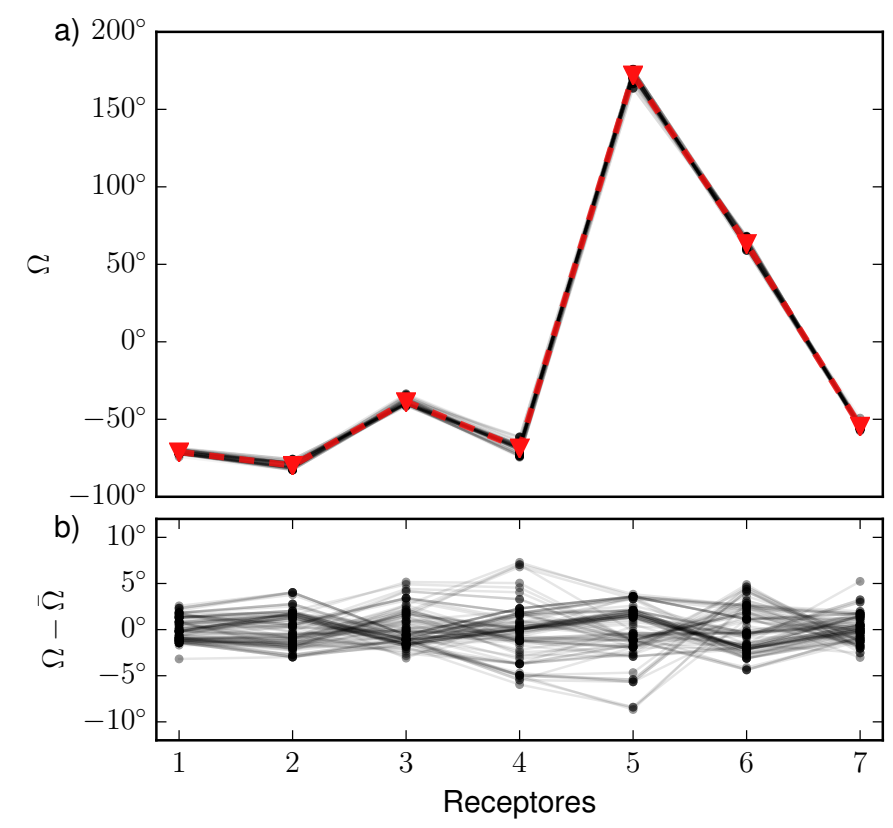

Figura 3.8. Resultados de las 1000 realizaciones llevadas a cabo para cada uno de los 21 punzados (solo se muestra uno de cada 200): (a) Ángulos de orientación calculados para cada receptor a partir de los punzados del "Set 1" de datos de campo (gris) y valores medios (rojo). (b) Diferencias entre los resultados obtenidos para cada punzado y los respectivos valores medios. 

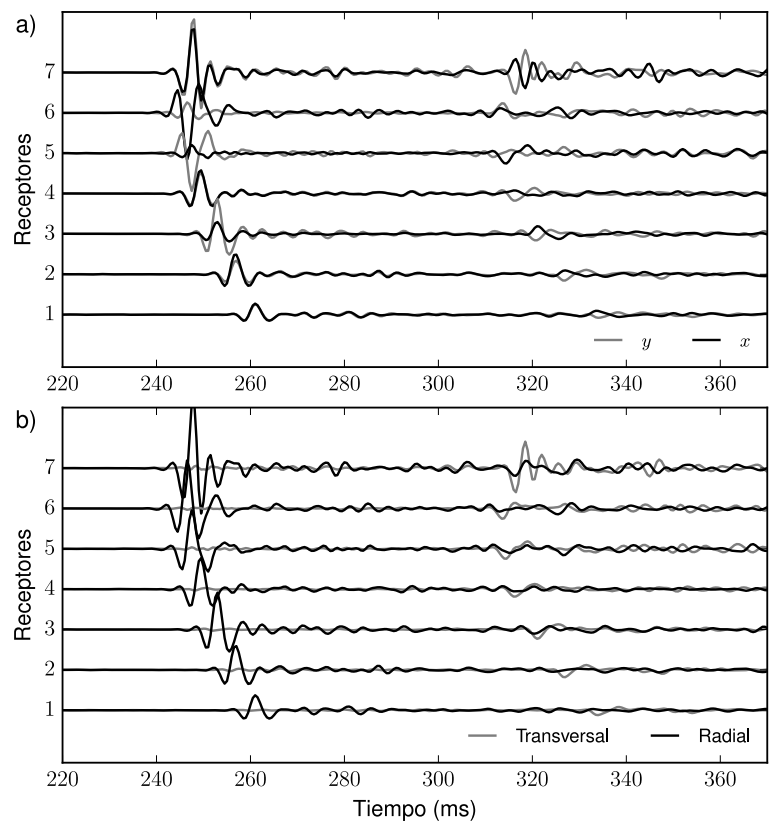

Figura 3.9. (a) Registro correspondiente a un punzado del "Set 1" de datos de campo (filtrado con un pasa-banda en el rango de frecuencias 30 $\mathrm{Hz}-300 \mathrm{~Hz}$ ); (b) Registro de (a) luego de la rotación al sistema radialtransversal-vertical a partir del ángulo de orientación obtenido con la estrategia propuesta. 

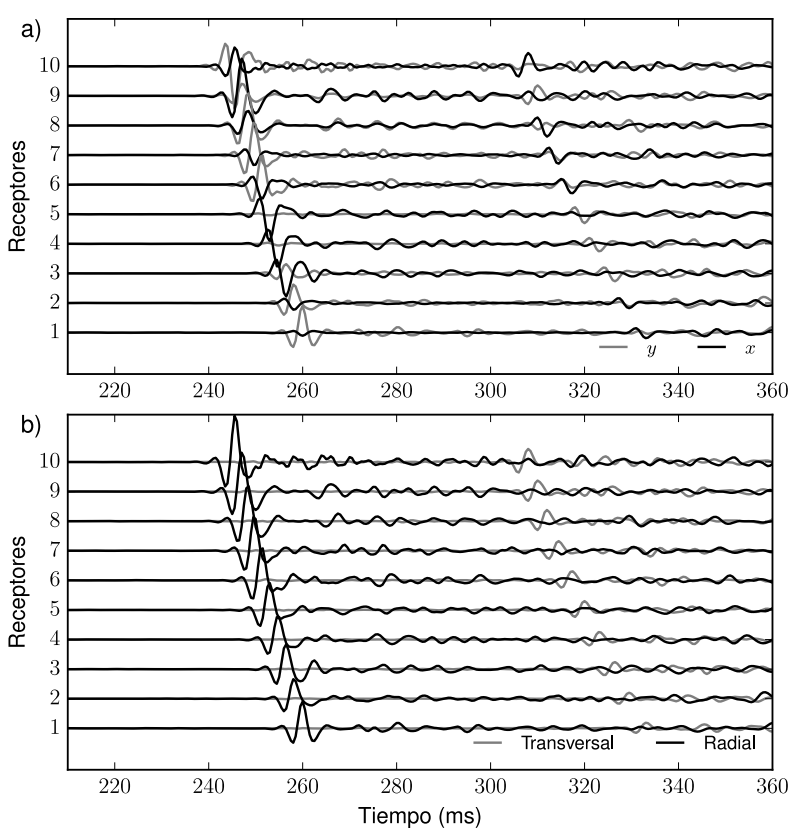

Figura 3.10. (a) Registro correspondiente a un punzado del "Set 2" de datos de campo (filtrado con un pasa-banda en el rango de frecuencias 30 $\mathrm{Hz}-300 \mathrm{~Hz}$ ); (b) Registro de (a) luego de la rotación al sistema radialtransversal-vertical a partir del ángulo de orientación obtenido con la estrategia propuesta. 


\subsection{Calibración de modelos de velocidades}

Como ya se mencionó, los modelos de velocidades que se utilizan en el monitoreo microsísmico se construyen a partir de perfiles sónicos de pozo. Estos perfiles son obtenidos por medio de la medición de los tiempos de tránsito de una señal por unidad de distancia, en la dirección del pozo. La señal utilizada es de alta frecuencia, en general entre $1 \mathrm{kHz}$ y $50 \mathrm{kHz}$ (Sheriff, 2002), muy superior a las frecuencias características de las señales microsísmicas, que pueden alcanzar frecuencias de algunos cientos de Hz. Los perfiles obtenidos son afectados por diversos factores tales como deformidades del pozo, invasión del lodo de perforación en las formaciones aledañas, entre otros (Sheriff y Geldart, 1995). Las velocidades obtenidas de esta manera presentan rápidas fluctuaciones resultando en funciones muy irregulares con la profundidad, un efecto que no es significativo frente a las longitudes de onda de las señales observadas. Más aún, son características locales de las formaciones, que no representan con gran fidelidad el comportamiento del medio en toda la región de interés, sino más bien en torno al pozo. Además, en la mayoría de los casos las herramientas utilizadas para el perfilaje solo miden velocidades en la dirección vertical. En consecuencia, es necesario realizar un ajuste de los perfiles sónicos para que éstos sean consistentes con las señales que se propagan por el medio, que en el caso del monitoreo microsísmico de pozo tienen direcciones de propagación predominantemente horizontales.

La construcción del modelo de velocidades requiere la segmentación de los perfiles sónicos en diferentes intervalos y la asignación de velocidades para cada uno de ellos. La segmentación se puede llevar a cabo manualmente, definiendo intervalos de características litológicas comunes basadas en información geológica, por medio de algún algoritmo de segmentación (Velis, 2007), o discretizando las profundidades en intervalos regulares. A continuación, a cada intervalo definido se le debe asignar una velocidad, a partir, por ejemplo, del cálculo de un promedio de Backus de los perfiles sónicos o considerando promedios simples de una versión suavizada de los mismos (Rutledge y Phillips, 2003; Maxwell, 2014; Grechka y Heigl, 2017).

Las laminaciones características de los minerales que conforman los reservorios tipo shale, en conjunto con la estratificación propia de los depósitos sedimentarios permiten que las shales puedan ser descriptas por medio de modelos de velocidades con anisotropía polar o transversalmente isótropos respecto de un eje de simetría, en general vertical (VTI) o con alguna inclinación (TTI), perpendicular a la estratificación (Sayers, 2005; Nadri et al., 2012). Ignorar la anisotropía de este tipo de reservorios introduce importantes errores en las posiciones estimadas de los eventos microsísmicos (Maxwell et al., 2010a; Erwemi et al., 2010)

Durante el desarrollo de las tareas que condujeron a la presente Tesis, se trabajó en conjunto con los Dres. Daniel Pérez, Danilo Velis y Juan Soldo en el desarrollo de una estrategia de inversión de modelos de velocidades anisótropos a partir de la información brindada por perfiles sónicos. El modelo de velocidades se asume compuesto por un conjunto de capas horizontales que presentan anisotropía VTI. En un medio VTI, las velocidades de propagación de las ondas no varían en las direcciones horizontales, sino únicamente en dirección vertical y la anisotropía puede ser caracterizada por medio de 
los llamados "parámetros de Thomsen" (Thomsen, 1986). El modelo de velocidades se obtiene como la solución a un problema de optimización que se resuelve por medio del algoritmo Very Fast Simulated Annealing descripto en el Capítulo 2. La inversión del modelo de velocidades, entonces, consiste en la determinación de cinco parámetros: las velocidades de ondas $\mathrm{P}, \mathrm{S}$ y los parámetros de Thomsen, considerando la formulación de anisotropía "débil" para cada uno de los intervalos considerados. La profundidad de la interfase que separa dos intervalos también se considera como una incógnita adicional, por lo que se tiene un total de seis incógnitas por capa. Para reducir la ambigüedad propia del problema, se consideran restricciones basadas en la relación existente entre el carácter anisótropo de las rocas de las formaciones de interés y su litología, como se describe más abajo.

\subsubsection{Fundamentos teóricos}

Un medio elástico transversalmente isótropo puede ser caracterizado por medio de cinco parámetros independientes (Shearer, 2009; Backus, 1962). En lo que sigue, nos interesa el caso particular de medios VTI, en los que la anisotropía se manifiesta únicamente en relación a la dirección vertical. El tensor de coeficientes elásticos $C_{i j k l}$ que permite vincular tensiones y deformaciones en un medio de estas características de acuerdo a la ley de Hooke tiene la forma (Udías, 1999; Thomsen, 1986):

$$
C_{i j k l}=\left[\begin{array}{cccccc}
A & (A-2 E) & C & 0 & 0 & 0 \\
(A-2 E) & A & C & 0 & 0 & 0 \\
C & C & B & 0 & 0 & 0 \\
0 & 0 & 0 & D & 0 & 0 \\
0 & 0 & 0 & 0 & D & 0 \\
0 & 0 & 0 & 0 & 0 & E
\end{array}\right]
$$

donde $A=C_{1111}, B=C_{3333}, C=C_{3311}, D=C_{2323}$, y $E=C_{1212}$. Si esta relación entre tensiones y deformaciones es empleada en la ecuación de movimiento, la ecuación de onda resultante tiene tres soluciones independientes: las ondas P, SH y SV, cuyas velocidades $v_{P}, v_{S H} \mathrm{y} v_{S V}$ dependen del ángulo $\theta$ entre la dirección de propagación y el eje de simetría (en el caso VTI, la dirección vertical). La onda P está polarizada aproximadamente en la dirección de propagación, mientras que las ondas SH y SV están polarizadas en dirección horizontal y vertical, respectivamente. Si $v_{P_{0}}$ y $v_{S_{0}}$ corresponden a las velocidades verticales de las ondas $\mathrm{P}$ y $\mathrm{S}$, las velocidades en función de la dirección de propagación resultan:

$$
\begin{aligned}
v_{P}(\theta)^{2} & =v_{P_{0}}^{2}\left[1+\varepsilon \sin ^{2} \theta+u(\theta)\right], \\
v_{S V}(\theta)^{2} & =v_{S_{0}}^{2}\left[1+\frac{v_{P_{0}}^{2}}{v_{S_{0}}^{2}} \varepsilon \sin ^{2} \theta-\frac{v_{P_{0}}^{2}}{v_{S_{0}}^{2}} u(\theta)\right], \\
v_{S H}(\theta)^{2} & =v_{S_{0}}^{2}\left[1+2 \gamma \sin ^{2} \theta\right],
\end{aligned}
$$


donde

$$
u(\theta)=\frac{1}{2} w\left[\left(1+\frac{4 \delta^{*}}{w^{2}} \sin ^{2} \theta \cos ^{2} \theta+\frac{4(w+\varepsilon) \varepsilon}{w^{2}} \sin ^{4} \theta\right)^{1 / 2}-1\right]
$$

con

$$
\begin{gathered}
w=1-\frac{v_{P_{0}}^{2}}{v_{S_{0}}^{2}}, \\
\varepsilon=\frac{A-B}{2 B}, \\
\gamma=\frac{E-D}{2 D}, y \\
\delta^{*}=\frac{1}{2 B^{2}}\left[2(C+D)^{2}-(B-D)(A+B-2 D)\right] .
\end{gathered}
$$

Las ecuaciones descriptas presentan una complejidad algebraica que dificulta la estimación de los correspondientes coeficientes elásticos por medio de algoritmos de inversión y, en consecuencia, la interpretación de los efectos de la anisotropía sobre la información sísmica. Frente a esta situación, Thomsen (1986) propone la aproximación de anisotropía débil, mediante la cual las expresiones para velocidades de propagación de las ondas P, SV y SH se simplifican a

$$
\begin{aligned}
v_{P}(\theta) & =v_{P_{0}}\left(1+\delta \sin ^{2} \theta \cos ^{2} \theta+\varepsilon \sin ^{4} \theta\right), \\
v_{S V}(\theta) & =v_{S_{0}}\left(1+\frac{v_{P_{0}}^{2}}{v_{S_{0}}^{2}}(\varepsilon-\delta) \sin ^{2} \theta \cos ^{2} \theta\right), \mathrm{y} \\
v_{S H}(\theta) & =v_{S_{0}}\left(1+\gamma \sin ^{2} \theta\right),
\end{aligned}
$$

donde

$$
\delta=\frac{(C+D)^{2}-(B-D)^{2}}{2 B(B-D)} .
$$

Los parámetros $\varepsilon, \delta$ y $\gamma$ son conocidos como parámetros de Thomsen. Estos parámetros son adimensionales y, en el caso de anisotropía débil, toman valores absolutos significativamente menores a 1.

\subsubsection{Planteo del problema inverso}

El problema inverso que se propone resolver busca estimar las propiedades del medio (velocidades y parámetros de Thomsen) utilizando como dato de entrada los tiempos de arribo de las señales generadas en una o más fuentes de posición conocida al conjunto de receptores utilizado para el monitoreo microsísmico. Si $n_{r}$ es la cantidad de receptores disponibles, en los cuales se realizó el picado de los tiempos de viaje de las ondas $\mathrm{P}, \mathrm{SV}$ y SH, el problema de inversión se resuelve por medio de la minimización 
de la función de costo

$$
J(\boldsymbol{m})=\left[\frac{1}{n_{r}}\left(\left\|(\Delta \mathbf{t}-\Delta \hat{\mathbf{t}})_{P-S H}\right\|_{2}^{2}+\left\|(\Delta \mathbf{t}-\Delta \hat{\mathbf{t}})_{P-S V}\right\|_{2}^{2}\right)\right]^{1 / 2},
$$

donde el vector $\boldsymbol{m}$ contiene los parámetros del modelo dados por las velocidades verticales de propagación y parámetros de Thomsen en las distintas capas $\boldsymbol{v}_{\boldsymbol{P}_{\mathbf{0}}}, \boldsymbol{v}_{\boldsymbol{S}_{\mathbf{0}}}, \boldsymbol{\varepsilon}$, $\boldsymbol{\delta}$ y $\boldsymbol{\gamma}$, y las profundidades de las interfases, $\boldsymbol{z}$. Los vectores $\Delta \mathbf{t}$ y $\Delta \hat{\mathbf{t}}$ corresponden a las diferencias de tiempos de arribo observadas y calculadas, respectivamente, para los pares de fases correspondientes. Esta función de costo es independiente del tiempo de origen de los eventos en cuestión, cuya precisa determinación durante la operación es compleja, por lo que las diferencias de tiempos de arribo coinciden con las diferencias de tiempos de viaje.

La función $J(\boldsymbol{m})$ es no lineal respecto de las variables $\boldsymbol{m}$, presenta discontinuidades y mínimos locales, por lo que su minimización requiere algún algoritmo de optimización global capaz de superar estas dificultades. Por esta razón, se considera al algoritmo Very Fast Simulated Annealing (VFSA) (Ingber, 1989; Velis, 1998), que no requiere el cálculo de derivadas y su solución no depende del modelo inicial. Los tiempos de viaje $\hat{t}$ entre las fuentes de posición conocida y los receptores son calculados por medio de un trazado de rayos que fue desarrollado para esta Tesis, y que contempla medios estratificados anisótropos. El trazado de rayos empleado se describe en el Apéndice A. Las fuentes de posición conocida consideradas aquí corresponden a punzados realizados al inicio de las distintas etapas de una fractura hidráulica, aunque la metodología descripta para la inversión de velocidades y parámetros de anisotropía no se limita a este tipo de fuentes.

Existe una importante relación de dependencia entre los parámetros de Thomsen y las velocidades de las ecuaciones 3.12, lo que en conjunto con el gran número de incógnitas, da lugar a una importante ambigüedad en el problema de optimización. Esta ambigüedad puede ser mitigada si se reduce el número de incógnitas y/o se imponen restricciones a las soluciones basadas en la información geológica disponible. Siguiendo a Mizuno et al. (2010) se asume que el grado de anisotropía del medio se asocia directamente al contenido de arcilla de las rocas. En consecuencia, los parámetros de Thomsen pueden ser escritos por medio de las relaciones

$$
\begin{aligned}
\boldsymbol{\varepsilon} & =\hat{\varepsilon} \mathbf{c}, \\
\boldsymbol{\delta} & =\hat{\delta} \mathbf{c}, \mathrm{y} \\
\boldsymbol{\gamma} & =\hat{\gamma} \mathbf{c},
\end{aligned}
$$

donde $\hat{\varepsilon}, \hat{\delta}$ y $\hat{\gamma}$ son factores de escala. El vector $\mathbf{c}$ tiene tantos elementos como capas tiene el modelo $\left(n_{l}\right)$ y cada uno de ellos está dado por

$$
c_{i}=\frac{\nu_{i}-\nu_{\min }}{\nu_{\max }-\nu_{\min }}, \quad i=1, \ldots, n_{l}
$$


donde $\nu_{i}$ representa al contenido de arcilla en la $i$-ésima capa y $\nu_{\min }$ y $\nu_{\max }$ son los valores mínimo y máximo para éste. Por lo general el contenido de arcilla puede ser estimado a partir de un perfil de gamma-ray, asumiendo que el máximo valor que éste muestra corresponde a formaciones netamente arcillosas y el valor mínimo a formaciones libres de arcillas (Corona y Mavko, 2008; Rider y Kennedy, 2011). Cuando el perfil de gamma-ray no está disponible, una aproximación a la cuantificación del contenido de arcilla está dada por el cociente $v_{P_{0}} / v_{S_{0}}$ (Mizuno et al., 2010; Leaney et al., 2014) en el caso de formaciones predominantemente arcillosas, o por $1 / v_{P_{0}}$ si se trata de sistemas carbonáticos (Leaney, 2014). Por consiguiente, de acuerdo a la formulación dada por las ecuaciones 3.15 a 3.18 en conjunto con las ecuaciones 3.12 , las incógnitas del problema son las velocidades verticales $\boldsymbol{v}_{\boldsymbol{P}_{\mathbf{0}}}$ y $\boldsymbol{v}_{\boldsymbol{S}_{\mathbf{0}}}$, las profundidades de las interfases $\boldsymbol{z}$ y los factores de escala $\hat{\varepsilon}, \hat{\delta}$ y $\hat{\gamma}$. Las velocidades verticales y las profundidades de las interfases son inicializadas a partir de la información que aportan los perfiles de pozo, y son ajustadas (total o parcialmente) como parte del proceso de calibración del modelo de velocidades.

\subsubsection{Ejemplo con datos de la Formación Vaca Muerta}

Con el propósito de evaluar la metodología descripta se muestra un ejemplo de calibración de un modelo de velocidades anisótropo (VTI) a partir de datos de campo registrados en un monitoreo microsísmico de un proceso de fracturación hidráulica en la Formación Vaca Muerta. En el área de estudio, la Formación Vaca Muerta tiene un espesor que supera los $350 \mathrm{~m}$ de margas con un contenido de carbonatos y cuarzos variables y un bajo porcentaje de arcillas (5-19\%). Distintas observaciones permiten asumir que la Formación Vaca Muerta se comporta como un medio VTI, con valores de los parámetros de Thomsen que ubican sus propiedades anisótropas aproximadamente en el rango "débil" (Fernandez-Concheso M., 2015; Willis et al., 2014) estimados a partir de observaciones de velocidades de tránsito de ondas Stoneley, que son sensibles a las propiedades de la formación en dirección transversal al eje del pozo (Chi y Tang, 2006). La geometría de adquisición del monitoreo microsísmico se muestra en la Figura 3.11 y una proyección bidimensional de la misma puede observarse en la Figura 3.12.

Las fuentes de posición conocida consideradas para llevar a cabo la calibración son cuatro punzados realizados al inicio de una etapa de fracturación hidráulica. El arreglo de siete receptores está ubicado en un pozo de monitoreo aproximadamente vertical, a una profundidad cercana a la de la zona de tratamiento. La ubicación de los punzados con respecto al pozo de monitoreo se puede ver en las Figuras 3.11 y 3.12.

Los registros correspondientes a los cuatro punzados considerados pueden verse en la Figura 3.13, en la que además se indican los tiempos de arribo picados para las fases $\mathrm{P}$ y SH que, a diferencia de la fase SV, son fácilmente distinguibles. Esto implica que el término correspondiente a las diferencias de tiempo entre las fases P y SV de la ecuación 3.14 no es considerado en este ejemplo. Los registros que se muestran en la figura han sido filtrados con un pasa-banda en el rango $30 \mathrm{~Hz}-300 \mathrm{~Hz}$ y rotados al sistema radial-transversal-vertical. 


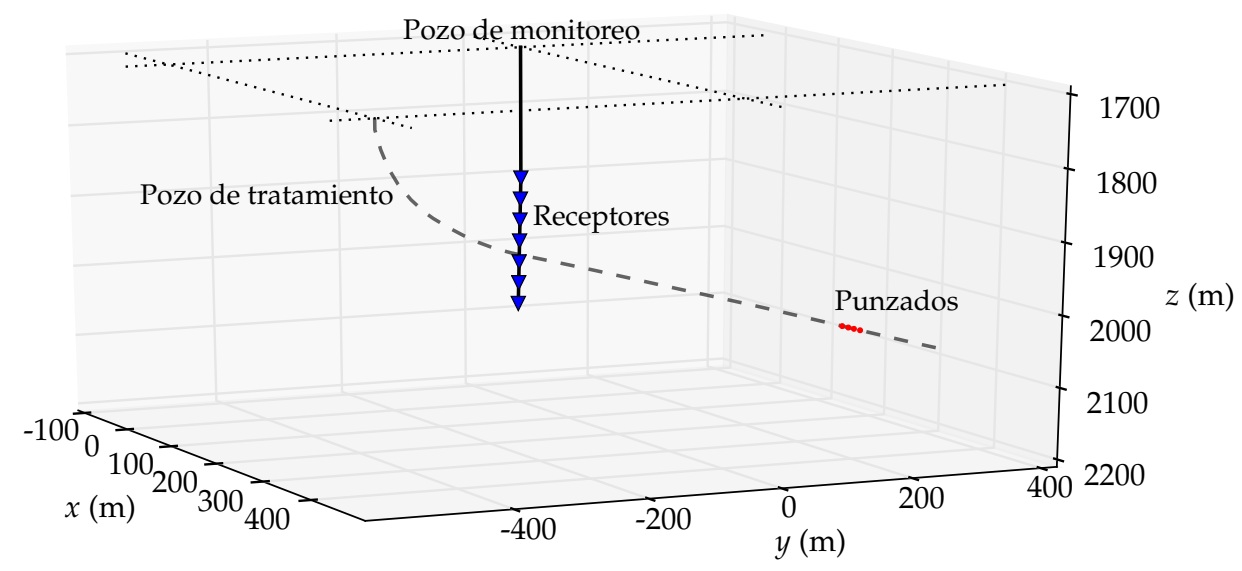

Figura 3.11. Geometría de adquisición.

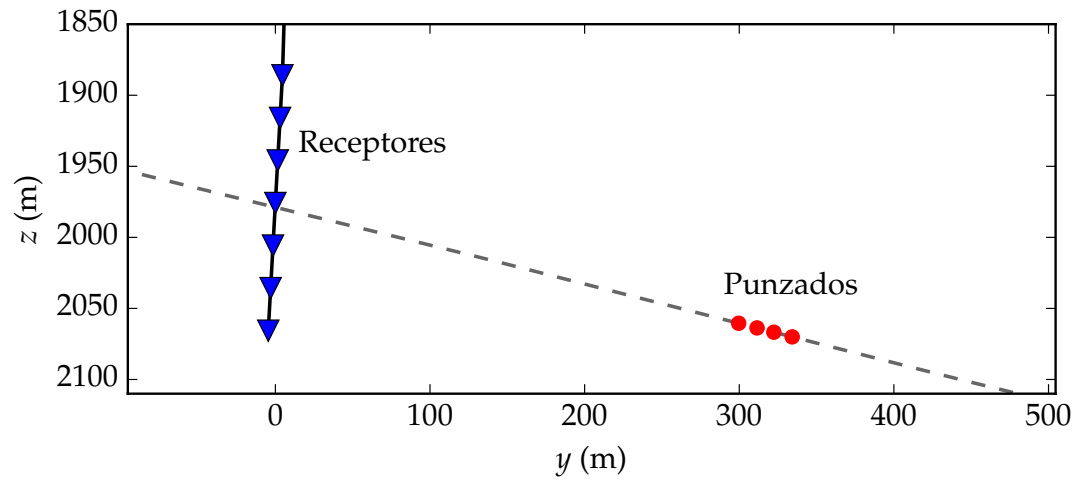

Figura 3.12. Proyección en el plano $y-z$ de la geometría de adquisición de la Figura 3.11. 

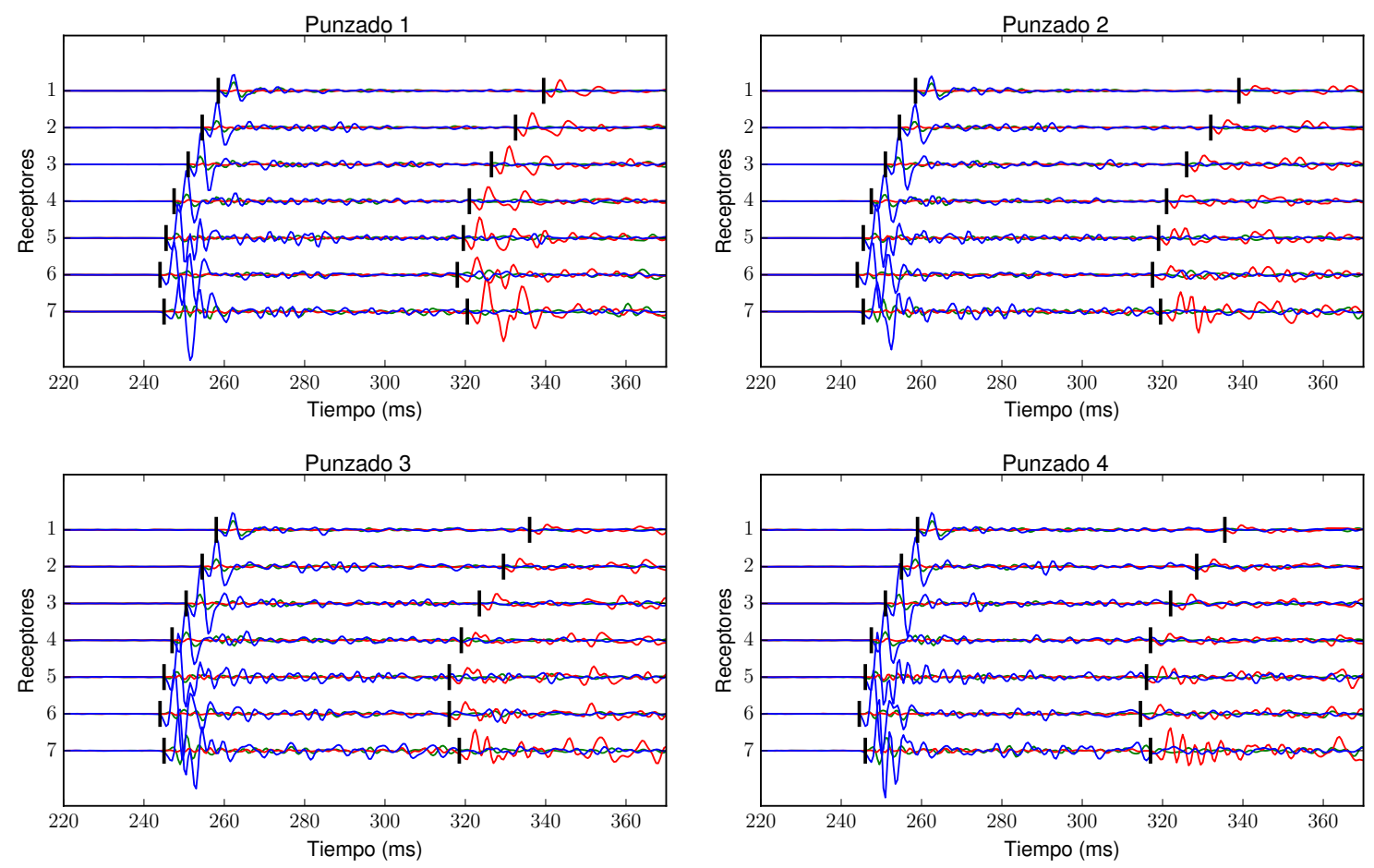

Figura 3.13. Registros microsísmicos correspondientes a los punzados utilizados para la calibración del modelo de velocidades, representados en el sistema RTV; y tiempos de arribo picados de las ondas P y SH (marcas verticales). 
Se contaba con un perfil sónico realizado en el pozo de monitoreo. Las correspondientes velocidades de ondas $\mathrm{P}$ y $\mathrm{S}$ obtenidas a partir de éste se muestran en las curvas grises de la Figura 3.14 para el intervalo de profundidades de interés. Como modelo inicial para realizar la calibración se generó un modelo discretizado a partir de suavizar las curvas de $v_{P}$ y $v_{S}$ del sónico, obteniendo los modelos de las curvas negras de la Figura 3.14. Por un lado, se realizó la calibración del modelo de velocidades suponiendo un medio estratificado isótropo. Para este cálculo, se permitió una variación en bloque de las velocidades, dentro del $5 \%$ del máximo. Este porcentaje para la variación de la velocidad respecto del modelo inicial es considerado excesivo (Maxwell et al., 2010a). Por ejemplo, para el caso de la onda P cuya velocidad máxima ronda los $4400 \mathrm{~m} / \mathrm{s}$ en el intervalo de profundidades consideradas, implica una variación superior a $200 \mathrm{~m} / \mathrm{s}$. El modelo isótropo obtenido se muestra en las curvas azules de la Figura 3.14. Notar que, particularmente para la velocidad de onda S, el modelo hallado se aleja considerablemente de la curva correspondiente al sónico. Si bien desde el punto de vista del problema de optimización de la ecuación 3.14 el modelo hallado supera al inicial, resulta un modelo no representativo de las observaciones. Por otro lado, se llevó a cabo la calibración del modelo de velocidades considerando anisotropía tipo VTI. Teniendo en cuenta que las rocas de la formación en cuestión son principalmente carbonáticas, se consideró una variación de los parámetros de anisotropía de acuerdo a $1 / v_{P}$. En este caso, se le permitió a las velocidades verticales $v_{P}$ y $v_{S}$ una variación significativamente menor al caso anterior, dentro del $2 \%$, con el fin de que el modelo obtenido sea más representativo de las observaciones (perfiles de pozo). Como se mencionó previamente, la calibración es llevada a cabo por medio del algoritmo VFSA. Por tratarse de una solución de carácter estocástico, la calibración se repitió 100 veces y se tomó como resultado final el mejor de todos los modelos, desde el punto de vista del valor de la función objetivo de la ecuación 3.14. En la práctica, dada la eficiencia del algoritmo utilizado, se trata de un proceso de algunos minutos. En todos los casos, las profundidades de las interfases entre capas consecutivas se mantuvieron fijas durante el proceso de optimización. La Figura 3.15 muestra los resultados de la calibración realizada, para las velocidades $v_{P}$ y $v_{S}$ y los parámetros de Thomsen $\varepsilon, \delta$ y $\gamma$. Las curvas grises representan a cada una de las soluciones de las 100 realizaciones mientras que las de colores corresponden a los respectivos valores determinados para el mejor de todos los modelos obtenidos. A modo de referencia, las curvas negras de $v_{P}$ y $v_{S}$ corresponden al modelo inicial.

Para evaluar los resultados de la calibración del modelo de velocidades, se realizó la localización de los punzados con los modelos obtenidos. El modelo óptimo es aquel que permite localizar a cada una de las fuentes exactamente en su posición conocida. En la Figura 3.16 se muestran los resultados de dicha localización utilizando el modelo inicial (sónico suavizado, puntos grises), el modelo calibrado considerando un medio isótropo (puntos azules), y el modelo VTI (puntos rojos). Si bien en este último caso se consideró el modelo indicado con colores en la Figura 3.15, todos los modelos obtenidos son igualmente aceptables dentro del criterio de convergencia considerado para el algoritmo de calibración, dado por el valor deseado de la función de costo. Se calcularon, además, 

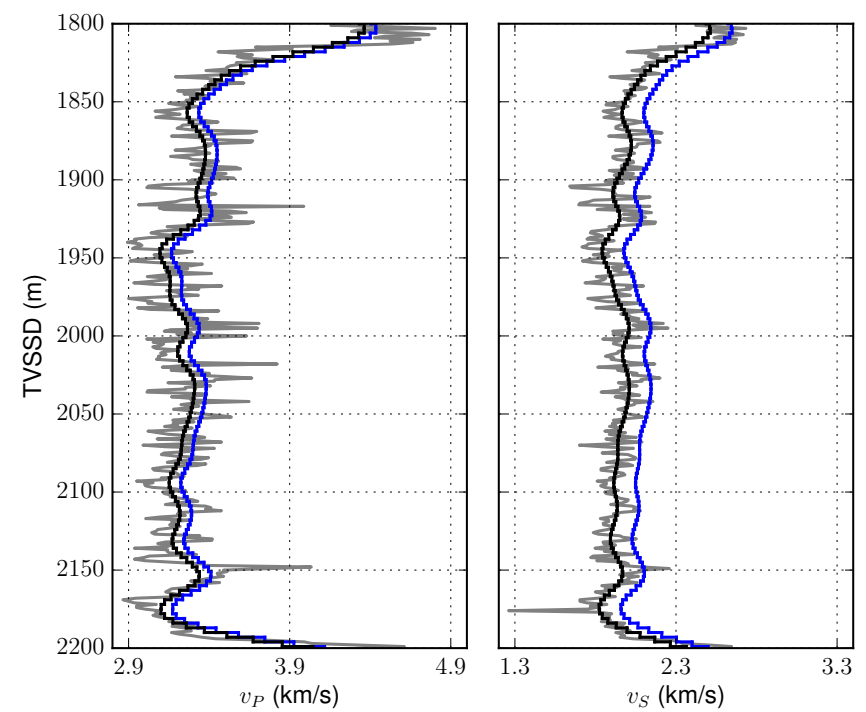

Figura 3.14. Perfiles sónicos (gris), modelo inicial utilizado para la calibración (negro) y modelo calibrado considerando isotropía (azul).
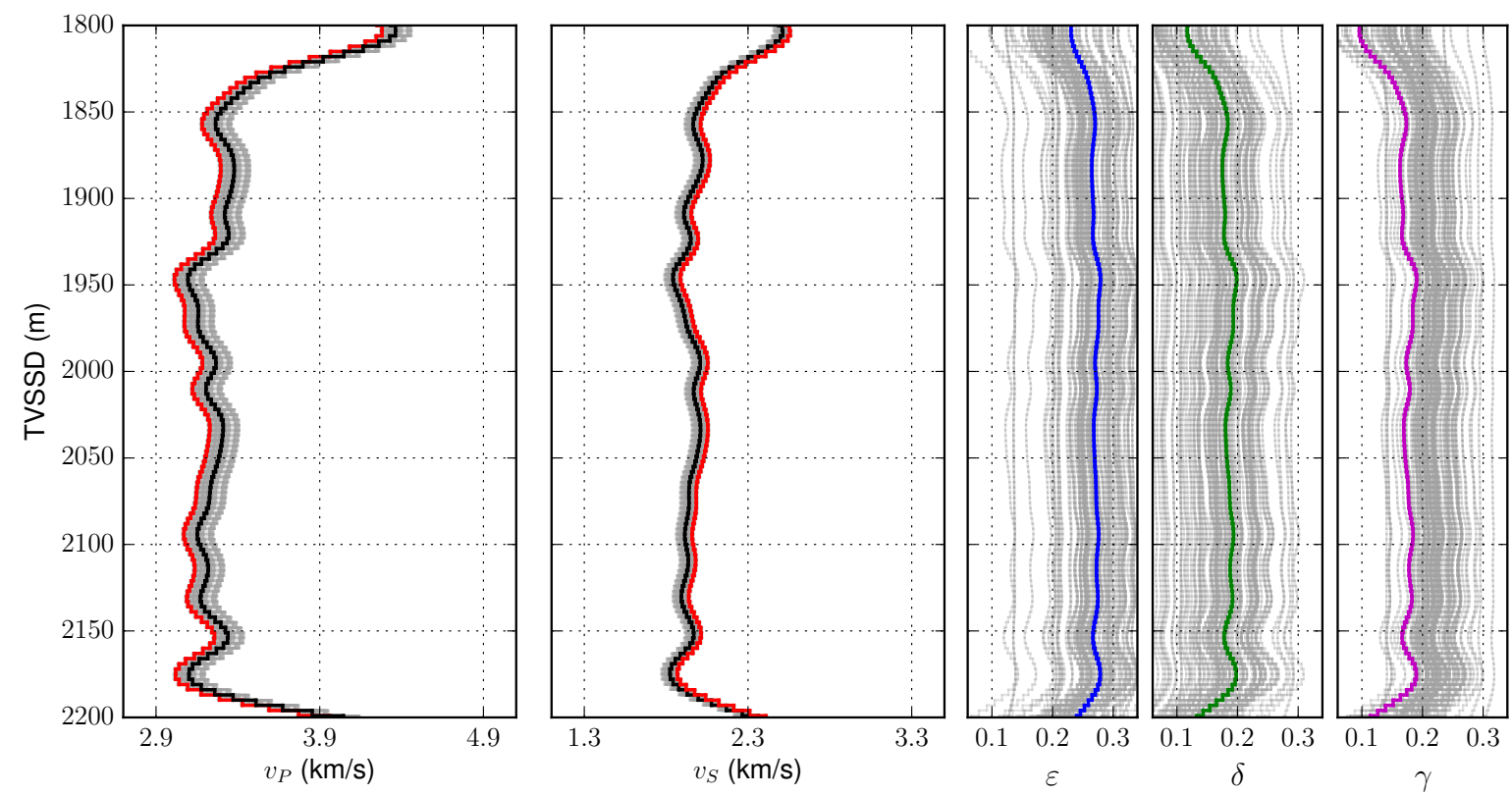

Figura 3.15. Modelos obtenidos en las 100 repeticiones de la optimización (gris); modelo inicial de $v_{P}$ y $v_{S}$ (negro). Las curvas en colores corresponden al mejor de todos los modelos obtenidos. 


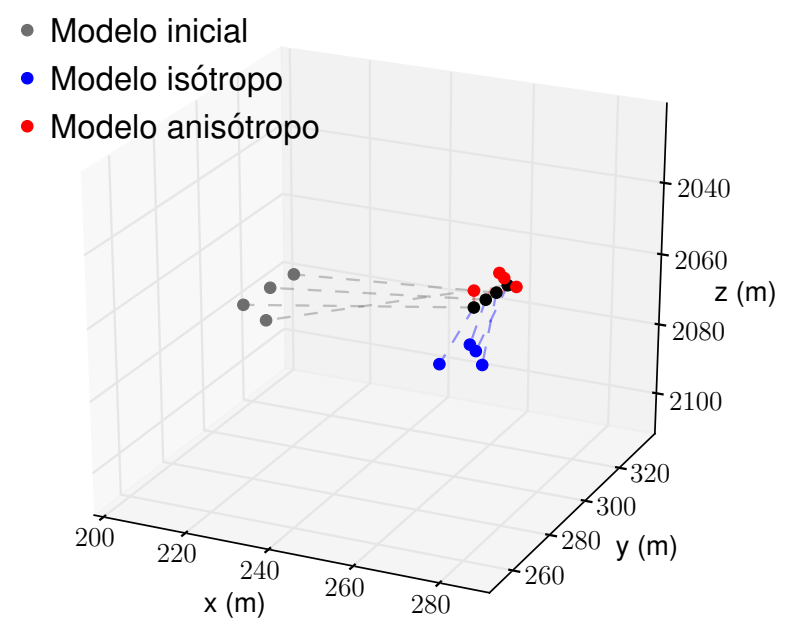

Figura 3.16. Resultados de las localizaciones de los punzados con los tres modelos considerados. Las posiciones reales de los punzados se indican en negro.

las distancias entre cada una de las posiciones estimadas y las conocidas para los tres modelos utilizados y los resultados se muestran en la Tabla 3.2. Las localizaciones obtenidas con el modelo inicial, que en promedio distan $54.3 \mathrm{~m}$ de las posiciones reales, justifican la necesidad de realizar la calibración de los perfiles sónicos tal como se explicó en la Sección 3.3, con el fin de caracterizar el medio en toda la región involucrada en la propagación y no exclusivamente la zona en torno al pozo. En todos los casos el mayor error se da en las coordenadas horizontales. Las posiciones de todos los punzados son estimadas unos $50 \mathrm{~m}$ más cerca del pozo monitor, lo que evidencia una subestimación de las velocidades horizontales. Por otra parte, las posiciones obtenidas con el modelo calibrado suponiendo isotropía distan de las posiciones exactas un promedio de $17 \mathrm{~m}$, mientras que las distancias para el caso de las posiciones estimadas con el modelo VTI se encuentran todas por debajo de los $8 \mathrm{~m}$ (4.9 m en promedio). Los errores en estas últimas posiciones son claramente tolerables teniendo en cuenta que se trata de fuentes que se encuentran a más de $400 \mathrm{~m}$ de distancia del arreglo de receptores y que el modelo utilizado no contempla cada una de las variaciones locales que presentan los medios reales.

\subsection{Conclusiones}

La estrategia basada en la energía, implementada como una simple suma de los cuadrados de las amplitudes de la onda $\mathrm{P}$, ha demostrado ser una forma sencilla pero efectiva de estimar los ángulos de orientación de sensores para el monitoreo microsísmico de pozo. Esta herramienta fue testeada con registros sintéticos y con dos juegos de datos de campo diferentes, mostrando resultados satisfactorios en todos los casos. Con el propósito de analizar estadísticamente los resultados y la sensibilidad del método ante la elección de los diversos parámetros y distintas fuentes de errores, se realizaron 


\begin{tabular}{cccc}
\hline & Inicial & Isótropo & VTI \\
\hline$r_{1}(\mathrm{~m})$ & 59.8 & 19.0 & 2.4 \\
$r_{2}(\mathrm{~m})$ & 51.1 & 20.2 & 5.0 \\
$r_{3}(\mathrm{~m})$ & 52.5 & 12.5 & 7.5 \\
$r_{4}(\mathrm{~m})$ & 53.4 & 16.3 & 4.7 \\
$\bar{r}(\mathrm{~m})$ & 54.3 & 17.0 & 4.9 \\
\hline
\end{tabular}

Tabla 3.2. Distancias de las posiciones estimadas de los punzados respecto de las exactas para los tres modelos considerados y distancias medias correspondientes a cada caso.

diferentes experimentos que consistieron en agregar errores a los tiempos de arribo determinados y modificar las longitudes de las ventanas consideradas para el cálculo. En todos los casos los pequeños desvíos estándar obtenidos, incluso en situaciones desafiantes, probaron la robustez de la estrategia. En consecuencia, cualquier algoritmo de picado automático y una longitud de ventana temporal fija son suficientes para una estimación apropiada de los ángulos de orientación, limitando la supervisión del usuario a eventuales correcciones de polaridad de las trazas.

Por otro lado, se mostró que la estrategia presentada en la Sección 3.3 permite calibrar modelos de velocidades a partir de fuentes de posición conocida. La estrategia partió de un modelo inicial generado a partir de la discretización y el suavizado de perfiles sónicos para reducir las rápidas variaciones que los caracterizan. Por medio de la aproximación del medio por un modelo anisótropo VTI en el rango de anisotropía débil y considerando una variación de los parámetros de Thomsen de acuerdo sus propiedades litológicas, la calibración realizada permitió obtener un modelo de velocidades para una zona de la Formación Vaca Muerta en la que se llevó a cabo el monitoreo microsísmico de un proceso de fracturación hidráulica. La eficiencia del algoritmo de optimización utilizado (VFSA) permite que ésta sea una tarea rápida y con resultados confiables. El modelo obtenido permitió determinar posiciones para los punzados que honran sus coordenadas conocidas dentro de una tolerancia aceptable, inferior a los $8 \mathrm{~m}$ de distancia. Por medio de la localización de los punzados con el modelo inicial y un modelo calibrado isótropo, se observó la importancia de considerar la anisotropía de la formación de interés para llevar a cabo el procesamiento de las señales microsísmicas.

Las herramientas presentadas en este capítulo permiten llevar a cabo los pasos principales del pre-procesamiento de la información microsísmica, otorgando a ésta las condiciones necesarias para llevar a cabo las distintas etapas del procesamiento propiamente dicho, que se describen en los siguientes capítulos. 


\section{Capítulo 4}

\section{Detección de eventos, picado de tiempos de arribo y estimación de backazimuths}

\subsection{Introducción}

La registración asociada al monitoreo microsísmico de un proceso de fracturación hidráulica implica el almacenamiento de una gran cantidad de datos. Una sola etapa del proceso de fractura puede requerir varias horas de registración a una alta frecuencia de muestreo ${ }^{1}$. La aplicación de los algoritmos de procesamiento microsísmico requiere la previa identificación de los eventos generados durante la fractura, cuya duración en tiempo es una pequeña proporción del registro total. Esto da origen a la necesidad de encontrar en el gran volumen de datos las porciones de registros con eventos de forma rápida, con la dificultad de que con frecuencia los eventos se encuentran enmascarados por el ruido. La detección de potenciales eventos microsísmicos en los registros continuos constituye el primer paso en el procesamiento de estas señales. Con el fin de incrementar la eficiencia del proceso de detección de potenciales microsismos, ésta se lleva a cabo sobre los registros preacondicionados, es decir, sobre los registros en los que ya fue aplicada la corrección correspondiente a la orientación de los sensores y, dependiendo del caso, un filtrado de los registros (Maxwell, 2014).

Además de la detección primaria de los eventos en el conjunto de registros, la localización de eventos microsísmicos por medio de estrategias basadas en el picado de tiempos de arribo requiere que éste sea llevado a cabo por medio de herramientas capaces de arrojar tiempos de arribo para la mayor cantidad de trazas posibles. Además, se busca que éstas se comporten de manera robusta ante las complejas condiciones de ruido características de los escenarios de fracturación hidráulica. Más aún, dicha

\footnotetext{
${ }^{1}$ Una hora de registro, con 10 receptores $3 \mathrm{C}$ muestreando a una tasa de $0.5 \mathrm{~ms}$ corresponde a $864 \mathrm{Mb}$ de datos almacenados. Teniendo en cuenta que una etapa microsísmica típica puede durar entre 5 y 8 horas, se requieren entre $4.3 \mathrm{~Gb}$ y $6.9 \mathrm{~Gb}$ para almacenar únicamente las trazas asociadas a una etapa.
} 
estrategia de localización requiere que los tiempos de arribos de ambas fases $\mathrm{P}$ y $\mathrm{S}$ sean determinados. Los errores en los tiempos de arribo de las fases $\mathrm{P}$ y $\mathrm{S}$ de un evento microsísmico se traducen directamente en errores en sus posiciones, en detrimento de una óptima interpretación de los resultados del monitoreo.

Los tiempos de arribo de las señales microsísmicas constituyen la principal fuente de información para llevar a cabo la localización. No obstante, dependiendo de la geometría de adquisición, puede resultar necesaria (o al menos, útil) información sobre la dirección de la cual proviene la energía. Entre los distintos tipos de geometrías de adquisición actualmente utilizadas para el monitoreo microsísmico de procesos de fracturación hidráulica, la disposición de arreglos de receptores en pozos de monitoreo verticales o aproximadamente verticales, es la geometría más frecuente (Maxwell, 2014; Eisner et al., 2009b). En esta situación, resulta necesario estimar la dirección de procedencia de las señales cuyas componentes horizontales permiten hallar el backazimuth del evento (dirección de procedencia de la señal respecto del norte geográfico) para poder restringir la determinación de las coordenadas de la fuente a un plano vertical que contenga a ésta y al arreglo de receptores (De Meersman et al., 2009; Jones et al., 2010). Más aún, en otros escenarios dados por múltiples pozos de monitoreo o pozos desviados, la información del backazimuth podría permitir restringir la búsqueda de la posición de la fuente a una pequeña porción del espacio, acelerando la búsqueda. Dado que los errores en la estimación del backazimuth constituyen la mayor fuente de incertidumbres en la localización de los eventos microsísmicos (Eisner et al., 2009a), es de gran importancia contar con herramientas confiables que permitan llevar a cabo la estimación del backazimuth de manera robusta ante las diferentes y complejas condiciones de ruido de las señales microsísmicas.

En el presente capítulo se describen, en primer lugar, las estrategias consideradas en esta Tesis para la detección de eventos microsísmicos y el picado de tiempos de arribo y las modificaciones propuestas para las mismas. Por otra parte, se enumeran y detallan las distintas herramientas implementadas con el fin de estimar el backazimuth de los eventos microsísmicos detectados. Finalmente, se describe un criterio de descarte de valores atípicos que resulta útil en el cálculo de un backazimuth único a partir de las múltiples observaciones obtenidas mediante un arreglo lineal de receptores.

\subsection{Detección de eventos microsísmicos}

La detección de eventos microsísmicos suele realizarse utilizando estrategias heredadas de la sismología global que declaran un evento cuando un cierto valor umbral es superado por un atributo calculado a partir de las trazas (Akram y Eaton, 2016). En general, este atributo está dado por el cociente del promedio de una cierta función característica en una ventana temporal corta sobre dicho promedio en una ventana temporal larga (Sabbione y Velis, 2012; Nippress et al., 2010). Estos métodos son conocidos como STA/LTA ${ }^{2}$ y en términos generales compara las amplitudes de una

\footnotetext{
${ }^{2}$ STA: short-term-average; LTA: long-term-average
} 
traza en torno a un determinado tiempo con las amplitudes previas a éste, considerando ventanas temporales como se indica en la Figura 4.1b. Un valor elevado del cociente STA/LTA representa un gran cambio en el comportamiento de la traza en relación al tiempo previo, lo cual podría indicar el arribo de una señal sísmica. Observar la relación de amplitudes entre ventanas de diferentes longitudes en lugar de observar directamente las amplitudes de las trazas permite mantener un umbral de detección constante durante toda la registración, teniendo en cuenta que el nivel de ruido suele variar a lo largo de la misma (Maxwell, 2014).

La estrategia de localización que se ha considerado en esta Tesis requiere del conocimiento de los tiempos de arribo tanto de la onda $\mathrm{P}$ como de la onda S asociada a cada evento microsísmico. Los métodos basados en el cociente STA/LTA permiten detectar fases individuales, sin discriminar si se trata de ondas P o S. Más aún, producto de la baja relación señal-ruido propia de los registros microsísmicos en ocasiones ocurre que alguna de estas fases resulta completamente enmascarada. En tal caso el evento correspondiente debe ser analizado con otras herramientas o bien descartado, siempre que la cantidad de eventos detectados sea representativa de la etapa de fracturación y, por lo tanto, lo permita.

\subsubsection{Detección de eventos por medio del picado automático de fases}

Existen numerosos métodos de tipo STA/LTA que difieren en la función característica considerada para el cálculo. Sabbione y Velis (2013) proponen un método para detectar arribos de señales microsísmicas basado en estrategias de picado de fases traza a traza cuya eficiencia sobre datos sismológicos fue evaluada previamente (Sabbione, 2012). Los autores proponen, además, una estrategia multicanal que, combinando los resultados obtenidos para trazas individuales, permite evitar falsas detecciones, altamente probables por el elevado ruido que generalmente contienen los registros.

A continuación, se describe brevemente la estrategia multicanal propuesta por Sabbione y Velis (2013) para los métodos de Baer y Kradolfer modificado (MBK) y de Allen modificado (MAM). El método de Allen modificado se basa en el cálculo del cociente STA/LTA de los promedios de una función característica dada por

$$
\begin{aligned}
C F_{i} & =s_{i}^{2}+C_{i}\left(s_{j}-s_{j-1}\right)^{2}, \text { con } \\
C_{i} & =\frac{\sum_{j=i}^{i}\left|s_{j}\right|}{\sum_{j=i}^{i}\left|s_{j}-s_{j-1}\right|},
\end{aligned}
$$

donde $s_{i}$ corresponde a la $i$-ésima muestra de la señal registrada. Una vez calculado el cociente STA/LTA (ver Figura 4.1b), éste es suavizado para evitar variaciones rápidas que conduzcan a falsas detecciones. Se declara una fase cuando el cociente suavizado supera un valor umbral predefinido (Figura 4.1c). Por su parte, el método de Baer y Kradolfer modificado no consiste en un método STA/LTA per se, sino que utiliza una 

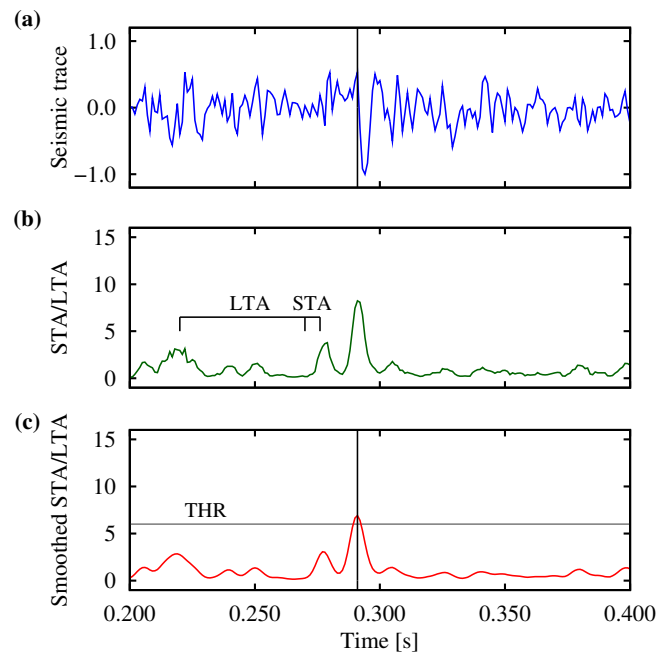

Figura 4.1. Método MAM; a) Traza y tiempo de arribo estimado; b) Cociente STA/LTA; c) Cociente STA/LTA suavizado y tiempo de arribo estimado en relación al valor umbral (THR). Extraído de Sabbione y Velis (2013).

aproximación de la función envolvente de la señal (Figura 4.2b), dada por

$$
E_{i}^{2}=s_{i}^{2}+\frac{\sum_{j=i}^{i} s_{j}^{2}}{\sum_{j=i}^{i}\left(s_{j}-s_{j-1}\right)^{2}}\left(s_{i}-s_{i-1}\right)^{2},
$$

y busca los tiempos en los que el cuadrado normalizado de la función envolvente

$$
B K_{i}=\frac{E_{i}^{4}-\tilde{\mu}_{E_{i}^{4}}}{\tilde{\sigma}_{E_{i}^{4}}},
$$

donde $\tilde{\mu}_{E_{i}^{4}}$ y $\tilde{\sigma}_{E_{i}^{4}}$ son la media y el desvío estándar estimados de $E_{i}^{4}$, respectivamente, supera al valor umbral (luego de ser suavizado). La Figura 4.2 ilustra un ejemplo de una traza sísmica, el correspondiente atributo $B K$ dado por la ecuación 4.4, y el atributo suavizado y el tiempo de arribo estimado. De acuerdo al criterio multitraza propuesto por Sabbione y Velis (2013), el registro es recorrido con una ventana móvil de una longitud similar a la esperada para una fase microsísmica. Una fase es declarada cuando el valor umbral es alcanzado en al menos la mitad de las trazas de una componente, dentro de la ventana en cuestión.

\subsubsection{Detección de eventos con identificación automática de ondas $\mathrm{P}$ y $\mathrm{S}$}

En esta Tesis se propone una modificación a la estrategia descripta en la Sección 4.2.1 que tiene por objetivo declarar un evento microsísmico cuando ambas fases, $\mathrm{P}$ y $\mathrm{S}$, fueron detectadas. Se busca, además, detectar eventos microsísmicos de forma automática en un 


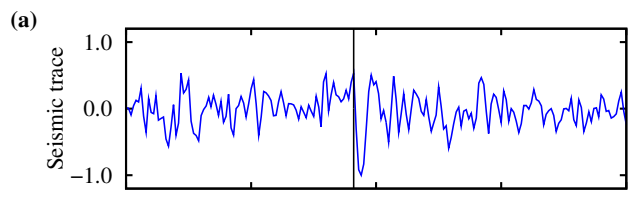

(b)

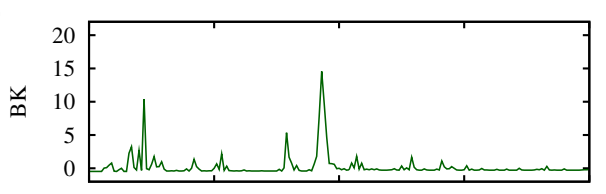

(c)

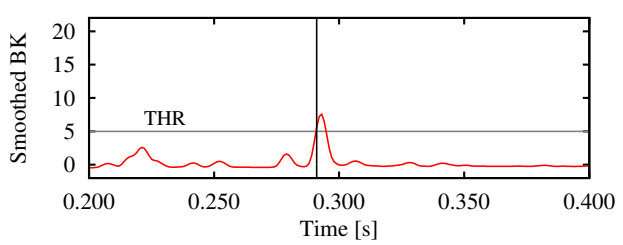

Figura 4.2. Método MBK; a) Traza y tiempo de arribo estimado; b) Atributo BK (ecuación 4.4); c) Atributo BK suavizado y tiempo de arribo estimado en relación al valor umbral (THR). Extraído de Sabbione y Velis (2013).

gran volumen de datos dado por un conjunto de registros temporalmente consecutivos, como podría ser una etapa completa de un proceso de fracturación hidráulica. Los pasos que conducen a la detección de acuerdo a este nuevo criterio se describen a continuación y se ilustran en la Figura 4.3.

1. Una ventana temporal móvil recorre de forma continua los registros originalmente separados en diferentes archivos (recuadro verde en la Figura 4.3a) buscando una fase de acuerdo a los criterios descriptos por Sabbione y Velis (2013). Entre los parámetros más importantes a definir se encuentran las longitudes de las ventanas utilizadas para el cálculo del cociente STA/LTA y el valor umbral que éste debe superar para detectar un arribo. Las ventanas consecutivas se solapan parcialmente para evitar omitir eventos cercanos a los extremos de las mismas. La ventana se desplaza por el registro hasta que una fase es detectada (Figura 4.3b, recuadro azul). Por ser la primera fase que satisface los criterios de detectabilidad definidos, se asume que se trata de una onda $\mathrm{P}$.

2. Si la fase hallada corresponde efectivamente a una onda $\mathrm{P}$, a continuación debería hallarse una onda $\mathrm{S}$, separada de la primera en un tiempo $\tau$ dentro de un cierto rango. Este rango queda definido por las distancias mínimas y máximas esperables para las posiciones de los potenciales eventos respecto del pozo monitor y por las velocidades de propagación de las ondas $\mathrm{P}$ y S (Figura 4.3b, recuadro rojo). Se busca, entonces, la presencia de una fase dentro de esta nueva ventana temporal.

3. Si la segunda fase es detectada, se evalúa una condición adicional para decidir si las dos fases halladas se corresponden con las ondas $\mathrm{P}$ y $\mathrm{S}$ de un mismo evento: las direcciones de los movimientos de partícula de ambas fases deben ser 
perpendiculares. Para evaluar esta condición se realiza el cálculo de las polaridades de las dos fases detectadas. Luego, si efectivamente se trata de las ondas $\mathrm{P}$ y $\mathrm{S}$ correspondientes a un evento microsísmico, el producto escalar de las respectivas direcciones de polarización debe ser cercano a cero, dentro de una cierta tolerancia modificable por el usuario. La condición debe cumplirse al menos para un dado porcentaje de receptores, parámetro modificable por el usuario teniendo en cuenta que, eventualmente, las condiciones de algunos receptores individuales pueden no ser favorables.

4. Salvo casos particulares en los que dos eventos tengan tiempos de arribo muy cercanos, las condiciones requeridas son suficientes para declarar un evento con sus correspondientes fases $\mathrm{P}$ y S, si éstas tienen amplitudes detectables. A partir de los tiempos de arribo observados para ambas fases se define una ventana que las contenga a ambas (Figura 4.3c, recuadro gris) y se continúa la búsqueda, operando del mismo modo con el resto del registro y detectando eventos consecutivos como muestra la Figura 4.3d.

El registro que se observa en la figura corresponde a una porción de un registro de campo obtenido en un monitoreo microsísmico de una fracturación hidráulica llevada a cabo en la Formación Vaca Muerta. Como resultado de la aplicación de este método se tienen los tiempos inicial y final de las ventanas que contienen a los eventos microsísmicos detectados y los tiempos picados para aquellas trazas en las que se satisficieron los criterios de detección. Esta información es fundamental para la aplicación de las siguientes etapas del procesamiento de las señales.

En la Figura 4.4 se muestran algunos ejemplos de eventos detectados en los registros correspondientes a una etapa de fracturación hidráulica. Las distintas subfiguras corresponden a ventanas de $300 \mathrm{~ms}$ que se obtuvieron como salida al aplicar la estrategia descripta. Dada la diferente magnitud de los eventos y a la variación de los niveles de ruido a lo largo de la etapa (asociada a las condiciones ambientales del proceso), la relación señal-ruido es variable, como se puede observar en las distintas ventanas. Aún así, en cada una de ellas se observan al menos dos señales que, de acuerdo a los criterios considerados, corresponden a las ondas $\mathrm{P}$ y $\mathrm{S}$ de los distintos eventos.

\section{Ejemplo sintético}

Con el fin de ilustrar la eficiencia de la detección automática descripta, se propone un ejemplo sintético que simula la registración de señales microsísmicas de una etapa de fracturación hidráulica. La Figura 4.5 ilustra la geometría considerada con ese fin. Un arreglo de 10 receptores $3 \mathrm{C}$ en un pozo de monitoreo vertical, con un espaciamiento vertical de $30 \mathrm{~m}$, registran las señales provenientes de una nube de 200 eventos sintéticos, que se propagan a través de un medio homogéneo e isótropo. Cada una de las fuentes fue modelada como una doble-cupla en el plano $(x, y)$ con deslizamiento en dirección $y$. Los fundamentos teóricos de la generación de registros sintéticos se describen en el Apéndice B. El mecanismo focal es el mismo para cada una de las fuentes, pero la generación aleatoria de las diferentes posiciones de las mismas permite que las 

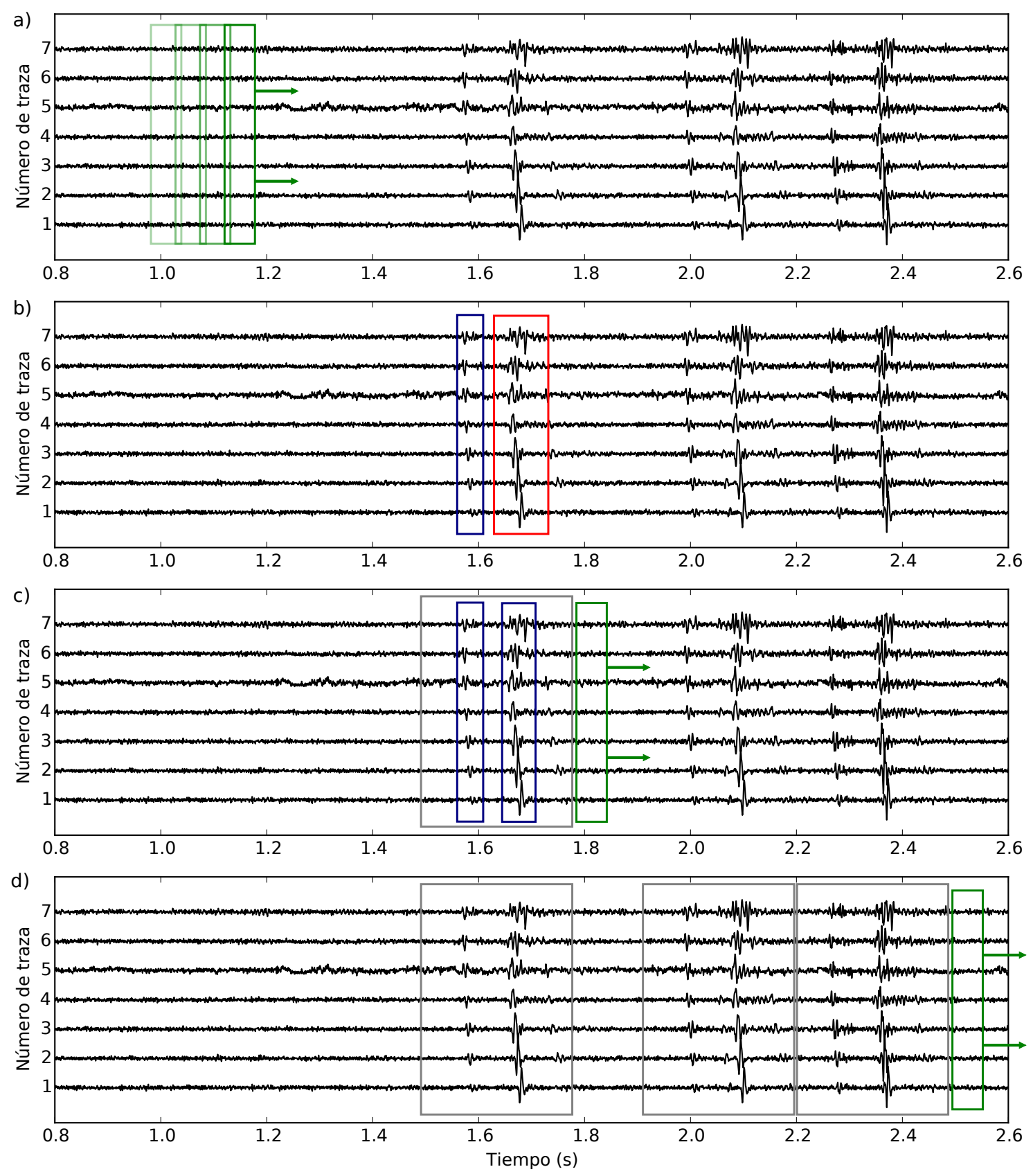

Figura 4.3. Detección de eventos microsísmicos por medio de ventanas móviles y búsqueda simultánea de las ondas $\mathrm{P}$ y S. Ver descripción en el texto. 

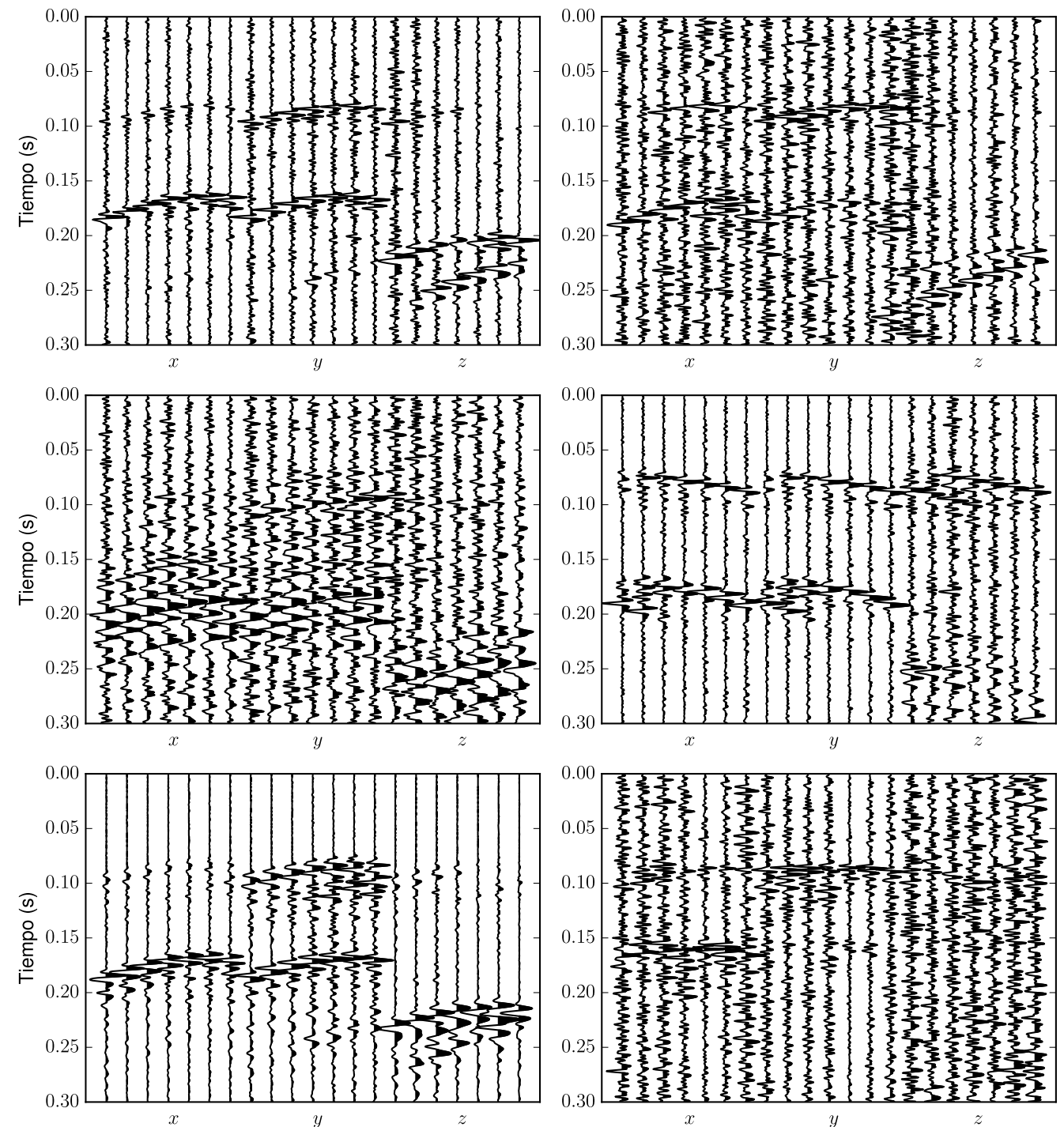

Figura 4.4. Ejemplos de eventos detectados en datos de campo. 


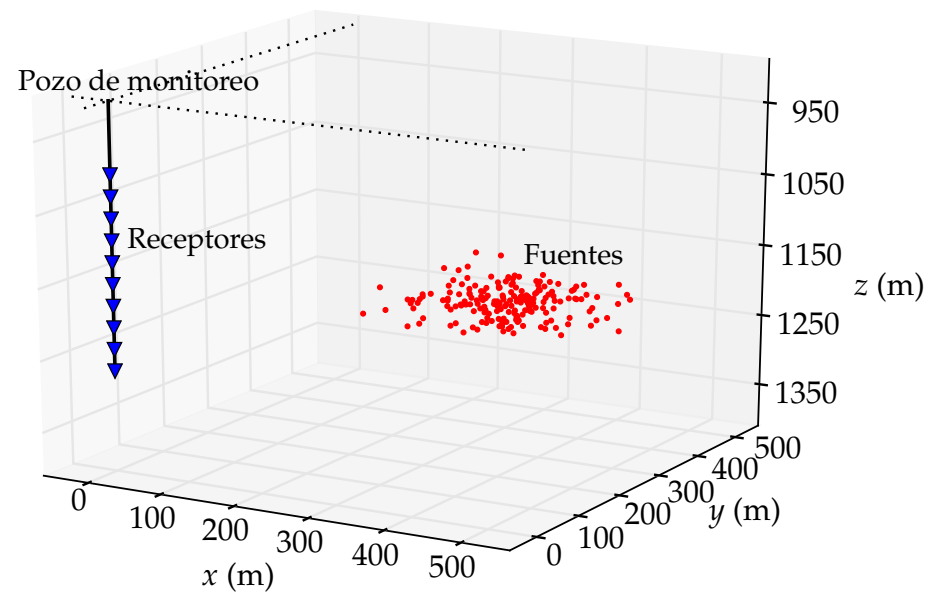

Figura 4.5. Geometría correspondiente al ejemplo sintético.

amplitudes observadas varíen para los distintos eventos, como se ejemplifica en los registros de la Figura 4.6. Por último, se adicionó ruido gaussiano sobre el cual se aplicó un filtro pasa-banda $(10-350 \mathrm{~Hz})$. Los datos sintéticos corresponden a una hora de registración en la que ocurrieron los 200 eventos. El tiempo de origen de los mismos fue obtenido de una distribución gaussiana con media 30 minutos y desvío estándar 15 minutos, con el fin de simular la distribución de eventos que durante la fracturación hidráulica tiene lugar aproximadamente en torno a los momentos puntuales en los que la presión inducida supera la presión natural de la formación.

El total de los registros generados fueron procesados con la estrategia propuesta y descripta en la Sección 4.2.2 considerando los métodos MAM y MBK. De los 200 eventos sintéticos, el método MAM condujo a la detección de 172 y el método MBK permitió detectar 174, es decir, un $86 \%$ y un $87 \%$ del total, respectivamente. En conjunto, ambos métodos permitieron detectar 184 de los 200 eventos, otorgándole a la detección un $92 \%$ de éxito. La Figura 4.7 ilustra la distribución de eventos modelados a lo largo del tiempo de registración y los eventos detectados (totales y discriminados por método considerado). El $8 \%$ de los eventos no fue detectado por ninguno de los dos métodos. En la Figura 4.8 se muestran ejemplos de estos casos. Un evento puede no ser detectado cuando alguna de las dos fases no satisface el criterio mínimo de detección: que al menos en la mitad de las trazas se supere el valor umbral seleccionado. Un ejemplo de este caso puede verse en el primer panel de la figura. Por otra parte, el éxito de la detección depende de que haya suficiente separación entre los eventos microsísmicos. En el caso de los paneles central e inferior de la Figura 4.8, las señales correspondientes a dos eventos distintos tienen tiempos de arribo muy cercanos, fases correspondientes a distintos eventos pueden ser interpretadas como las ondas $\mathrm{P}$ y $\mathrm{S}$ de un único evento, y por último ser descartadas al no satisfacer el criterio de ortogonalidad.

La estrategia de detección propuesta también puede fallar si, por ejemplo, el ruido presente en la señal altera las amplitudes relativas entre las componentes del registro al punto de que no se satisfaga el criterio de ortogonalidad, o si los eventos son tan cercanos al arreglo de receptores que no es posible una correcta separación de las distintas fases. 


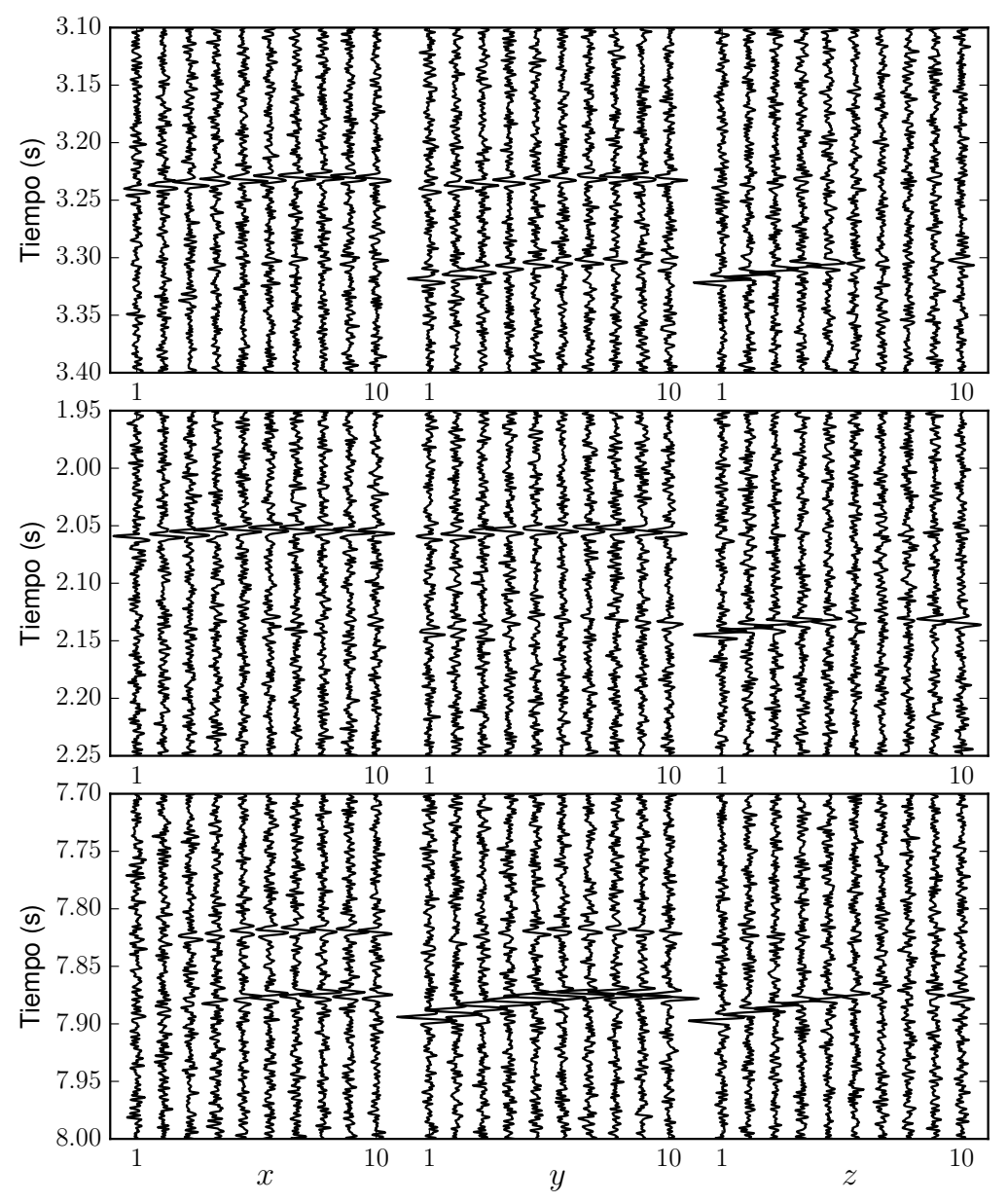

Figura 4.6. Ejemplos de registros sintéticos en los que las fases $\mathrm{P}$ y S muestran diferentes amplitudes relativas en respuesta al patrón de radiación propio de la fuente modelada y a la posición de la misma respecto del arreglo de receptores. 


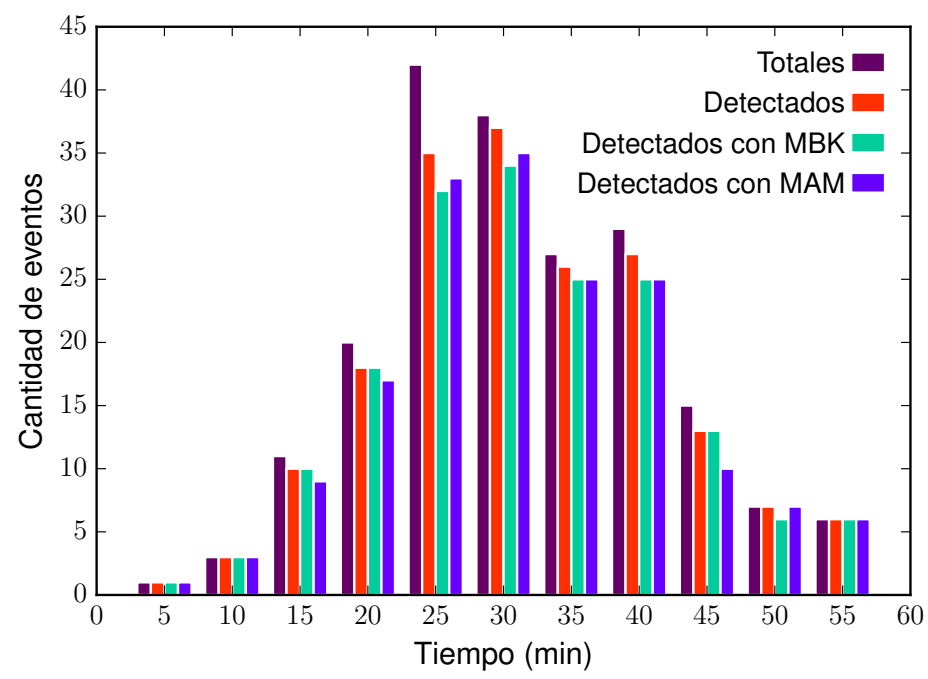

Figura 4.7. Resultados de la detección con los métodos MAM y MBK. Con fines comparativos, se muestran la cantidad y distribución de los eventos totales modelados.

Para descartar la omisión de eventos por las distintas razones posibles, una posibilidad es la detección de fases individuales tal como proponen Sabbione y Velis (2013) y un posterior agrupamiento de aquellas fases con una separación temporal propia de un posible evento microsísmico. La declaración de éste como tal, dependerá del criterio de un intérprete. A pesar de las dificultades mencionadas, la estrategia propuesta tiene una efectividad relativamente alta al procesar los datos reales considerados en los siguientes capítulos de esta Tesis.

En cualquier caso, la detección de eventos microsísmicos requiere por lo general de una posterior inspección de los resultados para descartar posibles falsas detecciones o evaluar la necesidad de un cambio en los criterios de detección.

\subsection{Picado de tiempos de arribo}

\subsubsection{Picado de tiempos de arribo por métodos STA/LTA}

La estrategia multitraza de detección de fases propuesta por Sabbione y Velis (2013) en la que se basa la detección de eventos microsísmicos descripta en la Sección 4.2 permite, además, obtener los tiempos de arribo de las fases en cuestión en cada una de las trazas en las que ésta fue observada. En el caso del método de Allen modificado (MAM), el tiempo de arribo de la señal en cada traza individual es definido en el máximo local del cociente STA/LTA suavizado, luego de que éste supera el valor umbral predeterminado (ver Figura 4.1c). Por su parte, para el método de Baer y Kradolfer modificado (MBK), el tiempo de arribo de la señal se ubica en la primera muestra en la que el cuadrado normalizado y suavizado de la función envolvente supera el valor umbral (ver Figura 4.2c). Las Figuras 4.9 y 4.10 muestran los tiempos picados para un evento 
66 Detección de eventos, picado de tiempos de arribo y estimación de backazimuths

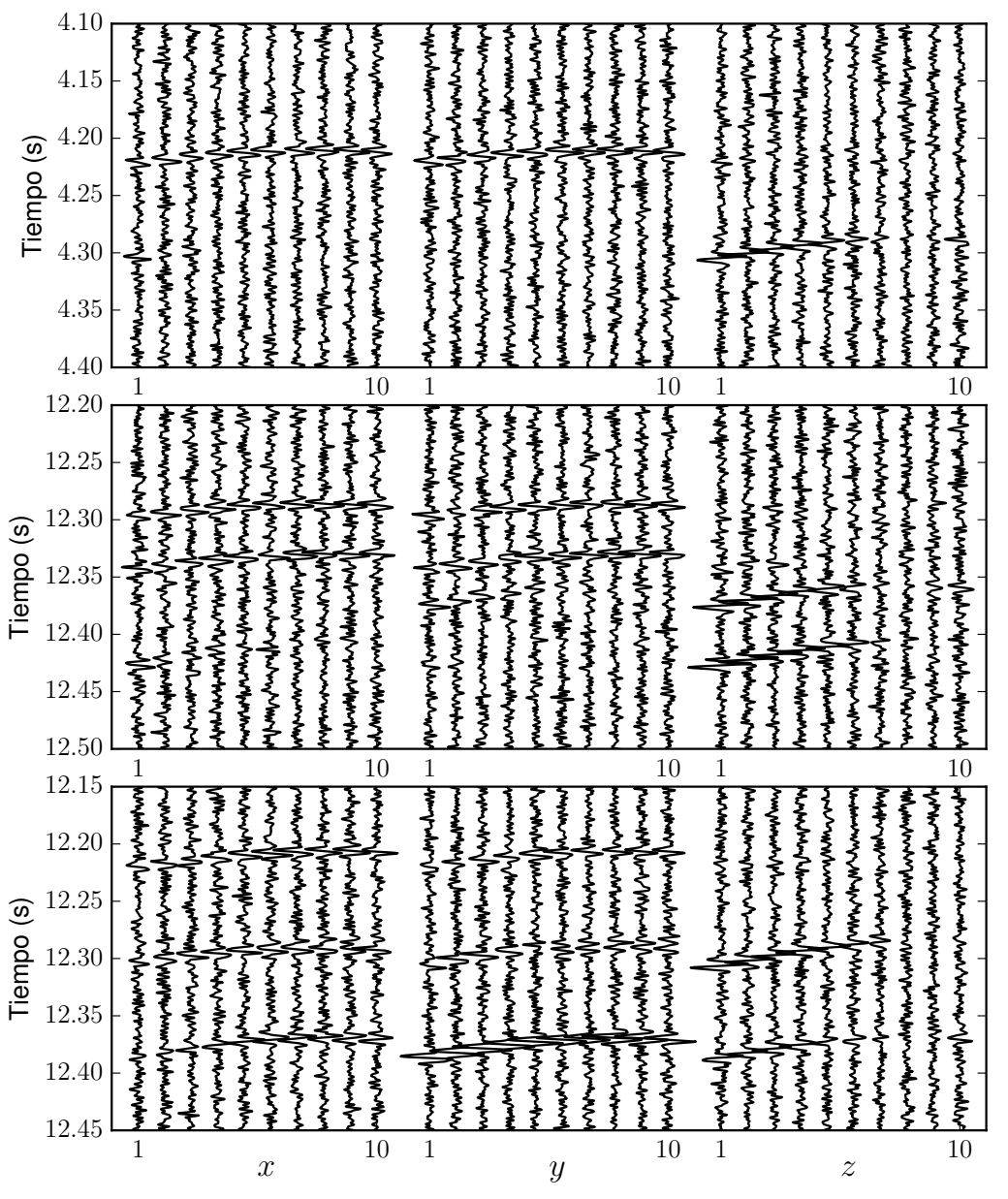

Figura 4.8. Ejemplos de registros sintéticos en los que la estrategia de detección no fue exitosa. 


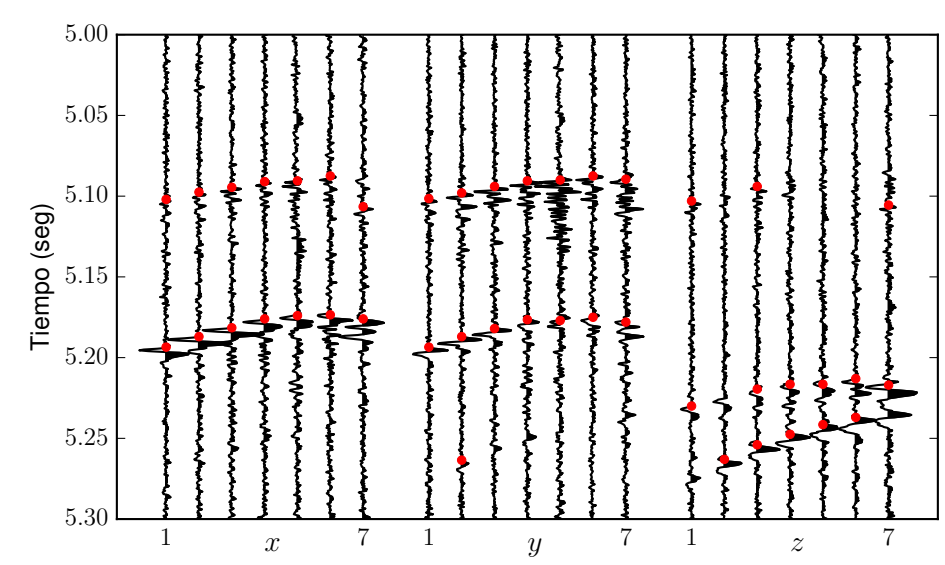

Figura 4.9. Tiempos de arribo estimados por medio del método MAM.

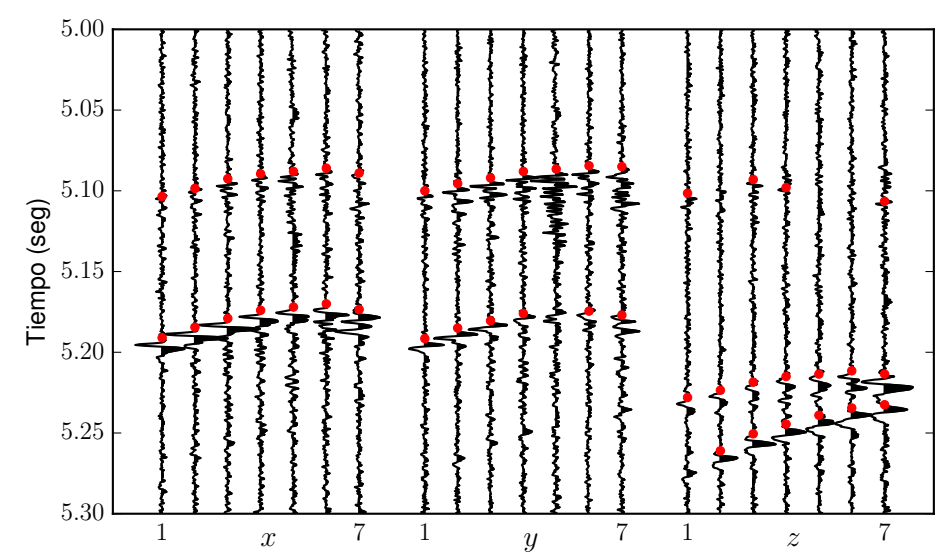

Figura 4.10. Tiempos de arribo estimados por medio del método MBK.

registrado durante una etapa de un proceso de fracturación hidráulica en la Formación Vaca Muerta, con los métodos MAM y MBK, respectivamente. En los dos casos fueron detectadas múltiples fases asociadas al evento. En torno a los 5.1 segundos se observa la onda $\mathrm{P}$, mientras que a los 5.2 y 5.23 segundos, aproximadamente, se observan fases que corresponderían a las ondas SH y SV generadas por la propagación de la energía del evento en un medio anisótropo. Se observa, además, un cuarto arribo (en torno a los 5.25 segundos) que podría responder a una reflexión en las capas inferiores del medio, en donde existe un importante contraste de velocidades. Se puede ver que, si bien para el evento del ejemplo la confiabilidad del picado de tiempos de arribo es alta, no se tienen picks en todas las trazas. Esto puede constituir una desventaja cuando se trate de eventos de menor relación señal-ruido, en los que la cantidad de información disponible para la posterior localización puede resultar considerablemente reducida. 


\subsubsection{Detección y picado de tiempos de arribo por reconoci- miento de patrones}

Los tiempos de arribo que arroja como resultado la estrategia de la Sección 4.3.1 son determinados traza a traza a partir de los criterios ya mencionados. Eventualmente, y dependiendo de las condiciones del dato en cuestión, puede ocurrir que se observen imprecisiones asociadas al ruido presente en la señal o a características muy locales del medio en torno a cada sensor individual. Es el caso, por ejemplo, del tiempo de arribo obtenido para la onda P en la componente $x$ del último sensor en la Figura 4.9, obtenido con el método MAM. Otra posibilidad, contemplada en esta Tesis, es la de utilizar tiempos de arribo determinados con algún criterio que se apoye en el comportamiento de todas las trazas en conjunto. Con ese fin, se consideró el método propuesto por Velis et al. (2015) que realiza la detección de arribos y, en un paso posterior, la atenuación del ruido o denoising. La detección de fases es llevada a cabo por medio de la resolución de un problema de reconocimiento de patrones y permite estimar los tiempos de arribo de las respectivas fases. Dado que los arribos de las señales microsísmicas a un arreglo de receptores lineal se caracterizan por una distribución hiperbólica en el conjunto de las trazas, el problema consiste en hallar aquella ventana hiperbólica en la que una medida de la energía o la coherencia de la señal es máxima. El objetivo es, entonces, encontrar los parámetros óptimos que caracterizan a tal hipérbola: las coordenadas de la fuente $x_{f}$ y $z_{f}$, el tiempo de origen $t_{0}$, y la velocidad efectiva del medio $v$, que se asume constante. Los autores proponen resolver esta tarea por medio de Very Fast Simulated Annealing (VFSA) dada la gran eficiencia del algoritmo para la resolución de problemas de inversión no lineales y la cantidad de parámetros a determinar. Como medida de energía o coherencia de la señal los autores proponen varias alternativas. A partir de los resultados y las recomendaciones de Velis et al. (2015), aquí se considera la energía de las trazas medias, dada por

$$
G\left(x_{f}, z_{f}, t_{0}, v\right)=\frac{1}{3 M} \sum_{i=1}^{M}\left[\left(\bar{s}_{i}^{x}\right)^{2}+\left(\bar{s}_{i}^{y}\right)^{2}+\left(\bar{s}_{i}^{z}\right)^{2}\right],
$$

donde $M$ es la longitud de la ventana, y $\bar{s}_{i}^{x}, \bar{s}_{i}^{y}$, y $\bar{s}_{i}^{z}$ son las $i$-ésimas muestras de la traza media normalizada de cada componente, a lo largo de la hipérbola que queda definida por $x_{f}, z_{f}, t_{0}, \mathrm{y} v$. El problema de optimización consiste en minimizar la función

$$
J\left(x_{f}, z_{f}, t_{0}, v\right)=1-G\left(x_{f}, z_{f}, t_{0}, v\right) .
$$

El método descripto siempre encuentra una solución, aquella que minimiza la función $J$, aunque no exista ningún evento presente en el registro. Adicionalmente, el método proporciona un indicador de la presencia de una señal para evitar falsas detecciones, dado por el cociente entre la energía del potencial arribo $E$ y la energía media del ruido $\bar{E}_{r}$ :

$$
R_{E}=\frac{E}{\bar{E}_{r}} .
$$


De este modo, la probabilidad de que la hipérbola solución del problema corresponda efectivamente a una fase de un evento microsísmico aumenta mientras más se aleje $R_{E}$ de 1 .

Una vez que una fase ha sido detectada, se lleva a cabo el segundo paso, la atenuación de ruido basada en la reconstrucción de rango reducido de la descomposición en valores singulares de la ventana hiperbólica hallada (Velis et al., 2015).

Uno de los parámetros que se obtiene a partir de la optimización es la velocidad efectiva del medio $v$, que se considera constante. Si bien se trata de una suposición que resulta suficiente para la detección de fases, los tiempos de arribo en cada traza individual en general no coinciden exactamente con los sugeridos por la hipérbola obtenida, dadas las heterogeneidades que presentan los medios reales. Los autores proponen una sincronización de los tiempos de arribo y la adición de las correspondientes correcciones de tiempo. Con este objetivo, se calcula la envolvente media de las trazas en la ventana hiperbólica obtenida y se busca el máximo de las correlaciones cruzadas entre esta envolvente y las envolventes individuales de cada traza, lo que determina las correcciones temporales que deben ser aplicadas en los tiempos de arribo individuales.

La solución del problema de optimización planteado permite hallar una única fase en el registro que se esté analizando. La identificación de esta fase como la onda $\mathrm{P}$ o $\mathrm{S}$ de un evento microsísmico debe hacerse a posteriori. Los autores proponen un proceso de deflación mediante el cual a través de la aplicación del método en forma iterativa pueden detectarse una a una las distintas fases presentes en el dato, considerando como registro de entrada en cada iteración al residuo de la iteración previa (registro menos fase detectada y con ruido atenuado).

Las Figuras 4.11, 4.12 y 4.13 ilustran los resultados de la aplicación de este método en el mismo ejemplo considerado en la Sección 4.3.1. Para ello, se aplicó el método considerando el proceso de deflación para determinar los tiempos de los cuatro arribos que se observan en el registro. Para la reconstrucción de rango reducido se consideraron en cada caso el $50 \%$ de los valores singulares de cada fase hallada. La Figura 4.11 muestra los registros originales y los tiempos de arribo determinados, que se obtuvieron producto de la detección. En todos los casos se observa que los tiempos de arribo siguen fielmente el comportamiento de cada fase. Para el caso de los últimos dos arribos, visibles en la componente $z$ del registro, se observan corrimientos en los tiempos de arribo en relación al inicio de cada fase. Esto se asocia al hecho de que se trata de señales muy cercanas, cuyas energías comienzan a mezclarse. Pueden obtenerse mejores resultados si se reduce el largo de la ventana temporal, por ejemplo, lo que permitiría aislar las energías de los distintos arribos. La Figura 4.12, por su parte, muestra el resultado de la reconstrucción de rango reducido de los cuatro arribos hallados. Si bien el porcentaje de valores singulares considerado para la reconstrucción no es el óptimo desde el punto de vista de la atenuación de ruido (especialmente para la onda $\mathrm{P}$ ), se puede ver que se ha conseguido aislar la mayor parte de las señales, como puede observarse en el residuo de la Figura 4.13 que corresponde al registro original de la Figura 4.11 menos la reconstrucción de la Figura 4.12. 


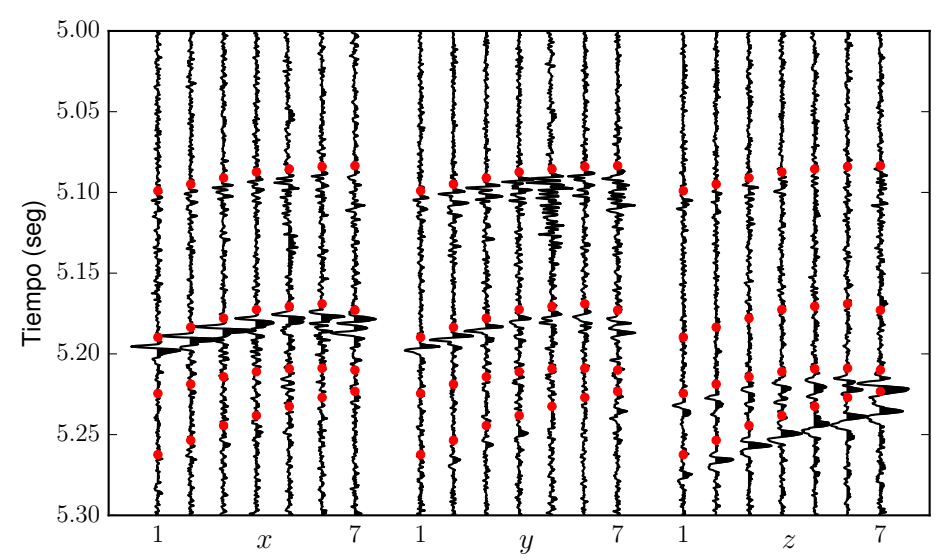

Figura 4.11. Tiempos de arribo obtenidos por medio de la estrategia basada en el reconocimiento de patrones.

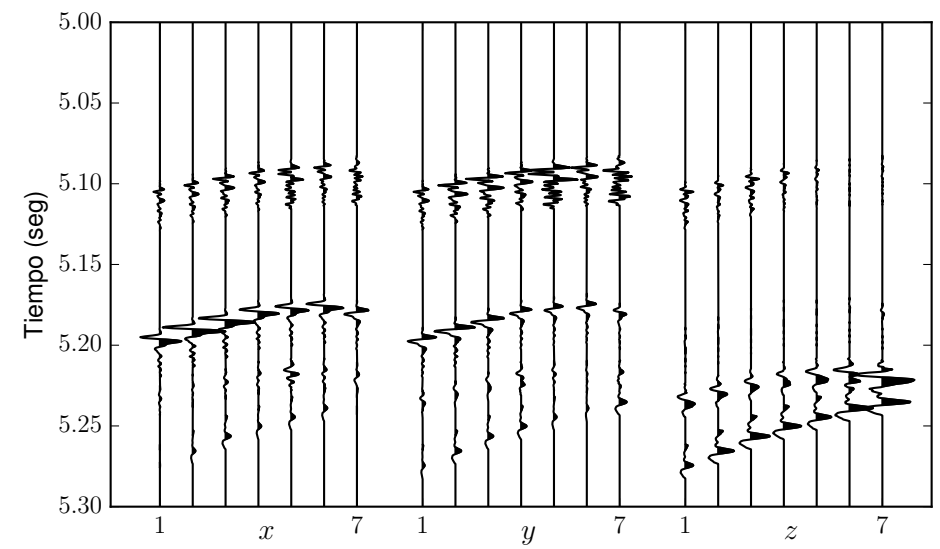

Figura 4.12. Reconstrucción del evento. 


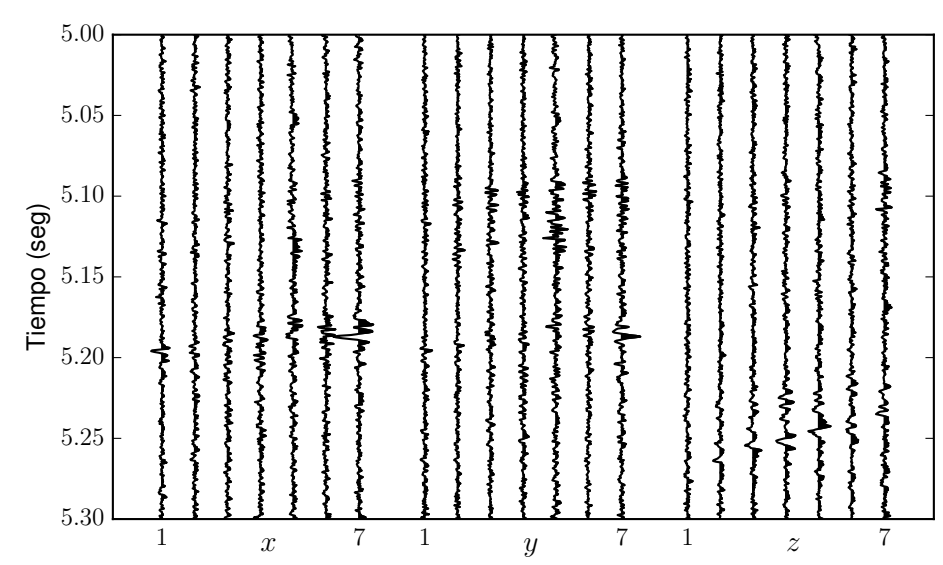

Figura 4.13. Residuo de la detección: diferencia entre el registro original y la reconstrucción del evento.

\subsection{Análisis de polarización}

La estimación del backazimuth, en términos generales, se realiza a partir del análisis de polarización de las ondas registradas. En el caso de las ondas P, la dirección de polarización coincide con la dirección de procedencia de la señal (en el caso de medios con anisotropía, la afirmación se cumple de forma aproximada). Asimismo, en el caso de las ondas $\mathrm{S}$ la dirección de procedencia de la señal puede obtenerse de la dirección de polarización, aunque en este caso la relación no es directa (Eisner et al., 2009b).

El cálculo del backazimuth puede llevarse a cabo de distintas formas, varias de las cuales han sido implementadas computacionalmente durante los trabajos que condujeron a esta Tesis y se describen a continuación.

\subsubsection{Estimación de la dirección de polarización por análisis de hodograma}

El movimiento de partículas en función del tiempo que tiene lugar ante el arribo de una señal microsísmica puede representarse por medio de un hodograma (Sheriff, 2002). En el caso ideal en el que el registro esté libre de ruido, el hodograma de los datos en torno al arribo de una fase presenta una dirección predominante que, en el caso de la onda $\mathrm{P}$, coincide con la dirección de propagación de la señal. La linealidad del movimiento de partículas generado será observable o no dependiendo del nivel de ruido en relación a la amplitud de la señal. A modo de ejemplo, en la Figura 4.14 se muestran los hodogramas correspondientes a la onda $\mathrm{P}$ de un evento microsísmico para tres receptores (datos de campo). En la figura se puede observar que en los tres casos el movimiento muestra una dirección predominante, aparentemente coincidente, como es de esperar dado que los tres receptores corresponden a un arreglo en un pozo aproximadamente vertical. 

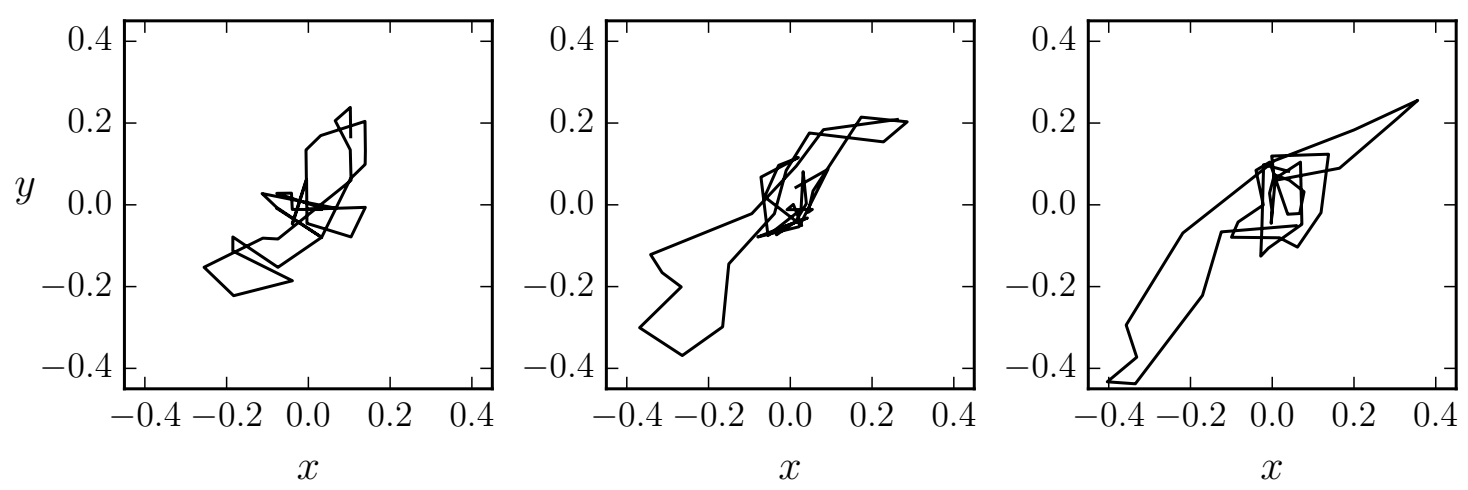

Figura 4.14. Ejemplos de hodogramas correspondientes a la onda $\mathrm{P}$ de un evento microsísmico (datos de campo) para distintos receptores.

Una forma sencilla de estimar la dirección predominante del movimiento es a partir del ajuste de una recta al hodograma correspondiente. Con el fin de reducir los efectos del ruido en esta estimación, una posibilidad es realizarla por medio de un ajuste por mínimos cuadrados ponderados. Es decir, que el backazimuth, $\beta$, puede obtenerse a partir de la solución del sistema de ecuaciones (Han, 2010):

$$
\mathbf{x}^{T} W \mathbf{x} t g(\beta)=\mathbf{x}^{T} W \mathbf{y},
$$

donde $\mathbf{x}$ e $\mathbf{y}$ son las componentes horizontales del registro microsísmico (en una ventana temporal de $M$ muestras) y la matriz $W$ contiene los pesos que pueden definirse como

$$
W_{i j}=\left(x_{i}^{2}+y_{j}^{2}\right) \delta_{i j}, \quad i, j=1, \ldots, M,
$$

de manera tal que al momento del ajuste toman mayor importancia aquellas muestras más distantes del origen, es decir, las de mayor amplitud. Para el $k$-ésimo receptor, entonces, puede obtenerse el backazimuth correspondiente a un evento mediante:

$$
\operatorname{tg}\left(\beta_{k}\right)=\frac{\sum_{i=1}^{M} W_{i i} x_{k_{i}} y_{k_{i}}}{\sum_{i=1}^{M} W_{i i} x_{k_{i}}^{2}},
$$

con $M$ igual a la longitud en muestras de la ventana que contiene a la onda $\mathrm{P}$ del evento. Notar que la solución de la ecuación 4.10 puede no indicar el ángulo correcto de la dirección de propagación sino diferir de éste en $180^{\circ}$. Esta ambigüedad, propia de la multivaluación de la función arcotangente, puede resolverse considerando la dirección que apunta a la posición esperada de la fuente. 


\subsubsection{Estimación de la dirección de polarización por diago- nalización de la matriz de varianza-covarianza de los datos}

La dirección de polarización de las fases asociadas a un evento microsísmico puede también estimarse de acuerdo a lo propuesto por Jurkevics (1988), asumiendo que el movimiento de partícula asociado a una onda $\mathrm{P}$ o $\mathrm{S}$ es predominantemente lineal. Esta estrategia consiste en la diagonalización de la matriz de varianza-covarianza de los datos registrados por un sensor, en una ventana temporal que contenga a la onda. Los elementos de la matriz de varianza-covarianza están dados por

$$
\sigma_{j k}=\frac{1}{M} \sum_{i=1}^{M} x_{i j} x_{i k},
$$

donde $M$ es la cantidad de muestras contenidas en la ventana y $j, k=1,2,3$ denotan la componente de movimiento considerada. Esta matriz, cuyas componentes no diagonales son, en general, no nulas, es real y simétrica y, por lo tanto, diagonalizable. Los autovectores de la matriz de varianza-covarianza corresponden a los ejes de un elipsoide que describe el movimiento de partículas en tres dimensiones. El autovector asociado al mayor autovalor corresponde al eje principal del elipsoide, la dirección de polarización de la onda. Las componentes horizontales de este vector permiten determinar el backazimuth. Nuevamente, la dirección obtenida presenta una ambigüedad de $180^{\circ}$ que puede ser salvada considerando la dirección esperada de la fuente.

\subsubsection{Estimación de la dirección de polarización basada en la energía}

De forma similar a lo explicado en la Sección 3.2, si las componentes horizontales de una ventana temporal que contiene a la onda $\mathrm{P}$ son rotadas a un sistema radialtransversal, la energía de la onda $\mathrm{P}$ debería hallarse completamente en la componente radial. De esta forma, es posible determinar la dirección de procedencia de la señal por medio de la búsqueda del ángulo de rotación que maximice la energía de la onda $\mathrm{P}$ en la componente radial (y la minimice en la componente transversal). La energía es calculada como la suma de los cuadrados de las amplitudes de la señal. En este caso, se puede evitar la resolución a posteriori de la ambigüedad de los $180^{\circ}$ por medio de la definición de un rango de búsqueda para el backazimuth que contenga a la dirección esperada de la fuente. Para cada receptor, la búsqueda del backazimuth se realiza de forma exhaustiva discretizando el rango de posibles valores cada, por ejemplo, $1^{\circ}$ (el bajo costo computacional de las operaciones involucradas no impiden la consideración de discretizaciones más finas).

En la Figura 4.15 se muestra un ejemplo de los backazimuths estimados para un evento microsísmico sintético con cinco receptores diferentes a partir de la onda P. Al correspondiente registro sintético se le añadió ruido gaussiano asumiendo tres relaciones 

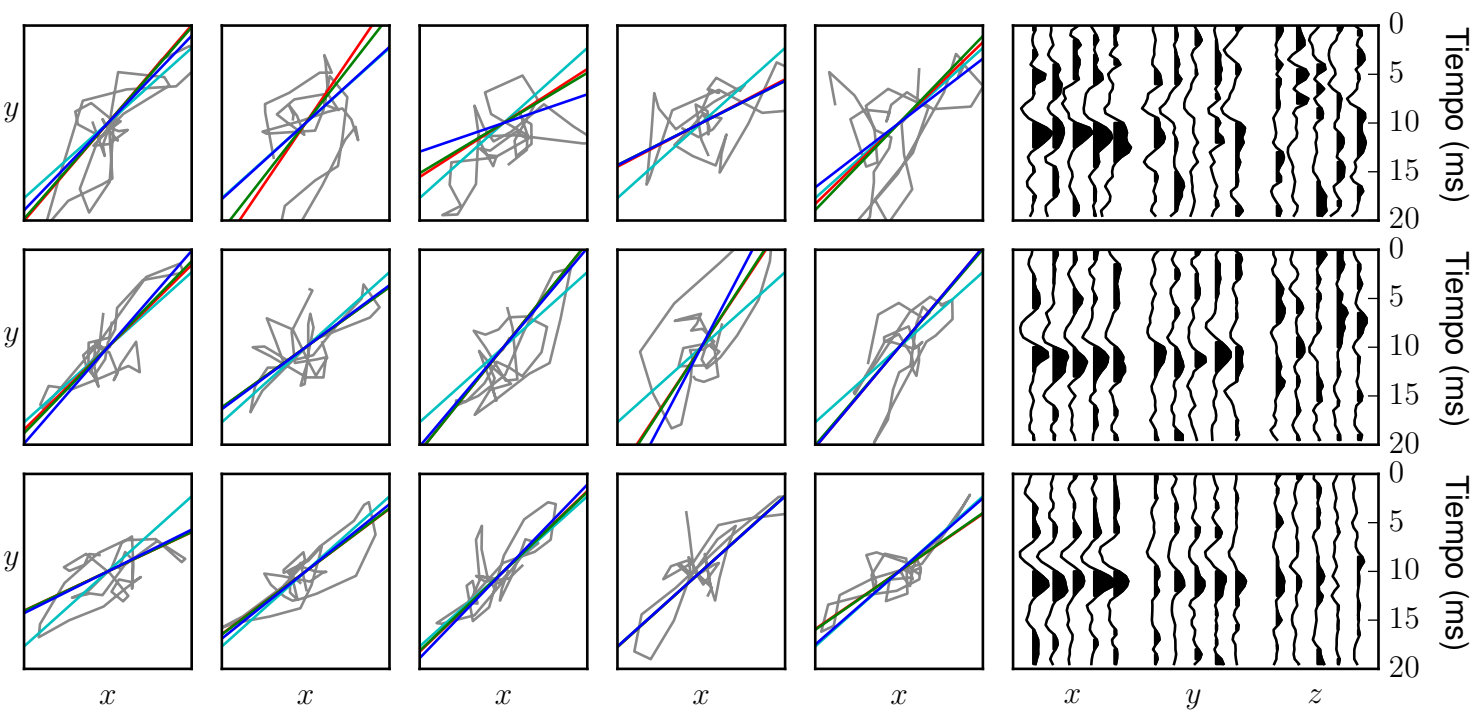

Figura 4.15. Backazimuths estimados para un evento microsísmico sintético con cinco receptores a partir de la onda $\mathrm{P}$, con las técnicas descriptas en las Secciones 4.4.1 (azul), 4.4.2 (rojo) y 4.4.3 (verde). El backazimuth real del evento se indica en cian. Los paneles de la derecha muestran los registros correspondientes, para tres diferentes relaciones señal-ruido, creciente hacia abajo.

señal-ruido diferentes (creciente hacia abajo). Los paneles de la derecha muestran las ventanas temporales de los correspondientes registros, de 20 ms de duración, definidas en torno al tiempo de arribo de la onda P. En éstos pueden observarse las amplitudes relativas del ruido respecto de la señal para cada uno de los tres casos. Por su parte, en las cinco primeras columnas se muestran los hodogramas correspondientes a cada sensor (gris), el backazimuth real del evento (cian) y las estimaciones realizadas por medio de las estrategias de las Secciones 4.4.1 (azul), 4.4.2 (rojo) y 4.4.3 (verde), respectivamente. Es claro que, independientemente de la técnica utilizada, la calidad de las estimaciones del backazimuth es altamente dependiente de la relación señal-ruido en cada sensor. Por otro lado, en la figura se puede observar que las estrategias basadas en el cálculo de la energía de la señal y en la diagonalización de la matriz de varianza-covarianza de los datos tienen un comportamiento similar para las distintas relaciones señal-ruido, mientras que las tres estrategias se comportan de la misma forma en los casos de mayor relación señal-ruido.

\subsubsection{Estimación del backazimuth a partir de la onda $\mathrm{S}$}

La dirección de polarización de la onda S no coincide con la dirección de propagación de la señal. Sin embargo, dado que con frecuencia las amplitudes de las ondas S son superiores a las de las ondas $\mathrm{P}$ y, por lo tanto, la relación señal-ruido es mejor, la utilización de la onda $\mathrm{S}$ puede reducir significativamente la incertidumbre en la 


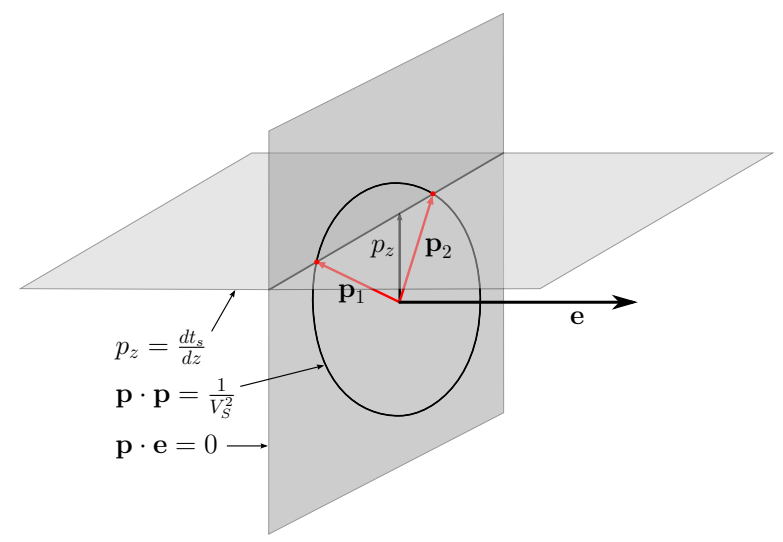

Figura 4.16. Estimación del backazimuth por medio de la onda S. Adaptada de Eisner et al. (2009b).

estimación del backazimuth. Si se trata de una propagación a través de un medio con un importante grado de anisotropía que permita identificar con claridad la onda SH, la dirección de propagación puede aproximarse como la dirección perpendicular a la polarización de dicha onda. Otra posibilidad, cuando este no es el caso, es proceder de acuerdo a lo propuesto por Eisner et al. (2009b) para un arreglo lineal de receptores en un medio homogéneo e isótropo. Para ello, se considera el vector lentitud, p, dado por la dirección de propagación sobre la velocidad, que debe satisfacer, por un lado, la ecuación Eikonal

$$
\mathbf{p} \cdot \mathbf{p}=V_{S}^{-2},
$$

donde $v_{S}$ es la velocidad de propagación de la onda S. Por otra parte, el vector de polarización de la onda $\mathrm{S}$, e, es perpendicular al vector lentitud, es decir,

$$
\mathbf{p} \cdot \mathbf{e}=0
$$

Por último, la derivada de los tiempos de arribo de la onda S con respecto a la dirección del pozo corresponde a la proyección de $\mathbf{p}$ en dicha dirección, es decir

$$
p_{z}=d t_{S} / d z
$$

En la Figura 4.16 se ilustran las ecuaciones 4.12 a 4.14. Existen dos vectores lentitud posibles que satisfacen las relaciones anteriores que se indican en rojo en la Figura 4.16. En la práctica se elige aquél que apunta en la dirección aproximada de la zona de tratamiento.

A modo de ejemplo, en la Figura 4.17 se muestra el backazimuth estimado (rojo) a partir de la onda $\mathrm{S}$ con cada uno de los 10 receptores de un arreglo vertical, para un evento microsísmico sintético. Además, se ilustran los movimientos de partículas asociados a las ondas P y S (en gris y negro, respectivamente). Se puede observar que el backazimuth estimado con la onda $\mathrm{S}$ en cada caso coincide aproximadamente con la 


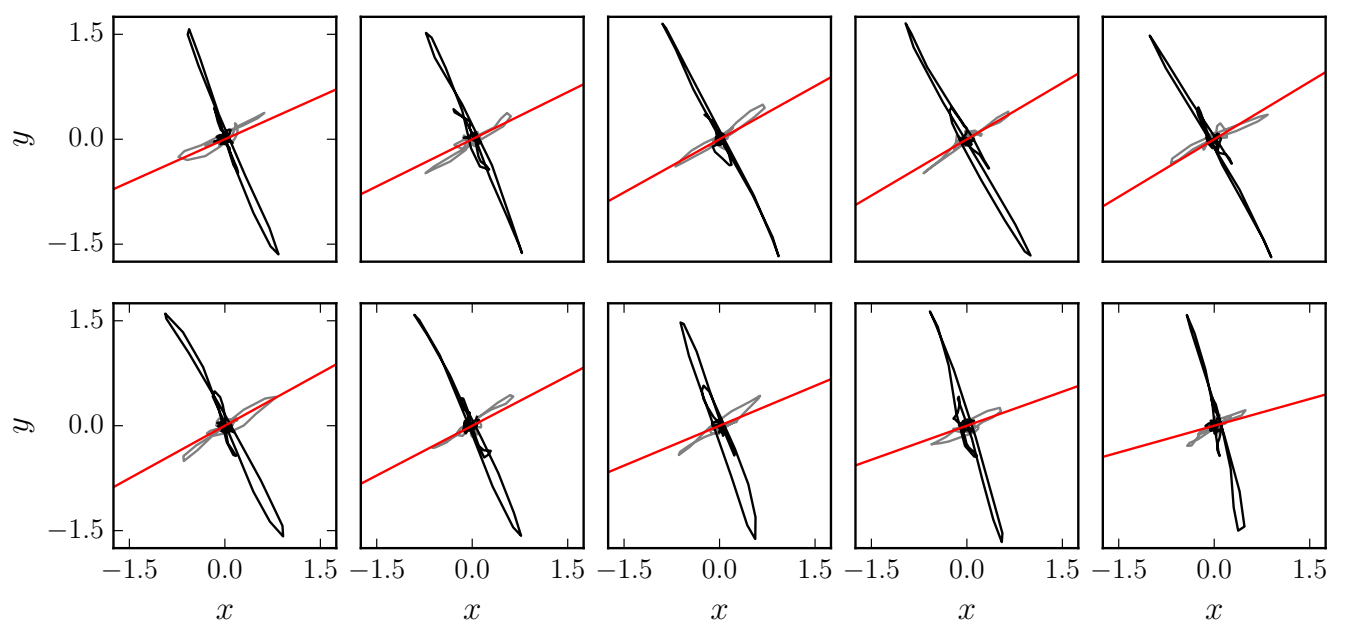

Figura 4.17. Backazimuths estimados a partir de la onda S (rojo) para un evento microsísmico sintético registrado en un arreglo vertical de 10 receptores. Movimiento de partículas asociado a la onda $\mathrm{P}$ (gris) y a la onda S (negro).

dirección de polarización de la onda $\mathrm{P}$ y que las amplitudes asociadas a la onda $\mathrm{S}$ son significativamente mayores a las de la onda P.

La estimación del backazimuth según este enfoque no es posible si la onda S está polarizada en la dirección del pozo. Si el pozo de monitoreo es vertical, por ejemplo, esto implicaría que $\mathbf{e}=e_{z} \hat{k}$ y para satisfacer la ecuación 4.13 necesariamente $p_{z}=0$, por lo que no se satisface la ecuación 4.14. Por otra parte, el cálculo de $p_{z}$ por medio de la ecuación 4.14 requiere que la estimación de los tiempos de arribo se realice con gran cuidado, evitando variaciones grandes entre receptores consecutivos.

Durante el desarrollo del trabajo que condujo a esta Tesis, esta estrategia fue implementada computacionalmente y testeada con datos sintéticos pero no fue utilizada con datos de campo, dado que la presencia de anisotropía y medios estratificados en todos los casos nos aparta de la hipótesis de medio homogéneo e isótropo en el cual está demostrada su utilidad (Eisner et al., 2009b).

\subsubsection{Estimación simultánea de backazimuths y tiempos de arribo}

Entre las estrategias consideradas para el picado de tiempos de arribo, una de las más utilizadas ha sido la propuesta por Velis et al. (2015). A continuación se describe una modificación a la estrategia descripta en la Sección 4.3.2, propuesta con el fin de determinar los tiempos de arribo de las fases $\mathrm{P}$ y $\mathrm{S}$ de un evento microsísmico sin acudir al proceso de deflación. La búsqueda se realiza en las porciones del registro en las que mediante la estrategia descripta en la Sección 4.2 se declararon eventos luego de detectar ambas fases P y S. A diferencia de las herramientas descriptas en las 
Secciones 4.4.1, 4.4.2, 4.4.3 y 4.4.4, en las que se obtiene una estimación del backazimuth para cada receptor, esta estrategia arroja como resultado un único backazimuth para cada evento, por lo cual su aplicabilidad requiere que el arreglo de receptores sea, al menos aproximadamente, lineal.

Como se describió, la búsqueda de eventos por reconocimiento de patrones arroja como resultado los parámetros que definen a una hipérbola: coordenadas espaciotemporales de la fuente $\left(x_{f}, z_{f}\right.$ y $\left.t_{0}\right)$ y una velocidad efectiva para el medio, $v$. La propuesta ahora es incorporar como incógnita del problema al backazimuth del evento y modificar la función de costo de manera tal de buscar dos ventanas hiperbólicas en simultáneo, cada una de las cuales corresponde a una fase. Las dos ventanas a determinar estarán definidas por las mismas coordenadas espacio-temporales de la fuente, pero por distintas velocidades efectivas, $v_{P}$ y $v_{S}$. Por otra parte, dichas ventanas no pueden superponerse ni ser excesivamente lejanas, sino presentar una separación temporal dentro de un cierto rango. Esto impone una condición sobre los parámetros $x_{f}, v_{P}$ y $v_{S}$ según la cual la diferencia de tiempos

$$
\Delta t=\frac{x_{f}}{v_{S}}-\frac{x_{f}}{v_{P}}
$$

debe encontrarse en el rango $\left(\Delta t_{\min }, \Delta t_{\max }\right)$ que puede definirse entre los parámetros de entrada y depende de las distancias esperadas (aproximables en función de la posición de la zona de tratamiento respecto del pozo monitor) y las velocidades aproximadas del medio. Por último, las ventanas pueden tener longitudes diferentes, teniendo en cuenta que la duración de las ondas $\mathrm{S}$ en los registros suele ser mayor a la de las ondas $\mathrm{P}$.

Previo al cálculo de la función de costo, a las componentes horizontales del registro se les aplica una rotación por un ángulo $\alpha$, de manera que las trazas horizontales correspondientes al $k$-ésimo receptor resultan

$$
\begin{aligned}
& \tilde{x}_{k}^{i}(\alpha)=x_{k}^{i} \cos (\alpha)+y_{k}^{i} \sin (\alpha), \\
& \tilde{y}_{k}^{j}(\alpha)=-x_{k}^{j} \sin (\alpha)+y_{k}^{j} \cos (\alpha),
\end{aligned}
$$

para cada componente $i, j$ de las ventanas de prueba correspondientes a las ondas $\mathrm{P} y$ $\mathrm{S}$, respectivamente. Consideremos la energía de las trazas medias de las dos ventanas y de las componentes horizontales por separado:

$$
\begin{aligned}
& G_{P}^{x}=G_{P}^{x}\left(x_{f}, z_{f}, t_{0}, v_{P}, \alpha\right)=\frac{1}{M_{P}} \sum_{i=1}^{M_{P}}\left[\bar{s}_{i}^{x_{P}}(\alpha)\right]^{2}, \\
& G_{P}^{y}=G_{P}^{y}\left(x_{f}, z_{f}, t_{0}, v_{P}, \alpha\right)=\frac{1}{M_{P}} \sum_{i=1}^{M_{P}}\left[\bar{s}_{i}^{y_{P}}(\alpha)\right]^{2},
\end{aligned}
$$


para la ventana correspondiente a la onda $\mathrm{P}, \mathrm{y}$

$$
\begin{aligned}
& G_{S}^{x}=G_{S}^{x}\left(x_{f}, z_{f}, t_{0}, v_{S}, \alpha\right)=\frac{1}{M_{S}} \sum_{i=1}^{M_{S}}\left[\bar{s}_{i}^{x_{S}}(\alpha)\right]^{2}, \\
& G_{S}^{y}=G_{S}^{y}\left(x_{f}, z_{f}, t_{0}, v_{S}, \alpha\right)=\frac{1}{M_{S}} \sum_{i=1}^{M_{S}}\left[\bar{s}_{i}^{y_{S}}(\alpha)\right]^{2},
\end{aligned}
$$

para la ventana correspondiente a la onda $\mathrm{S}$, con $M_{P}$ y $M_{S}$ sus respectivas longitudes. Si los parámetros que definen las hipérbolas $\left(x_{f}, z_{f}, t_{0}, v_{P}\right.$ y $\left.v_{S}\right)$ son los óptimos, existe un ángulo $\alpha$ tal que al aplicar las rotaciones de las ecuaciones 4.16 y 4.17, las energías calculadas mediante las ecuaciones 4.18 y 4.21 son máximas, y las energías de las ecuaciones 4.19 y 4.20 son mínimas. En otras palabras, el ángulo $\alpha$ óptimo será aquel que permita concentrar toda la energía de la onda $\mathrm{P}$ en la primer componente y la energía de la onda $\mathrm{S}$ en la segunda componente. Dicho ángulo $\alpha$ es el ángulo complementario del backazimuth, es decir, $\alpha=90^{\circ}-\beta$.

Se define, entonces, la nueva función de costo como

$$
J\left(x_{f}, z_{f}, t_{0}, v_{P}, v_{S}, \alpha\right)=1-\frac{1}{2}\left[\left(G_{P}^{x}-G_{P}^{y}\right)+\left(G_{S}^{y}-G_{S}^{x}\right)\right] .
$$

El ejemplo que se describe a continuación tiene por objetivo ilustrar la modificación propuesta para el código de detección y picado de fases por reconocimiento de patrones. En la Figura 4.18 se muestran las componentes $x$ e $y$ de una porción de registro que contiene un evento microsísmico registrado con un arreglo de siete receptores dispuesto en un pozo de monitoreo aproximadamente vertical (datos de campo). Como se puede observar, las energías de las ondas P y S están distribuidas en ambas componentes. Las ventanas hiperbólicas móviles en las componente $x$ e $y$ se ilustran en la Figura 4.18, en colores rojo y azul respectivamente. En la figura se muestran las ventanas óptimas halladas para este ejemplo, en el que se consideró $M_{P}=60$ y $M_{S}=80$, es decir, $30 \mathrm{~ms}$ y $40 \mathrm{~ms}$ respectivamente, pues el intervalo de muestreo para estos datos es $d t=0.5 \mathrm{~ms}$.

El conjunto de parámetros $\left(x_{f}, z_{f}, t_{0}, v_{P}, v_{S}\right)$ que maximicen en simultáneo las energías de las trazas medias contenidas en las dos ventanas será el que mejor represente al evento, mientras que el valor óptimo del ángulo $\alpha$ será aquél que permita concentrar la energía de la onda P en la primer componente, como se muestra en la Figura 4.19. Esto es equivalente a rotar las componentes horizontales al sistema radial-transversal como se explicó en la Sección 4.4.3.

Si en la ventana temporal que se estudia están presentes las ondas P y S asociadas a un evento microsísmico (y no hay superposición de eventos), esta estrategia permite, entonces, obtener de manera simultánea los tiempos de arribo de las dos fases (Figura 4.19, puntos verdes) y el backazimuth del evento, que constituyen la principal información requerida para llevar a cabo la localización. 

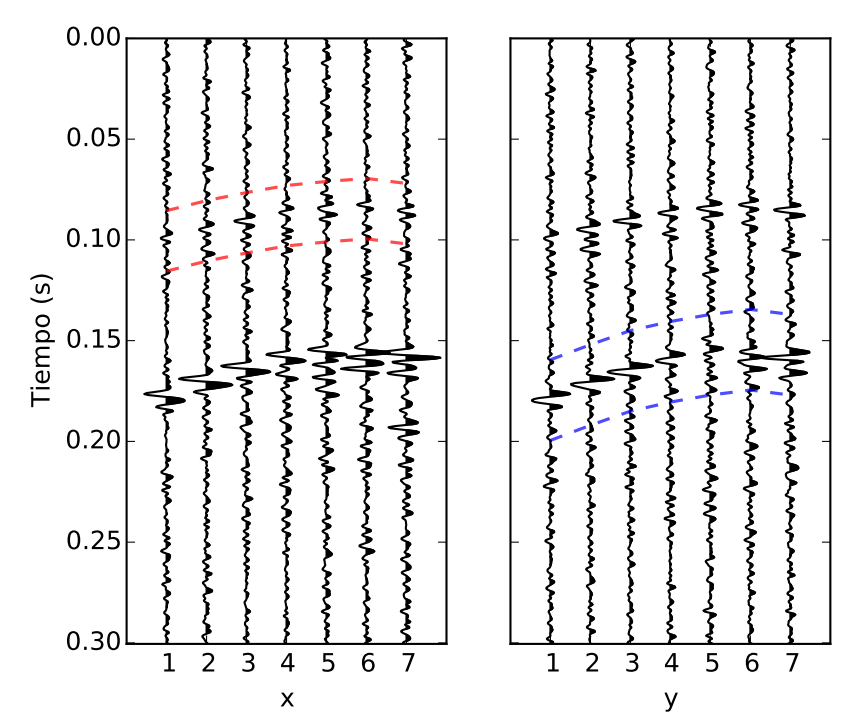

Figura 4.18. Registro original. Las ventanas de búsqueda en las componentes $x$ e $y$ son indicadas en color rojo y azul respectivamente.
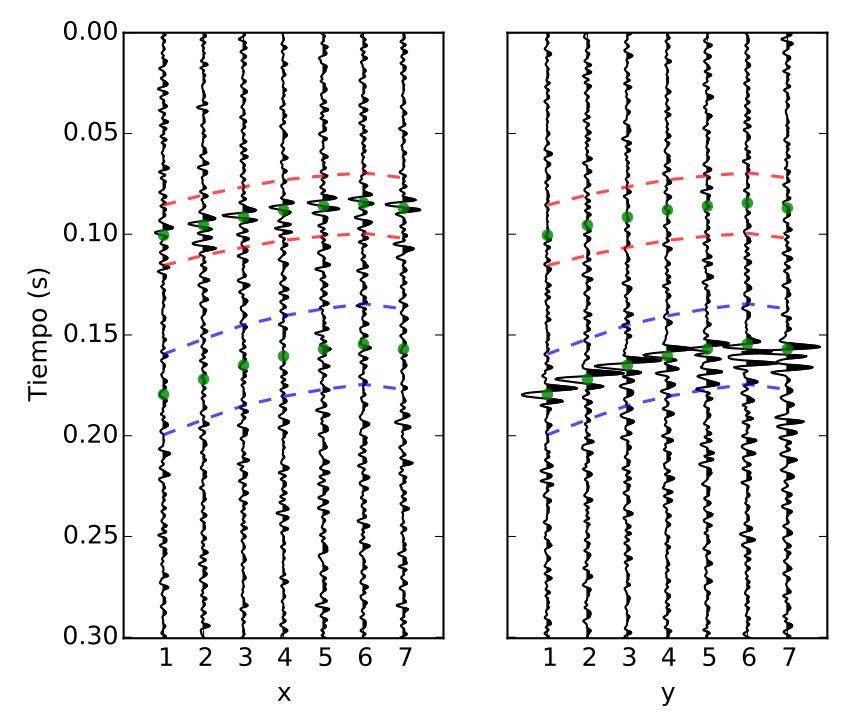

Figura 4.19. Registro rotado de acuerdo al backazimuth estimado. 
80 Detección de eventos, picado de tiempos de arribo y estimación de backazimuths

\begin{tabular}{ccccccccccc}
\hline & 1 & 2 & 3 & 4 & 5 & 6 & 7 & 8 & 9 & 10 \\
\hline $\bar{\beta}$ & 38.1 & 33.8 & 38.8 & 37.4 & 33.2 & 34.7 & 38.5 & 39.0 & 42.0 & 34.0 \\
\hline$\sigma_{\beta}$ & 1.0 & 0.7 & 0.7 & 1.2 & 0.8 & 0.8 & 0.7 & 1.0 & 0.9 & 1.9 \\
\hline
\end{tabular}

Tabla 4.1. Valores medios y desvíos estándar para los backazimuths obtenidos para las 50 mejores soluciones luego de 75 repeticiones para 10 registros sintéticos diferentes.

Adicionalmente, en la modificación al código propuesta se definen los indicadores

$$
\begin{aligned}
R_{P} & =e_{P}^{x} / e_{P}^{y}, \mathrm{y} \\
R_{S} & =e_{S}^{y} / e_{S}^{x},
\end{aligned}
$$

donde $e_{x}$ y $e_{y}$ corresponden a las energías en las componentes $x$ e $y$ respectivamente y los supraíndices indican la ventana considerada. De esta manera, si el cálculo del backazimuth fue correcto, debería ocurrir que $e_{P}^{x}>e_{P}^{y}$ y que $e_{S}^{y}>e_{P}^{x}$, y por lo tanto $R_{P}>1$ y $R_{S}>1$. Estos indicadores podrían utilizarse para asociar a las hipérbolas halladas una probabilidad de que efectivamente contengan las fases $\mathrm{P}$ y $\mathrm{S}$ de un evento y considerarla luego para la evaluación de algún criterio de aceptación de eventos. Por ejemplo, podría pedirse que ambos indicadores sean mayores a 2 para aceptar un evento. Es decir, que la energía de la onda $\mathrm{P}$ sea al menos el doble en la componente $x$ que en la $y$, y al revés para la onda $\mathrm{S}$.

Con el fin de evaluar los resultados para la estimación del backazimuth por medio de esta estrategia, se llevó a cabo un ejemplo sintético. Se generaron 10 registros sintéticos a partir de una fuente ficticia a los que se añadió ruido aleatorio. La posición de la fuente es la misma en todos los casos y la única diferencia entre los registros es el ruido agregado. El backazimuth de la fuente es $40.6^{\circ}$. La Figura 4.20 ilustra un registro sintético antes y después de la rotación de acuerdo al backazimuth calculado. En ésta se observa que la energía de la onda $\mathrm{P}$ se concentra en la primer componente y la energía de la onda $\mathrm{S}$ en la segunda, luego de rotar con el ángulo $\alpha$ estimado. Para cada uno de estos registros, y con fines estadísticos, se aplicó el algoritmo descripto un total de 75 veces con diferentes semillas para la generación aleatoria de parámetros de las ventanas hiperbólicas de búsqueda iniciales. Del total de repeticiones se tomaron las 50 en las que se alcanzó un menor valor para la función de costo, con el fin de evitar eventuales valores atípicos que pueden ocurrir dada la naturaleza estocástica del método. Los valores medios y los desvíos estándar para cada registro se muestran en la Tabla 4.1. Puede verse que los valores medios obtenidos difieren hasta $8^{\circ}$ del valor real del backazimuth, pero que los desvíos asociados son en todos los casos menores a $2^{\circ}$. Estas diferencias son aceptables teniendo en cuenta que los errores en la estimación del backazimuth con onda P pueden tener desvíos de hasta $29^{\circ}$ (Eisner et al., 2009a). Los errores en los valores medios son introducidos por el ruido agregado a los datos, mientras que los desvíos muestran que los resultados de las múltiples repeticiones de la optimización son consistentes. 

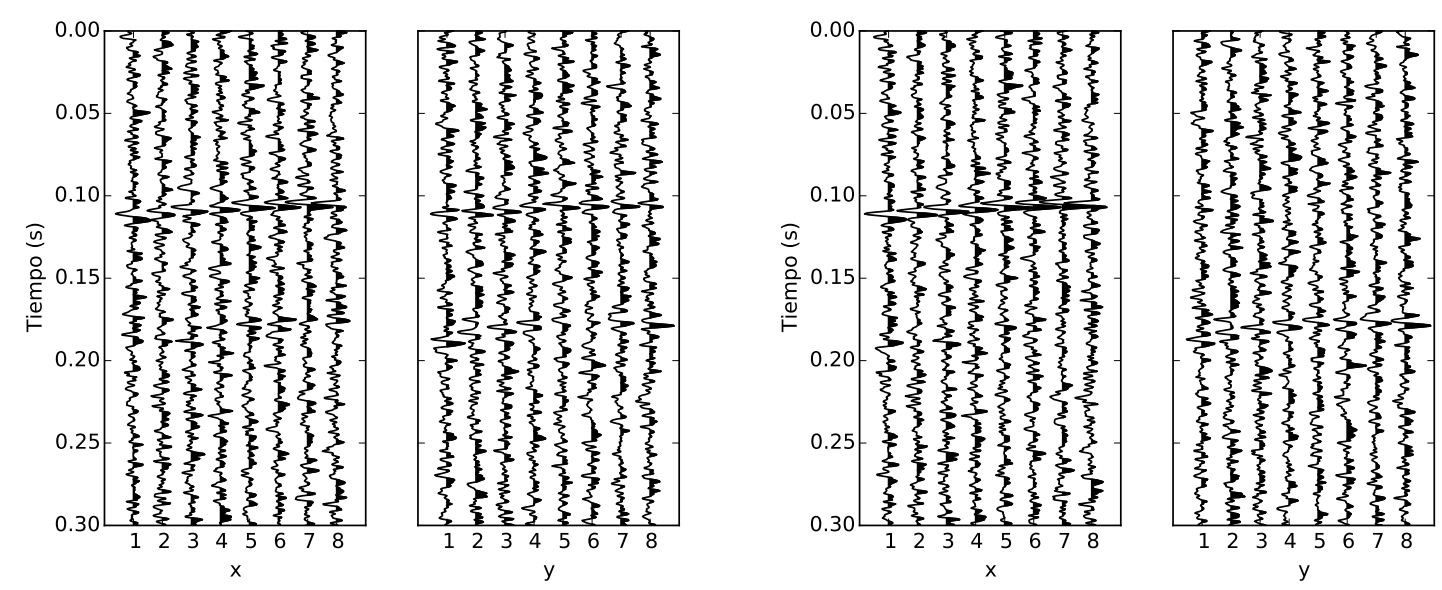

Figura 4.20. Ejemplo sintético antes (izquierda) y después (derecha) de la rotación al sistema radial-transversal.

\subsubsection{Incertidumbres en la estimación del backazimuth}

Cuando el monitoreo microsísmico es llevado a cabo con un arreglo de receptores dispuesto en un pozo vertical en un medio con isotropía acimutal, la estimación del backazimuth permite reducir las dimensiones de la localización a un plano que contiene al arreglo de receptores y al evento en cuestión. Si se realiza la estimación del backazimuth por medio de alguna de las estrategias descriptas que ejecutan el cálculo para cada traza de manera individual, es necesario establecer un criterio para estimar un único backazimuth a partir de todas las observaciones. La opción más directa es la de tomar la media simple de todas las estimaciones. Esto conlleva la suposición de que las estimaciones obtenidas tienen distribución gaussiana. Sin embargo, la cantidad de muestras disponibles no permite garantizar que la media calculada es representativa de la media real de la población. La presencia de ruido con amplitudes importantes en relación a las amplitudes de la señal y las heterogeneidades locales que puede presentar el medio pueden dar lugar a valores atípicos del backazimuth calculado en receptores individuales que alteran el promedio significativamente. Una alternativa al cálculo de la media simple es discriminar aquellos receptores en los que la relación señal-ruido es baja, lo que reduce la confiabilidad de la información que aportan. Otra posibilidad consiste en detectar los valores atípicos para excluirlos del cálculo del backazimuth medio, asumiendo que éstos corresponden a observaciones de pobre calidad cuya eliminación contribuye a mejorar la estimación de la media. En cualquier caso, debe tenerse en cuenta que dada la poca cantidad de observaciones disponibles, no puede descartarse un gran número de estimaciones. A continuación se evalúan las dos opciones mencionadas, a partir de un conjunto de 240 eventos detectados en una etapa de fracturación hidráulica con un arreglo de siete receptores (datos de campo). Para cada evento y para cada receptor se estimó el backazimuth de acuerdo a la estrategia descripta en la Sección 4.4.3. La relación señal-ruido de cada evento se obtuvo del promedio de las relaciones señal-ruido calculadas para la onda $\mathrm{P}$ en cada receptor. 


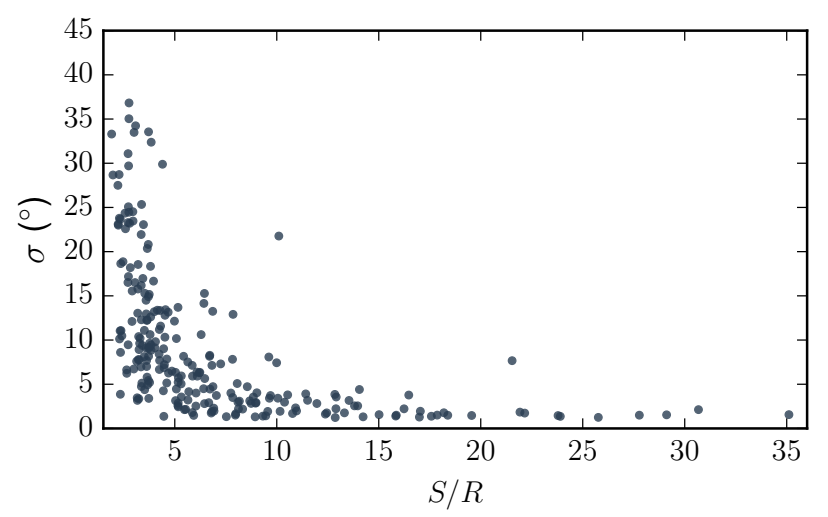

Figura 4.21. Desvíos estándar medios vs. relaciones señal-ruido medias.

Estas últimas se obtuvieron a partir de calcular las sumas de los valores absolutos de las amplitudes en una ventana que contiene a la onda $\mathrm{P}$ (definida a partir del tiempo de arribo estimado) y en una ventana previa a ésta, del doble de longitud. La relación señal-ruido, entonces, se obtuvo como el cociente entre ambas cantidades.

La Figura 4.21 muestra que, como es de esperar, las bajas relaciones señal-ruido se asocian a mayores desvíos en las estimaciones del backazimuth, si consideramos el total de las observaciones asumiendo que se distribuyen de forma normal. De aquí resulta natural pensar que eliminando del cálculo a aquellos receptores en los que la relación señal-ruido sea inferior a un cierto valor umbral es posible reducir los desvíos. Luego, el backazimuth único se calcula a partir del promedio simple de las estimaciones para las cuales la relación señal-ruido superó el valor umbral. En el ejemplo que se muestra aquí se descartaron del cálculo del backazimuth medio a aquellos receptores para los cuales $S / R<2$. Un valor umbral superior a 2 implicaría, en aquellos eventos de menores magnitudes, eliminar la mayor parte de la información disponible.

El descarte de los valores atípicos, por otra parte, podría realizarse eliminando aquellos backazimuths que distan del valor medio en un múltiplo del desvío estándar. Es decir, aquellas observaciones $x_{i}$ tales que

$$
\left|x_{i}-\overline{\mathbf{x}}\right|>k \sigma \text {. }
$$

Esta opción resulta útil cuando se trata de muestras de tamaños considerables. En caso contrario, la contribución de los valores atípicos resulta lo suficientemente importante como para alterar significativamente los valores de la media y la desviación estándar, con lo cual este criterio de descarte no es confiable. Un único valor atípico puede aumentar tanto el desvío de la muestra, que luego dicho valor no sea eliminado.

Como alternativa se propone utilizar un criterio similar, pero basado en la desviación absoluta respecto de la mediana (DAM). La ventaja de considerar la mediana de los datos en lugar de su valor medio radica en que ésta es un parámetro robusto no 

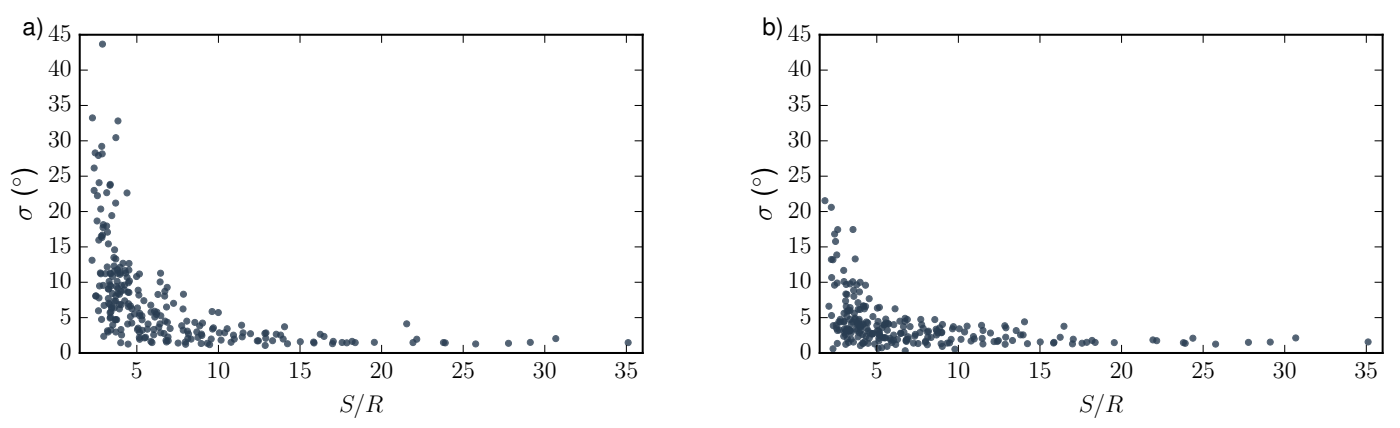

Figura 4.22. Desvíos estándar medios vs. relaciones señal-ruido medias luego del descarte de valores atípicos basado en: a) la relación señal-ruido y b) la DAM.

influenciado por valores atípicos. La DAM, $\tilde{\sigma}$, se define como

$$
\tilde{\sigma}=b M(|\mathbf{x}-M(\mathbf{x})|),
$$

donde $M(y)$ es la mediana de la muestra $y$, y $b$ es una constante de consistencia que, en el caso de asumir que la distribución de las observaciones es gaussiana, toma el valor $b=1.4826$ (Rousseeuw y Croux, 1993). El criterio de descarte consiste ahora en eliminar aquellos valores $x_{i}$ tales que

$$
\left|x_{i}-M(\mathbf{x})\right|>k \tilde{\sigma}
$$

con $k \geq 1$. Finalmente el backazimuth y la correspondiente desviación se recalcula a partir de las observaciones no descartadas.

El rango de posibles backazimuths para cada evento es acotado. En general, se puede restringir a una zona en torno a la región esperada de ocurrencia de eventos microsísmicos. Como máximo, se tiene un rango de $180^{\circ}$ para los posibles ángulos (salvo cambios de polaridad). En consecuencia, en condiciones de desvíos significativos un valor de $k$ grande puede generar rangos de aceptabilidad que cubran todos los posibles ángulos y, por lo tanto, no descartar ningún valor atípico. A partir de esta observación, para este ejemplo se consideró $k=1$. Sin embargo, esto supone la eliminación de al menos una observación para cada evento, incluso en los casos en los que los desvíos sean pequeños. Para evitar esta situación, el criterio es aplicado solo en los casos en los que el desvío inicial supera los $5^{\circ}$.

En la Figura 4.22a se muestran los desvíos calculados luego de la eliminación de backazimuths estimados en receptores de baja relación señal-ruido $(S / R<2)$, mientras que en la Figura 4.22b se muestran los desvíos obtenidos luego de la eliminación de valores atípicos de acuerdo al criterio de la DAM con $k=1$. En este último caso, la reducción en los desvíos respecto de los correspondientes al conjunto inicial de observaciones (Figura 4.21) es significativamente mayor para el segundo criterio. El desvío medio para las observaciones iniciales es de $9.2^{\circ}$, y se reduce a $7.6^{\circ}$ al eliminar las 

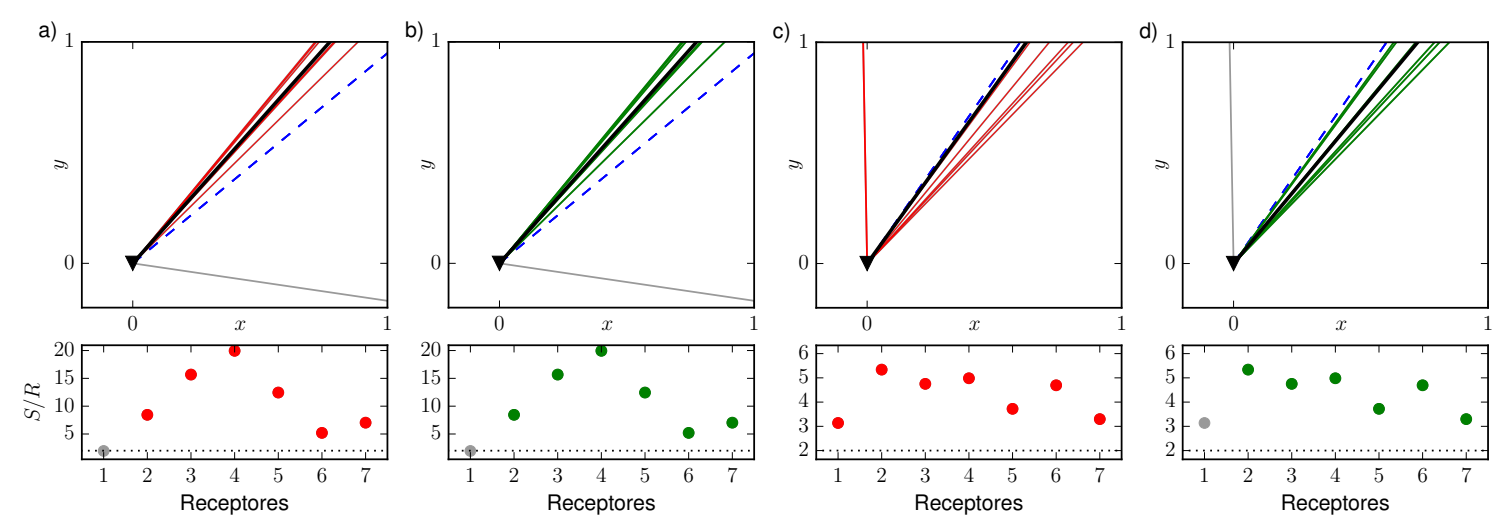

Figura 4.23. Ejemplo de la eliminación de observaciones para dos eventos microsísmicos de acuerdo a los criterios basados en a) y c) la relación señal-ruido; y b) y d) la DAM.

estimaciones obtenidas en receptores con baja relación señal-ruido, y a $4.1^{\circ}$ para el caso DAM. El hecho de que no se produzcan grandes reducciones de los desvíos al eliminar observaciones con baja relación señal-ruido puede explicarse por medio de la Figura 4.23 que ilustra cómo es la eliminación de observaciones en casos particulares. Los pares a)-b) y b)-c) corresponden a las estimaciones de backazimuth de dos eventos microsísmicos. Los paneles superiores ilustran las direcciones halladas (en planta), mientras que los inferiores las relaciones señal-ruido en cada uno de los receptores disponibles. En éstos, la línea punteada indica el valor umbral de descarte de estimaciones por relación señalruido $(S / R=2)$. En los paneles superiores las líneas punteadas azules corresponden a la media simple de todos los backazimuths estimados, la línea negra indica la media luego del descarte de observaciones y en gris se muestran las observaciones descartadas. Las Figuras 4.23a y 4.23c corresponden a los resultados de aplicar el criterio basado en la relación señal-ruido, mientras que $4.23 \mathrm{~b}$ y $4.23 \mathrm{~d}$ corresponden al descarte de valores atípicos por medio de la DAM. En el primer evento, ambos criterios descartan una misma observación (correspondiente al receptor 1) y la media estimada a partir de los restantes difiere significativamente de la media inicial. En este caso, el valor atípico está asociado a una baja relación señal-ruido. Este no siempre es el caso, dado que variaciones locales en las características del medio pueden dar lugar a errores en la dirección estimada, aún cuando el nivel de ruido sea mucho menor al de la señal. Este es el caso del evento asociado a las Figuras $4.23 \mathrm{c}$ y $4.23 \mathrm{~d}$, en el que existe un claro valor atípico que no es descartado por su relación señal-ruido, pero sí por distar de la mediana de las observaciones en más de una DAM. En el primer caso (Figura 4.23c), la media, ahora pesada por las relaciones señal-ruido de los receptores, es muy similar a la inicial y está claramente sesgada por el valor atípico.

A modo de conclusión, la eliminación de aquellas observaciones que presenten comportamientos erráticos o muy diferentes al resto es necesaria con el fin de reducir las incertidumbres en la estimación del backazimuth, que luego se traducen en incertidumbres en la localización de eventos microsísmicos. Una posibilidad es descartar las estimaciones obtenidas en receptores en los que la relación señal-ruido no supera 
un determinado valor umbral, sin embargo, es posible que existan valores atípicos asociados a relaciones señal-ruido por encima de tal valor, con lo cual este criterio no garantiza la reducción de las incertidumbres. En algunos casos particulares, puede incluso aumentar los desvíos como puede observarse en el valor de $\sigma$ cercano a $45^{\circ}$ en la Figura 4.23. Como alternativa, se propone el uso de la desviación absoluta respecto de la mediana (DAM), un criterio estadístico para realizar la eliminación de valores atípicos de utilidad en muestras pequeñas, para el cual se asumió que las estimaciones de backazimuths tienen distribución gaussiana. En el ejemplo considerado, que consistió en el cálculo de backazimuths para un total de 240 eventos reales, este criterio permitió reducir los desvíos promedio en más de un $50 \%$.

Otro posible criterio para la eliminación de valores atípicos que puede ser utilizado parte de la suposición de que los backazimuths obtenidos para cada receptor son una pequeña muestra de una población de distribución gaussiana cuya media es el backazimuth real del evento, $\beta$, (Han, 2010; Aster et al., 2005). Como la cantidad de observaciones, $N$, es pequeña se puede considerar la variable

$$
t=\frac{\tilde{\beta}-\bar{\beta}}{s / \sqrt{N}}
$$

que sigue una distribución de Student con $N-1$ grados de libertad, donde $\tilde{\beta}$ es el backazimuth obtenido partir de una traza individual, $\bar{\beta}$ corresponde a la media de la muestra y $s$ es una estimación de la desviación estándar, calculada como

$$
s^{2}=\frac{1}{N-1} \sum_{i=1}^{N}\left(\beta_{i}-\bar{\beta}\right)^{2} .
$$

Este criterio parte del hecho de que la correspondiente función de densidad de probabilidad (fdp) de la variable $t$ dada por

$$
f(t \mid N)=\frac{\Gamma\left(\frac{N+1}{2}\right)}{\Gamma\left(\frac{N}{2}\right)} \frac{1}{\sqrt{N \pi}} \frac{1}{\left(1+\frac{t^{2}}{N}\right)^{\frac{N+1}{2}}}
$$

tiende a una distribución normal cuando $N$ tiende a infinito. En la ecuación 4.30, $\Gamma(x)=\int_{0}^{\infty} \xi^{x-1} e^{-\xi} d \xi$.

Se obtiene el valor medio de $t$ a partir de maximizar su fdp y recalculando $\bar{\beta}$ y $\sigma$ en consecuencia. Luego, se pueden remover los valores atípicos a partir de eliminar aquellas estimaciones del backazimuth que difieren de la nueva media en más de un desvío estándar. Este proceso puede aplicarse de forma iterativa teniendo los cuidados necesarios para no reducir demasiado el tamaño de la muestra.

Este criterio fue implementado siguiendo a Han (2010) y utilizado en las primeras etapas del desarrollo de las tareas de investigación que condujeron a esta Tesis, como se mostrará en el Capítulo 5. Si bien los resultados que permitía obtener en términos de eliminación de valores atípicos eran similares a los arrojados por el criterio basado en la DAM, la aplicación práctica resulta más conveniente en este último caso, por lo que 
más tarde, al momento de procesar datos de campo, se optó por este último. El criterio de la DAM no involucra el cálculo de funciones adicionales (como la función $\Gamma(x)$ de la ecuación 4.30) ni considera inicialmente la media o el desvío de las observaciones.

\subsection{Conclusiones}

Con el propósito de aislar las porciones de registros que contienen eventos microsísmicos, se consideró la estrategia multicanal propuesta por Sabbione y Velis (2013), que fue adaptada para su aplicación a los registros de campo disponibles. Se propuso una modificación a esta herramienta mediante la cual los registros son barridos de forma continua y un evento es declarado cuando ambas fases, P y S, son detectadas. Esta estrategia fue evaluada en registros sintéticos realistas, alcanzando un alto porcentaje de éxito. Asimismo, la nueva herramienta fue utilizada satisfactoriamente para la detección de eventos en datos de campo. Los eventos detectados de esta forma deben ser posteriormente inspeccionados visualmente para descartar posibles falsas detecciones.

Por otra parte, se presentaron las herramientas disponibles para el picado de tiempos de arribo. La primera de ellas corresponde a la estrategia multicanal de detección y picado ya mencionada, mientras que la segunda involucra el reconocimiento de patrones dentro de las porciones de registros donde previamente se detectaron eventos. Esta última es de particular interés, pues se introdujo una modificación que permite, en simultáneo, estimar los tiempos de arribo de las ondas $\mathrm{P}$ y S de un evento y el backazimuth correspondiente, sin recurrir al proceso de deflación. Esta herramienta requiere que el arreglo de receptores sea aproximadamente lineal, lo cual se satisface en la mayoría de las geometrías de adquisición generalmente empleadas, y brinda un único backazimuth para todo el arreglo de receptores.

Otras estrategias de estimación del backazimuth brindan una solución para cada receptor disponible. Varias de éstas fueron implementadas computacionalmente y adaptadas para el procesamiento de eventos detectados en registros de campo. En escenarios de adquisición dados por un pozo aproximadamente vertical en un medio con isotropía acimutal, es necesario estimar un único backazimuth a partir de todos los disponibles, lo que permite reducir el problema de la localización de eventos a dos dimensiones. Con este fin, se evaluaron distintas posibilidades para eliminar aquellas estimaciones del backazimuth que no resulten confiables, y reducir así la incertidumbre en la estimación de este ángulo. Se observó que la eliminación de valores atípicos por medio del cálculo de la desviación absoluta respecto de la mediana de las observaciones (DAM) es una herramienta útil en este sentido. Por medio de la aplicación de este criterio a un conjunto de eventos detectados en datos de campo, el cálculo de un único backazimuth alcanzó desvíos significativamente menores a los que normalmente podrían obtenerse mediante la utilización de la onda P (Eisner et al., 2009a). 


\section{Capítulo 5}

\section{Localización de eventos microsísmicos}

\subsection{Introducción}

Como ya se ha mencionado a lo largo de esta Tesis, uno de los principales objetivos del monitoreo microsísmico de procesos de fracturación hidráulica en reservorios no convencionales es la determinación de las coordenadas de las fuentes microsísmicas. La distribución espacio-temporal de estos eventos brinda información que permite interpretar la deformación producida por la inyección: el tamaño y orientación de las redes de fracturas generadas, las características de su crecimiento en el tiempo y el volumen de roca estimulado, entre otros resultados (Cipolla et al., 2012; Kendall et al., 2011; Rutledge y Phillips, 2003).

Las diferentes estrategias existentes para realizar la localización de eventos microsísmicos pueden ser clasificadas en dos grandes grupos. Los métodos basados en la determinación o el picado de los tiempos de arribo de las ondas $\mathrm{P}$ y $\mathrm{S}$ asociadas a un evento microsísmico conforman el primero de estos grupos. Estos tiempos de arribo son utilizados para la construcción de una función de costo que se minimiza para estimar las coordenadas de la fuente. Por otra parte, existen métodos de localización cuyo enfoque se asimila a los métodos que se aplican en sísmica de reflexión, como los algoritmos de migración tipo Kirchhoff. Estos métodos se basan en la detección de un evento que maximiza alguna medida de la coherencia de la señal (Gajewski y Tessmer, 2005; Baker et al., 2005; Drew et al., 2013; Rentsch et al., 2007). En esta Tesis se consideró el primero de estos enfoques. En este capítulo se describen los trabajos realizados con este fin.

En primer lugar, entre los primeros pasos llevados a cabo como parte de este doctorado, se estudiaron el problema de la localización, los pasos previos requeridos para llevarla a cabo y distintas posibilidades en relación a la geometría de adquisición de los datos. En esta primera etapa se trabajó con datos sintéticos, simulados de forma realista, y se planteó la automatización de la secuencia de procesamiento que conduce a la localización de eventos microsísmicos. En este trabajo, que fue publicado en la 
revista internacional Journal of Applied Geophysics (Lagos y Velis, 2018), se presentó un flujo de procesamiento integrado y optimizado que concatena los distintos procesos que permiten obtener coordenadas de eventos microsísmicos a partir de registros 3C. En la Sección 5.2 del presente capítulo se detallan los procesos mencionados y el flujo de procesamiento propuesto. Para realizar la localización de eventos microsísmicos se propuso la utilización de dos métodos de optimización global: Very Fast Simulated Annealing (VFSA) y Particle Swarm Optimization (PSO). Ambos algoritmos fueron evaluados en términos de su eficacia en la obtención de una solución y las incertidumbres asociadas, y fueron comparados con el clásico Grid Search (GS) desde el punto de vista de su eficiencia computacional.

Por otra parte, luego de disponer de datos de campo, el planteo del problema de la localización de eventos microsísmicos fue adaptado a dichos registros, evaluando diferentes funciones de costo para el mismo y contemplando modelos de velocidades más complejos. En la segunda parte de este capítulo (Sección 5.3) se describen estas consideraciones y se muestran los resultados de localizar eventos microsísmicos en datos de campo, en continuidad con las tareas desarrolladas en los capítulos previos. Para esto, fueron también utilizados los algoritmos VFSA y PSO.

\subsection{Secuencia automática de procesamiento en da- tos sintéticos}

A continuación se consideran los distintos pasos que conducen a la localización de fuentes siguiendo un enfoque basado en la determinación de los tiempos de arribo de las señales microsísmicas a los receptores dispuestos para el monitoreo de las mismas. En términos generales, esta secuencia de procesamiento consiste en la detección de las ondas $\mathrm{P}$ y $\mathrm{S}$ en los registros, la determinación de sus correspondientes tiempos de arribo y la estimación de las coordenadas de las fuentes utilizando un modelo de velocidades conocido a priori. Por medio del cálculo de la diferencia de tiempos de arribo entre las ondas P y S es posible estimar la distancia entre la fuente y los receptores (Eisner et al., 2009a). Para hallar las coordenadas en un espacio tridimencional, entonces, es necesario determinar previamente la dirección de la cual proviene la energía (backazimuth) (Maxwell et al., 2010a). La estimación del backazimuth puede ser realizada por medio del estudio del movimiento de partícula asociado a las fases registradas (Eisner et al., 2010). En la presente sección se muestra un flujo de trabajo en el que se concatenan los distintos pasos que conducen a la localización de eventos microsísmicos. En primer lugar, se lleva a cabo la detección de las ondas P y S, la determinación de sus tiempos de arribo y una posterior remoción del ruido presente en las ventanas que contienen a las ondas detectadas. El backazimuth de cada evento se obtiene a partir del análisis de polarización de las ondas P y S asociadas. Se considera, además, una simple estrategia basada en la energía de las fases correspondientes para decidir cuál de las estimaciones de backazimuths es más confiable. Por último los eventos son localizados de manera automática a través de la resolución de un problema de optimización no-lineal, que 
aprovecha los backazimuths previamente estimados para reducir el espacio de búsqueda. Para resolver este problema se utilizan los algoritmos de optimización VFSA (Ingber, 1989) y Particle Swarm Optimization (PSO) (Kennedy y Eberhart, 1995; Shaw y Srivasta, 2007). Se consideran dos geometrías de adquisición diferentes que conducen a la búsqueda de la posición de cada evento como la solución de problemas en dos y tres dimensiones.

Todos estos pasos fueron concatenados en un mismo script de Bash que puede ser utilizado para obtener las coordenadas de las fuentes prácticamente sin intervención del usuario.

En cuanto a los algoritmos de optimización, se realizó una comparación de sus desempeños desde el punto de vista de su eficiencia computacional y se los comparó con la clásica búsqueda exhaustiva o Grid Search (GS), utilizada en varios softwares comerciales.

\subsubsection{Métodos involucrados}

La Figura 5.1 muestra los principales pasos de la cadena de procesamiento automática utilizada, que conduce a la localización de eventos microsísmicos en situaciones bi- o tri-dimensionales. Como datos de entrada, se requiere un modelo de velocidades, información sobre cantidad y ubicación de los receptores, un espacio de búsqueda inicial y los datos microsísmicos $3 \mathrm{C}$ observados. Por simplicidad se omiten pasos intermedios vinculados a la manipulación de entradas y salidas y varios procesos asociados. En las siguientes secciones se describen los procesos relevantes de esta cadena y se discuten algunas prácticas útiles y limitaciones al enfrentarse a bajas relaciones señal-ruido o grandes conjuntos de datos.

\section{Detección y denoising}

Para este paso se utiliza la técnica desarrollada por Velis et al. (2015) que se describió en la Sección 4.3.2. La detección incluye la determinación de los tiempos de arribo y se realiza por medio de la búsqueda de altos valores de coherencia en ventanas hiperbólicas que barren todas las trazas en simultáneo. Esta búsqueda es realizada por medio del algoritmo VFSA, que le otorga al método un alto grado de eficiencia. Se considera la energía de las trazas medias como medida de coherencia de la señal (ecuación 4.5). La salida de este paso incluye una serie de parámetros que definen la hipérbola óptima y los tiempos de arribo del evento, entre otros. Como todos los canales disponibles se procesan en simultáneo, la variación de los tiempos de arribo con la profundidad es suave, lo cual es útil para la estimación del backazimuth a partir de la onda S (Sección 4.4.4).

La reducción del ruido o denoising se realiza por medio de una aproximación de rango reducido de la descomposición en valores singulares (SVD) de la señal en la 


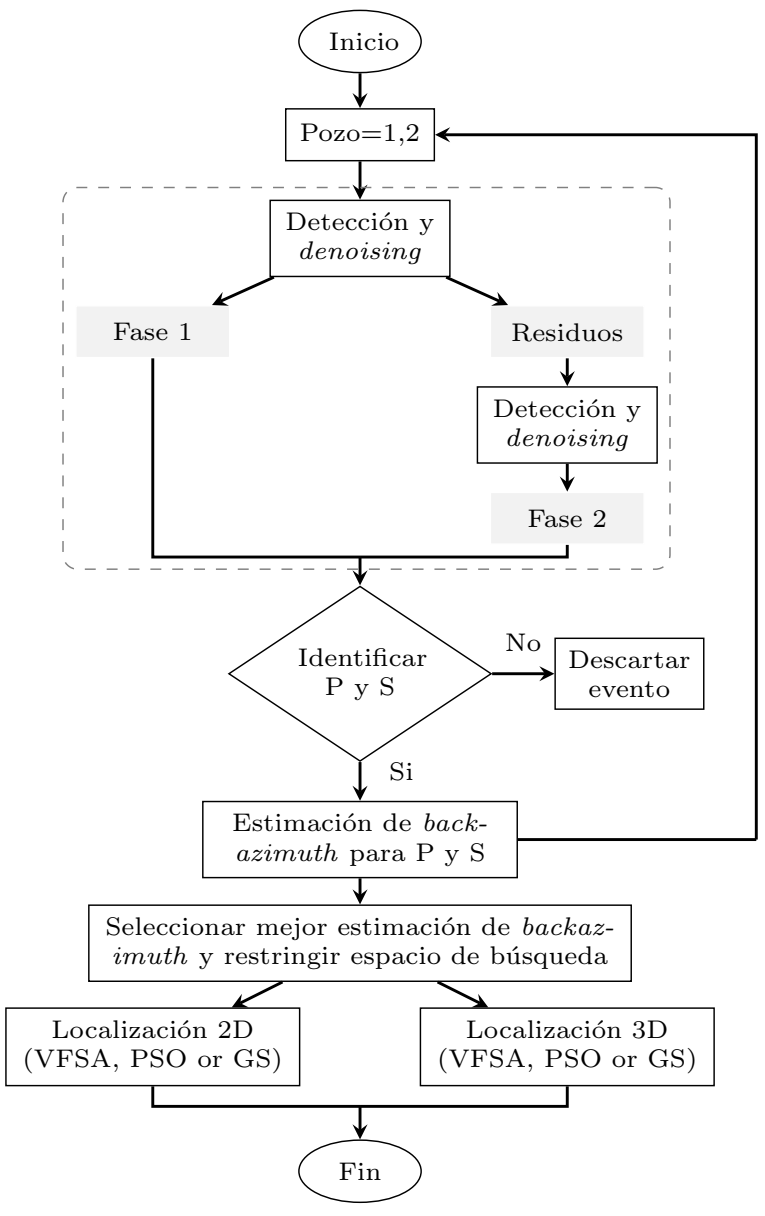

Figura 5.1. Diagrama de flujo que describe la cadena de los principales procesos que conducen a la localización de eventos microsísmicos. 
ventana hiperbólica que contiene el evento y fue obtenida en el paso anterior:

$$
S_{q}=\sum_{i=1}^{q} \sigma_{i} \mathbf{u}_{i} \mathbf{v}_{i}^{T}, \quad q<N
$$

donde $N$ es el número de trazas, $S_{q}$ es una matriz de tamaño $M \times N$ y rango $q$ que contiene la aproximación a la forma de onda de la fase en cuestión, y $\mathbf{u}_{i}, \mathbf{v}_{i}$ y $\sigma_{i}$ $(i=1, N)$ son los vectores y valores singulares, respectivamente, de la SVD de $S_{q}$ con $q=N$. En la práctica se han obtenido buenos resultados con $q=1$ o 2 , asegurando que todas las formas de onda sean similares luego de la aproximación de rango reducido.

Además de los tiempos de arribo de la señal detectada, el algoritmo brinda un indicador de su energía relativa:

$$
R=\frac{E}{\bar{E}_{n}},
$$

donde $E$ es la energía de la fase detectada y $\bar{E}_{n}$ es la energía media del ruido. Ambas cantidades se calculan en ventanas hiperbólicas de tamaño $M \times N$.

Dado un conjunto de datos microsísmicos 3C, la maximización de la función $G$ (ecuación 4.5) conduce a la detección de una fase, aquella cuya energía es mayor. Por lo tanto, si se busca detectar tanto la onda $\mathrm{P}$ como la $\mathrm{S}$, el procedimiento debe ser aplicado dos veces, considerando los residuos del primer paso (registro original menos el resultado de la primera detección y denoising) como el dato de entrada del segundo. Comparando sus tiempos de arribo es posible definir a qué fase corresponde cada señal detectada. Incluimos controles adicionales para evitar detecciones falsas como ocurriría, por ejemplo, en casos de baja relación señal-ruido, donde la maximización de $G$ podría conducir a la detección de señales espurias. Para ello se considera el indicador de la ecuación 5.2 , que en tal caso resulta $R \approx 1$.

La Figura 5.2 ilustra la doble aplicación del algoritmo al dato (deflación). En el primer panel, que representa el dato original, la onda $\mathrm{S}$ puede ser identificada a simple vista, mientras que la $\mathrm{P}$ apenas se reconoce debido a su baja relación señal-ruido. Luego del primer paso, la onda $\mathrm{S}$ fue detectada y el ruido removido adecuadamente (Figura 5.2b). En la Figura 5.2c se muestra el resultado de haber aplicado la detección y el denoising a los residuos (registro de la Figura 5.2a menos registro de la Figura 5.2b), donde la onda $\mathrm{P}$ se puede ver claramente.

\section{Estimación del backazimuth}

Como ya se mencionó, las ondas P y S tienen diferentes comportamientos a partir de los cuales se puede estimar la dirección de propagación de las señales (Jurkevics, 1988; Eisner et al., 2009a). En el caso de un medio isótropo, la polarización de dichas ondas es paralela a la dirección de propagación, para el caso de la onda $\mathrm{P}$, y perpendicular a ésta, para el caso de la onda S (Capítulo 4, Sección 4.4). Por un lado, entonces, la estimación del backazimuth es más directa para el caso de la onda P. Por otro lado, la relación señal-ruido, por lo general, es mayor para las ondas S que para las P. Por 

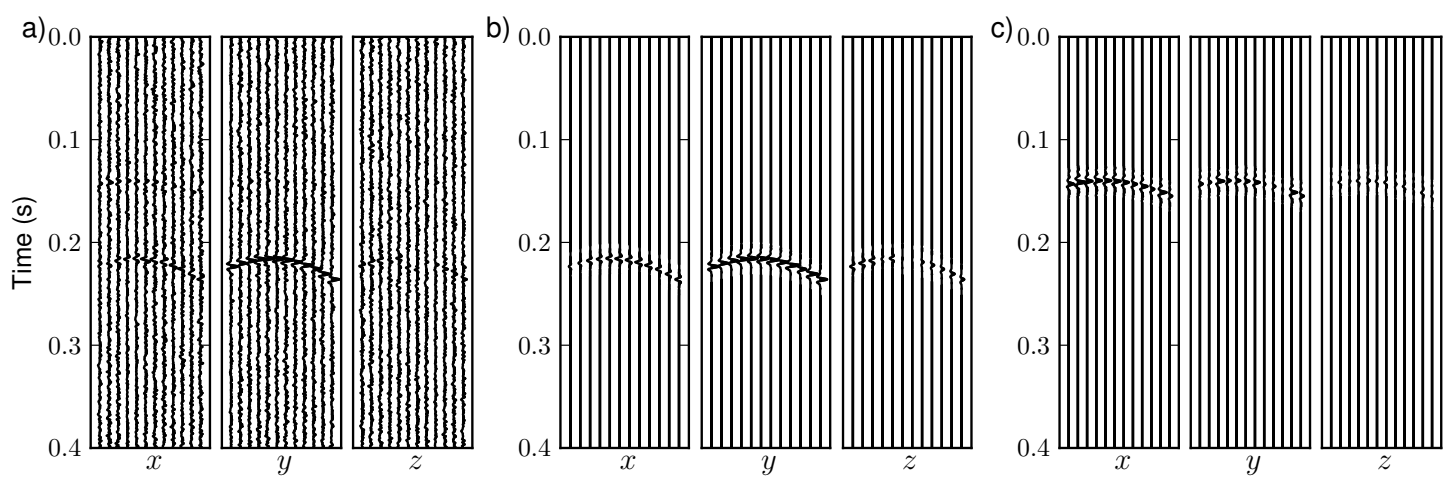

Figura 5.2. a) Registro sintético; b) y c) resultados luego de la primera y segunda aplicación del algoritmo de detección y denoising, respectivamente.

esta razón, es conveniente poder estimar el backazimuth a partir de las ondas S (Eisner et al., 2009b).

En primer lugar es necesario realizar el análisis de polarización de ambas fases, para lo cual utilizamos el método propuesto por Jurkevics (1988) que se describió en la Sección 4.4.2. En términos generales, consiste en el cálculo de la matriz de varianza-covarianza de las tres componentes de los registros de las ondas $\mathrm{P}$ o S. El vector de polarización se obtiene a partir del autovector asociado al mayor autovalor de dicha matriz. En el caso de la onda P, éste se corresponde, además, con la dirección de propagación. En el caso de la onda S, procedemos de acuerdo a lo propuesto por Eisner et al. (2009b) para un arreglo lineal de receptores en un medio isótropo (Sección 4.4.4).

En adelante nos referimos al backazimuth real de un evento microsísmico como $\beta$ y a su estimación como $\hat{\beta}$. Ya sea que $\hat{\beta}$ se estime usando el análisis de polarización de $\mathrm{P}$ o S, se tiene una solución para cada uno de los $N$ receptores disponibles. A partir de estas estimaciones se calcula un único backazimuth de acuerdo al criterio basado en la distribución de Student (ver Capítulo 4, Sección 4.4.6).

Dependiendo de las posiciones relativas de fuentes y receptores, las amplitudes de las ondas $\mathrm{P}$ y S pueden ser notablemente diferentes. Luego de numerosas pruebas observamos que los errores eran mayores para $\hat{\beta}_{P}$ que para $\hat{\beta}_{S}$ para casos de baja relación señal-ruido, pues el impacto del ruido es mayor para el primero, como ya se explicó. Por el contrario, para casos de niveles de ruido bajos, los errores son mayores para $\hat{\beta}_{S}$, pese a que las amplitudes de las ondas S son superiores a las de las ondas P. En otras palabras, si ambas ondas tuvieran idéntica relación señal-ruido, los backazimuths estimados a partir de la onda $\mathrm{P}$ serían más confiables que los obtenidos con la onda S. Por otro lado, para relaciones señal-ruido moderadas es aconsejable el uso de la onda S. Como ya se explicó, además, no es posible obtener $\hat{\beta}_{S}$ cuando la onda S está polarizada en la dirección del pozo.

Por lo tanto, proponemos el uso del indicador de energía $R$ (ecuación 5.2), que puede ser calculado para cada fase y componente de manera individual, para decidir automáticamente qué fase es más confiable para estimar el backazimuth. En pocas 


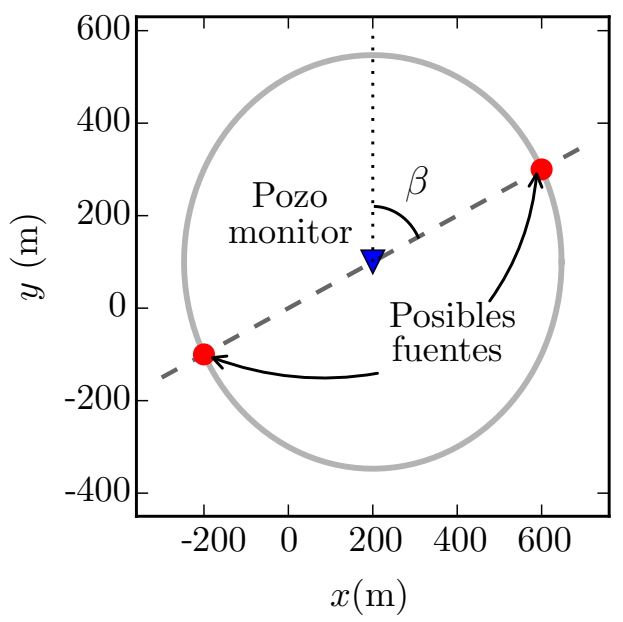

Figura 5.3. Representación de la ambigüedad de los $180^{\circ}$.

palabras, debería utilizarse $\hat{\beta}_{P}$ en aquellos casos en los que $R$ es mayor para la onda $\mathrm{P}$ que para al menos las dos componentes horizontales de la onda $\mathrm{S}$ en simultáneo $\left(R_{P}>R_{S}^{x}\right.$ y $\left.R_{P}>R_{S}^{y}\right)$. En cualquier otro caso, se debe utilizar $\hat{\beta}_{S}$.

Por último, dada la conocida ambigüedad de los $180^{\circ}$ que surge cuando se tiene un medio en el que las velocidades son acimutalmente isótropas (Figura 5.3), y teniendo en mente que nuestro objetivo es la automatización del proceso, asumimos que las señales provienen de las regiones estimuladas. Esta suposición es válida si realmente no está ocurriendo en simultáneo ningún tipo de desplazamiento de fluidos o relajación de esfuerzos asociados con etapas previas (Eisner et al., 2009b), lo que podría ser confundido con eventos de la etapa que está siendo monitoreada. Por lo tanto, solo consideramos los eventos que ocurren dentro de la "región esperada", que definimos a partir de un ángulo de $110^{\circ}$, lo suficientemente grande para abarcar a los posibles backazimuths. Aquellas señales que provengan de regiones exteriores no son considerados y deben evaluarse individualmente para determinar si corresponden o no a eventos de interés.

\section{Localización}

Con el fin de estimar las coordenadas espaciales de un evento microsísmico se minimiza la función de costo

$$
J\left(x_{f}, y_{f}, z_{f}\right)=\left[\frac{1}{N_{c}} \sum_{i=1}^{N_{c}}\left(\Delta t_{i}-\Delta t_{i}^{o b s}\right)^{2}\right]^{1 / 2},
$$

donde $N_{c}=3 \times N$ es el número de canales y $\Delta t_{i}$ y $\Delta t_{i}^{\text {obs }}$ son las diferencias de tiempos modeladas y observadas entre los tiempos de arribo de S y P. Esta ecuación no-lineal puede ser minimizada por medio de diferentes métodos. Como ya se explicó, realizamos esta minimización por medio de VFSA (Ingber, 1989) y PSO (Shaw y Srivasta, 2007), 

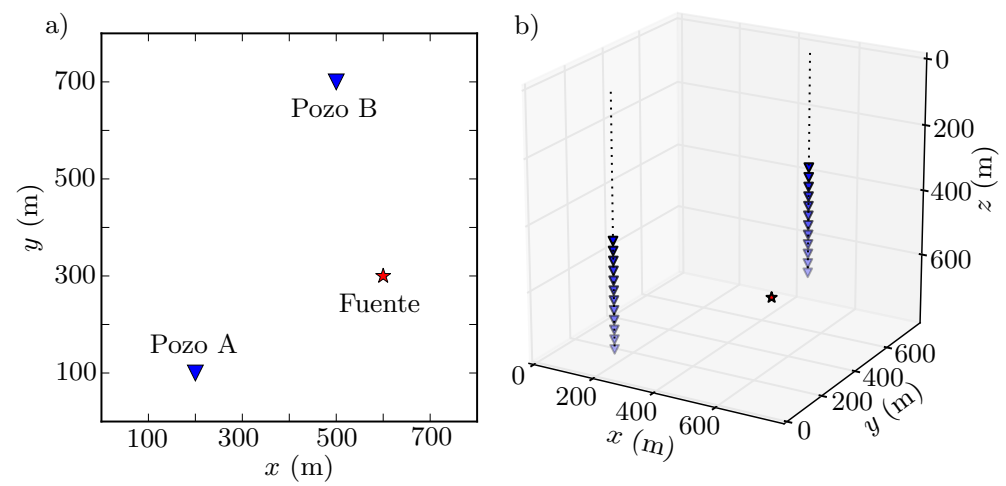

Figura 5.4. Geometría de adquisición.

que han demostrado ser mucho más eficientes que los métodos estándar tales como el Grid Search (Lagos et al., 2014).

Para la implementación del GS utilizamos grillas regulares con celdas de lado $h$ que abarcan todo el espacio de búsqueda predefinido. La función de costo es evaluada en cada nodo, en cada iteración. Para la primera iteración definimos $h=50 \mathrm{~m}$ para todo el espacio de búsqueda. Luego de cada iteración, se toma $h=h / 2$ y se redefine el espacio de búsqueda en torno al mínimo obtenido en la iteración previa. Se repite el proceso hasta que se alcanza un criterio de corte. Para facilitar los análisis estadísticos que se describen más adelante, la posición de la esquina inferior izquierda de la grilla de la primera iteración se selecciona de manera aleatoria dentro de un elemento de tamaño $h$.

\subsubsection{Resultados}

Para evaluar la eficiencia de los métodos de optimización desde un punto de vista estadístico consideramos dos modelos dados por diferentes geometrías de adquisición. El primer modelo incluye un único pozo de monitoreo vertical (pozo A) con un arreglo de 12 receptores cuya coordenada inicial es $(200,100,350) \mathrm{m}$, con una separación vertical de $30 \mathrm{~m}$, en un subsuelo dado por un semiespacio homogéneo e isótropo con $v_{P}=3500 \mathrm{~m} / \mathrm{s} \mathrm{y} v_{S}=2200 \mathrm{~m} / \mathrm{s}$. Esto constituye un problema de localización $2 \mathrm{D}$, donde las coordenadas $x_{f}$ e $y_{f}$ son reemplazadas por la distancia horizontal entre la fuente y el arreglo de receptores, una vez que $\hat{\beta}$ ha sido estimado. El segundo modelo incluye un segundo pozo de monitoreo (pozo B) con un arreglo de 12 receptores que inicia en la coordenada $(500,700,350) \mathrm{m}$, con la misma separación vertical. En este caso, realizamos una localización 3D, ya que la información del backazimuth no es utilizada para reducir el número de incógnitas. Consideramos una fuente en $\left(x_{f}, y_{f}, z_{f}\right)=(600,300,600) \mathrm{m}$ y asumimos que se trata de una fractura por cizalla en el plano $(x, z)$ con desplazamiento en la dirección $-x$. La Figura 5.4 ilustra la distribución espacial de los pozos descriptos y la fuente ficticia.

La señal que se propaga es una ondícula de Ricker con una frecuencia pico de $100 \mathrm{~Hz}$. Con fines estadísticos, generamos un conjunto de 400 registros sintéticos con 
la misma fuente pero distintas realizaciones de ruido. Los registros son contaminados con ruido gaussiano de banda limitada con relación señal-ruido global igual a 3 , lo que conduce a relaciones señal-ruido para la onda $\mathrm{P}$ menores que para la onda $\mathrm{S}$, cercanas a 1. La relación señal-ruido se calcula como el cociente entre la máxima amplitud de la señal (considerando a ambas fases) y la máxima amplitud del ruido.

Evaluamos el desempeño de los algoritmos para dos valores deseados de la función de costo (misfit): $0.5 \mathrm{~ms}$ y $1 \mathrm{~ms}$. Dado que los intervalos de muestreo microsísmico de pozo pueden ser de $0.25 \mathrm{~ms}$ o menores (Eisner et al., 2010), los misfits esperados son consistentes con un error en la estimación de los tiempos de arribo de 2 y 4 muestras, respectivamente. Para lograr una mayor eficiencia, elegimos el espacio de búsqueda tan pequeño como sea posible, teniendo el cuidado de no eliminar regiones de potencial ocurrencia de eventos. En todos los casos, el proceso iterativo se detiene cuando la función de costo satisfizo el misfit o cuando se alcanzó un máximo de 10000 evaluaciones de la función de costo.

\section{Ejemplo de localización 2D}

A continuación se muestran los resultados de resolver el problema de optimización para el caso de la geometría $2 \mathrm{D}$, para cada una de los 400 registros sintéticos y con los tres algoritmos de optimización descriptos. Con fines estadísticos repetimos la optimización 100 veces en cada caso, utilizando diferentes semillas para la generación de números aleatorios. Los resultados de una única repetición pueden verse en la Figura 5.5. Como es de esperar, dada la geometría de adquisición caracterizada por un único pozo de monitoreo vertical, la mayor incertidumbre se asocia a la estimación del backazimuth, lo que puede observarse claramente en la forma de arco de la nube de eventos, que respetan la distancia al pozo.

La Tabla 5.1 resume los resultados luego de promediar las 100 repeticiones para cada una de las 400 realizaciones y para los dos misfits deseados considerados. Los errores absolutos en las coordenadas estimadas $\left(e_{x}, e_{y} \mathrm{y} e_{z}\right)$ son muy similares para los tres algoritmos y se corresponden con los errores frecuentes obtenidos en la localización de eventos microsísmicos con similar geometría de adquisición (Eisner et al., 2009a). Las cantidades denominadas $\sigma_{x}, \sigma_{y}$ y $\sigma_{z}$ representan las incertidumbres en la correspondiente coordenada estimada debidas a la naturaleza estocástica de los algoritmos. En la práctica se calculan como los desvíos estándar luego de 100 repeticiones y 400 realizaciones. Dado un cierto misfit deseado, las incertidumbres son similares para los tres algoritmos y en todos los casos representan una pequeña proporción de los errores absolutos en las coordenadas. De lo anterior se desprende que la única diferencia en cuanto al desempeño de los tres algoritmos de optimización radica en la eficiencia computacional de los mismos. Es claro que tanto PSO como VFSA requieren una cantidad de evaluaciones de la función de costo significativamente menor que GS, siendo PSO y VFSA aproximadamente 2 y 4 veces más rápidos que GS, respectivamente. 


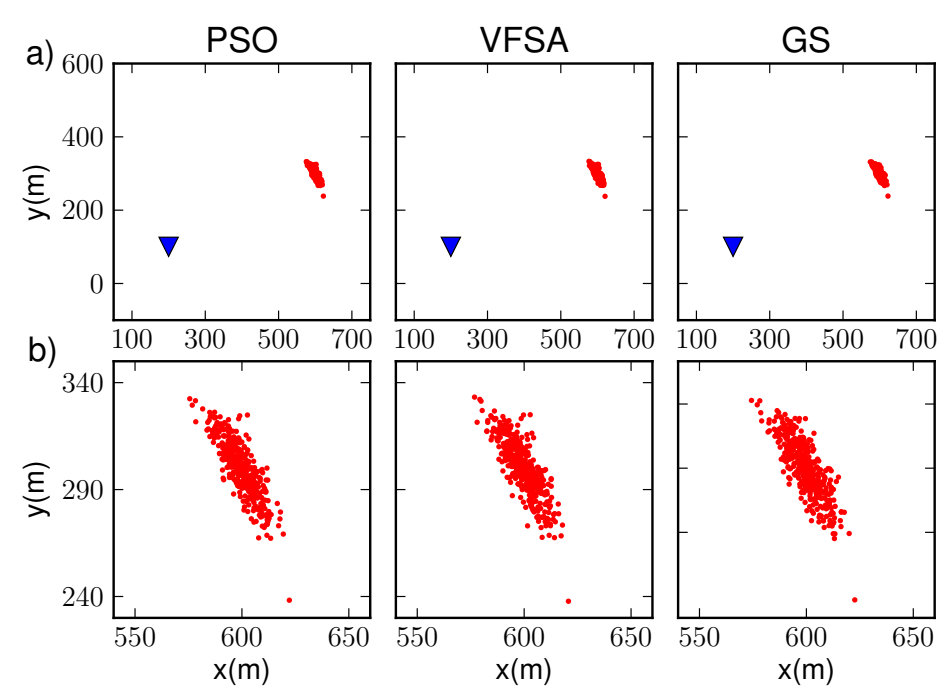

Figura 5.5. Ejemplo de localización 2D: a) Posiciones estimadas de la fuente (400 realizaciones). b) Zoom de la nube de soluciones.

\begin{tabular}{ccccccc}
\hline & \multicolumn{3}{c}{ Misfit: 0.5 ms } & \multicolumn{3}{c}{ Misfit: 1.0 ms } \\
\hline & PSO & VFSA & GS & PSO & VFSA & GS \\
\hline$e_{x}(\mathrm{~m})$ & 5.9 & 5.9 & 6.0 & 6.2 & 6.3 & 6.3 \\
$e_{y}(\mathrm{~m})$ & 10.6 & 10.7 & 10.7 & 10.7 & 10.7 & 10.7 \\
$e_{z}(\mathrm{~m})$ & 5.6 & 6.2 & 7.5 & 10.7 & 12.0 & 14.1 \\
$\sigma_{x}(\mathrm{~m})$ & 1.1 & 1.2 & 1.4 & 2.1 & 2.4 & 2.6 \\
$\sigma_{y}(\mathrm{~m})$ & 0.6 & 0.6 & 0.7 & 1.2 & 1.3 & 1.4 \\
$\sigma_{z}(\mathrm{~m})$ & 3.8 & 4.0 & 3.9 & 7.1 & 7.4 & 7.5 \\
$N_{E}$ & $248 \pm 11$ & $170 \pm 8$ & $552 \pm 15$ & $190 \pm 7$ & $122 \pm 5$ & $463 \pm 29$ \\
Speed-up & 2.2 & 3.3 & 1 & 2.4 & 3.8 & 1 \\
\hline
\end{tabular}

Tabla 5.1. Ejemplo de localización 2D: errores en las coordenadas estimadas, incertidumbres y número de evaluaciones $\left(N_{E}\right)$ de la función de costo (valores medios luego de 400 realizaciones y 100 repeticiones). 


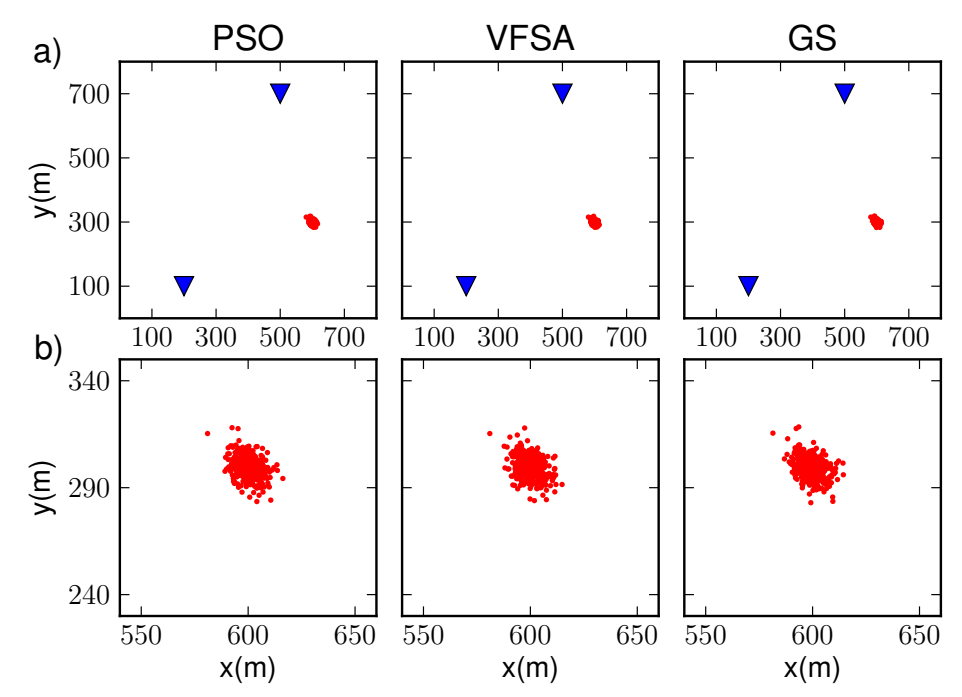

Figura 5.6. Ejemplo de localización 3D: a) Posición estimada de la fuente (400 realizaciones). b) Zoom de la nube de soluciones.

\section{Ejemplo de localización 3D}

La Figura 5.6 muestra los resultados de la localización 3D correspondiente a una de las 100 repeticiones para las 400 realizaciones. La Tabla 5.2, por su parte, resume los resultados promediados para los mismos misfits deseados que en el ejemplo 2D. Nuevamente los errores en la localización están dentro de los valores típicos, pero son menores que en el caso 2D dado que se ha eliminado la incertidumbre introducida por el backazimuth al incluir información de un segundo pozo. Los errores en la localización son mayores para la componente vertical, como es de esperar de acuerdo con Eisner et al. (2009a). Tal como en el ejemplo 2D, las 100 repeticiones de la optimización con los diferentes algoritmos permiten evaluar los errores absolutos en el posicionamiento de las fuentes que, independientemente de los efectos de las distintas realizaciones de ruido, son similares para los tres algoritmos. Dado que para la localización 3D los algoritmos deben explorar un espacio tridimensional, el promedio de evaluaciones de la función de costo es mayor que para el caso 2D. El mayor cambio corresponde al GS, que requiere cerca de 4 y 8 veces la cantidad de evaluaciones de la función de costo requeridas por PSO y VFSA, respectivamente.

\section{Restricción del espacio de búsqueda}

En el caso de la localización 3D, la información provista por los dos pozos de monitoreo hacen prescindible la estimación del backazimuth. Sin embargo, podemos aprovecharla para restringir el espacio de búsqueda y así lograr una mayor eficiencia computacional. Asumimos que la posición real de la fuente está en algún lugar cercano a la intersección de las dos direcciones dadas por el backazimuth estimado para ambos pozos (Figura 5.7a). Este sería el caso de un modelo de velocidad en el cual solo 


\begin{tabular}{ccccccc}
\hline & \multicolumn{3}{c}{ Misfit: 0.5 ms } & \multicolumn{3}{c}{ Misfit: 1.0 ms } \\
\hline & PSO & VFSA & GS & PSO & VFSA & GS \\
\hline$e_{x}(\mathrm{~m})$ & 3.7 & 3.8 & 3.8 & 4.5 & 4.9 & 4.9 \\
$e_{y}(\mathrm{~m})$ & 3.8 & 3.9 & 3.9 & 4.6 & 5.0 & 5.0 \\
$e_{z}(\mathrm{~m})$ & 4.8 & 5.3 & 5.6 & 8.6 & 10.3 & 10.6 \\
$\sigma_{x}(\mathrm{~m})$ & 1.5 & 1.7 & 1.7 & 2.8 & 3.1 & 3.0 \\
$\sigma_{y}(\mathrm{~m})$ & 1.5 & 1.7 & 1.7 & 2.7 & 3.1 & 3.0 \\
$\sigma_{z}(\mathrm{~m})$ & 3.1 & 3.3 & 3.2 & 5.8 & 6.5 & 6.4 \\
$N_{E}$ & $444 \pm 16$ & $243 \pm 13$ & $1910 \pm 182$ & $328 \pm 129$ & $148 \pm 7$ & $1165 \pm 225$ \\
Speed-up & 4.3 & 7.9 & 1 & 3.5 & 7.9 & 1 \\
\hline
\end{tabular}

Tabla 5.2. Ejemplo de localización 3D: errores en las coordenadas estimadas, incertidumbres y número de evaluaciones $\left(N_{E}\right)$ de la función de costo (valores medios de las 400 realizaciones y 100 repeticiones).

a)

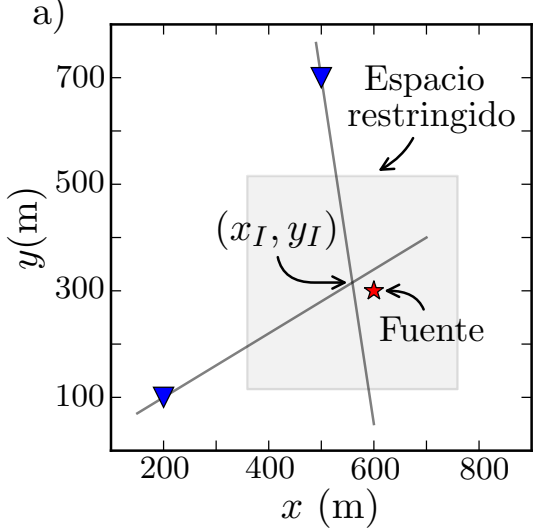

b)

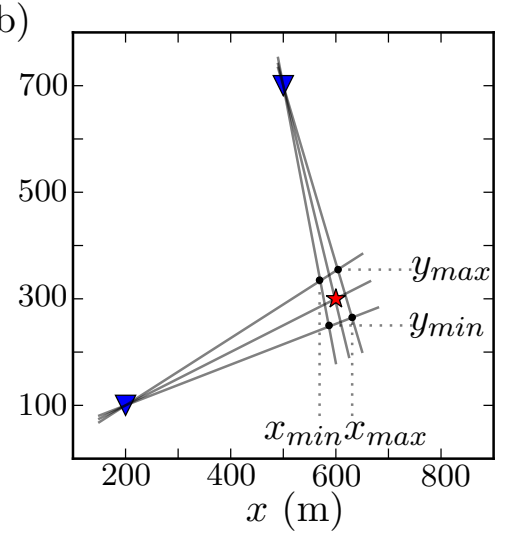

Figura 5.7. a) Restricción del espacio de búsqueda basada en la información de backazimuths. b) Determinación de la extensión del espacio de búsqueda (ver explicación en el texto).

se consideran variaciones de la velocidad con la profundidad, tales como medios estratificados horizontalmente. A partir del análisis estadístico que se describe a continuación se estableció un criterio para definir la extensión adecuada del espacio de búsqueda. Consideramos el mismo conjunto de 400 realizaciones que corresponden a una fuente ficticia ubicada en $\left(x_{f}, y_{f}, z_{f}\right)=(600,300,600) \mathrm{m}$. Luego de la detección y el denoising, estimamos el correspondiente backazimuth para ambos pozos. En este caso se consideró para este cálculo la estrategia descripta en la Sección 4.4.2. La Tabla 5.3 resume los valores medios resultantes, que son muy cercanos a los backazimuths reales, y las desviaciones estándar. Asumiendo que los backazimuths estimados siguen una distribución gaussiana, la probabilidad de que $\beta$ se encuentre dentro del intervalo definido por el valor medio más menos $3 \sigma$ es del $99 \%$. Este rango define una región potencial en torno al punto de intersección $\left(x_{I}, y_{I}\right)$, como se muestra en la Figura 5.7b. Para este caso particular, $\left(x_{\min }, x_{\max }\right)=(553,650) \mathrm{m}$ y $\left(y_{\min }, y_{\max }\right)=(240,364) \mathrm{m}$. Este análisis puede considerarse para evaluar la variabilidad esperada del punto de intersección (y el tamaño del espacio de búsqueda) para una dada relación señal-ruido. 


\begin{tabular}{ccc}
\hline & Pozo A & Pozo B \\
\hline$\beta$ & $63.4^{\circ}$ & $166.0^{\circ}$ \\
$\hat{\beta}$ (valor medio) & $63.4^{\circ} \pm 1.9^{\circ}$ & $166.3^{\circ} \pm 1.0^{\circ}$ \\
\hline
\end{tabular}

Tabla 5.3. Backazimuth real y valor medio de las estimaciones para el conjunto de 400 realizaciones de una misma fuente.

\begin{tabular}{cccc}
\hline & PSO & VFSA & GS \\
\hline Sin restricción & 740 & 385 & 7758 \\
Con restricción & 444 & 243 & 1910 \\
Speed-up & 1.7 & 1.6 & 4.1 \\
\hline
\end{tabular}

Tabla 5.4. Valor medio de la cantidad de evaluaciones de la función de costo (y los correspondientes speed-ups) luego de 400 realizaciones.

Teniendo en cuenta estos resultados, en la práctica determinamos el punto de intersección $\left(x_{I}, y_{I}\right)$ para cada evento. Este punto es el centro del espacio de búsqueda para las coordenadas horizontales. Luego, definimos el tamaño del espacio de búsqueda como el triple del tamaño de la región estimada anteriormente. Es decir, $\left(x_{I} \pm 150 \mathrm{~m}, y_{I} \pm\right.$ $150 \mathrm{~m}$ ). Estos son los valores utilizados para el ejemplo de localización 3D. En los casos en los que $\hat{\beta}$ no es confiable o en los que el punto de intersección está muy lejos de la posición esperada de la fuente, agrandamos el espacio de búsqueda para que abarque toda la región estimulada.

Podríamos hacer un análisis similar para restringir el espacio de búsqueda para $z_{f}$. Sin embargo, dado que en general las velocidades varían más con la profundidad que con cualquier otra dirección, la información de la inclinación y el correspondiente punto de intersección no sería confiable. Por esta razón, preferimos definir un rango para la coordenada vertical lo suficientemente amplio. En los ejemplos considerados aquí el rango considerado es $(200,1000) \mathrm{m}$. Lo mismo podría hacerse para otras geometrías, por ejemplo en el caso de un único pozo desviado u otras situaciones en las que la localización 2D no sea posible.

El impacto que la restricción del espacio de búsqueda tiene en el costo computacional de la localización de eventos microsísmicos se puede ver analizando los resultados de la Tabla 5.4. Allí se muestran los promedios de las cantidades de evaluaciones de la función de costo con un misfit deseado de 0.5 ms considerando o sin considerar la restricción. El tamaño (en metros) de los espacios de búsqueda horizontales es de $300 \times 300 \mathrm{y}$ $1000 \times 1000$, respectivamente. Como es de esperar, el número de evaluaciones de la función de costo aumenta significativamente cuando el espacio de búsqueda no se restringe, especialmente para GS, que sería 20 y no 8 veces más lento que VFSA si no se considerara la restricción. 


\subsection{Localización con datos de campo}

La aplicación de las estrategias de localización de eventos microsísmicos descriptas anteriormente a datos de campo, correspondientes a registros microsísmicos registrados durante procesos de fracturación hidráulica, requirió una generalización de las mismas a situaciones más complejas. Los datos de campo utilizados en esta Tesis corresponden a registros obtenidos en la República Argentina y las geometrías y condiciones generales de los mismos son representativas de las adquisiciones que actualmente se realizan en el territorio. De esta manera, el problema debió ser analizado con el foco en estas situaciones. En términos generales, la adaptación de las herramientas de localización descriptas para datos de campo requirió evaluar la función de costo que generara menores incertidumbres en las coordenadas resultantes y la utilización de modelos de velocidades más complejos. En este caso, dadas las características generales de las formaciones en cuestión y las geometrías de adquisición típicas, se consideran modelos de velocidades VTI obtenidos de acuerdo a lo explicado en el Capítulo 3. Además, se plantea la localización como un problema bidimensional, teniendo en cuenta que los arreglos de receptores son aproximadamente verticales. Por otra parte, se evaluó el comportamiento de los algoritmos de optimización VFSA y PSO ante las nuevas condiciones.

A continuación se describe el análisis realizado con este objetivo y se muestra un ejemplo correspondiente a la localización de los eventos detectados durante una etapa de un proceso de fracturación hidráulica.

\subsubsection{Tiempos de arribo}

Dada una fuente microsísmica en un medio homogéneo e isótropo, la energía liberada por ésta se propaga por el medio y es registrada por un sensor luego de un tiempo de viaje

$$
t=\frac{d}{v}=\frac{\sqrt{\Delta x^{2}+\Delta z^{2}}}{v}=\frac{\Delta z}{v \cos \theta},
$$

donde $d$ es la distancia entre la fuente y el receptor en la dirección que los une, $\Delta x$ y $\Delta z$ las correspondientes distancias horizontal y vertical, respectivamente, $v$ es la velocidad de propagación de las ondas por el medio y $\theta$ es el ángulo de incidencia de la energía respecto de la dirección vertical, como muestra la Figura 5.8a.

El momento cronológico en el que la energía correspondiente a las ondas $\mathrm{P}$ y $\mathrm{S}$ asociadas al evento alcanza al receptor, o tiempo de arribo, depende del tiempo de ocurrencia del evento o tiempo de origen, $T_{0}$, y del tiempo de viaje de la fase en cuestión, es decir,

$$
\begin{aligned}
& T_{P}=T_{0}+t_{P}=T_{0}+\frac{d}{v_{P}}, \\
& T_{S}=T_{0}+t_{S}=T_{0}+\frac{d}{v_{S}} .
\end{aligned}
$$



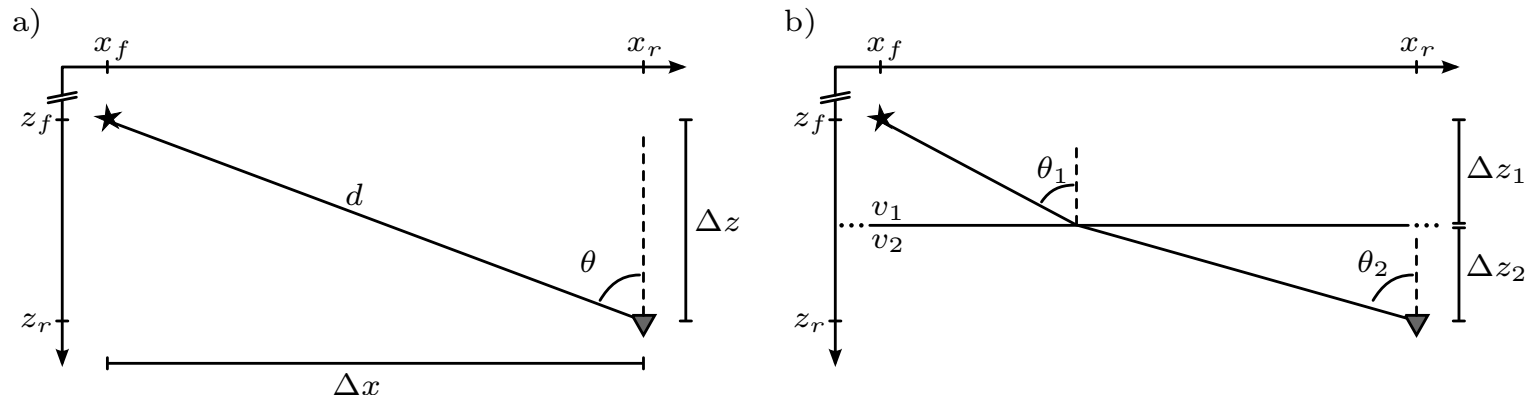

Figura 5.8. Rayo sísmico para una señal generada en una fuente y registrada en un único sensor en un medio a) homogéneo y b) de dos capas con características diferentes.

Si se desconoce la posición de la fuente, la observación de los tiempos de arribo de las ondas $\mathrm{P}$ y $\mathrm{S}$ en un único sensor permitiría calcular la distancia entre éste y la fuente, de acuerdo a

$$
d=\left(T_{S}-T_{P}\right)\left(\frac{1}{v_{S}}-\frac{1}{v_{P}}\right)^{-1} .
$$

Si se cuenta con un arreglo de receptores, el cálculo de las respectivas distancias permitiría estimar la posición de la fuente por medio de una simple triangulación.

En el caso de un medio de dos capas homogéneas e isótropas con distintas velocidades de propagación como el de la Figura 5.8b, el tiempo de viaje para una fase generada en la fuente microsísmica resulta

$$
t=\frac{\Delta z_{1}}{v_{1} \cos \theta_{1}}+\frac{\Delta z_{2}}{v_{2} \cos \theta_{2}} .
$$

Los ángulos $\theta_{1}$ y $\theta_{2}$ satisfacen la Ley de Snell, es decir

$$
\frac{\sin \theta_{1}}{v_{1}}=\frac{\sin \theta_{2}}{v_{2}} .
$$

Esta relación es una consecuencia del principio de Fermat, que establece que el camino que recorre la onda o rayo sísmico es aquel para el cual el tiempo de viaje es estacionario, es decir, que la variación de primer orden del tiempo de viaje respecto de las posibles trayectorias es cero (Sheriff, 2002). La estimación de la posición de la fuente a partir de la observación de tiempos de arribo, en este caso, no es tan directa como una triangulación a partir de distancias a distintos receptores calculadas de acuerdo a la ecuación 5.7. Por el contrario, la localización de la fuente involucra el cálculo de la trayectoria que cumpla el principio de Fermat.

Generalizando la ecuación 5.8 a un medio estratificado de $N$ capas con anisotropía VTI, como los considerados en esta Tesis, el tiempo de viaje de una fase microsísmica está dado por

$$
t_{\nu}=\sum_{i=1}^{N} \frac{\Delta z_{i}}{v_{i}^{\nu}\left(\theta_{i}\right) \cos \theta_{i}}
$$


donde $\nu$ denota la fase $(P, S V$ o $S H)$ y las velocidades de las ondas asociadas a un evento microsísmico dependen del ángulo de incidencia del rayo en cada una de las capas, de acuerdo a las ecuaciones 3.12.

La estimación de la posición de la fuente a partir de los tiempos de arribo se vuelve un problema complejo descripto por ecuaciones altamente no lineales. Esto potencia la necesidad de plantear a la localización de eventos como un problema de inversión que se resuelva mediante algoritmos de optimización globales capaces de lidiar con la no linealidad y la multiplicidad de mínimos locales de la función de costo.

\subsubsection{Función de costo}

La localización de una fuente microsísmica implica la estimación de sus coordenadas espaciales (y de su tiempo de origen). En este problema, y de acuerdo a las definiciones de la Sección 2.1, los parámetros del modelo, m, son las coordenadas espacio-temporales $\left(\mathbf{x}_{f}, T_{0}\right)$ de la fuente, las observaciones $\mathbf{d}$ son el conjunto de tiempos de arribo, $T_{\nu}^{r}$, de las señales a cada uno de los $N$ receptores disponibles y las relaciones que los vinculan, que definen el problema directo, tienen la forma

$$
T_{\nu}^{r}=T_{0}+t_{\nu}\left(\mathbf{x}_{f}, \mathbf{x}_{r}\right),
$$

con $r=1, \ldots, N$ el número de receptor y $\nu=\mathrm{P}, \mathrm{SV}, \mathrm{SH}$. Los tiempos de viaje $t_{\nu}$ son los definidos en la ecuación 5.10, cuyo cálculo implica encontrar el rayo que cumple con el principio de Fermat y se lleva a cabo por medio de un trazado de rayos.

Existe un importante compromiso entre el tiempo de origen de un evento y la distancia de éste a los receptores. Esto genera una gran incertidumbre en la relación entre $\mathbf{m}$ y $\mathbf{d}$, en particular si se dispone de una única fase. A modo de ejemplo, el tiempo de arribo de una señal microsísmica que se propaga por un medio homogéneo bidimensional, que tiene la forma

$$
T=T_{0}+\frac{d}{v}=T_{0}+\frac{\sqrt{\left(x-x_{f}\right)^{2}+\left(z-z_{f}\right)^{2}}}{v},
$$

es tal que para cualquier distancia $d>0$ existe un tiempo de origen $T_{0}$ que satisface la relación, de manera que el problema no tiene solución única. Por este motivo, los métodos de localización basados en el picado de tiempos de arribo requieren la observación de las ondas $\mathrm{P}$ y $\mathrm{S}$ de los eventos microsísmicos, que comparten el tiempo de origen, $T_{0}$. En efecto, una posibilidad para la definición de la función de costo del problema de optimización consiste en considerar las diferencias de tiempos de arribo de las distintas fases asociadas a un evento microsísmico, puesto que estas son independientes del tiempo de origen, coinciden con las diferencias de tiempos de viaje y permiten una mejor estimación de la distancia entre la fuente y cada uno de los receptores. Es decir, que la localización de eventos microsísmicos de acuerdo a este enfoque consiste en hallar las coordenadas que minimizan la discrepancia entre las diferencias de tiempos de viaje observadas y calculadas. En el caso de un medio 

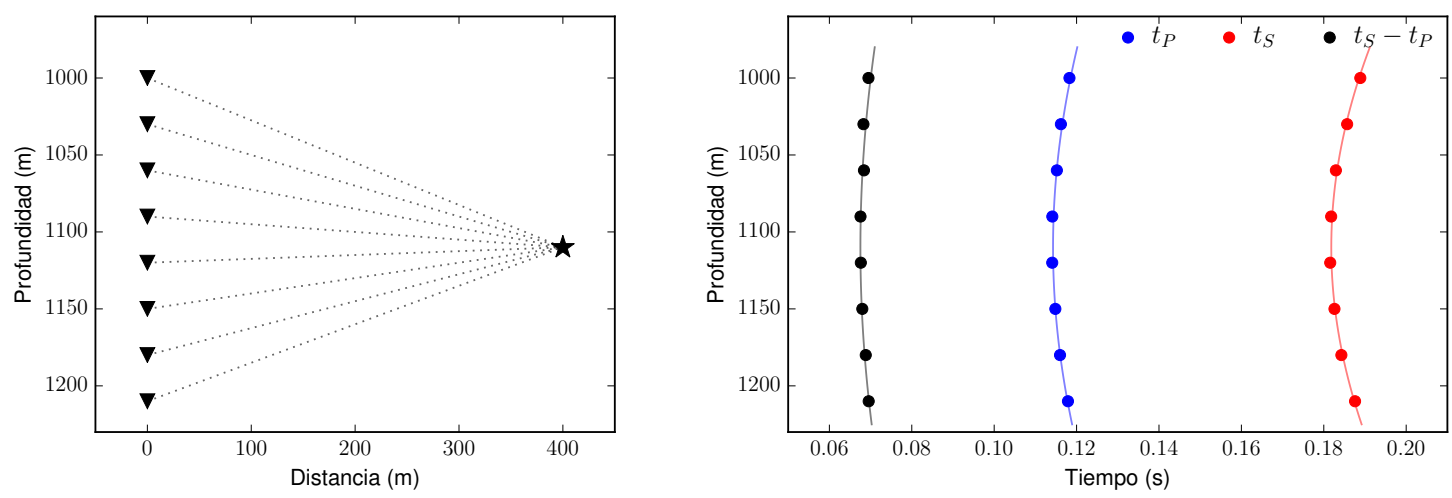

Figura 5.9. Fuente en un medio homogéneo y un arreglo vertical de sensores (izquierda). Tiempos de arribo de las ondas $\mathrm{P}$ y $\mathrm{S}$ y diferencia de tiempos de arribo (izquierda).

anisótropo, ésta puede ser representada mediante la función de costo:

$$
\begin{aligned}
J^{D D}=\left\{\frac{1}{2 N} \sum_{i=1}^{N}\right. & {\left[\left(\left(t_{S H}-t_{P}\right)^{o b s}-\left(t_{S H}-t_{P}\right)^{c a l c}\right)^{2}\right.} \\
+ & \left.\left.\left(\left(t_{S V}-t_{P}\right)^{o b s}-\left(t_{S V}-t_{P}\right)^{c a l c}\right)^{2}\right]\right\}^{1 / 2} .
\end{aligned}
$$

Llamamos dobles diferencias de tiempos a la ecuación 5.13. Notar que la función $J^{D D}$ tiene unidades de tiempo. Los tiempos de viaje calculados se obtienen por medio del trazado de rayos que se describe en el Apéndice A.

Durante el desarrollo de las tareas que condujeron a esta Tesis, se testeó la localización de eventos por medio de la función de costo de la ecuación 5.13 considerando modelos de velocidades VTI y arreglos de receptores verticales. Se observó que, pese a que permite estimar la posición horizontal de la fuente (asociada a la distancia al arreglo) con gran precisión, presenta una gran incertidumbre en la dirección vertical que ralentiza la convergencia de los algoritmos de optimización. Para entender esta observación, supongamos un ejemplo simple de un evento microsísmico en un medio homogéneo bidimensional. En este caso solo se tienen dos fases, P y S, quedando la ecuación 5.13 reducida a

$$
J^{D D}=\left\{\frac{1}{N} \sum_{i=1}^{N}\left(\left(t_{S}-t_{P}\right)^{o b s}-\left(t_{S}-t_{P}\right)^{c a l c}\right)^{2}\right\}^{1 / 2} .
$$

La Figura 5.9 (izquierda) muestra la geometría considerada para el ejemplo: una única fuente de coordenadas $\left(x_{f}, z_{f}\right)$, a $400 \mathrm{~m}$ en dirección horizontal respecto de un arreglo vertical de 8 receptores. Asumiendo un tiempo inicial $T_{0}=0$, los tiempos de arribo coinciden con los tiempos de viaje. Estos tiempos se muestran en la Figura 5.9 (derecha). Las curvas azul y roja corresponden al tiempo de viaje en función de la 
profundidad, $t(z)$, para las ondas $\mathrm{P}$ y S, respectivamente. Los puntos indican los arribos a cada uno de los receptores, a los que además se ha agregado ruido aleatorio para simular errores en el picado. Notar que la ecuación 5.12 puede ser escrita como

$$
\left(T-T_{0}\right)^{2}=\frac{\left(x-x_{f}\right)^{2}}{v^{2}}+\frac{\left(z-z_{f}\right)^{2}}{v^{2}},
$$

que en el caso de un arreglo lineal, como el del ejemplo, se corresponde con la ecuación de una hipérbola (Velis et al., 2015). El tiempo mínimo para las hipérbolas $t(z)$ del ejemplo se da a la profundidad de la fuente. Es decir, el ápice de la hipérbola, que se distingue claramente en la Figura 5.9 (derecha), brinda información importante sobre la coordenada vertical del evento. En cambio, la curva negra y los puntos correspondientes, que indican las diferencias de tiempos de arribo, $t_{S}-t_{P}$, no brinda información clara sobre la profundidad del evento, pues la curvatura propia de esta función de la profundidad es significativamente menor que para los tiempos individuales. La curvatura de las curvas continuas de la Figura 5.9 (derecha) está dada por ${ }^{1}$

$$
\kappa(z)=\frac{x_{f}^{2} u^{2}}{\left[x_{f}^{2} u^{2}+\left(u^{2}+1\right)\left(z-z_{f}\right)^{2}\right]^{3 / 2}},
$$

donde $u=v_{P}$ para el caso de $t_{P}(z), u=v_{S}$ para $t_{S}(z)$, y $u=\left(1 / v_{S}-1 / v_{P}\right)^{-1}$ para la diferencia de tiempos $\Delta t(z)=t_{S}(z)-t_{P}(z)$. En cualquiera de los tres casos, la curvatura es máxima para $z=z_{f}$, con $\kappa\left(z_{f}\right)=1 /\left(x_{f} u\right)$. Si $\lambda=v_{p} / v_{s}$, puede demostrarse que $\kappa_{\Delta t}\left(z_{f}\right) / \kappa_{t_{P}}\left(z_{f}\right)=\lambda-1$ y $\kappa_{\Delta t}\left(z_{f}\right) / \kappa_{t_{S}}\left(z_{f}\right)=1-1 / \lambda$. Teniendo en cuenta que para la mayoría de las rocas consolidadas $\lambda$ toma valores entre 1.5 y 2 , las relaciones anteriores toman valores entre 0.5 y 1 , y entre 0.3 y 0.5 , respectivamente. Es decir, las diferencias de tiempos de arribo presentan una curvatura que por lo general es significativamente menor a las curvaturas de los tiempos de arribo originales. Sumando este efecto a los eventuales errores en el picado se genera un aumento en la incertidumbre en la dirección vertical, pues un gran rango de profundidades de la fuente podría dar lugar a las mismas observaciones.

Si calculamos el valor de la función de costo para diferentes profundidades, fijando la coordenada horizontal en la posición de la fuente, $J^{D D}\left(x_{f}, z\right)$, se obtiene la curva negra de la Figura 5.10 (asumiendo $v_{p}=3500 \mathrm{~m} / \mathrm{s}$ y $v_{s}=2200 \mathrm{~m} / \mathrm{s}$ ). De la misma forma, si se fija la profundidad y se calcula la función de costo para diferentes coordenadas $x$ se obtiene la curva gris, $J^{D D}\left(x, z_{f}\right)$. Con el fin de compararlas, las respectivas coordenadas de la fuente fueron restadas de las abscisas. La función de costo cambia significativamente más rápido en dirección horizontal que en dirección vertical. Un error de una muestra en el picado de tiempos de arribo en registros con un intervalo de muestreo de 0.5 milisegundos puede conducir a un valor de la función de costo

\footnotetext{
${ }^{1}$ Dada una curva $\mathbf{g}$ parametrizada, si $\mathbf{g}^{\prime}(t) \neq 0, \forall t$, la curvatura de $\mathbf{g}$ puede calcularse como $\kappa=\left\|\mathbf{g}^{\prime}(t) \times \mathbf{g}^{\prime \prime}(t)\right\| /\left\|\mathbf{g}^{\prime}(t)\right\|^{3}$ (Marsden y Tromba, 1991). La ecuación 5.16 surge de realizar este cálculo considerando la curva $\mathbf{g}(z)=\left(z, \frac{1}{u} \sqrt{x_{f}^{2}+\left(z-z_{f}\right)^{2}}\right)$.
} 


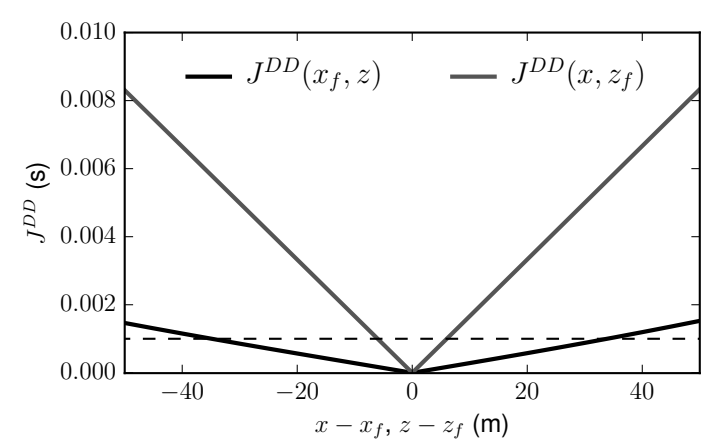

Figura 5.10. Función de costo dada por las dobles diferencias de tiempos de arribo en las direcciones vertical y horizontal respecto de la posición real de la fuente.

de $1 \times 10^{-3} \mathrm{~s}$, de manera que este es un límite razonable para utilizar como valor deseado para la convergencia de los algoritmos de optimización. Como indica la línea punteada de la Figura 5.10, este valor de la función de costo es alcanzado en un rango de unos $70 \mathrm{~m}$ en la dirección vertical, mientras que se reduce a unos $12 \mathrm{~m}$ en dirección horizontal.

Frente a esta situación y con el fin de reducir la incertidumbre en la dirección vertical generada al considerar diferencias de los tiempos de arribo, se evaluó la posibilidad de modificar la función de costo. El objetivo es considerar las distintas fases asociadas a un evento microsísmico, como en el caso de la función de costo de la ecuación 5.13, sin perder la información de la curvatura de los tiempos de arribo, que permite restringir las posibles profundidades de la fuente. Para esto se propuso la función

$$
\begin{aligned}
J^{S D}=\left\{\frac { 1 } { 3 N } \sum _ { i = 1 } ^ { N } \left[\left(T_{P}^{o b s}-T_{P}^{c a l c}\right)^{2}\right.\right. & +\left(T_{S H}^{o b s}-T_{S H}^{c a l c}\right)^{2} \\
& \left.\left.+\left(T_{S V}^{o b s}-T_{S V}^{c a l c}\right)^{2}\right]\right\}^{1 / 2} .
\end{aligned}
$$

Los tiempos de arribo calculados $T_{\nu}^{\text {calc }}$ con $\nu=P, S H, S V$ dependen del tiempo de origen $T_{0}$ y del tiempo de viaje (función de las coordenadas de la fuente). Por consiguiente, esta formulación de la función de costo agrega una incógnita al problema de optimización. Es de esperar que, dado el compromiso existente entre el tiempo de origen de un evento y la distancia de éste a los receptores, aumente la incertidumbre en la dirección horizontal. Para evaluar este efecto, en la Figura 5.11 (izquierda) se muestra la función de costo de la ecuación 5.17 para el mismo ejemplo de una única fuente en un medio homogéneo e isótropo, calculada para una profundidad fija igual a la de la fuente sintética y variando la coordenada horizontal y el tiempo de origen (en segundos). El tiempo de origen exacto para la fuente sintética es $T_{0}=0$. El contorno amarillo corresponde a $J^{S D}=1 \times 10^{-3} \mathrm{~s}$. El rango de posibles valores de $x$ para el cual la función de costo es menor a este valor es de unos $20 \mathrm{~m}$, superior a los $12 \mathrm{~m}$ que 

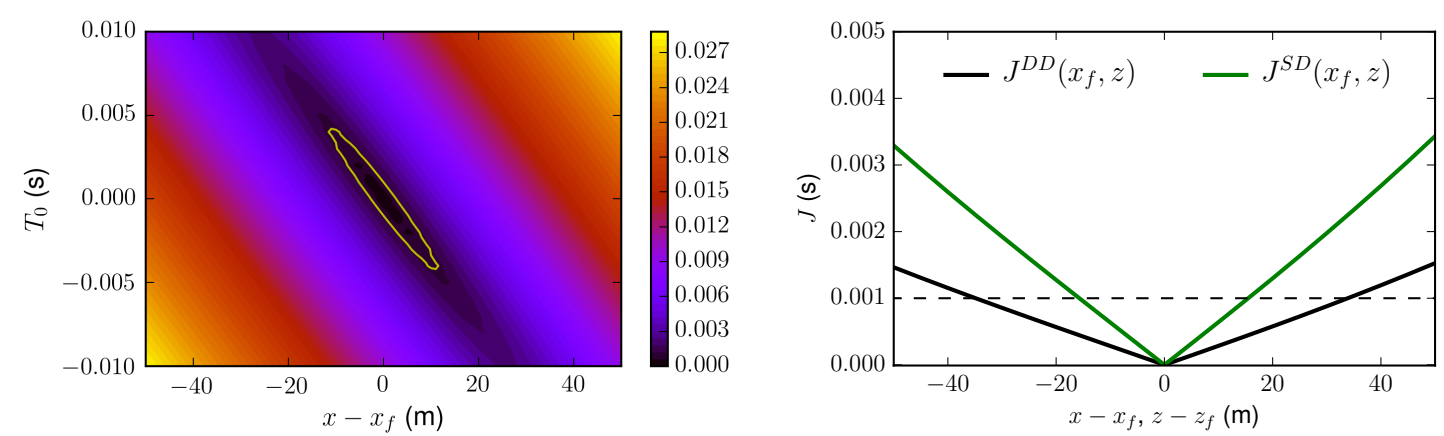

Figura 5.11. Función de costo basada en las simples diferencias para una profundidad fija (izquierda). El contorno amarillo corresponde a $J^{S D}=$ $1 \times 10^{-3}$ s. Comparación entre $J^{D D}$ y $J^{S D}$ para distintas profundidades y coordenada horizontal fija (derecha).

se tenían para el caso de la función $J^{D D}$. El rango de posibles valores del tiempo de origen, $T_{0}$, por su parte, es menor a \pm 5 milisegundos en torno al tiempo exacto. La importancia de un error de esta magnitud en el tiempo de origen no es tan significativa frente a los errores en las coordenadas espaciales, pues solo constituyen un pequeño error en el orden cronológico de eventos que se distribuyen a lo largo de varias horas, de manera que el orden general de ocurrencia de los mismos no se ve modificado de forma apreciable.

Por otro lado, se calculó la función de costo para distintas profundidades, manteniendo la coordenada horizontal y el tiempo de origen fijos en sus valores exactos. El resultado se muestra en la Figura 5.11 (derecha), donde además, con fines comparativos, se incluye la función $J^{D D}$ con $z$ variable, para $x=x_{f}$. El rango de valores de $z$ para los cuales la función de costo es menor a $1 \times 10^{-3}$ s se reduce de casi $70 \mathrm{~m}$ para $J^{D D}$ a aproximadamente $30 \mathrm{~m}$ para $J^{S D}$. En otras palabras, el planteo de la función de costo de la ecuación 5.17 permite restringir las posibles profundidades de la fuente significativamente más que la función de costo de las dobles diferencias. La inclusión del $T_{0}$ como incógnita del problema aumenta el rango de las posibles coordenadas $x$. No obstante, la proporción de aumento es mucho menor a la reducción de la incertidumbre en la dirección vertical, y es comparativamente menor a la incertidumbre que pueden generar otros efectos, como se muestra más adelante en este capítulo.

En el caso de modelos de velocidades más complejos, como los considerados para la localización de eventos en esta Tesis, la situación en relación al comportamiento de las funciones de costo es similar a la descripta. En la Figura 5.12 se muestran las funciones de costo $J^{D D}$ (izquierda) y $J^{S D}$ (derecha) para tres fuentes sintéticas a diferentes profundidades, considerando un modelo de velocidades VTI calibrado a partir de modelos de velocidades $v_{P}$ y $v_{S}$ extraídos de perfiles de pozo. Si bien en ambos casos se observa una mayor incertidumbre en la dirección vertical respecto de la dirección horizontal, puede verse que en el caso de la función de costo dada por las simples diferencias de tiempos de arribo, $J^{S D}$, el rango de posibles valores de profundidad que 
satisfacen $J^{S D}<1 \times 10^{-3}$ s es significativamente menor que para $J^{D D}$ en todos los casos.

\subsubsection{Resultados}

Se realizó la localización de eventos detectados en datos de campo. A continuación se muestran los resultados obtenidos para una etapa de un proceso de fracturación hidráulica llevado a cabo en la Formación Vaca Muerta de la Cuenca Neuquina. En las Figuras 5.13 y 5.14 se muestra la geometría de adquisición para la etapa en cuestión. El pozo de tratamiento o de inyección se indica con línea punteada. La región del pozo de tratamiento señalada con rojo corresponde a la zona en la que se realiza la estimulación hidráulica de la formación en esta etapa. Es de esperar que los eventos microsísmicos tengan lugar en un entorno de esta zona, lo que nos permite realizar una estimación de los límites del espacio de búsqueda de los eventos. Los distintos pasos previos a la localización, que fueron enumerados en capítulos anteriores, fueron aplicados sobre los datos:

1. Se generó un modelo de velocidades a partir de los perfiles sónicos disponibles para el pozo de monitoreo. Las velocidades dadas por éstos fueron suavizadas, discretizadas y calibradas de la forma descripta en el Capítulo 3, asumiendo un medio con anisotropía VTI restringida de acuerdo a $1 / v_{P}$.

2. Luego del cálculo de los ángulos de orientación de los sensores a partir de punzados realizados al principio de la etapa mediante el método descripto en el Capítulo 3, Sección 3.2, los registros de toda la etapa fueron rotados al sistema de coordenadas $(x, y, z)$ (coincidentes con las direcciones Este, Norte y vertical).

3. Los eventos procesados fueron aquellos detectados por medio de la estrategia introducida en la Sección 4.2. Los resultados fueron inspeccionados visualmente para descartar posibles falsas detecciones o situaciones de eventos superpuestos, como los que se muestran en la Figura 5.15. Esto condujo a un total de 240 eventos.

4. Se estimaron los tiempos de arribo por medio de la estrategia basada en el reconocimiento de patrones (Sección 4.3.2) considerando la modificación que permite la estimación simultánea del backazimuth (Sección 4.4.5). Los tiempos estimados fueron observados y corregidos manualmente cuando fue necesario, para reducir la contribución de errores en el picado a la localización, y con el fin de limitar las posibles incertidumbres a las asociadas al problema de optimización en sí mismo. En la Figura 5.16 se ilustran casos particulares en los que fue necesaria la corrección manual de los tiempos de arribo. En la figura, los puntos negros indican los tiempos estimados y las cruces las correcciones manuales. La relación señal-ruido, sumada a arribos que pueden interpretarse como provenientes de reflexiones cercanas como los del panel inferior de la figura o arribos múltiples como en el caso del panel central, entre otros efectos, dificultan la tarea de 

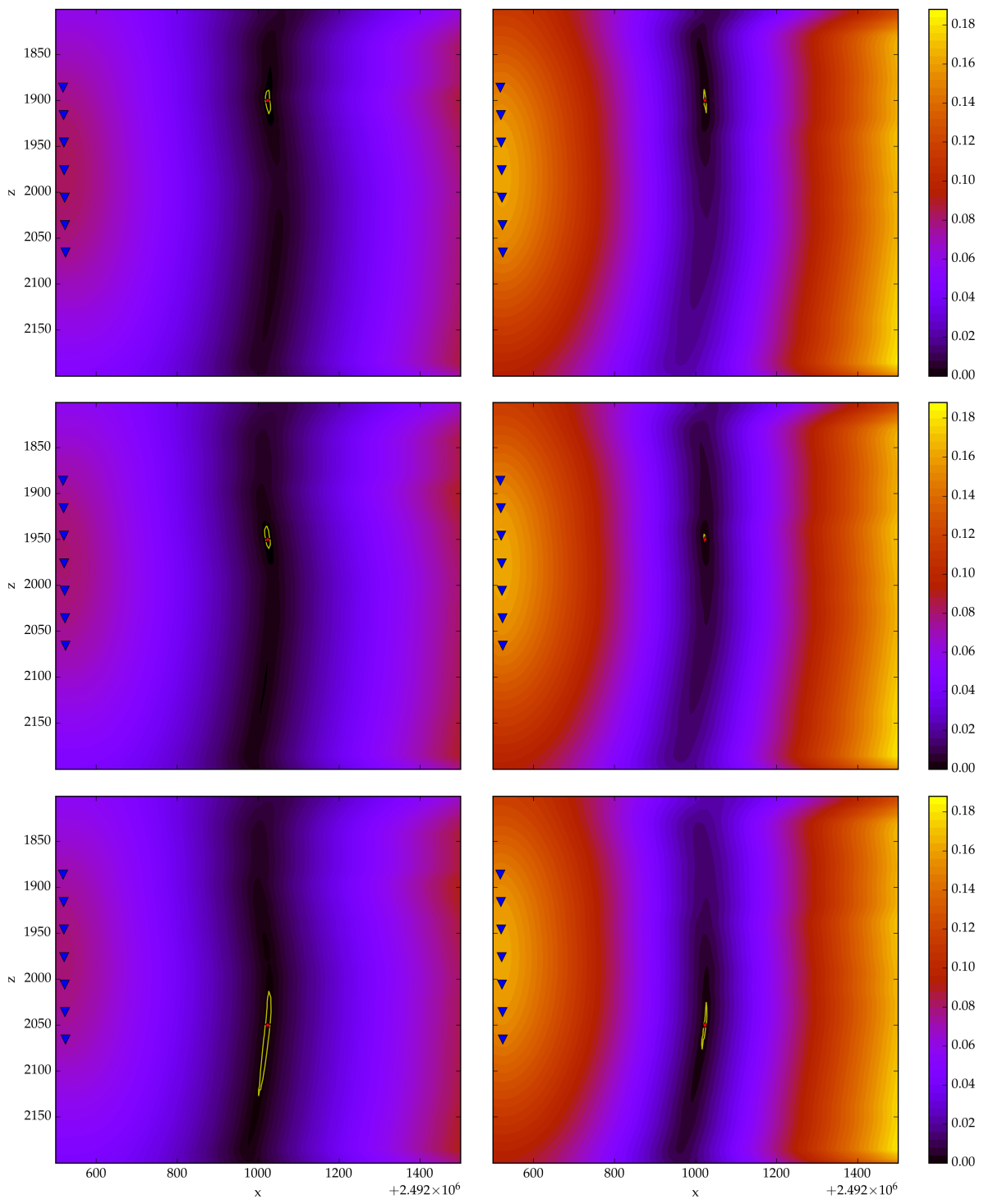

Figura 5.12. Funciones de costo $J^{D D}$ (izquierda) y $J^{S D}$ (derecha) considerando un medio VTI, un arreglo de receptores aproximadamente vertical y tres fuentes sintéticas de diferentes profundidades. 


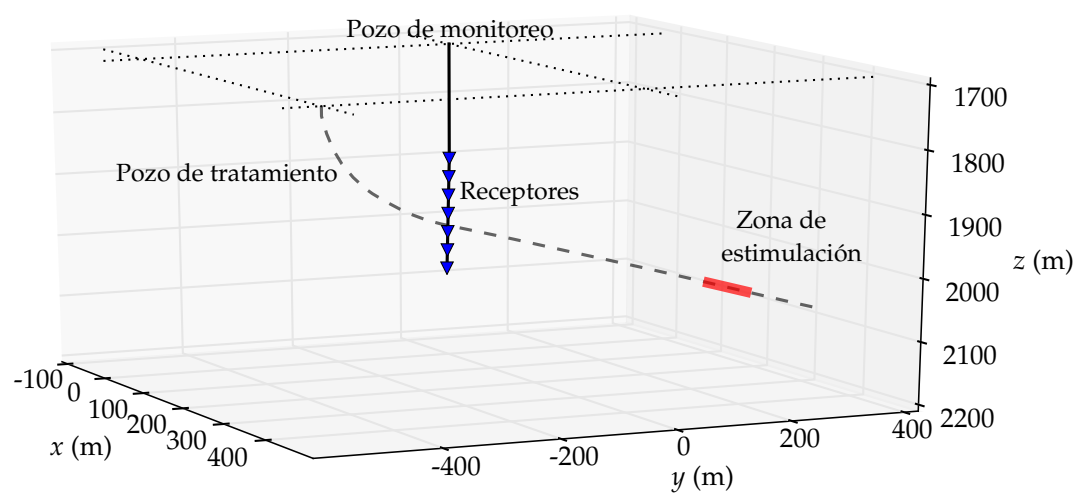

Figura 5.13. Geometría de adquisición en 3D.
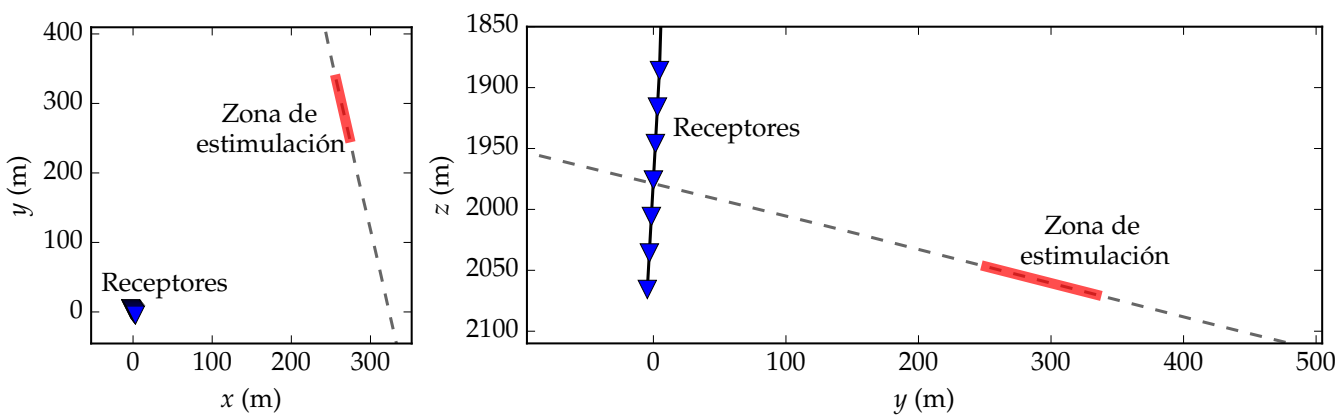

Figura 5.14. Geometría de adquisición proyectada en los planos $(x, y)$ (izquierda) e $(y, z)$ (derecha).

estimación de tiempos de arribo por reconocimiento de patrones. Por otra parte, también se calcularon los backazimuths por medio del criterio basado en la energía (Sección 4.4.3), considerando el criterio de descarte de valores atípicos basado en el cálculo del desvío respecto de la media absoluta (Sección 4.4.6). En este caso se consideró un filtrado previo de los datos por medio de un filtro pasa-banda (30 $\mathrm{Hz}-300 \mathrm{~Hz}$ ). Las diferencias respecto de los estimados previamente no fueron significativas para la gran mayoría de los eventos. Se optó por el segundo caso solo porque éste otorgaba una medida directa de la incertidumbre (desvíos) que se considera más adelante en este capítulo.

Dado que el arreglo de receptores está dispuesto de forma aproximadamente vertical y que fueron estimados los backazimuths correspondientes a cada evento detectado, la localización se resuelve como un problema bidimensional en el que se estima la distancia horizontal al arreglo de receptores (medida desde la posición del primer receptor) y la profundidad del evento. Los rangos considerados para el espacio de búsqueda son $(200,800)$ m para la distancia horizontal y $(1850,2000) \mathrm{m}$ para la profundidad. Las coordenadas geográficas $(x, y)$ de cada evento son posteriormente calculadas a partir de la distancia y el backazimuth. Se considera la función de costo basada en las simples diferencias (ecuación 5.17). Los tiempos de viaje calculados, necesarios para evaluar la función de costo en los diferentes puntos de prueba del espacio de búsqueda son 


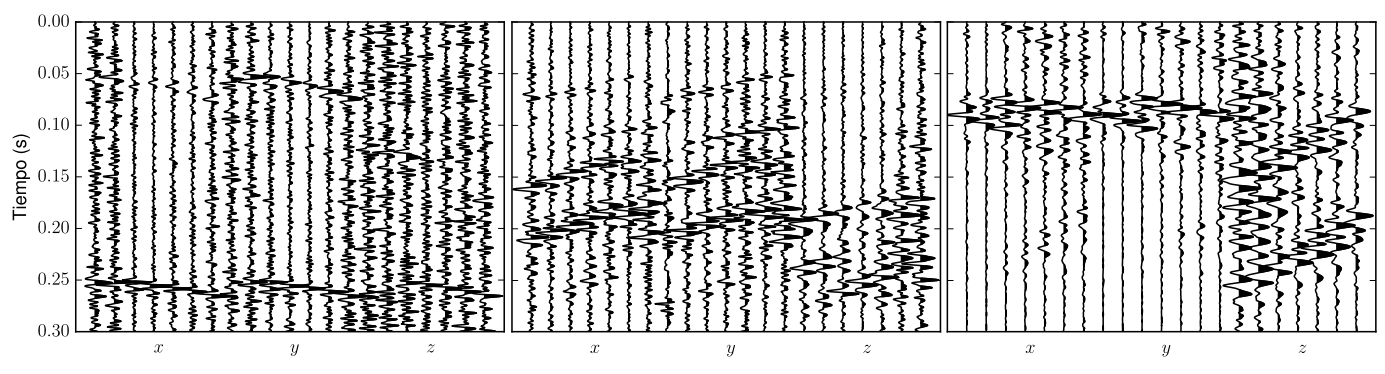

Figura 5.15. Ejemplos de detecciones descartadas.
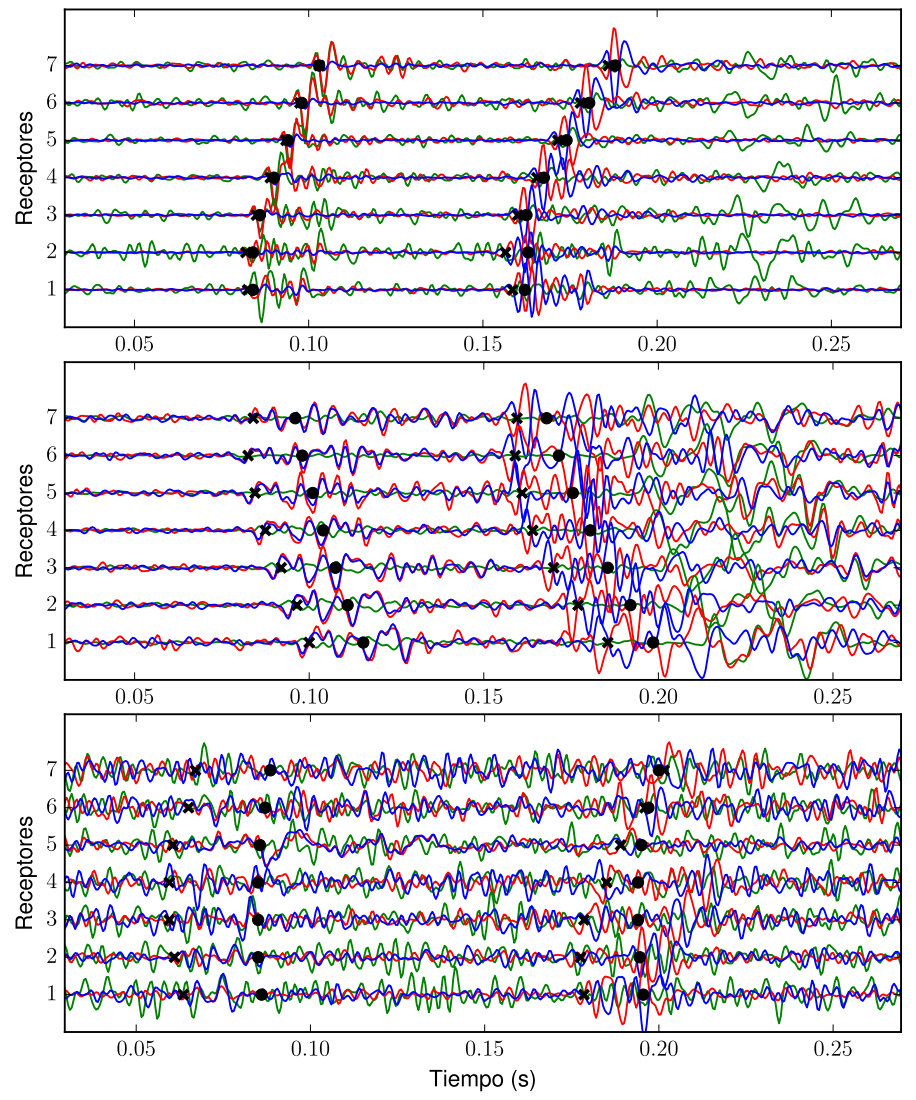

Figura 5.16. Correcciones (cruces) a los tiempos de arribo estimados mediante la estrategia basada en el reconocimiento de patrones (puntos). 


\begin{tabular}{ccc}
\hline & VFSA & PSO \\
\hline$J^{S D}=1 \times 10^{-3} \mathrm{~s}$ & 233 & 487 \\
$J^{S D}=0.5 \times 10^{-3} \mathrm{~s}$ & 740 & 1037 \\
\hline
\end{tabular}

Tabla 5.5. Valor medio de la cantidad de evaluaciones de la función de costo requeridas por cada algoritmo para alcanzar un dado valor deseado de la función de costo.

calculados por medio del trazado de rayos descripto en el Apéndice A, que contempla medios VTI. La localización fue llevada a cabo considerando tanto el algoritmo VFSA como el PSO. En ambos casos, se estableció un máximo de evaluaciones de la función de costo de 2000. Para el caso de VFSA, esto implica un máximo de iteraciones de 2000, mientras que para PSO depende de la cantidad de partículas consideradas. Dadas las dimensiones del espacio de búsqueda y las posibles complejidades del modelo de velocidades, se consideraron 100 partículas y un máximo de 20 iteraciones.

Una primera prueba tiene por objetivo comparar la cantidad de evaluaciones de la función de costo requerida por cada algoritmo para alcanzar un determinado valor deseado de la misma. Como ya se mencionó, un valor de la función de costo de $J^{S D}=1 \times 10^{-3}$ s es aceptable como umbral para la convergencia de los algoritmos de optimización. Se realizó la localización con ambos algoritmos suponiendo dicho valor deseado de la función de costo y la mitad de éste. La Tabla 5.5 resume los resultados alcanzados en relación a la cantidad de evaluaciones requeridas por cada algoritmo para alcanzar una solución (valores medios para los 240 eventos). En concordancia con los resultados de la Sección 5.2, el algoritmo VFSA requiere una menor cantidad de evaluaciones de la función de costo que PSO para alcanzar un mismo valor deseado de la misma. En la Figura 5.17 se muestran los resultados de la localización por medio de VFSA. Los resultados obtenidos en relación a las coordenadas estimadas son similares para ambos algoritmos, por lo que no se muestran los resultados obtenidos mediante PSO.

A partir de resultados como los observados en la Figura 5.17 y de las diversas pruebas realizadas, se observó que, dependiendo del caso, la función de costo para este modelo de velocidades puede alcanzar valores significativamente menores al establecido como valor deseado. En consecuencia, aumentar la exigencia en el criterio de convergencia permite reducir la dispersión observada en la nube de eventos, principalmente en dirección vertical. Por lo tanto, con el fin de reducir dicha dispersión se repitió la localización de los eventos, esta vez considerando como único criterio de corte el límite máximo de 2000 evaluaciones de la función de costo preestablecido. Si se respeta el criterio ya mencionado, según el cual un valor esperado de la función de costo de 1 ms es de esperar dados los errores típicos del picado de tiempos de arribo (Eisner et al., 2010), esto no significa que los resultados de esta prueba sean estrictamente mejores que los anteriores. Sin embargo, permiten evaluar comparativamente las soluciones alcanzadas por ambos algoritmos y contemplar la posibilidad de reducir el valor deseado de la función de costo, lo que implicaría asumir que en este caso los errores, tanto en el modelo de velocidad como en el picado de tiempos de arribo, son muy pequeños. En las 

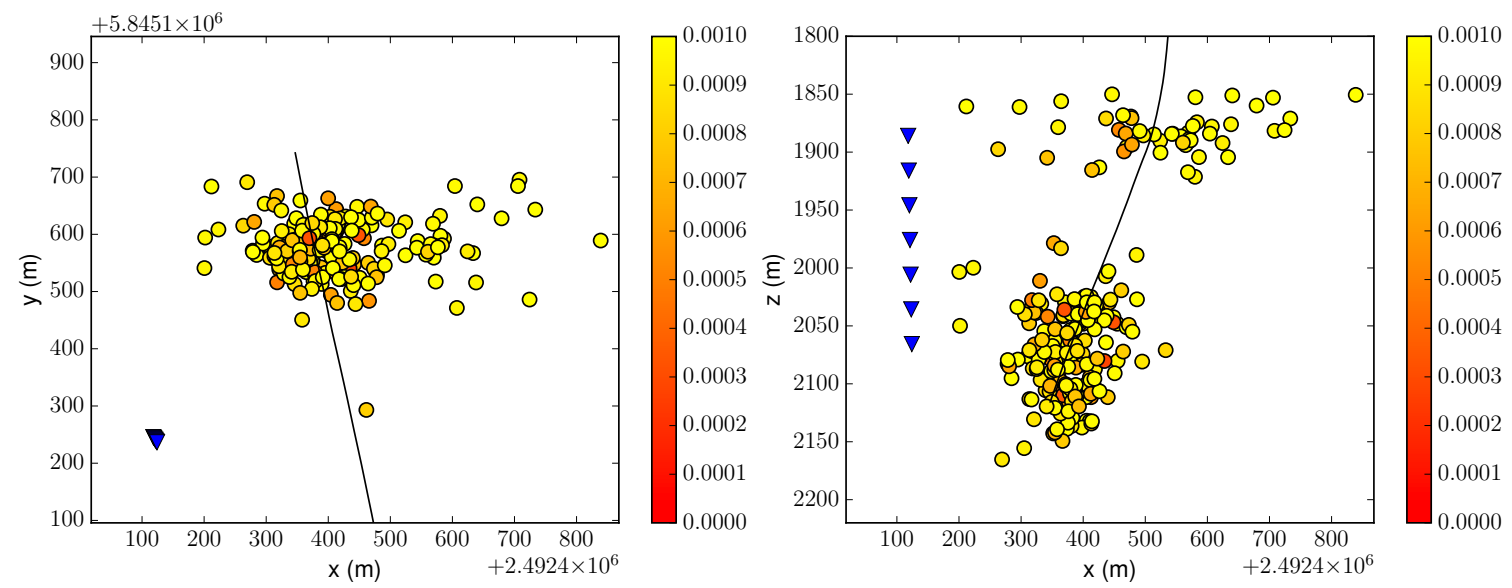

Figura 5.17. Localización con VFSA de los 240 eventos correspondientes a una etapa de fracturación, considerando un valor deseado de la función de costo $J^{S D}=1 \times 10^{-3} \mathrm{~s}$ como criterio de convergencia. Los colores de los eventos indican el valor alcanzado de la función de costo (en segundos) para cada uno de ellos.

Figuras 5.18 y 5.19 se muestran las localizaciones estimadas con los algoritmos VFSA y PSO, respectivamente. Se puede ver que los resultados obtenidos con los dos algoritmos son similares. En términos generales, se observan mayores valores de la función de costo para los eventos más superficiales. La dificultad en la localización para estas fuentes radica en el hecho de que no se disponía de información suficiente para una calibración correcta del modelo de velocidades a estas profundidades, pues los punzados utilizados para la calibración se ubican a lo largo del pozo de tratamiento. Los eventos para los cuales la función de costo de la solución supera el valor $J^{S D}=1 \times 10^{-3}$ s se indican con cuadrados. Los resultados muestran que en algunas ocasiones, PSO no alcanzó este valor de la función de costo en la cantidad de iteraciones permitida, mientras que esto ocurrió una única vez para VFSA. Por otra parte, dado el carácter poblacional de PSO, éste muestra una mayor facilidad para escapar del mínimo local asociado a una interfase del modelo de velocidades en torno a los $1880 \mathrm{~m}$ de profundidad. Por último, en las Figuras 5.20 y 5.21 se puede ver la distribución espacio-temporal de los eventos localizados, con la hora de origen de cada uno indicada con la escala de colores.

\subsubsection{Incertidumbres en la localización}

Existen diversos factores que contribuyen a las incertidumbres en las posiciones estimadas en la localización de eventos microsísmicos. Estos factores y las incertidumbres en la localización ocasionadas por ellos han sido ampliamente estudiadas por diversos autores (Jones et al., 2014; Gajewski et al., 2009; Maxwell, 2009; Kidney et al., 2010). La precisión en la solución depende de factores tales como el modelo de velocidades considerado, la geometría de adquisición (cantidad de receptores y la distribución de los mismos respecto de la zona de tratamiento) y los errores en la determinación de 

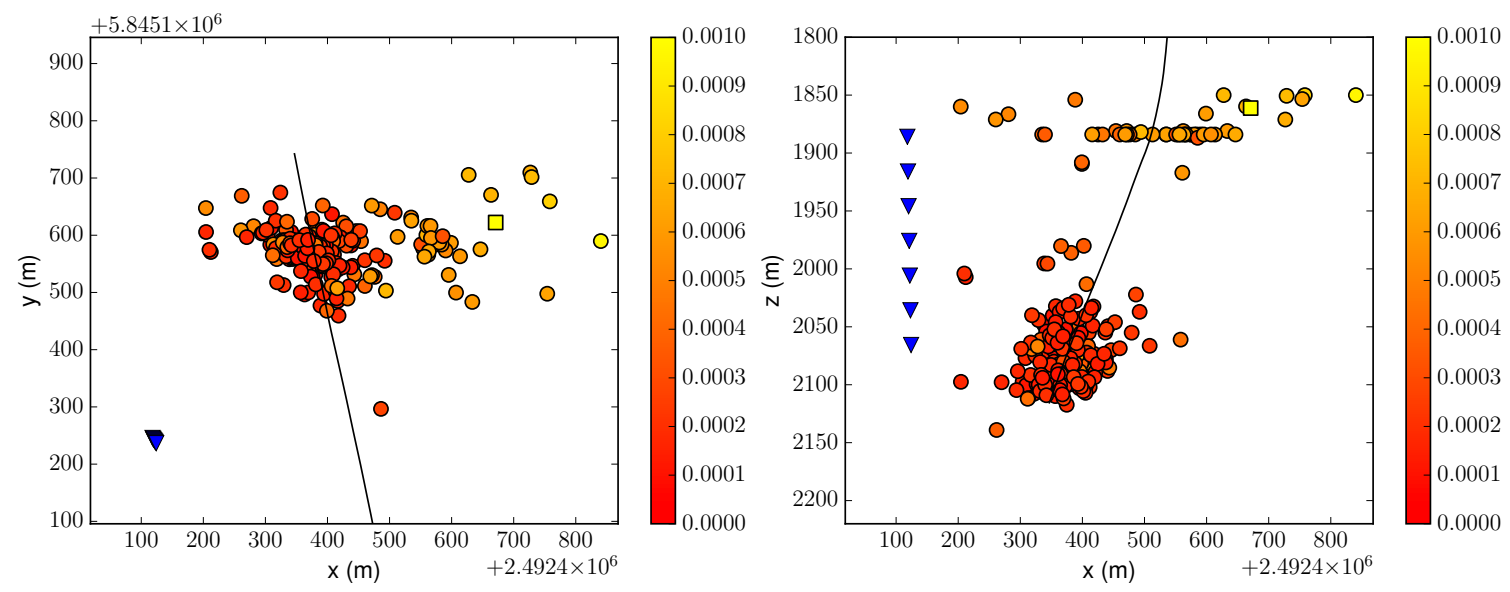

Figura 5.18. Localización con VFSA de los 240 eventos correspondientes a una etapa de fracturación tras 2000 evaluaciones de la función de costo. Los colores de los eventos indican el valor alcanzado de la función de costo (en segundos) para cada uno de ellos.
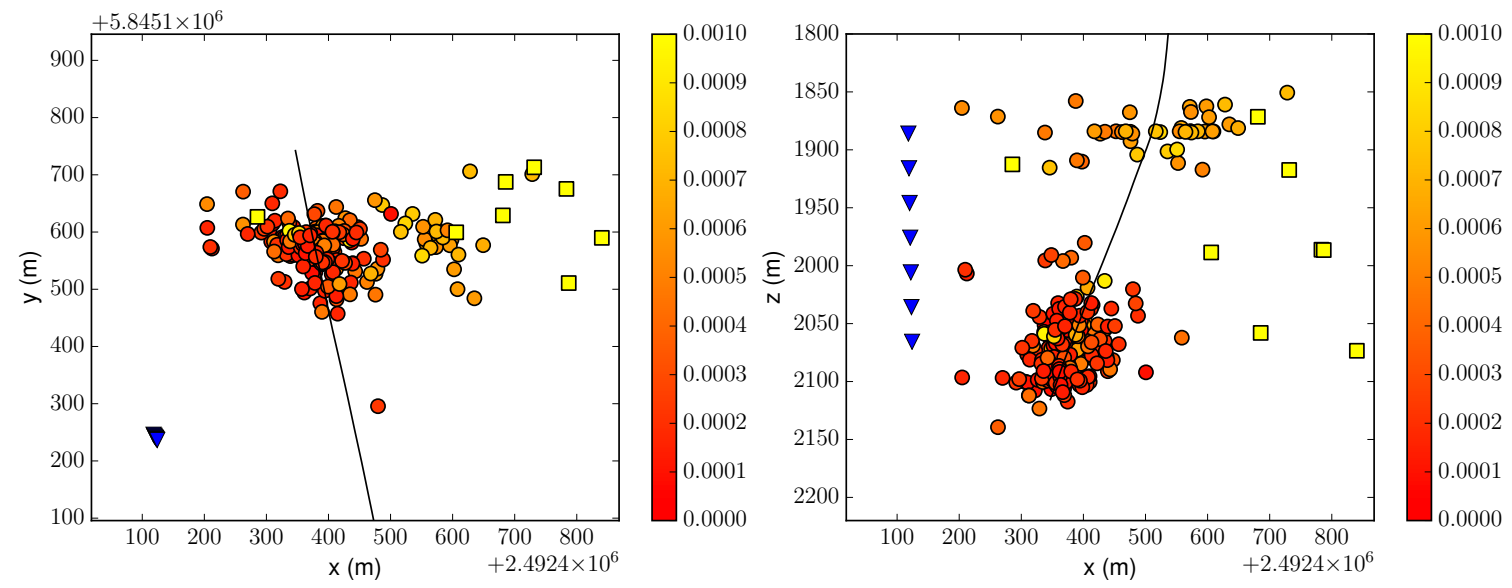

Figura 5.19. Localización con PSO de los 240 eventos correspondientes a una etapa de fracturación tras 2000 evaluaciones de la función de costo. Los colores de los eventos indican el valor alcanzado de la función de costo (en segundos) para cada uno de ellos. 

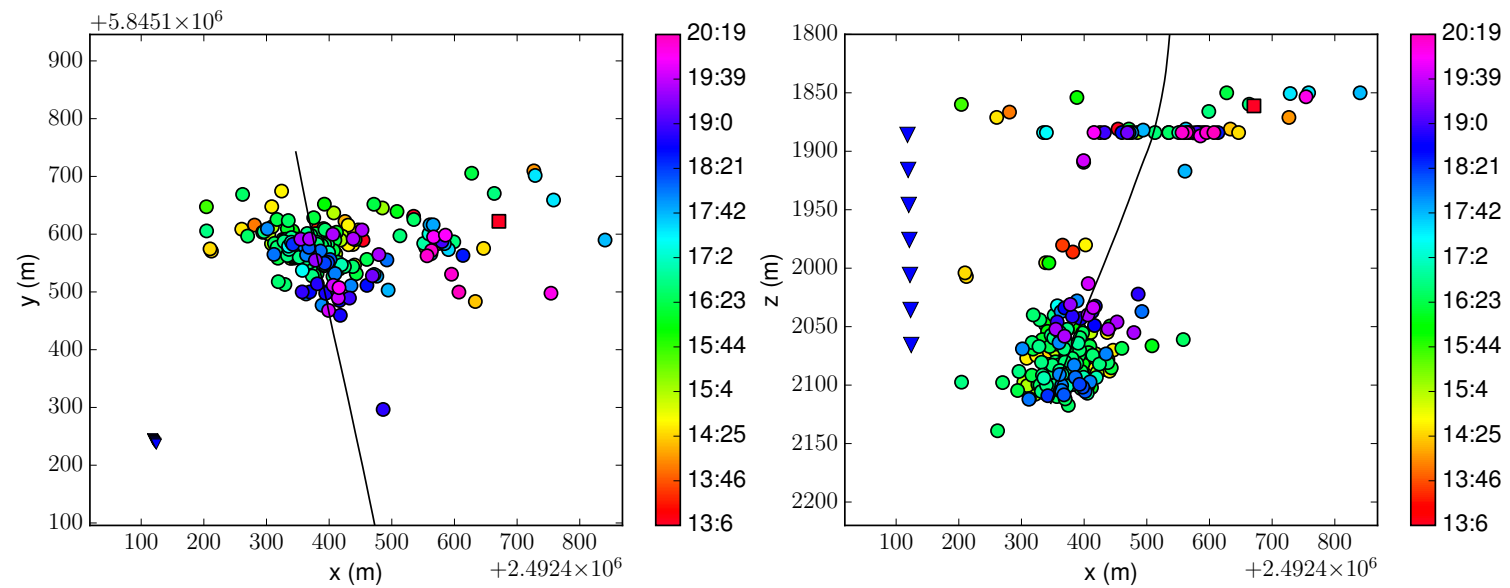

Figura 5.20. Localización con VFSA de los 240 eventos correspondientes a una etapa de fracturación tras 2000 evaluaciones de la función de costo. La escala de colores corresponde a la hora de origen de los eventos.
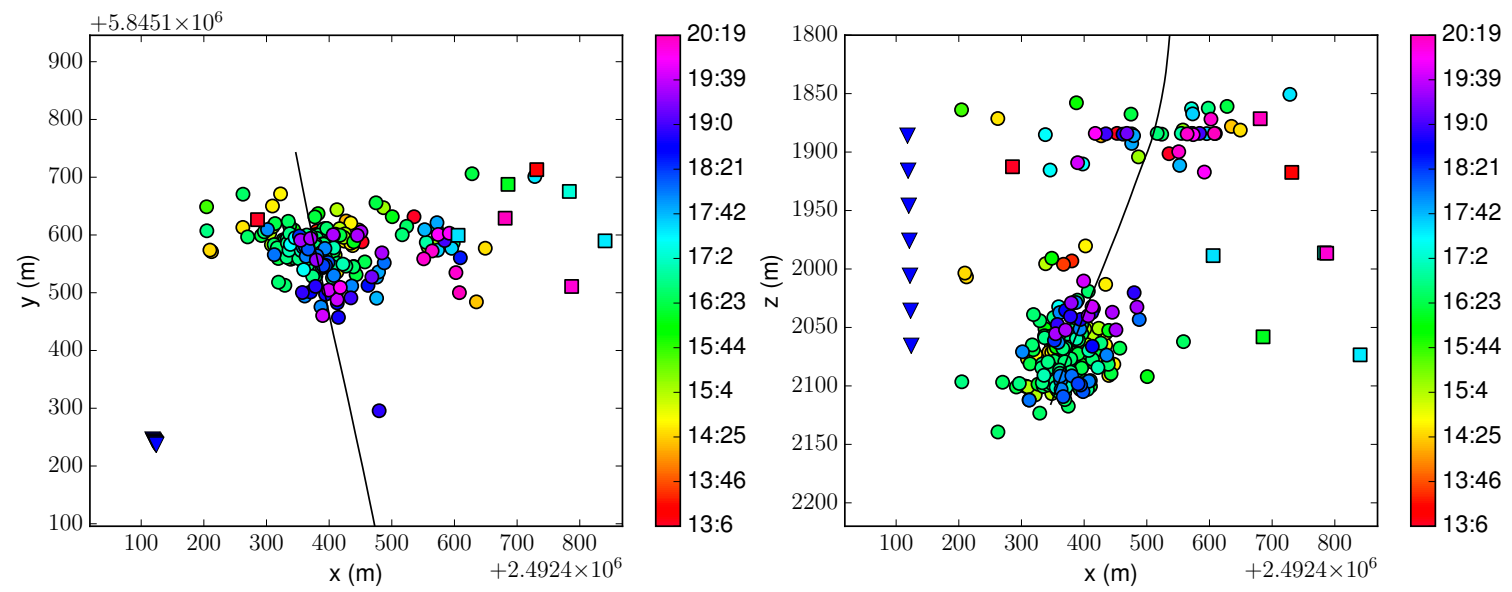

Figura 5.21. Localización con PSO de los 240 eventos correspondientes a una etapa de fracturación tras 2000 evaluaciones de la función de costo. La escala de colores corresponde a la hora de origen de los eventos. 
los tiempos de arribo de las señales microsísmicas. Además, errores en las posiciones de los receptores, estimadas a partir de los perfiles de desviación del pozo monitor, y la determinación de las orientaciones de los sensores también pueden contribuir a aumentar la incertidumbre en las posiciones estimadas de los eventos microsísmicos (Eisner et al., 2009a). Asímismo, como se observó en la Sección 5.3.3, las decisiones en relación al valor deseado de la función de costo o la convergencia de los algoritmos utilizados también tienen influencia sobre las incertidumbres resultantes.

La mayoría de los autores coinciden en que la mayor contribución a las incertidumbres en la localización la aportan los errores en el modelo de velocidad. Por medio de simulaciones Monte Carlo, Jones et al. (2014) y Maxwell (2009), por ejemplo, ejemplifican esta situación, observando que las incertidumbres obtenidas aumentan con la distancia al arreglo de receptores y que los errores en el modelo de velocidades pueden dar lugar a una concentración de las soluciones en las discontinuidades del modelo de velocidad. Este efecto se observó en las Figuras 5.18 y 5.19, en los eventos más superficiales, en donde la información disponible para una adecuada calibración del modelo de velocidades no es suficiente. La presencia de estos errores de manera sistemática puede dar lugar a errores en la interpretación de la geometría de las fracturas (Maxwell et al., 2010a). El efecto de la distancia al arreglo en el aumento de las incertidumbres es especialmente evaluado por Kidney et al. (2010). Es importante tener esto en cuenta al momento de interpretar una nube de eventos, pues puede conducir a decisiones imprecisas en tiempo real, que ocasionen una estimulación pobre, materiales desperdiciados y una evaluación incorrecta de potenciales riesgos. Por su parte, Eisner et al. (2009a) muestra que las incertidumbres asociadas a geometrías de adquisición dadas por un único pozo de monitoreo vertical son mayores en la dirección vertical que en la dirección radial, tal como se observó en la Sección 5.3.2 o en los ejemplos sintéticos de la Sección 5.2.2. Ésta es mayor, además, mientras menor sea la apertura del arreglo, independientemente de la cantidad de receptores. Asimismo, la incertidumbre es mayor (en ambas direcciones) para eventos que ocurren fuera del rango de profundidades del arreglo y puede potenciarse dependiendo de las características del modelo de velocidades para las distintas profundidades (Maxwell, 2009). De acuerdo a los ejemplos considerados por los autores, en una geometría típica dada por un único pozo vertical los errores en las profundidades estimadas pueden alcanzar las decenas de metros en la mayoría de los casos. Por su parte, en la dirección radial los errores no son significativos en comparación con los obtenidos en profundidad, consistentemente con la menor incertidumbre en dirección vertical observada en los ejemplos mencionados.

En las coordenadas horizontales de los eventos, los mayores errores son producto de la dificultad en la estimación del backazimuth, que es altamente dependiente de la relación señal-ruido de cada evento en particular. De acuerdo a Eisner et al. (2010) la estimación del backazimuth puede alcanzar un desvío estándar de $29^{\circ}$ para la onda $\mathrm{P}$ y $10^{\circ}$ para la onda $\mathrm{S}$, dando lugar a desvíos de decenas de metros en la dirección acimutal respecto del pozo monitor. Tal es el caso del ejemplo ilustrado en la Figura 5.5 de la Sección 5.2.2. 
Un análisis de los errores en la localización basado en la linealización del problema, permitiría una evaluación limitada de los mismos resultando en una representación inadecuada de los errores reales (Jones et al., 2014). Por esta razón, distintos autores optan por un análisis no lineal basado en simulaciones Monte Carlo. Como se mencionó y puede observarse en la bibliografía consultada, las incertidumbres tienen diversos orígenes y se comportan de manera diferente en cada situación dependiendo de la geometría de adquisición y de las características del medio principalmente. A modo de ejemplo, se realizó la localización de un conjunto de 25 fuentes sintéticas suponiendo una geometría de adquisición dada por un pozo monitor como el de la Figura 5.13 y un modelo de velocidades VTI como el considerado para realizar las localizaciones en la Sección 5.3.3. En primer lugar, la localización se repitió 50 veces considerando en cada realización, errores en los tiempos de arribo observados obtenidos de una distribución gaussiana con media en el tiempo de arribo exacto y desvío $1 \mathrm{~ms}$ tanto para la onda $\mathrm{P}$ como para la onda S. Por otra parte, se realizó la localización de las fuentes sintéticas asumiendo errores en el modelo de velocidad. En cada realización, se agregó al modelo original un error para cada velocidad y cada parámetro de anisotropía obtenido de una distribución gaussiana con desvío igual al $2 \%$ del máximo valor de cada parámetro en el rango de profundidades de interés. La localización se repitió también un total de 50 veces. Los resultados obtenidos se muestran en la Figura 5.22a y 5.22b en las que los puntos negros indican las posiciones reales de las fuentes sintéticas. Estos resultados reproducen las observaciones realizadas por los distintos autores. La contribución a las incertidumbres en la localización de los errores en el modelo de velocidades es significativamente mayor que la de los errores en la determinación de tiempos de arribo para los desvíos en dichos tiempos y en los parámetros del modelo de velocidades considerados. Además, las incertidumbres tienden a aumentar con la distancia al arreglo y son menores para aquellos eventos que se encuentran a profundidades más cercanas a las del centro del arreglo. En la Figura 5.22c se muestra el resultado de repetir la localización de las fuentes combinando los casos anteriores: 50 realizaciones de los errores en los tiempos de arribo, y 50 realizaciones de los errores en el modelo de velocidad (un total de 2500 localizaciones).

Implícitamente, la función de costo contempla los errores cometidos al suponer un cierto modelo de velocidades y determinar los tiempos de arribo. A partir de evaluar el comportamiento de la misma en un entorno a las posiciones obtenidas, es posible obtener una estimación de las incertidumbres como producto de todo el procesamiento, incluyendo además las contribuciones de la localización en sí misma. Se calcularon las incertidumbres en las localizaciones de los eventos de la etapa microsísmica obtenidas en la Sección 5.3.3 (Figuras 5.18 y 5.19) y se construyeron las correspondientes elipses de error calculadas a partir de definir un entorno de la posición hallada en el que la función de costo satisface el valor deseado $J^{S D}=1 \times 10^{-3} \mathrm{~s}$. Los ejes vertical y horizontal en dirección radial de las elipses se definen a partir de los puntos en tales direcciones en los que la función de costo supera dicho valor. Las elipses obtenidas para las localizaciones estimadas con los algoritmos VFSA y PSO se muestran en las Figuras 5.23 y 5.24, respectivamente. En color rojo se indican aquellos eventos para los 

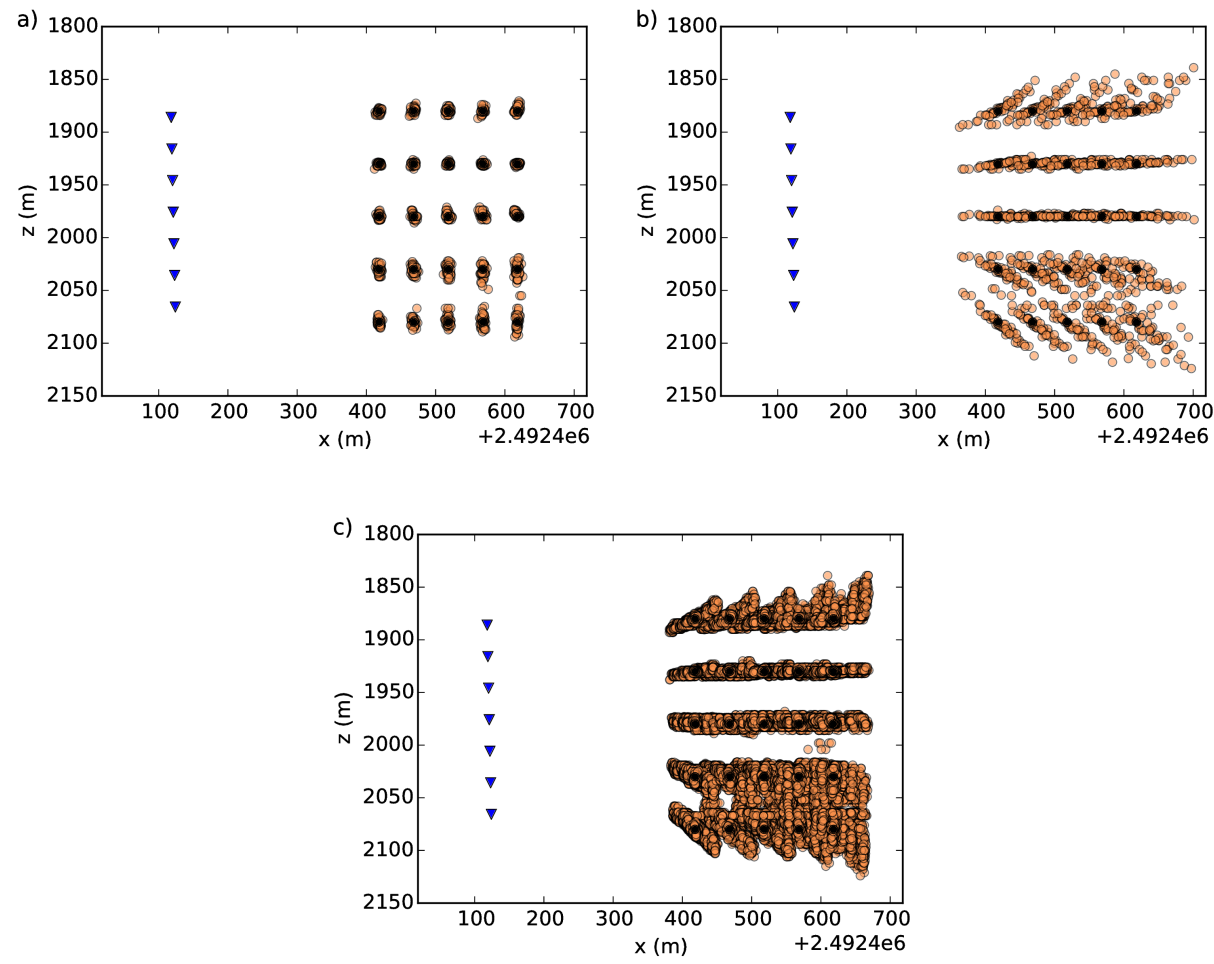

Figura 5.22. a) Incertidumbres en la localización generadas por errores en los tiempos de arribo; b) incertidumbres generadas por errores en el modelo de velocidades; c) ambas contribuciones en simultáneo. 

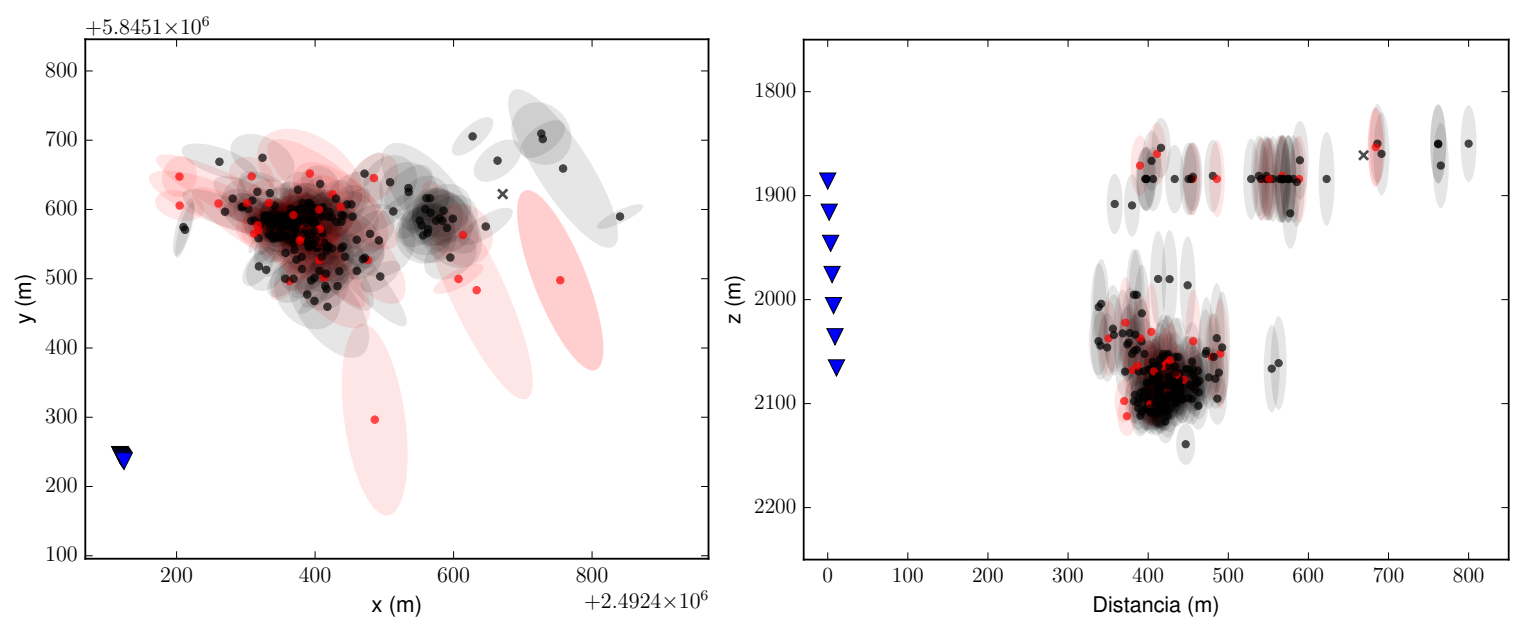

Figura 5.23. Elipses de error para las localizaciones estimadas con VFSA.
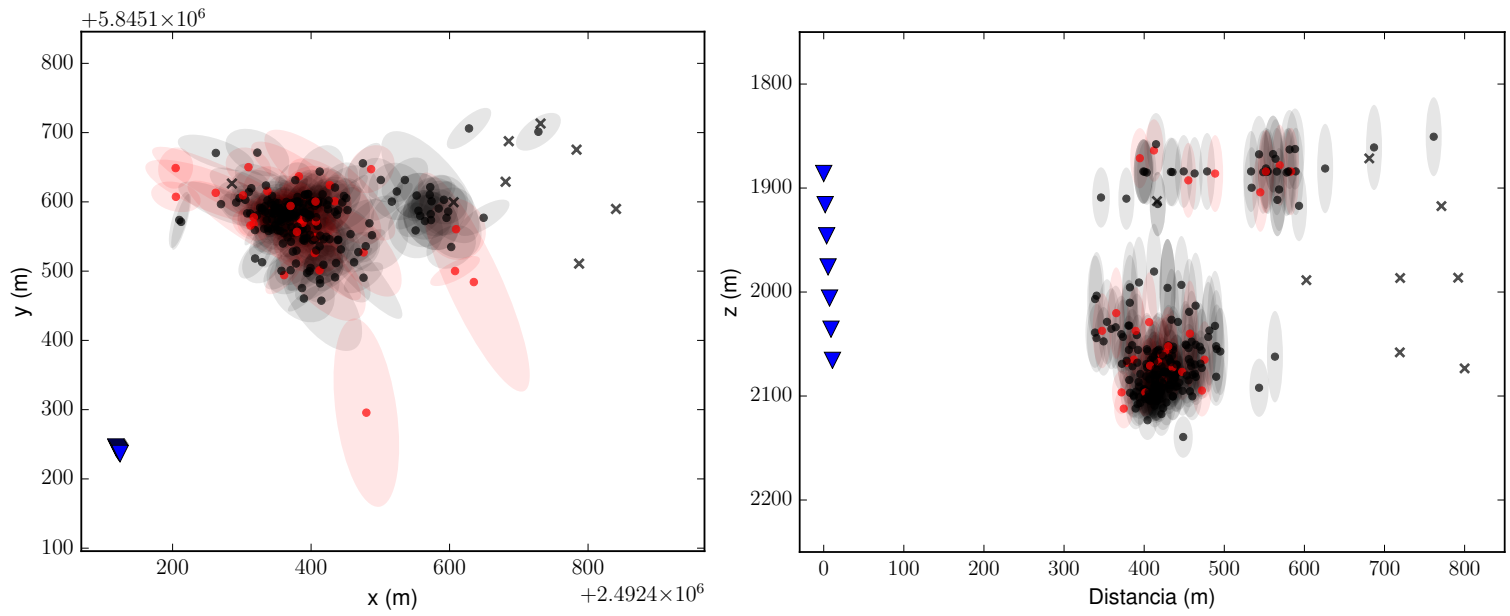

Figura 5.24. Elipses de error para las localizaciones estimadas con PSO.

cuales la relación señal-ruido de la onda P (con la que se calculan los backazimuths) es menor a 3 y con negro el resto de los eventos. Para aquellas fuentes para las cuales el valor deseado de la función de costo no fue alcanzado, se asume que la localización no fue exitosa y se las indica con cruces en las figuras. Por su parte, en la dirección acimutal respecto del pozo monitor, el eje de la elipse es definido a partir del desvío estimado en el cálculo del backazimuth, multiplicado por la distancia al pozo. Como es de esperar, dada la geometría de adquisición, las incertidumbres son significativamente menores en la dirección radial que en la vertical, y es en la dirección acimutal donde se observan las mayores incertidumbres, generadas por las estimaciones del backazimuth. Asimismo, se observa que aquellos eventos con elipses más elongadas en la dirección acimutal son, en general, los de menores relaciones señal-ruido, indicando la influencia de la calidad de la señal en la precisión alcanzada en la localización. 


\subsection{Conclusiones}

En primer lugar se implementó un procedimiento automático y optimizado que concatena las diferentes etapas del procesamiento que conducen a la localización de fuentes microsísmicas. El método utilizado para realizar la detección de los eventos y el posterior denoising o atenuación de ruido provee la entrada a los algoritmos de estimación de backazimuth y localización, incluyendo los indicadores de la energía, que son útiles para evaluar la confiabilidad de las fases detectadas y evitar detecciones falsas, y un criterio para la identificación de ondas P y S. Además, brinda tiempos de arribo y formas de onda consistentes entre trazas, que son utilizadas para los pasos siguientes.

La localización involucró un problema de optimización no-lineal cuyo objetivo fue minimizar la discrepancia entre las diferencias de tiempo entre las ondas $\mathrm{S}$ y $\mathrm{P}$ observadas y calculadas. El problema fue resuelto por medio de dos algoritmos de optimización globales: PSO y VFSA. En el caso de la localización 2D el problema tiene solo dos incógnitas, dado que la estimación del backazimuth, realizada de manera automática en un paso previo, permite limitar el espacio de búsqueda a un plano que contiene la fuente y el arreglo de receptores. En el caso 3D, la localización involucra tres coordenadas. Para este caso, se planteó una estrategia para restringir el espacio de búsqueda basada en los backazimuths estimados para dos pozos de monitoreo. Esta restricción del espacio de búsqueda permitió acelerar significativamente el cálculo. Por otra parte, se observó que el criterio basado en la energía puede ser utilizado para decidir de manera automática en qué casos utilizar el backazimuth calculado con P o S.

Se mostró que tanto PSO como VFSA son algoritmos muy efectivos y eficientes en términos del costo computacional cuando se los compara con el clásico GS. En este sentido, VFSA resultó ser hasta 8 veces más rápido que GS y 2 veces más rápido que PSO para la localización 3D. En el caso 2D, VFSA y PSO resultaron 4 y 2 veces más rápidos que GS, respectivamente.

La secuencia automática de procesamiento descripta en la Sección 5.2 fue aplicada al procesamiento de datos sintéticos y constituyó el paso inicial en el entendimiento de las diferentes etapas del procesamiento de datos microsísmicos y en la evaluación de los algoritmos VFSA y PSO en la localización de eventos.

La aplicación de la metodología propuesta para la localización de eventos con datos de campo implicó no solo la adaptación de los distintos pasos del procesamiento sino además la de los algoritmos de optimización considerados para la resolución de este problema. Se observó que la complejidad del modelo de velocidades asumido potencia aún más la necesidad de plantear al problema como una optimización a resolver mediante algoritmos globales eficientes frente a problemas no lineales con múltiples mínimos locales. Por otra parte, se replanteó la función de costo del problema a partir de las simples diferencias de tiempos de arribo. Este cambió fue impulsado por la necesidad de reducir las incertidumbres en la dirección vertical que surgen de considerar las dobles diferencias de tiempos de arribo, en las que se pierde la forma de las curvas de tiempo de arribo, que posee información importante sobre las profundidades de los eventos. El problema de optimización planteado a partir de la función propuesta 
permite, por un lado, estimar el tiempo de origen de cada evento en forma simultánea a sus coordenadas espaciales. Por otro lado. el compromiso existente entre la distancia del evento al arreglo de receptores y el tiempo de origen genera un aumento en las incertidumbres en la dirección radial. No obstante, este cambio no es apreciable frente al que se observa en la coordenada vertical, para la cual las incertidumbres se reducen significativamente. Los cambios observados en las incertidumbres en la dirección vertical al considerar las simples diferencias fueron evaluados en modelos simples y verificados mediante la consideración de modelos complejos dados por medios estratificados con presencia de anisotropía.

Se realizó la localización de eventos ocurridos durante procesos de fracturación hidráulica, lo que implicó la aplicación de los diferentes pasos descriptos en capítulos previos. Esto implicó la inclusión de un trazado de rayos a los algoritmos de optimización que permitiera considerar medios más complejos. Dadas las características del reservorio en el cual fue realizado el proceso de fracturación hidráulica en el que se registraron los datos disponibles, se asumió un medio VTI. Ambos algoritmos (VFSA y PSO) mostraron ser efectivos en la resolución del problema, siendo VFSA el más eficiente en términos de costo computacional, como era de esperar dados los resultados observados con datos sintéticos. Es decir, VFSA requiere menor cantidad de evaluaciones de la función de costo que PSO para alcanzar un dado valor deseado de la misma. Por otra parte, ante una misma cantidad de evaluaciones de la función de costo ambos algoritmos arrojan resultados similares. Sin embargo, el caracter poblacional de PSO le permite al algoritmo escapar de mínimos locales particularmente en aquellas regiones en las que no existía información suficiente para una óptima calibración del modelo de velocidades. Los resultados muestran que estos algoritmos y el planteo del problema realizado constituyen una herramienta útil y confiable para la localización de eventos microsísmicos.

Por último, se analizaron las incertidumbres de las soluciones obtenidas. Para esto se propuso considerar el comportamiento de la función de costo en un entorno de la posición estimada de la fuente, asumiendo que ésta refleja los errores cometidos en la calibración del modelo de velocidades y el picado de tiempos de arribo. Para esto, se calcularon elipses de error en los planos $(x, y)$ y $(r, z)$, cuyos ejes fueron definidos a partir de la función de costo en torno a cada solución y de los desvíos obtenidos en el cálculo del backazimuth. En general, y como era de esperar, las incertidumbres son mayores en la dirección vertical que en la radial. Asímismo, los resultados muestran la gran influencia que las incertidumbres en la estimación del backazimuth tienen sobre las correspondientes a la dirección transversal en la localización. Esto permite confirmar la importancia de la eliminación de valores atípicos en las estimaciones de backazimuths que se detalló en el Capítulo 4. 


\section{Capítulo 6}

\section{Estimación de magnitudes momento}

\subsection{Introducción}

Cuantificar el tamaño o la energía de las microfracturas que dan origen a las señales microsísmicas es de gran interés en la interpretación de los resultados del monitoreo microsísmico. Para ello se busca determinar la magnitud momento de los eventos, $M_{w}$, que puede obtenerse por medio de la estimación del momento sísmico, $M_{0}$, un atributo directamente asociado al tamaño de las microfracturas. La magnitud momento de los eventos microsísmicos es especialmente valiosa para el cálculo del volumen de roca estimulado durante el proceso de fracturación hidráulica, para caracterizar posibles tendencias en la disposición de los eventos asociadas a la geometría de adquisición, y para evaluar la eficiencia del procedimiento en general (Shemeta y Anderson, 2010; Maxwell et al., 2009; Maxwell, 2014).

En la práctica, la estimación del momento sísmico puede hacerse tanto en el dominio del tiempo como en el de las frecuencias. En el dominio de las frecuencias existen dos estrategias alternativas: (1) aproximar el espectro para un rango de bajas frecuencias, y (2) ajustar un modelo al espectro de amplitud de la señal. En este capítulo se muestra la aplicación de esta última estrategia, que permite explotar la información contenida en todo el rango de frecuencias disponible y es potencialmente útil para la estimación de otros parámetros de la fuente, como el tamaño de la microfractura o la caída de esfuerzos asociada. Con el fin de realizar el ajuste de modelos teóricos a los espectros de amplitud de las señales en cuestión, se planteó un problema de optimización que solucionamos por medio de Very Fast Simulated Annealing (VFSA) aprovechando su alta eficiencia en la resolución de problemas no lineales. En primer lugar, se estudiaron los alcances del planteo del problema realizado. Con este objetivo, por medio de un ejemplo pseudo-sintético y un ejemplo dado por un evento real se evaluó la posibilidad de considerar distintas incógnitas para el problema y el impacto que esto tiene en la magnitud momento estimada. Por último, se describen las modificaciones realizadas a la metodología propuesta con el fin de adaptarla para su aplicación automática en grandes 
conjuntos de eventos microsísmicos detectados en datos de campo, se muestran los correspondientes resultados y se discuten los alcances y limitaciones de la metodología con relación a las aproximaciones realizadas.

\subsection{Fundamentos teóricos}

\subsubsection{Desplazamientos en campo lejano, momento sísmico y magnitud momento}

Las distancias entre fuentes y receptores típicas de los escenarios de monitoreo microsísmico de interés son lo suficientemente grandes en relación a las longitudes de onda características de las señales como para poder asumir que los efectos en los receptores son los propios del campo lejano de una fuente microsísmica (Aki y Richards, 2002). El desplazamiento en campo lejano (en un punto $\mathbf{x}$ del espacio) generado por la componente $j k$ del tensor momento sísmico correspondiente a una fuente en $\mathbf{x}=0$, en un medio homogéneo, está dado por (Shearer, 2009):

$$
u_{i}(\mathbf{x}, t)=\frac{1}{4 \pi \rho c^{3} r} R_{i j k} \dot{M}_{j k}\left(t-\frac{r}{c}\right)
$$

donde $\rho$ es la densidad del medio, $c$ es la velocidad de propagación de las ondas $\left(v_{P}\right.$ o $v_{S}$ según corresponda), $r$ es la distancia a la fuente y $\dot{M}$ es la derivada temporal del tensor momento sísmico. El factor $R_{i j k}$ corresponde al patrón de radiación, que depende de las posiciones relativas entre fuente y receptor y de la orientación de la fractura, y adopta la forma

$$
\begin{aligned}
R_{i j k}^{P} & =\frac{x_{i} x_{j} x_{k}}{r^{3}}, \\
R_{i j k}^{S} & =\frac{\left(r^{2} \delta_{i j}-x_{i} x_{j}\right) x_{k}}{r^{3}},
\end{aligned}
$$

para las ondas $P$ y $S$, respectivamente.

La dependencia temporal del tensor momento sísmico de la ecuación 6.1 surge de plantear que el desplazamiento que ocurre a ambos lados de una fractura en general no es instantáneo, sino que tiene una duración temporal finita. A esto se suma el hecho de que, en el campo cercano, el desplazamiento es permanente. Es decir, el tensor momento sísmico $M(t)$ debe ser tal que los desplazamientos en campo cercano adopten la forma que muestra la Figura 6.1a. En el campo lejano, por su parte, el desplazamiento, proporcional a la derivada temporal del tensor momento sísmico, no tiene componentes permanentes: todos los puntos retornan a su posición original luego de finalizado el pulso (Figura 6.1b). Para el caso de una fuente de tipo doble-cupla dada por una falla en el plano $\left(x_{1}, x_{2}\right)$ con desplazamiento en la dirección $x_{1}$, por ejemplo, los únicos elementos no nulos son $M_{13}=M_{31}=M_{0}$ y los desplazamientos en campo 

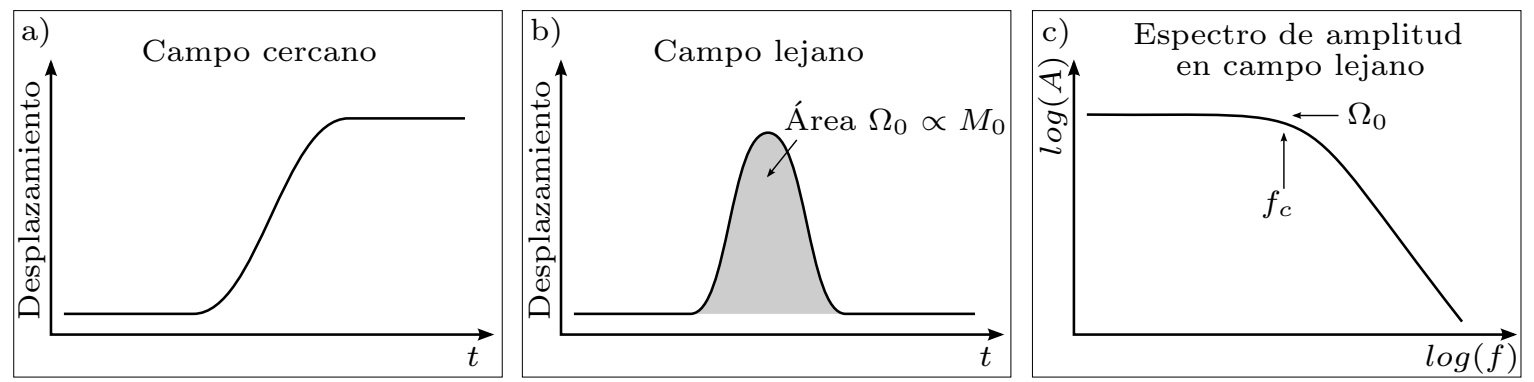

Figura 6.1. a) Desplazamiento en campo cercano; b) Desplazamiento en campo lejano; c) Espectro de amplitud en campo lejano. Adaptada de Shearer (2009).

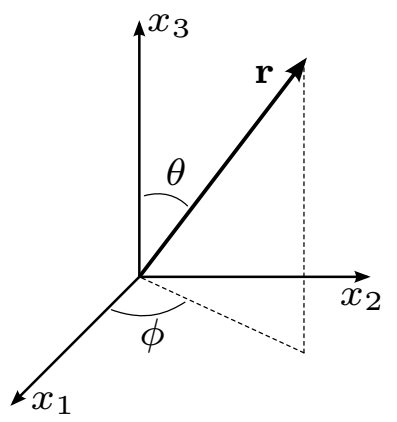

Figura 6.2. Coordenadas esféricas $(\theta, \phi)$ del vector $\mathbf{r}$, relativas a una falla en el plano $\left(x_{1}, x_{2}\right)$ con deslizamiento en la dirección $x_{1}$.

lejano resultan

$$
\mathbf{u}=\frac{1}{4 \pi \rho c^{3} r} R(\theta, \phi) \dot{M}_{0}\left(t-\frac{r}{c}\right) \hat{\mathbf{r}}
$$

donde las coordenadas cartesianas fueron reemplazadas por coordenadas esféricas

$$
\begin{aligned}
& x_{3} / r=\cos \theta, \\
& x_{1} / r=\sin \theta \cos \phi, \\
& x_{i} / r=\hat{r}_{i},
\end{aligned}
$$

de acuerdo a la convención indicada en la Figura 6.2. Los factores asociados al patrón de radiación para las ondas $P$ y $S$ quedan

$$
\begin{aligned}
& R^{P}(\theta, \phi)=\sin 2 \theta \cos \phi, \mathrm{y} \\
& R^{S}(\theta, \phi)=\cos 2 \theta \cos \phi \hat{\boldsymbol{\theta}}-\cos \theta \sin \phi \hat{\boldsymbol{\phi}}
\end{aligned}
$$

donde $\hat{\boldsymbol{\theta}}$ y $\hat{\boldsymbol{\phi}}$ son versores en las direcciones de $\theta$ y $\phi$, respectivamente. La amplitud del desplazamiento se asocia al "tamaño" del evento.

El área bajo la curva del pulso de la Figura 6.1b corresponde al límite del espectro de amplitud de la señal para bajas frecuencias, $\Omega_{0}$. Integrando la ecuación 6.4 con 
respecto al tiempo se llega a

$$
M_{0}=\frac{4 \pi \rho c^{3} r \Omega_{0}}{R(\theta, \phi)} .
$$

Es decir que a partir de analizar el espectro de un evento para las menores frecuencias es posible obtener el momento sísmico correspondiente a dicho evento. Sin embargo, esta relación requiere del conocimiento del patrón de radiación caracterizado por el factor $R(\theta, \phi)$, que solo es completamente conocido cuando se conoce el mecanismo focal del evento. Conocer este factor con rigurosidad implica conocer previamente el mecanismo focal del evento, mediante la inversión del correspondiente tensor momento sísmico. En general, éste es un paso posterior a la estimación de magnitudes, por lo cual no se dispone de un valor preciso para cada evento. Más aún, en la mayoría de los casos la limitada distribución de sensores de los monitoreos microsísmicos de pozo no permite la resolución del tensor momento sísmico de manera precisa e implica la aplicación de restricciones y la realización de suposiciones en relación al tipo de fuente (Grechka et al., 2017; Eyre y van der Baan, 2015; Eaton y Forouhideh, 2011). Dada esta situación, el factor asociado al patrón de radiación es en general reemplazado por el promedio del mismo para toda la esfera focal, que toma el valor 0.52 para la onda $P$ y 0.63 para la onda $S$ (Boore y Boatwright, 1984; Maxwell, 2014). Naturalmente, la utilización de los valores promedio en lugar de la correspondiente corrección por patrón de radiación, introduce errores en el cálculo de magnitudes. De acuerdo a Daniel et al. (2013) el error en la magnitud estimada puede ser de hasta 0.5 si se consideran fases individuales. En el caso de fracturas de tipo doble-cupla, por ejemplo, los patrones de radiación de las ondas $\mathrm{P}$ y $\mathrm{S}$ son tales que los máximos de amplitud en un caso coinciden con los planos nodales del otro (Aki y Richards, 2002). En consecuencia, la magnitud obtenida a partir de solo la onda $\mathrm{P}$ o la onda $\mathrm{S}$ queda sobrestimada en un caso y subestimada en el otro. De esta manera, considerar un promedio de ambos resultados permite reducir el error asociado al desconocimiento del patrón de radiación.

La importancia del cálculo del momento sísmico radica en el hecho de que es el parámetro más utilizado para caracterizar la fuerza o el tamaño de un evento, dado que se relaciona directamente con las dimensiones de la falla (Shearer, 2009; Aki y Richards, 2002) de acuerdo a

$$
M_{0}=\mu \bar{D} A,
$$

donde $\bar{D}$ es el desplazamiento promedio de la falla y $A$ es su área. El momento sísmico es, además, la característica del evento considerada en la escala de magnitudes propuesta por Hanks y Kanamori (1979), según la cual

$$
M_{w}=\frac{2}{3} \log \left(M_{0}\right)-6,
$$

donde $M_{w}$ es la magnitud momento del evento. Si bien esta no es la única escala de magnitudes existente, es la que permite vincular la magnitud del evento con características físicas del mismo. 


\subsubsection{Modelado del espectro de amplitud}

El espectro de amplitud de los desplazamientos generados por una fuente de dimensiones finitas visto en escala logarítmica presenta, en general, un comportamiento plano para las bajas frecuencias con amplitud $\Omega_{0}$ y un decaimiento para las altas frecuencias a partir de un cierto valor, llamado frecuencia corner, $f_{c}$, como se ilustra en la Figura 6.1c (Udías, 1999). Existen distintos modelos de fuente, cada uno con un espectro de amplitud asociado que satisface las características generales mencionadas. La expresión matemática general que adoptan los espectros de amplitud de dichos modelos está dada por (Shearer, 2009):

$$
\Omega(f)=\frac{\Omega_{0}}{\left(1+\left(f / f_{c}\right)^{\gamma n}\right)^{1 / \gamma}},
$$

donde además de los ya mencionados $\Omega_{0}$ y $f_{c}$ intervienen la tasa de decaimiento a altas frecuencias, $n$ y una constante $\gamma$ que define qué tan pronunciado es el inicio de la caída en torno a la frecuencia $f_{c}$.

Entre los modelos más utilizados que responden a esta formulación se encuentran el de Brune (1970) y el de Boatwright (1980). De acuerdo al primero de ellos, que asume un deslizamiento dado por una cizalla instantánea en un área circular, $n=2$ y $\gamma=1$. Por su parte, y dado que lograba un mejor ajuste de sus datos, Boatwright (1980) propuso $n=2$ y $\gamma=2$. Para contemplar los efectos de la atenuación sobre el espectro de amplitud de las señales, en lugar de la ecuación 6.13 se considera (Abercrombie, 1995):

$$
\Omega(f)=\frac{\Omega_{0} e^{-\pi f t / Q}}{\left(1+\left(f / f_{c}\right)^{\gamma n}\right)^{1 / \gamma}},
$$

donde $Q$ corresponde al factor de calidad del medio y $t$ al tiempo de viaje de la onda en cuestión.

A partir del registro de señales correspondientes a eventos microsísmicos es posible, entonces, estimar la magnitud momento del evento, $M_{w}$, por medio del ajuste del espectro de amplitud de los desplazamientos al modelo de la ecuación 6.14 que permita obtener una aproximación a $\Omega_{0}$, y de la utilización de las ecuaciones 6.10 y 6.12. La elección del modelo a utilizar (Brune o Boatwright) depende de cada juego de datos en particular, dado que las características de los registros están gobernadas por las propiedades del medio y los mecanismos focales de la fuente (tamaño, tipo y orientación espacial de la microfractura). En general, esta decisión se puede tomar en forma previa al procesamiento de la información, teniendo en cuenta análisis previos de los registros en cuestión o de información obtenida en etapas anteriores, por ejemplo.

\subsubsection{Combinación de la información: Stack}

El ruido presente en los registros constituye una importante dificultad para el ajuste de un modelo al espectro de amplitud de las señales. Esto puede verse en la Figura 6.3, para la cual una única traza fue generada combinando un evento modelado de acuerdo 


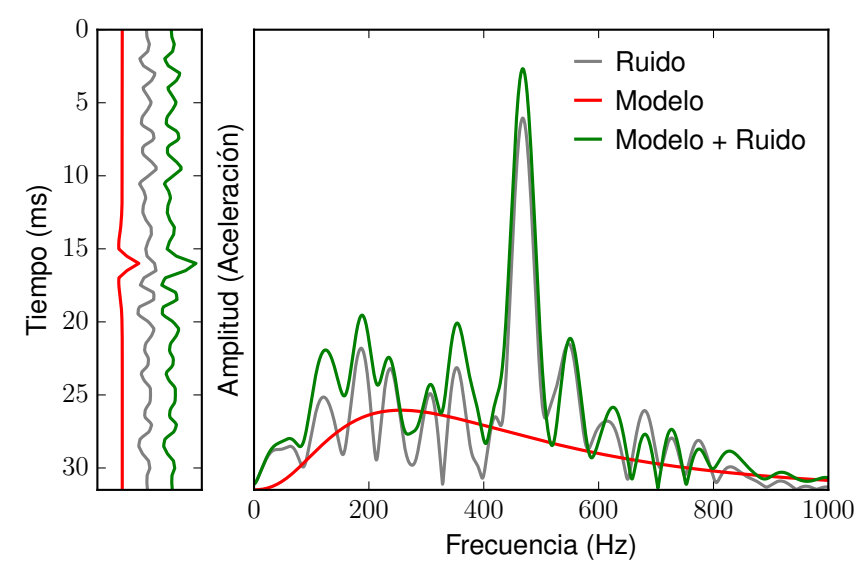

Figura 6.3. Espectro de amplitud (en aceleración) del evento modelado y del ruido.

a la ecuación 6.14 con ruido real, registrado durante un monitoreo microsísmico. El espectro de amplitud de la traza resultante (curva verde) es la suma de los espectros de amplitud de las aceleraciones individuales del evento modelado y del ruido, que comparten todo el rango de frecuencias con amplitudes comparables.

Con el fin de reducir la contribución del ruido, se calcula un stack lineal de las trazas que contienen un cierto evento, previo al ajuste del modelo. Si el evento está sincronizado en todas las trazas, el stack permite mejorar la relación señal-ruido y, adicionalmente, reduce la cantidad de cómputos necesarios, ya que solo un espectro será ajustado a cada evento en lugar de uno por traza. La Figura 6.4a muestra un conjunto de trazas que, como ya se describió, corresponden a un evento modelado al que se agregó ruido. La traza roja corresponde al stack. En la Figura 6.4 se puede observar que la semejanza del espectro de amplitud (en aceleración) del stack respecto a la del modelo es muy superior a la de los espectros de las trazas individuales.

\subsubsection{Problema de optimización}

El problema que debe ser resuelto para lograr ajustar un modelo al espectro de amplitud del stack de las trazas consiste en la minimización de la función

$$
E\left(\Omega_{0}, f_{c}, Q, \gamma, n\right)=\left[\frac{1}{N} \sum_{i=1}^{N}\left(\Omega^{\text {stack }}\left(f_{i}\right)-\Omega^{\text {mod }}\left(f_{i}\right)\right)^{2}\right]^{1 / 2}
$$

donde $\Omega^{\text {stack }}$ y $\Omega^{\text {mod }}$ corresponden a los espectros de amplitud del stack y del modelo, respectivamente. Para llevar a cabo esta tarea, utilizamos VFSA. 

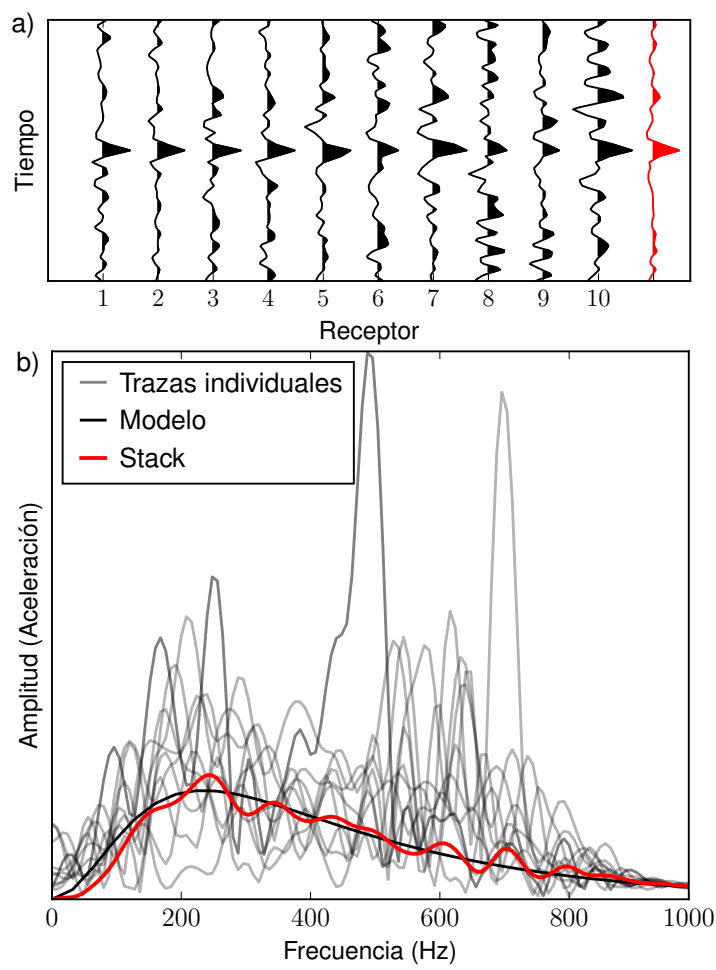

Figura 6.4. (a) Registro del evento microsísmico: trazas individuales (negro) y stack (rojo). (b) Espectro de amplitud de las trazas individuales y del stack.

\subsection{Ejemplos}

\subsubsection{Ejemplo pseudo-sintético}

La función de costo dada por la ecuación 6.15 depende de varios parámetros. Algunos de ellos, especialmente los que definen el comportamiento del espectro en alta frecuencia $(Q, \gamma$ y $n)$ son altamente dependientes entre sí. En consecuencia, no es posible obtener todos estos parámetros de manera simultánea como soluciones al problema de optimización. Por lo tanto, algunos de ellos deben ser definidos a priori. En este ejemplo aplicamos el procedimiento descripto y proponemos cuatro escenarios que difieren en el subconjunto de incógnitas consideradas en el problema de optimización. Con el fin de evaluar el error en los resultados, consideramos un conjunto de 100 registros pseudo-sintéticos que fueron generados con las ecuaciones de la Sección 6.2. Para ello, se consideró un evento sintético de magnitud $M_{w}=-1$, con $f_{c}=200 \mathrm{~Hz}$, en un medio caracterizado por $\rho=2700 \mathrm{~kg} / \mathrm{m}^{3}$ y $c=3500 \mathrm{~m} / \mathrm{s}$. Para estos registros se supuso, además, un conjunto de 10 receptores $3 \mathrm{C}$ (un total de 30 trazas) ubicados a $400 \mathrm{~m}$ del evento, y se les adicionó ruido real registrado durante un monitoreo microsísmico. Se consideró para ello una relación señal-ruido igual a 1 tomada como el cociente entre la máxima amplitud absoluta de la ondícula modelada y la máxima amplitud absoluta de las 30 trazas de ruido real utilizado, lo cual se traduce 
en una relación señal-ruido promedio de aproximadamente 2.5 para todo el registro. En todos los casos se consideraron los mismos parámetros para la definición del modelo y los registros solo difieren en el ruido adicionado. Los ajustes fueron llevados a cabo en ventanas de $30 \mathrm{~ms}$ en torno a la señal modelada. Una síntesis cuantitativa de los errores obtenidos en estos experimentos se presenta en la Tabla 6.1 y se describen a continuación. Éstos son calculados como el promedio de los errores relativos obtenidos para las 100 realizaciones, para el correspondiente parámetro estimado. Es decir, en cada realización se calcularon los errores relativos

$$
\varepsilon_{\alpha}=\frac{\alpha-\alpha_{0}}{\alpha_{0}} 100 \%
$$

donde $\alpha$ y $\alpha_{0}$ corresponden al parámetro $\left(\Omega_{0}, f_{c}, Q\right.$ o $\left.\gamma\right)$ estimado y modelado, respectivamente, y se promediaron los resultados obtenidos. La situación más frecuente es aquella en la que $Q, \gamma$ y $n$ son definidos teniendo en cuenta información a priori sobre el medio y el comportamiento de las señales. De esta forma, solamente deben determinarse $\Omega_{0}$ y $f_{c}$. Realizamos la optimización para este caso, que llamamos "Prueba 1", considerando $Q=100, \gamma=1$ y $n=2$ (modelo de Brune), que corresponden a los valores utilizados para la generación del evento sintético. Los errores relativos medios son de alrededor del $14 \%$ para ambas incógnitas, como se muestra en la Tabla 6.1. La Figura 6.5a muestra los espectros de amplitud (en desplazamiento) ajustados al stack de cada evento de manera individual, el espectro medio y el modelo. La dispersión observada en los espectros individuales se debe a ruido residual que no fue completamente removido por el stack.

En el segundo escenario, el factor de calidad $Q$ también es una incógnita del problema. Por lo tanto, en la "Prueba 2" se evaluó la posibilidad de determinar de forma simultánea los parámetros $\Omega_{0}, f_{c}$ y $Q$. La Figura 6.5b muestra los espectros individuales obtenidos para cada uno de los 100 registros y su espectro medio, en comparación con el modelo con el cual el evento fue generado. En este caso, se puede ver que ignorar la información del factor de calidad $Q$ aumenta considerablemente los errores en la frecuencia corner estimada, pero no introduce mayores cambios en los errores en $\Omega_{0}$. Nuevamente, la dispersión es causada por el ruido residual presente en los stacks.

Las Pruebas 3 y 4 están relacionadas. En el primer caso, se fija el valor de $Q$ y se evalúa la posibilidad de independizarnos de cualquier suposición vinculada al comportamiento del espectro en altas frecuencias. En otras palabras, estudiamos la capacidad del procedimiento para determinar si el evento se comporta siguiendo un modelo de Brune, de Boatwright o ninguno de ellos. De esta manera, en la "Prueba 3" obtenemos $\Omega_{0}, f_{c}$ y $\gamma$ como salida del problema de optimización. En este caso, la dispersión en los espectros estimados aumenta significativamente en comparación con las pruebas anteriores (ver Figura 6.5c). Otorgarle a $\gamma$ la posibilidad de variar le permite al algoritmo de optimización encontrar conjuntos de parámetros que expliquen mejor al stack, lo cual no necesariamente implica recuperar el modelo con el cual se generó el ejemplo sintético. Esto genera errores en $\Omega_{0}$, el parámetro que más nos interesa aquí, 

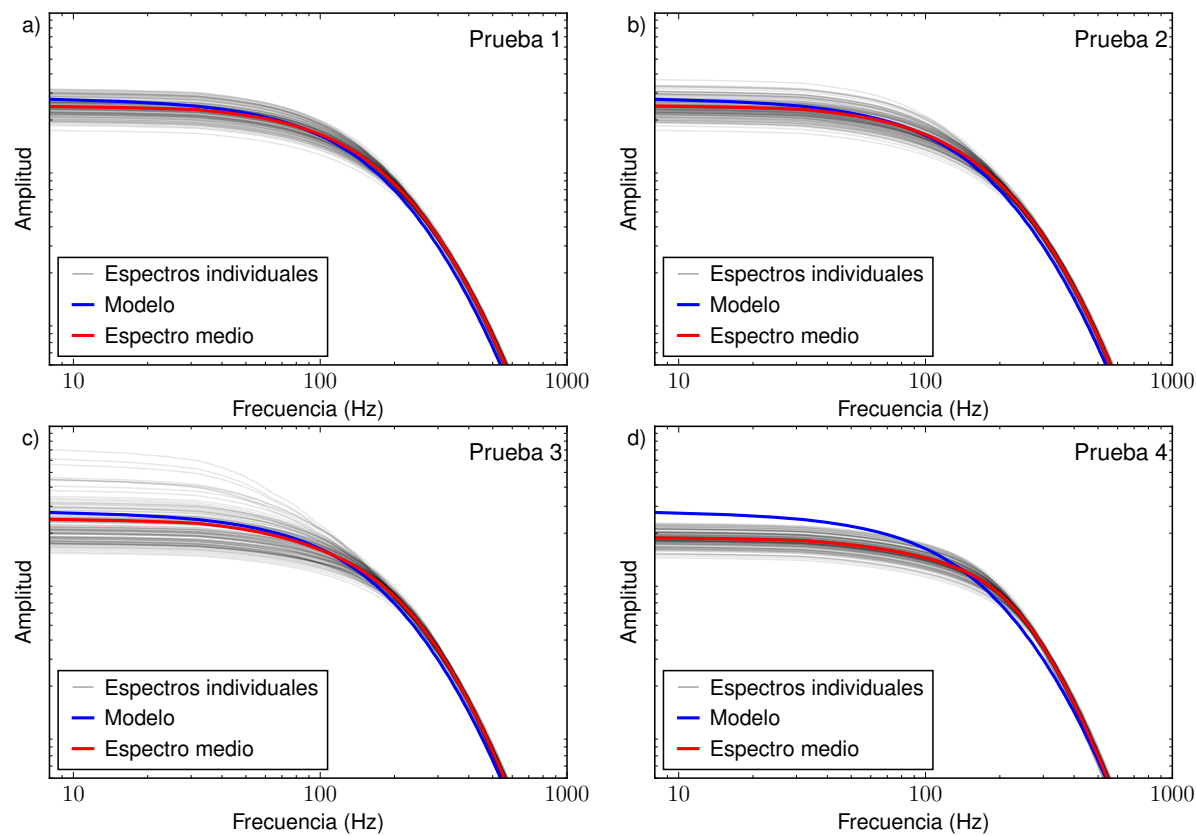

Figura 6.5. Modelo considerado para la generación de los registros pseudosintéticos (azul) y espectros obtenidos mediante la optimización (para cada uno de los 100 stacks) y su media. Las pruebas difieren en el conjunto de parámetros que se consideran incógnitas en el problema de optimización (ver descripción en el texto).

mayores a los dos casos anteriores. Sin embargo, aún resta saber si es posible prescindir de la información sobre el comportamiento de las señales a alta frecuencia.

La "Prueba 4" apunta a estudiar qué tan significativo puede llegar a ser el error si se realiza una elección incorrecta del modelo que se ajusta a los espectros. Teniendo en cuenta que el evento sintético sigue a un modelo de Brune, evaluamos, entonces, la influencia que tiene en los parámetros de interés asumir que la señal sigue a un modelo de Boatwright. En otras palabras, asumimos $\gamma=2$ y optimizamos para $\Omega_{0}$ y $f_{c}$. La Tabla 6.1 muestra que esta suposición aumenta levemente los errores medios en $\Omega_{0}$. Sin embargo, los resultados están claramente sesgados, como puede verse en la Figura 6.5d. El valor de $\Omega_{0}$ es, en todos los casos, subestimado.

\begin{tabular}{ccccc}
\hline & Prueba 1 & Prueba 2 & Prueba 3 & Prueba 4 \\
\hline$\varepsilon_{\Omega_{0}}$ & $14.5 \%$ & $15.2 \%$ & $28.7 \%$ & $33.2 \%$ \\
$\varepsilon_{f_{c}}$ & $14.2 \%$ & $32.0 \%$ & $13.7 \%$ & $13.3 \%$ \\
$\varepsilon_{Q}$ & - & $12.1 \%$ & - & - \\
$\varepsilon_{\gamma}$ & - & - & $40.0 \%$ & - \\
\hline
\end{tabular}

Tabla 6.1. Resultados del problema de optimización con diferentes incógnitas. 
Es importante tener presente la relación no-lineal que existe entre el momento sísmico escalar $M_{0}$ (y por lo tanto $\Omega_{0}$ ) y nuestro parámetro de interés, $M_{w}$, que se describe en la ecuación 6.12. Como consecuencia de esta relación, los errores relativos obtenidos para $\Omega_{0}$ en particular, no son significativos cuando se traducen a errores en el valor de $M_{w}$ calculado, como se muestra en la Tabla 6.2. A modo de ejemplo, la tercera columna de esta tabla cuantifica dichos errores en la magnitud momento de un evento de referencia de $M_{w}=-1.5$. Estos errores se mantienen por debajo de los descriptos por Stork et al. (2014) causados por otros factores tales como el uso de promedios para las correcciones por patrón de radiación, la longitud de las ventanas consideradas, el número de receptores disponibles, la precisión en la determinación de tiempos de arribo, entre otras típicas fuentes de error. Por consiguiente, a partir de los resultados de las Pruebas 3 y 4 y teniendo en cuenta la Tabla 6.2, el comportamiento del espectro a alta frecuencia que obtenemos como solución al problema de optimización no es relevante para la estimación de $M_{w}$, pero debe estudiarse si se desea determinar otros parámetros de la fuente a partir de ello. Más adelante en este capítulo se mostrará el cálculo de magnitudes momento en datos de campo en el que el ajuste se realiza para grandes cantidades de eventos y que no involucra grandes tiempos de cálculo. Esto implica que pueda realizarse el ajuste considerando eventualmente ambos modelos (Brune y Boatwright) para definir cuál de ellos es más adecuado para los datos considerados y reducir así los errores asociados a la estimación del comportamiento en alta frecuencia. Es decir, si bien las pruebas 3 y 4 permiten observar que aunque el valor de $\gamma$ contribuye a los errores en el valor final de magnitud momento, no es crítico para éste, de manera que no son casos de interés para el procesamiento de eventos reales.

\begin{tabular}{ccc}
\hline$\varepsilon_{\Omega_{0}}$ & $\varepsilon_{M_{w}}$ & $M_{w}=-1.5$ \\
\hline $10 \%$ & $<2 \%$ & 0.03 unidades \\
$20 \%$ & $<4 \%$ & 0.06 unidades \\
$30 \%$ & $<7 \%$ & 0.1 unidades \\
\hline
\end{tabular}

Tabla 6.2. Errores en la amplitud a baja frecuencia y en la magnitud momento.

\subsubsection{Ejemplo con datos de campo}

A continuación se ilustra la aplicación del procedimiento propuesto a la estimación de la magnitud momento de un evento microsísmico real. El esquema de procesamiento consiste en los siguientes pasos:

1. Detectar el evento en los registros y determinar los tiempos de arribo de todas las fases identificables (ondas $\mathrm{P}, \mathrm{SH}, \mathrm{SV}$ ).

2. Localizar el evento: estimar las coordenadas espaciales de la fuente para calcular la distancia entre ésta y los receptores, $\mathrm{R}$. 


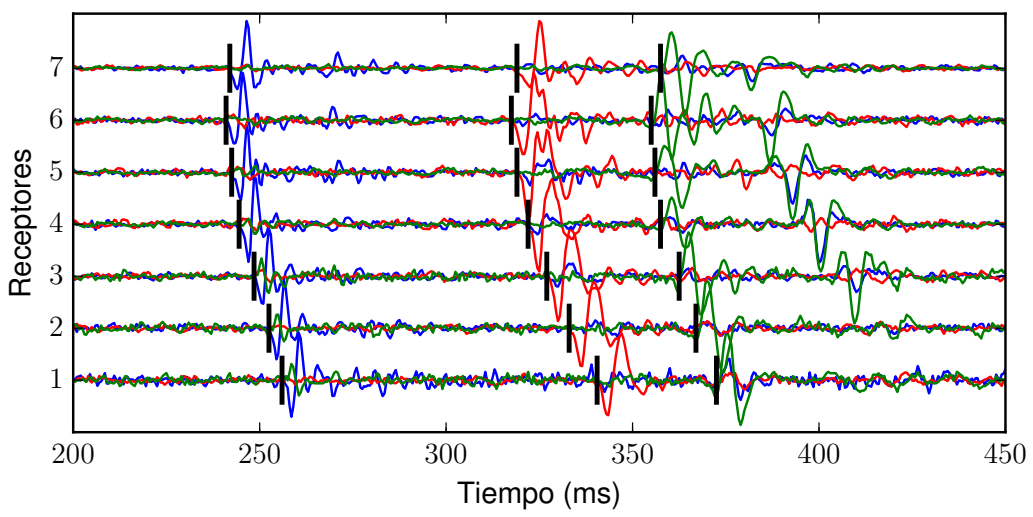

Figura 6.6. Registro correspondiente a un evento microsísmico y tiempos de arribo estimados para las ondas $\mathrm{P}, \mathrm{SH}$ y $\mathrm{SV}$.

3. Sincronizar y realizar el stack de las trazas que contienen cada fase, y calcular su correspondiente espectro de amplitud.

4. Ajustar un modelo al espectro de amplitud de cada fase. Esto permite la estimación de la amplitud a baja frecuencia para la onda $\mathrm{P}, \Omega_{0}^{P}$, y para la onda $\mathrm{S}, \Omega_{0}^{S}=$ $\sqrt{\left(\Omega_{0}^{S H}\right)^{2}+\left(\Omega_{0}^{S V}\right)^{2}}$ (Baig y Urbancic, 2010).

5. Calcular la magnitud momento a partir de los espectros a baja frecuencia de las ondas P y S y estimar la magnitud momento del evento como un promedio entre ambas.

En el presente ejemplo, se procedió de la forma descripta para un evento microsísmico individual. El registro correspondiente al evento considerado se muestra en la Figura 6.6, en la cual sus componentes se muestran en el sistema radial-tangencial-vertical (curvas azul, roja y verde, respectivamente) respecto de la posición estimada del mismo. Las tres fases (P, SH y SV) fueron detectadas y posteriormente sincronizadas. Los tiempos de arribo, estimados mediante la estrategia multicanal descripta en la Sección 4.3.1, se indican con barras verticales en la Figura 6.6. Por su parte, la Figura 6.7 muestra los stacks obtenidos para cada fase, cuyos correspondientes espectros de amplitud son las curvas negras de la Figura 6.8. Al ajustar un modelo a cada espectro de amplitud, consideramos las siguientes situaciones:

1. el evento sigue un modelo de Boatwright $(\gamma=2)$ y el factor de calidad es conocido $(Q=100)$, por lo que solo se deben determinar $\Omega_{0}$ y $f_{c}$;

2. similar al caso anterior, pero considerando un modelo de Brune $(\gamma=1)$;

3. $\gamma$ es una incógnita y $Q=100 ;$ y

4. $\gamma=1$ y $Q$ son incógnitas del problema. 

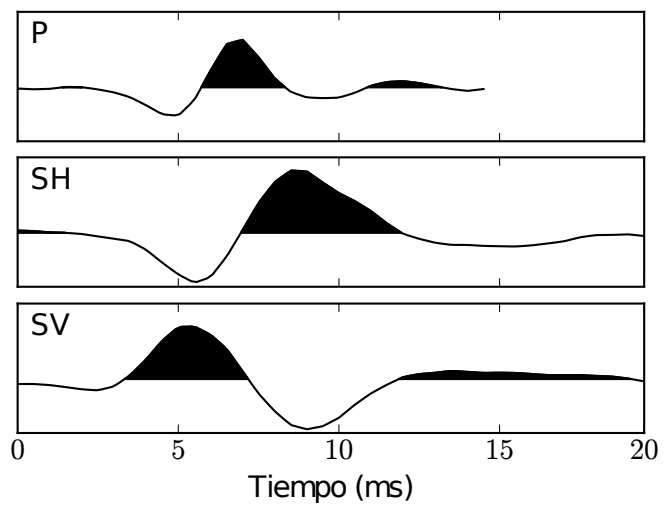

Figura 6.7. Stacks calculados para las fases P, SV y SH de la Figura 6.6.

Los resultados para cada fase se muestran en la Figura 6.8. Puede verse que mientras para bajas frecuencias todos los modelos estimados tienen comportamientos similares, las diferencias más significativas aparecen en las frecuencias altas. La mayor diferencia la presenta el modelo en el que $Q$ fue obtenido como parte de la solución al problema de optimización. Esto estaría indicando que el valor considerado por defecto para los otros casos no es lo suficientemente preciso para estos datos. Para poder arribar a una conclusión al respecto deberían analizarse más eventos del mismo procedimiento de estimulación hidráulica. La Tabla 6.3 reúne los valores de los parámetros obtenidos para cada fase y en cada situación. Allí se observa que en el caso en que estimamos $Q$, la función de costo $E$ alcanza un valor menor que en cualquier otro caso, lo cual es esperable porque aumentamos en número de grados de libertad. Por otro lado, el comportamiento en alta frecuencia de este evento en particular se asemeja más a un modelo de Boatwright que a uno de Brune ( $E$ es más pequeño en el primer caso). Los valores hallados para la frecuencia corner pueden ser muy distintos dependiendo del número de incógnitas del problema de optimización y de la fase considerada para el cálculo. Estas diferencias deben evaluarse con mayor cuidado si se desea una caracterización de la fuente más detallada. Estimamos la magnitud momento del evento para cada uno de los cuatro experimentos y obtuvimos $M_{w}=-2.01, M_{w}=-2.03$, $M_{w}=-2.15$ y $M_{w}=-2.18$ para los experimentos (1), (2), (3) y (4) respectivamente, lo que muestra que independientemente de la aproximación a alta frecuencia considerada, las diferencias en los valores de $M_{w}$ obtenidos resultan poco significativas, comparables a los errores descriptos por Stork et al. (2014) asociados a otros factores ajenos al ajuste de espectros. Aún así, es posible evitar los errores asociados al ajuste de los parámetros que definen el comportamiento en altas frecuencias. La eficiencia computacional de la herramienta desarrollada para el procesamiento de grandes cantidades de eventos (que se describe a continuación) permite considerar distintos casos y eventualmente evaluar comparativamente los posibles parámetros asociados al comportamiento de los espectros a altas frecuencias para todos los eventos en conjunto. 


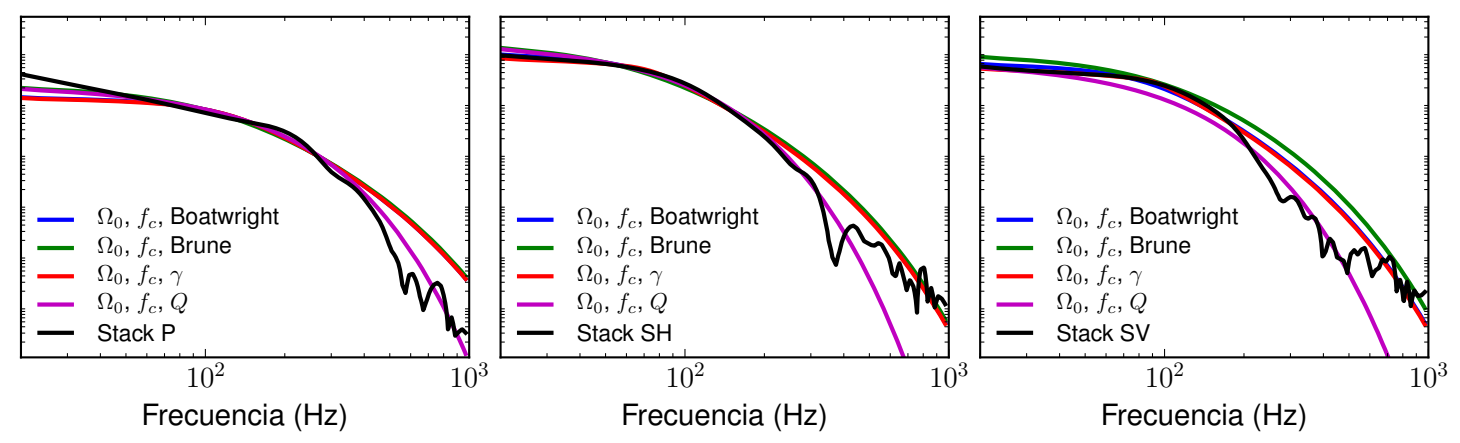

Figura 6.8. Resultados del ajuste de diferentes modelos al stack de las ondas P, SH y SV. Los modelos difieren en el conjunto de incógnitas consideradas para el problema de optimización.

\begin{tabular}{|c|c|c|c|c|c|c|}
\hline & & $\Omega_{0}\left(\times 10^{-12}\right)$ & $f_{c}(\mathrm{~Hz})$ & $Q$ & $\gamma$ & $E$ \\
\hline \multirow{5}{*}{$\mathrm{P}$} & 1 & 9.0 & 102 & - & - & 2.7 \\
& 2 & 5.7 & 121 & - & - & 2.5 \\
& 3 & 5.5 & 123 & - & 2.16 & 2.5 \\
& 4 & 9.5 & 398 & 40 & - & 1.7 \\
\hline \multirow{5}{*}{$\mathrm{SH}$} & 1 & 62.9 & 60 & - & - & 5.1 \\
& 2 & 42.1 & 68 & - & - & 3.6 \\
& 3 & 35.0 & 72 & - & 4.84 & 3.1 \\
& 4 & 66.6 & 193 & 41 & - & 2.2 \\
\hline \multirow{5}{*}{$\mathrm{SV}$} & 1 & 39.3 & 76 & - & - & 6.1 \\
& 2 & 27.4 & 84 & - & - & 4.8 \\
& 3 & 22.2 & 90 & - & 10.10 & 4.1 \\
& 4 & 45.5 & 213 & 46 & - & 4.0 \\
\hline
\end{tabular}

Tabla 6.3. Resultados de la aplicación del procedimiento a un evento microsísmico real considerando distintas situaciones que difieren en las incógnitas del problema de optimización. 


\subsection{Estimación de magnitudes momento en datos de campo}

El cálculo de magnitudes momentos de eventos microsísmicos depende en gran medida de la calidad de la información disponible sobre éstos. Como se ha mencionado, no solo es necesaria la identificación de los eventos en los registros microsísmicos, sino que además se debe disponer de tiempos de arribo estimados con precisión y de las posiciones de los eventos en el espacio. Por lo tanto, una vez que las estrategias descriptas en los capítulos anteriores fueron adaptadas y aplicadas a datos de campo, fue posible llevar a cabo las modificaciones necesarias para aplicar las herramientas de estimación de magnitudes desarrolladas, de forma automática y sobre un gran volumen de eventos, como se describe en esta sección.

\subsubsection{Estimación conjunta de $\Omega_{0}^{P}, \Omega_{0}^{S}$ y $f_{c}$}

Luego de evaluar los resultados del ajuste de espectros de amplitud por medio de VFSA sobre datos pseudo-sintéticos, se buscó implementar la estrategia para procesar grandes cantidades de eventos microsísmicos registrados durante procesos de fracturación hidráulica. El objetivo es obtener un único valor de magnitud momento para todas las fases disponibles del evento, combinando los problemas de optimización individuales en una única función de costo. Es decir, ajustando en simultáneo los espectros de todas las fases disponibles. La función de costo del problema a resolver resulta, entonces:

$$
E\left(\boldsymbol{\Omega}_{\mathbf{0}}, f_{c}^{*}\right)=\left(\sum_{k=1}^{3}\left[\frac{1}{N} \sum_{i=1}^{N}\left(\Omega_{\nu_{k}}^{\text {stack }}\left(f_{i}\right)-\Omega_{\nu_{k}}^{\text {mod }}\left(f_{i}\right)\right)^{2}\right]\right)^{1 / 2}
$$

donde $\nu_{k}=P, S V, S H, \Omega_{0}=\left(\Omega_{0}^{P}, \Omega_{0}^{S V}, \Omega_{0}^{S H}\right)$ y $f_{c}^{*}$ es una frecuencia corner generalizada que será modificada al ser utilizada para modelar el espectro de la ecuación 6.14 dependiendo la fase. Aquí se tuvo en cuenta lo observado por Madariaga (1976), en cuyo trabajo concluye que la frecuencia corner asociada a la onda $\mathrm{P}$ es aproximadamente un $50 \%$ mayor a la frecuencia corner de las ondas S en la mayor parte de la esfera focal. De esta forma, para calcular los $\Omega^{\text {mod }}$ de la ecuación 6.17 se considera $f_{c}^{P}=f_{c}^{*}$ y $f_{c}^{S H}=f_{c}^{S V}=1.5 f_{c}^{*}$. La incorporación del parámetro $f_{c}^{*}$ y de su relación con las frecuencias corner de las ondas $\mathrm{P}$ y $\mathrm{S}$ tiene por objetivo introducir una restricción adicional a los espectros estimados a partir del stack, teniendo en cuenta que éste puede contener ruido residual, particularmente para eventos de baja relación señal-ruido o en el caso de contar con arreglos de pocos receptores.

Notar que en la función de costo de la ecuación 6.17 no se explicita la dependencia de ésta con $n, \gamma$ y $Q$ presente en la ecuación 6.15. Es decir, para el procesamiento de múltiples eventos observados en datos reales se optó por definir a priori el modelo a ajustar y el factor de calidad del medio, $Q$. Esta decisión se tomó teniendo en cuenta que el foco se puso en la estimación de magnitudes y no en otros parámetros 
de la fuente como el radio de las fracturas o la caída de esfuerzos y que, como se observó anteriormente, estos tres parámetros no tienen una influencia significativa en la magnitud estimada. Además, el factor de calidad debe ser aproximadamente el mismo para todos los eventos, pues es una propiedad del medio y no de cada fuente en particular. Por otra parte, y por la misma razón ya explicada, el muestreo de las frecuencias $f_{i}$ de la ecuación 6.17 se realizó de forma logarítmica, de modo tal que las diferencias de los espectros observado y calculado tengan un mayor peso en las bajas frecuencias.

Para el cálculo de los stacks utilizados para la comparación con los modelos, por su parte, se aprovecharon las localizaciones estimadas para cada uno de los eventos, de manera de poder rotar convenientemente los registros y separar las energías correspondientes a cada una de las fases en distintas componentes. Luego, el stack de cada fase observada es calculado a partir de las trazas de la respectiva componente. La Figura 6.9a muestra un ejemplo de una porción de registro que contiene un evento registrado durante un monitoreo microsísmico, del cual se tienen estimaciones de tiempos de arribo y de sus coordenadas espaciales, obtenidas mediante las estrategias desarrolladas en capítulos previos. Las ventanas indicadas en el registro corresponden a las utilizadas para el cálculo de magnitudes momento mediante las ondas $\mathrm{P}$ y S, definidas en torno a sus respectivos tiempos de arribo. En la Figura $6.9 \mathrm{~b}$ se muestran dichas ventanas temporales (notar la sincronización de los eventos de las trazas individuales) luego de la rotación al sistema radial-tangencial y los stacks correspondientes. Los paneles superiores corresponden a la onda $\mathrm{P}$ y los inferiores a la onda S. Por su parte, la Figura 6.9c muestra los espectros de amplitud de los stacks (curvas negras) y los modelos ajustados con la técnica descripta (curvas rojas) para las ondas P (arriba) y S (abajo).

\subsubsection{Resultados}

Se aplicó la herramienta desarrollada en datos de campo. En el siguiente ejemplo se muestra lo obtenido para una etapa (de aproximadamente 7 horas de duración) de un proceso de fracturación hidráulica. Se trata del mismo conjunto de datos que fue localizado en el Capítulo 5, Sección 5.3. Los resultados se ilustran en la Figura 6.10, en la que la escala de colores indica las magnitudes momento de los eventos. Una serie de consideraciones fueron necesarias previas al cálculo de las magnitudes para este juego de datos. En primer lugar, si bien las especificaciones de los instrumentos con los que se registraron las señales garantizaban una respuesta plana del mismo en el rango de frecuencias de interés, no se conocía con seguridad la ganancia que estos aplicaron a los datos disponibles. En consecuencia, se realizó una calibración del programa a partir de eventos del mismo conjunto de datos de los cuales se conocían sus magnitudes para hallar el factor multiplicativo que permite que las amplitudes del dato y de los modelos sean comparables. Por otra parte, se asumió un valor del factor de calidad $Q=100$ tanto para las ondas $\mathrm{P}$ como para las $\mathrm{S}$ y un valor de $\gamma=2$, es decir, un modelo de Boatwright. Estos dos valores fueron puestos a prueba por medio de la repetición de la optimización para distintos valores de $Q$ y para $\gamma=1$, donde se observó que 

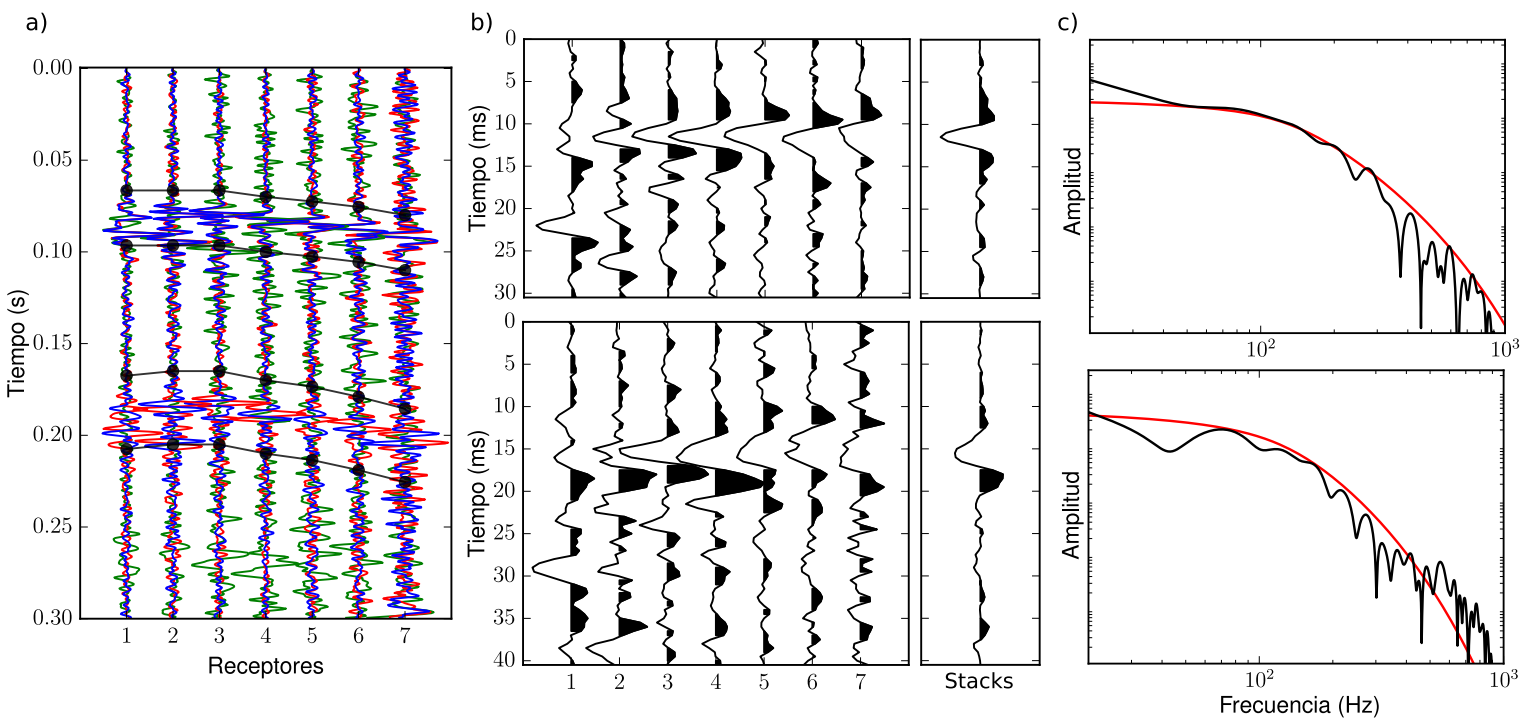

Figura 6.9. a) Ejemplo de un evento real y las correspondientes ventanas consideradas para el cálculo de magnitudes momento. b) Ondas P y S contenidas en las componentes radial (arriba) y tangencial (abajo) respectivamente y stacks de cada una. c) Ajuste de modelos (rojo) al espectro de los stacks (negro).

los ajustes fueron mejores para los valores asumidos. A partir de los datos de pozo disponibles y el modelo de velocidades calibrado se asumieron valores promedio de densidad, $\rho=2400 \mathrm{~kg} / \mathrm{m}^{3}$, y de velocidad, $v_{p}=3300 \mathrm{~m} / \mathrm{s}$ y $v_{s}=1900 \mathrm{~m} / \mathrm{s}$. Además, se consideraron ventanas temporales de $30 \mathrm{~ms}$ para la onda $\mathrm{P}$ y $40 \mathrm{~ms}$ para la onda S. La comparación de los espectros se realiza desde los $20 \mathrm{~Hz}$ hasta la frecuencia de Nyquist (1000 Hz). El cálculo de magnitudes momento con la herramienta desarrollada, ejecutada en una computadora personal estándar, requirió menos de 3 minutos para este ejemplo.

\subsection{Discusión}

A partir de la bibliografía disponible sobre el tema, las múltiples pruebas realizadas y, especialmente a través del trabajo llevado a cabo con datos reales, se realizaron algunas observaciones que merecen ser mencionadas.

La estimación de magnitudes momento de eventos microsísmicos, para la cual existen diversas estrategias tanto en el dominio del tiempo como en el de la frecuencia más allá del enfoque propuesto en esta Tesis, requiere de la realización de una importante cantidad de aproximaciones. Cada software utilizado por las diferentes compañías de servicios geofísicos puede considerar diferentes bases, realizar el cálculo con una u otra fase, y dar lugar a valores muy diferentes de magnitudes momento para un mismo conjunto de datos (Shemeta y Anderson, 2010). Entre las aproximaciones necesarias, que fueron mencionadas a lo largo de este capítulo, se encuentran las expresiones 

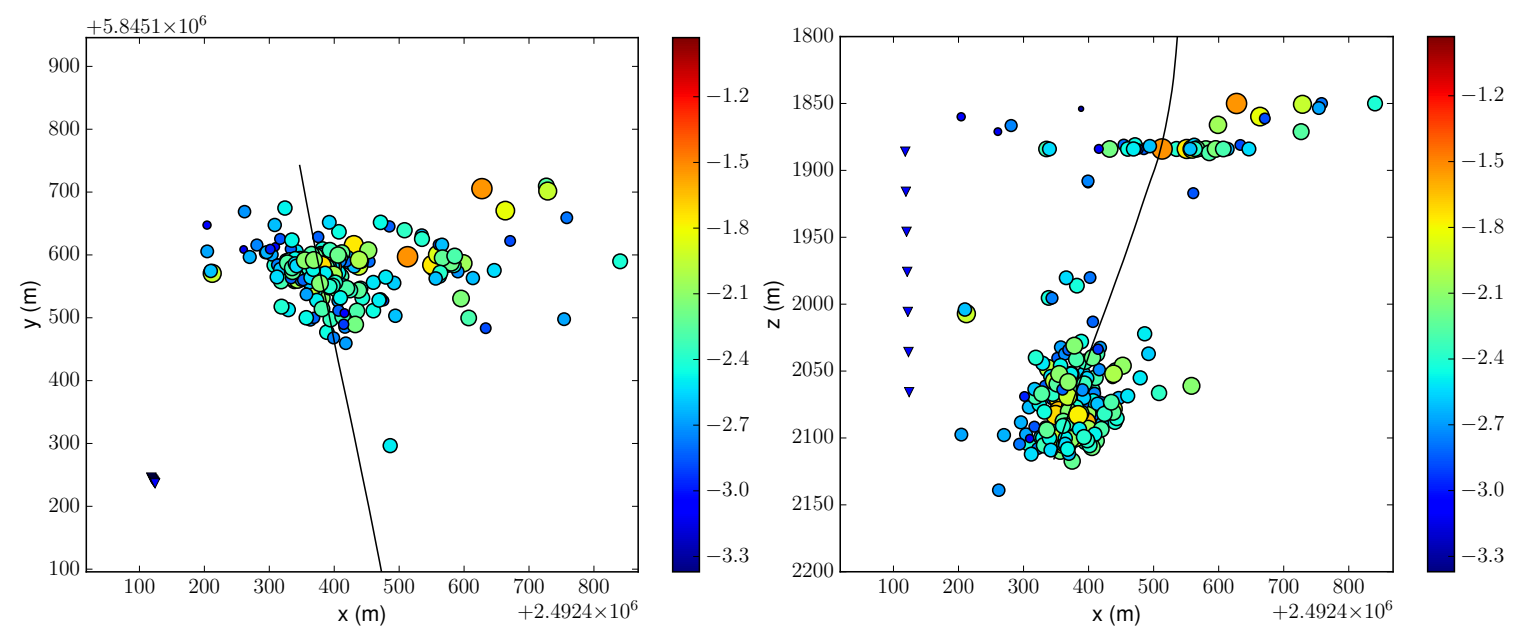

Figura 6.10. Magnitudes momento estimadas para los eventos correspondientes a una etapa de fractura.

matemáticas que constituyen la base teórica de la estimación de magnitudes, como las ecuaciones 6.1 o 6.10 que surgen de considerar medios homogéneos. Además, el factor correspondiente al patrón de radiación $R(\theta, \phi)$ es reemplazado por un promedio estimado para toda la esfera focal. La cantidad de receptores limita la efectividad del cálculo del stack para reducir la contribución del ruido al espectro de las señales. Esto puede tener un efecto importante en particular en la estimación de la frecuencia corner para eventos con baja relación señal ruido, pues la amplitud de la señal para esas frecuencias puede ser menor a la del ruido. Por otra parte, otro efecto vinculado a la adquisición tiene que ver con que la respuesta exacta de los instrumentos utilizados para registrar no siempre es bien conocida y, más aún, puede modificarse significativamente para diferentes temperaturas o de acuerdo a las condiciones del pozo (Jiao et al., 2014; Shemeta y Anderson, 2010). Esto da lugar a la necesidad de realizar algún tipo de calibración de las amplitudes registradas para poder llevar a cabo los ajustes de espectros. Sin embargo, los valores de magnitud momento en un conjunto de eventos respeta un "orden" relativo, es decir aquellos eventos más energéticos presentan valores más grandes de magnitud y viceversa, más allá del valor absoluto de magnitud estimado para cada uno de ellos. En resumen, salvo en el caso en que pueda realizarse una calibración a partir de un evento de magnitud conocida, es conveniente interpretar a los valores obtenidos para las magnitudes momento de un conjunto de eventos microsísmicos como "magnitudes relativas" en lugar de "magnitudes absolutas". Los valores estimados de magnitud momento de un conjunto eventos están atados a una serie de suposiciones que deben ser tenidas en cuenta al momento de interpretarlos o de considerarlos para cálculos posteriores, independientemente de la estrategia por la que se haya optado para su cálculo. 


\subsection{Conclusiones}

Se realizó el cálculo de magnitudes momento $M_{w}$ por medio del ajuste de espectros de amplitud. Con este fin, se combinó la información de las distintas trazas por medio de un stack lineal, lo cual permitió reducir la contribución del ruido a los errores en las magnitudes obtenidas y reducir el tiempo de cálculo. Para la optimización se propuso utilizar VFSA aprovechando las virtudes del algoritmo en la resolución eficiente de problemas de optimización no lineales.

Por medio de ejemplos pseudo-sintéticos y un ejemplo real se comprobó, por un lado, la utilidad del algoritmo VFSA en la estimación de múltiples parámetros que caracterizan al modelo del espectro de los datos. Por otro lado, se observó que los valores de magnitud momento estimados no son significativamente sensibles a los parámetros que gobiernan el comportamiento de los espectros a altas frecuencias a pesar de que éstos afectan las estimaciones de $\Omega_{0}$. Las diferencias entre los valores de magnitud momento obtenidos en los diferentes casos se encuentran dentro de los errores que pueden obtenerse producto de otros factores $\left(R P_{c}\right.$, longitud de la ventana temporal, etc.), algunos de los cuales no pueden controlarse al momento del procesamiento (por ejemplo, la cantidad de receptores disponibles).

A partir de las observaciones anteriores y luego de disponer de estrategias confiables para el procesamiento previo al cálculo de magnitudes (detección de eventos, picado de tiempos de arribo, localización), las herramientas para el cálculo de magnitudes fueron adaptadas para el procesamiento automático de grandes volúmenes de datos. Se logró desarrollar una herramienta automática para el cálculo de magnitudes momento a través del ajuste de espectros de amplitud mediante VFSA. Luego de las correspondientes correcciones asociadas a la respuesta del instrumento y de la evaluación de las características del medio, éstas permiten realizar el cálculo de magnitudes momento en datos de campo de forma rápida (algunos minutos en una computadora personal estándar) y robusta ante situaciones de relaciones señal-ruido desafiantes, superadas por la utilización del stack de los datos.

De acuerdo a lo observado mediante los ejemplos pseudo-sintéticos, el comportamiento de los espectros a altas frecuencias y los modelos considerados para su ajuste requieren un análisis más profundo si se desea realizar la estimación de otros parámetros de la fuente, como el radio de la microfractura o la caída de esfuerzos asociada a ésta. No obstante, la evaluación de diferentes parámetros para caracterizar el comportamiento a altas frecuencias propio de cada juego de datos puede ser llevada a cabo sin mayores dificultades dado el breve tiempo de cálculo requerido por la herramienta desarrollada para la estimación de magnitudes. 


\section{Capítulo 7}

\section{Conclusiones}

\section{Conclusiones generales}

El objetivo principal de este trabajo de investigación y desarrollo era la generación de herramientas que contribuyan a las tecnologías vinculadas al monitoreo de los costosos procesos asociados a la fracturación hidráulica en reservorios no convencionales en la República Argentina. Las herramientas desarrolladas que se presentan en esta Tesis permiten llevar a cabo el procesamiento de las señales microsísmicas en su totalidad y/o la supervisión o control de los resultados parciales de procesamientos hechos por terceros. Por consiguiente, el objetivo principal se ha alcanzado satisfactoriamente.

Los desarrollos que aquí se describieron se llevaron a cabo considerando la geometría de adquisición más frecuentemente utilizada, dada por arreglos de receptores ubicados en pozos aproximadamente verticales y a la profundidad de la zona de tratamiento. No obstante, la aplicación de las estrategias presentadas pueden extenderse a otras geometrías, como el caso de pozos inclinados y horizontales, o arreglos dispuestos en superficie.

Las tareas desarrolladas consistieron en la modificación de herramientas preexistentes y el desarrollo de estrategias nuevas, con su correspondiente implementación computacional (códigos en lenguajes Fortran o Python) que permitieran realizar el procesamiento de las señales microsísmicas mediante métodos alternativos a los utilizados comúnmente por los softwares comerciales. En efecto, se dispone ahora de herramientas para la orientación de sensores microsísmicos de pozo, calibración de modelos de velocidades anisótropos a partir de los tiempos de arribo de fuentes de posición conocida, la detección automática de eventos en registros microsísmicos, el análisis de polarización de las ondas registradas con el fin de estimar la dirección de procedencia de las mismas, la localización espacio-temporal de las fuentes microsísmicas y el cálculo de las magnitudes momento asociadas. Todas las herramientas desarrolladas fueron ampliamente testeadas con datos sintéticos y aplicadas luego al procesamiento de datos reales provistos por la industria con resultados satisfactorios. 


\section{Capítulo 3}

En el Capítulo 3, por un lado, se introdujo una estrategia basada en la energía de las señales procedentes de punzados, registradas en sensores de pozo, que permite hallar los ángulos de orientación de dichos sensores de una forma sencilla a partir del conocimiento de las posiciones de los punzados y de los ángulos de inclinación y acimut del pozo en los niveles en los que se ubican los sensores. Mediante ejemplos con datos sintéticos y de campo, con diferentes condiciones de ruido, se mostró que ésta resulta una estrategia robusta que requiere una mínima intervención del usuario, asociada exclusivamente al picado de los tiempos de arribo de las señales y a eventuales correcciones de polaridad. La orientación de los sensores permite rotar convenientemente los registros para referirlos luego a un sistema de coordenadas adecuado, lo cual resulta imprescindible para la ubicación espacial de los eventos registrados.

Por otra parte, se describió un método para llevar a cabo la calibración de modelos de velocidades. Partiendo de modelos de velocidades extraídos de perfiles de pozo y considerando los tiempos de arribo y las posiciones de fuentes conocidas, el método permite obtener modelos anisótropos VTI, en los que además se considera la litología de las formaciones como una restricción para el cálculo de los parámetros de anisotropía. La estrategia, que consiste en hallar las velocidades y parámetros de anisotropía que mejor expliquen los tiempos de arribo observados, se resuelve por medio del algoritmo VFSA que permite alcanzar una solución de forma rápida y confiable. La calidad de la solución obtenida queda demostrada por la localización de los punzados con el modelo de velocidades obtenido, que conduce a posiciones cercanas a las conocidas para cada fuente. Estas resultan significativamente mejores que las posiciones que se obtienen de considerar el modelo inicial obtenido de los datos del pozo, o modelos calibrados sin ningún tipo de consideración en relación a la anisotropía del medio. Estas dos tareas constituyen los primeros pasos que necesariamente deben llevarse a cabo con el propósito de procesar señales microsísmicas.

\section{Capítulo 4}

En el Capítulo 4 se describió una estrategia de detección que tiene por objetivo aislar porciones del gran volumen de datos que se registran durante un monitoreo microsísmico que contengan información valiosa asociada a la presencia de eventos microsísmicos. Para ello, se adecuaron estrategias preexistentes al procesamiento de datos en formato SEG-Y y se estableció un criterio adicional de detección mediante el cual se declara un evento cuando pueden distinguirse las fases $\mathrm{P}$ y S asociadas al mismo. La estrategia fue testeada en datos sintéticos alcanzando un alto porcentaje de éxito y fue utilizada para la detección de eventos en datos de campo con resultados satisfactorios.

Por otra parte, se describieron los métodos de picado de tiempos de arribo disponibles, y las estrategias de estimación del backazimuth que fueron implementadas computacionalmente y evaluadas durante la realización de este trabajo. En particular, se describe la modificación llevada a cabo sobre una de las estrategias de picado de 
tiempos de arribo, basada en el reconocimiento de patrones. Ésta consiste en estimar de manera simultánea los tiempos de arribo de ambas fases $\mathrm{P}$ y S y el backazimuth del evento. Es decir, esta estrategia permite obtener en un único procedimiento, la información de cada evento necesaria para llevar a cabo la localización. El criterio considerado en este caso asume un arreglo de receptores aproximadamente lineal y arroja como resultado un único backazimuth para el conjunto de receptores. Las otras estrategias implementadas brindan un valor de este ángulo para cada uno de los receptores disponibles. Se propuso, en consecuencia, una estrategia de eliminación de valores atípicos basada en el cálculo de la desviación absoluta de las observaciones respecto de su mediana (DAM), que logra reducir significativamente la incertidumbre en la estimación del backazimuth, que se traduce en la reducción de la principal fuente de incertidumbres en la localización.

\section{Capítulo 5}

Los tiempos de arribo de las distintas fases asociadas a un evento microsísmico, su correspondiente backazimuth y un modelo de velocidades apropiado, que pueden obtenerse mediante las técnicas descriptas en los Capítulos 3 y 4, constituyen la información necesaria para llevar a cabo la localización del evento. En el Capítulo 5 se describe, en primer lugar, un flujo de procesamiento que conduce a la localización de eventos microsísmicos concatenando las distintas etapas del procesamiento, en el cual se consideraron datos sintéticos y que fue el primer paso en la evaluación de los dos algoritmos de optimización globales utilizados, VFSA y PSO, como métodos alternativos al tradicional Grid Search. Las pruebas realizadas mostraron la gran eficiencia computacional de los primeros en comparación con el último, en particular para el caso de VFSA. Se mostró además, la importancia de la estimación del backazimuth en la restricción del espacio de posibles soluciones tanto para la reducción de incertidumbres como para la aceleración de la convergencia de los algoritmos de optimización.

Por otra parte, los códigos computacionales fueron posteriormente adaptados en respuesta a las necesidades que surgieron frente al tratamiento de datos de campo. Los cambios principales consistieron en la consideración de una nueva función de costo que permite estimar en simultáneo el tiempo de origen y las coordenadas espaciales de la fuente y reduce las incertidumbres en la coordenada $z$ de los eventos. Asímismo, esta función de costo permite la inclusión de modelos de velocidades más complejos al cálculo, para lo cual se contempló un trazado de rayos para la obtención de los tiempos de viaje. Los resultados obtenidos para datos de campo registrados en la Formación Vaca Muerta muestran que el planteo del problema y los algoritmos considerados para su resolución constituyen una herramienta útil y confiable para la localización de eventos microsísmicos. Las incertidumbres de las soluciones alcanzadas, que fueron estimadas mediante las correspondientes elipses de error, se encuentran dentro de las esperadas de acuerdo a la bibliografía consultada. 


\section{Capítulo 6}

Toda la información disponible sobre cada uno de los eventos y del medio entre éstos y los receptores forma parte de la información necesaria para el cálculo de magnitudes momento, como se describió en el Capítulo 6. En éste, se realizó la estimación de magnitudes momento en el dominio de la frecuencia, por medio del ajuste de los espectros de amplitud de los stacks de las trazas a modelos teóricos que involucran información del medio y de las posiciones relativas entre fuentes y receptores. El ajuste fue llevado a cabo por medio de VFSA, cuyo rendimiento fue puesto a prueba a través de ejemplos pseudo-sintéticos y el procesamiento de una etapa completa del monitoreo de un proceso estimulación hidráulica, evaluando los resultados de realizar el ajuste sobre distintos juegos de parámetros y su influencia sobre las magnitudes estimadas. La metodología propuesta se adaptó para el procesamiento automático de grandes cantidades de eventos detectados en datos de campo, dando lugar a magnitudes momento estimadas a partir de combinar la información de todas las fases disponibles.

\subsection{Contribuciones científicas}

Las herramientas presentadas en esta Tesis han sido evaluadas mediante diferentes ejemplos con datos sintéticos y datos de campo registrados en procesos de fracturación hidráulica en la Formación Vaca Muerta. Los correspondientes resultados han sido presentados de forma parcial o total en diversas publicaciones. Durante el desarrollo del plan de Tesis se escribieron 3 artículos (1 publicado, 2 en prensa) en revistas de circulación internacional con referato (2 de ellos con primera autoría), y 7 trabajos presentados en congresos científicos nacionales e internacionales (4 como primer autor), de los cuales 4 fueron trabajos completos.

En particular, la estrategia de orientación de sensores de pozo basada en la energía de las señales correspondientes a fuentes de posiciones conocidas que se describe en el Capítulo 3, Sección 3.2, fue publicada en la revista de circulación internacional Journal of Geophysics and Engineering (Lagos y Velis (2019), versión digital disponible).

Las distintas etapas en el desarrollo de la herramienta de calibración de modelos de velocidades que se introduce en el Capítulo 3, Sección 3.3, fueron presentadas en la IPSES'17-XXVIII Reunión Científica de la Asociación Argentina de Geofísicos y Geodestas (Pérez et al., 2017), como resumen expandido en la 88th Society of Exploration Geophysicists International Exhibition and Annual Meeting (Pérez et al., 2018), en la revista Mecánica Computacional (Pérez et al., 2016), y por medio de un trabajo que ha sido aceptado para su publicación en la revista de circulación internacional Journal of Seismic Exploration (Pérez et al. (2019), publicación estimada para mediados de 2019). Mi participación en el desarrollo de esta herramienta, que fue realizada a modo de colaboración con el trabajo del Dr. Pérez, se basó en el estudio de la bibliografía disponible en el tema, la manipulación de los datos reales (aplicación de las estrategias de detección de eventos y picado de tiempos de arribo de los punzados, orientación de los sensores, generación de modelos de velocidades iniciales a partir de perfiles sónicos), 
además de las discusiones pertinentes y la colaboración en la redacción de los trabajos mencionados.

El análisis de polarización de ondas, presentado en el Capítulo 4 y en particular su importancia en la localización de eventos microsísmicos fue presentado en la XXVII Reunión Científica de la Asociación Argentina de Geofísicos y Geodestas (Lagos y Velis, 2014). Los resultados de la localización de eventos microsísmicos por medio de los algoritmos VFSA y PSO y la secuencia de procesamiento automática propuesta en el Capítulo 5, Sección 5.2, fueron presentados como resumen expandido en la 84th Society of Exploration Geophysicists International Exhibition and Annual Meeting (Lagos et al., 2014) y publicados en la revista de circulación internacional Journal of Applied Geophysics (Lagos y Velis, 2018).

Por su parte, la estrategia de estimación de magnitudes momento introducida en el Capítulo 6 fue presentada en la IPSES'17-XXVIII Reunión Científica de la Asociación Argentina de Geofísicos y Geodestas (Lagos y Velis, 2017a), y como trabajo completo en la XVII Reunión de Trabajo en Procesamiento de la Información y Control (Lagos y Velis, 2017b).

\subsection{Contribuciones tecnológicas y desarrollos}

Las herramientas desarrolladas han sido transferidas al sector productivo en el marco del Convenio técnico específico firmado entre la Universidad Nacional de La Plata e YPF Tecnología S.A. que se desarrolló entre los años 2016 y 2018. Además de la escritura de diversos capítulos en los correspondientes Reportes Técnicos del convenio, se entregaron los códigos computacionales desarrollados para ser utilizados por la empresa.

Las estrategias descriptas a lo largo de este trabajo de Tesis fueron en su gran mayoría implementadas computacionalmente como códigos en lenguaje Fortran 95/2003. Además, se implementaron herramientas auxiliares de manipulación de datos, visualización o picado manual de tiempos de arribo, entre otras, principalmente en lenguaje Python. Entre los principales códigos desarrollados se encuentran:

- Código en lenguaje Fortran para el cálculo de los ángulos de orientación de sensores a partir de la energía de las señales correspondientes a fuentes de posición conocida, y de la información de inclinación y acimut del pozo de monitoreo.

- Código en lenguaje Fortran para aplicar las correspondientes rotaciones a registros SEG-Y a los sistemas de coordenadas geográfico o radial-tangencial-vertical.

- Códigos en lenguaje Fortran para la detección de eventos microsísmicos con identificación automática de las ondas P y S. Este código, además, hace uso de modificaciones a subrutinas preexistentes que implementan la estrategia multitraza de Sabbione y Velis (2013), que fueron adaptadas para el tratamiento de registros SEG-Y. 
- Códigos en lenguaje Fortran que implementan las distintas herramientas para análisis de polarización descriptas en el Capítulo 4.

- Códigos en lenguaje Fortran para la obtención de tiempos de arribo de las ondas P y S y estimación simultánea de backazimuth, basado en el código desarrollado por el director de esta Tesis para la detección de fases por reconocimiento de patrones (Velis et al., 2015).

- Código en lenguaje Fortran que implementa el algoritmo Particle Swarm Optimization.

- Código en lenguaje Fortran para la estimación de magnitudes momento.

- Código en lenguaje Fortran para el trazado de rayos en medios estratificados anisótropos, que fue luego modificado por el Dr. Daniel Pérez.

- Códigos auxiliares en lenguaje Python para llevar a cabo la determinación manual de tiempos de arribo, el cálculo de las incertidumbres en la localización y definición de las correspondientes elipses de error, la eliminación de valores atípicos en las estimaciones de backazimuth para cada receptor de forma individual, y la visualización y manipulación de registros en formato SEG-Y. 


\section{Apéndice A}

\section{Trazado de rayos}

El trazado de rayos que aquí se describe se implementó con el fin de calcular tiempos de viaje de señales microsísmicas propagándose por medios estratificados con anisotropía VTI. El código desarrollado fue utilizado para el cálculo de los tiempos de viaje necesarios para la calibración de modelos de velocidades y la localización de eventos microsísmicos.

El tiempo de viaje de una onda sísmica propagándose por un medio estratificado de $N$ capas como el de la Figura A.1, puede ser calculado como la suma de los tiempos de viaje en cada capa, a lo largo de los segmentos que conforman el rayo sísmico:

$$
t(\mathbf{x})=\sum_{k=1}^{N} \frac{x_{k+1}-x_{k}}{v_{k} \sin \phi_{k}},
$$

donde $\mathbf{x}$ es el vector que contiene a las coordenadas horizontales $x_{k}$, que corresponden a las intersecciones del rayo con las interfases del medio estratificado. Los ángulos $\phi_{k}$ indican la dirección del rayo en cada capa respecto de la vertical (normal a las interfases, definidos por las coordenadas de las intersecciones del rayo en el techo y la base de la capa) y $v_{k}$ es la velocidad de propagación de las ondas en la capa.

En el caso de un medio con anisotropía VTI, las velocidades en el $k$-ésimo tramo del rayo sísmico dependen del correspondiente ángulo $\phi_{k} \mathrm{y}$ por lo tanto de las coordenadas del vector x. Además, una fuente tiene tres rayos asociados, correspondientes a las ondas P, SV y SH. Las velocidades correspondientes a los mencionados rayos en la $k$-ésima capa de un medio estratificado con anisotropía VTI pueden aproximarse por (Thomsen, 1986):

$$
\begin{aligned}
v_{k}^{P}\left(\phi_{k}\right) & =v_{k}^{P_{0}}\left(1+\delta_{k} \sin ^{2} \phi_{k} \cos ^{2} \phi_{k}+\varepsilon_{k} \sin ^{4} \phi_{k}\right), \\
v_{k}^{S V}\left(\phi_{k}\right) & =v_{k}^{S_{0}}\left(1+\left(\frac{v_{k}^{P_{0}}}{v_{k}^{S_{0}}}\right)^{2}\left(\varepsilon_{k}-\delta_{k}\right) \sin ^{2} \phi_{k} \cos ^{2} \phi_{k}\right), \\
v_{k}^{S H}\left(\phi_{k}\right) & =v_{k}^{S_{0}}\left(1+\gamma_{k} \sin ^{2} \phi_{k}\right),
\end{aligned}
$$


donde $v_{k}^{P_{0}}$ y $v_{k}^{S_{0}}$ corresponden a las velocidades verticales de las ondas $\mathrm{P}$ y $\mathrm{S}$ y $\varepsilon_{k}, \delta_{k} \mathrm{y}$ $\gamma_{k}$, conocidos como parámetros de Thomsen, caracterizan la anisotropía de la capa $k$.

Dadas las posiciones de una fuente y un receptor en un dado modelo de velocidades, las intersecciones del rayo sísmico con las diferentes interfases del medio son desconocidas y, por lo tanto, también lo son los ángulos $\phi_{k}$, de manera que el cálculo del tiempo de viaje se vuelve un problema complejo cuya resolución requiere la aplicación de métodos no lineales de optimización. Para ello, es necesario tomar en consideración que el rayo sísmico debe satisfacer el Principio de Fermat, según el cual la variación de primer orden del tiempo de viaje respecto del camino recorrido debe ser estacionaria. Para las geometrías consideradas en esta Tesis, esto significa que el tiempo de propagación entre fuente y receptor dado por la ecuación A.1 debe ser mínimo.

En esta Tesis se planteó el trazado de rayos en medios estratificados con anisotropía VTI como un problema de valores de contorno. Es decir, dados el punto inicial (la fuente) y el punto final de su trayectoria (el receptor), se modifican las coordenadas horizontales de las intersecciones del rayo con las distintas interfases buscando aquellas para las cuales el tiempo de viaje es mínimo. A modo de ejemplo, la Figura A.1 muestra un rayo cuyos puntos inicial y final tienen coordenadas horizontales $x_{1}$ y $x_{5}, \mathrm{y}$ coordenadas móviles $x_{2}, x_{3}$ y $x_{4}$. Esta estrategia de trazado de rayos se conoce como bending, y se resolvió por medio del método de gradientes conjugados, aprovechando que se tienen expresiones analíticas para todas las derivadas del tiempo de viaje en función de las coordenadas horizontales de las intersecciones, $x_{i}, i=2, \ldots, N^{1}$. En otras palabras, el problema consiste en mover las coordenadas $x_{i}$ del rayo como se indica en la Figura A.1, hasta hallar el rayo cuyo tiempo de viaje sea mínimo.

Para resolver el problema por medio del método de gradientes conjugados se hizo uso de las subrutinas disponibles en Numerical Recipes (Press et al., 1996). En particular, se utilizó la subrutina frprmn, que implementa dicho método de forma multidimensional, asumiendo que la función de interés, $f(\mathbf{x})$, puede ser aproximada por una forma cuadrática

$$
f(\mathbf{x}) \approx f\left(\mathbf{x}_{0}\right)+\vec{\nabla} f\left(\mathbf{x}_{0}\right) \mathbf{x}+\frac{1}{2} \mathbf{x}^{T} H\left(\mathbf{x}_{0}\right) \mathbf{x}
$$

en un entorno del mínimo $\mathbf{x}_{0}$, donde $H\left(\mathbf{x}_{0}\right)$ corresponde a la matriz Hessiana de la función $f(\mathbf{x})$ en el punto $\mathbf{x}_{0}$. La subrutina frprmn implementa la versión FletcherReeves-Polak-Ribiere del algoritmo, que permite prescindir del conocimiento de la matriz Hessiana y es apropiada para el caso en que la función de interés no corresponde exactamente a una forma cuadrática. Además, resuelve el problema por medio de una serie de minimizaciones unidimensionales (a cargo de la función auxiliar linmin) a lo largo de direcciones generadas de manera recursiva, mediante la evaluación del vector gradiente, $\vec{\nabla} f\left(\mathbf{x}_{k}\right)$, en los sucesivos puntos $\mathbf{x}_{k}$, donde $k$ corresponde al número de iteración. Además de la ya mencionada función linmin y entre otras funciones auxiliares, la subrutina frprmn requiere funciones que calculen el valor de $f(\mathbf{x})$ y $\vec{\nabla} f(\mathbf{x})$

\footnotetext{
${ }^{1}$ De acuerdo a la notación empleada, $i=1$ corresponde a la fuente, mientras que $i=N+1$ corresponde al receptor.
} 


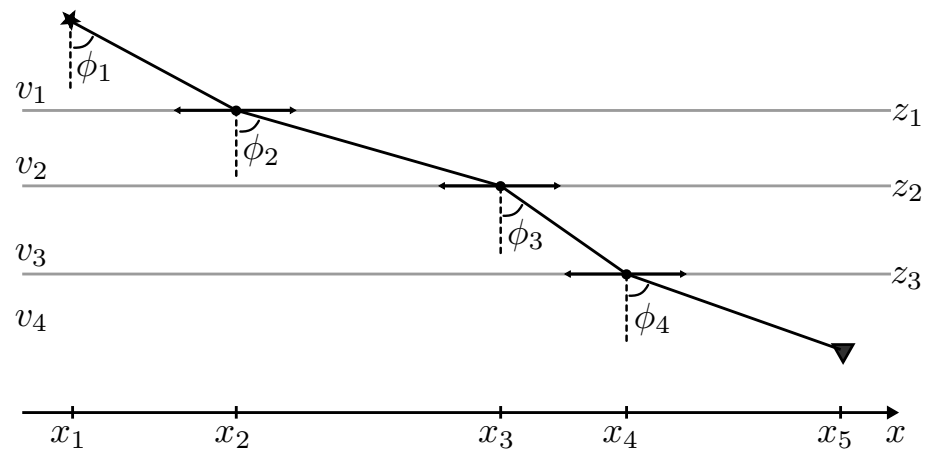

Figura A.1. Rayo sísmico para una onda propagándose entre una fuente y un receptor. El rayo óptimo se obtiene modificando las coordenadas horizontales (bending) de las intersecciones del rayo con las interfases del medio hasta cumplir el principio de Fermat.

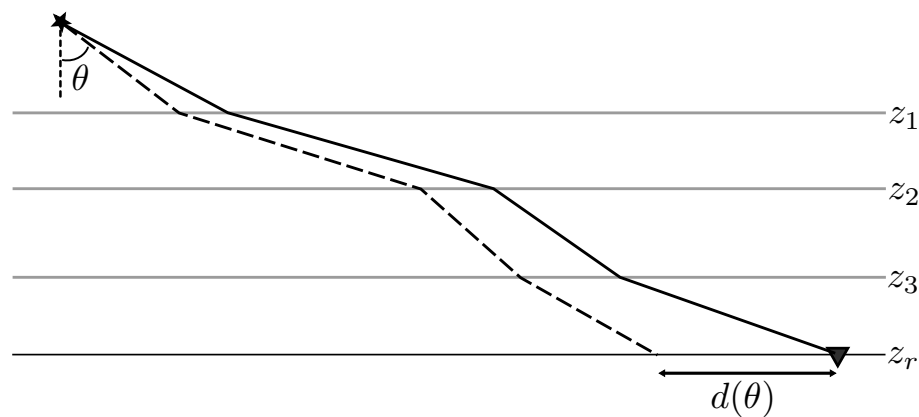

Figura A.2. Shooting para el cálculo de una aproximación inicial del rayo sísmico.

en los puntos $\mathbf{x}_{k}$. En el caso del trazado de rayos que se desea resolver, la función $f(\mathbf{x})$ corresponde al tiempo de viaje $t(\mathbf{x})$ de la ecuación A.1. Por su parte, la $i$-ésima componente del vector gradiente $\vec{\nabla} f(\mathbf{x})$ está dada por la derivada parcial de la función $f(\mathbf{x})$ respecto de la coordenada $x_{i}, i=2, \ldots, N$, que tiene la forma

$$
\frac{\partial t}{\partial x_{i}}=\frac{\partial}{\partial x_{i}}\left[\frac{x_{i}-x_{i-1}}{v_{i-1} \sin \phi_{i-1}}+\frac{x_{i+1}-x_{i}}{v_{i} \sin \phi_{i}}\right]
$$

y cuyo cálculo involucra la derivación de las velocidades de las ecuaciones A.2 y de los ángulos $\phi_{i}$ y $\phi_{i-1}$, que también son funciones de la coordenada $x_{i}$.

Para asegurar la convergencia del método de gradientes conjugados es necesaria una buena aproximación inicial. Si asumimos que la anisotropía no es muy fuerte, una buena aproximación estaría dada por un rayo propagándose entre los mismos puntos asumiendo un medio isótropo. Una forma sencilla de calcular el rayo inicial es por medio de un shooting: un problema de valores iniciales en el que se busca cuál es el ángulo de partida (desde la fuente) que permite alcanzar el receptor. El problema de encontrar la aproximación inicial fue, en principio, planteado de esta 


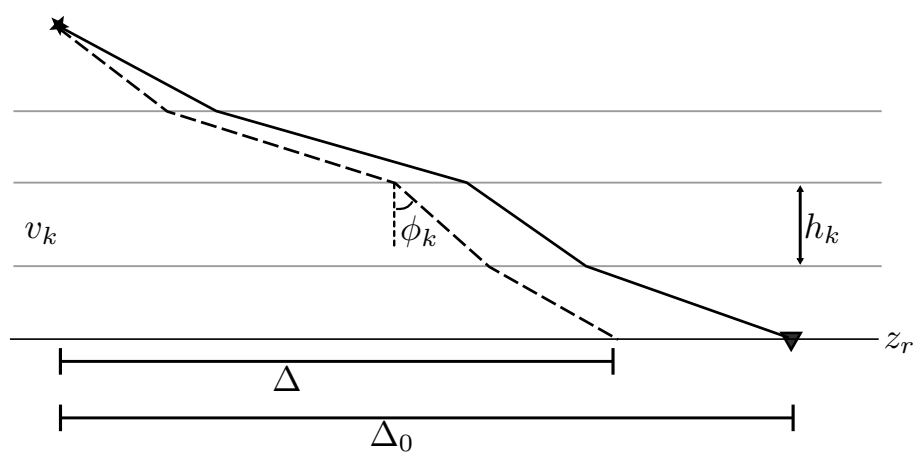

Figura A.3. Cálculo de la aproximación inicial del rayo sísmico según Yue y Xiao-fei (2005).

manera, aprovechando el hecho de que el cálculo es directo dada la isotropía supuesta. De acuerdo a lo ilustrado en la Figura A.2, el rayo inicial se obtiene buscando de forma exhaustiva el ángulo $\theta$ para el cual la distancia $d$, medida en dirección horizontal entre el rayo y el receptor a la profundidad de éste, es mínima. En la medida en que se fueron considerando modelos más complejos, se observó que este planteo del rayo inicial tenía un comportamiento inestable y computacionalmente costoso ante situaciones de capas delgadas, principalmente. En consecuencia, se consideraron los cambios en el código propuestos por el Dr. Daniel Pérez, basados en el trabajo realizado por Yue y Xiao-fei (2005), que se describen a continuación.

Un corolario del principio de Fermat es la llamada Ley de Snell, según la cual la refracción de un rayo en una interfase entre dos medios de velocidades diferentes se caracteriza por la relación:

$$
\frac{\sin \phi_{1}}{v_{1}}=\frac{\sin \phi_{2}}{v_{2}},
$$

donde $\phi_{1}$ y $\phi_{2}$ corresponden a los ángulos de los rayos respecto de la dirección normal a la interfase. De esta manera, teniendo en cuenta que la relación debe respetarse en cada interfase atravesada por el rayo, es posible caracterizar toda su trayectoria por medio del denominado parámetro del rayo:

$$
p=\frac{\operatorname{sen} \phi}{v} .
$$

La distancia horizontal recorrida por un rayo hasta alcanzar la profundidad del receptor, de acuerdo a la Figura A.3 está dada por:

$$
\Delta=\sum_{k=1}^{N} h_{k} \tan \phi_{k}=\sum_{k=1}^{N} \frac{p v_{k} h_{k}}{\cos \phi_{k}}=p \sum_{k=1}^{N} \frac{h_{k} v_{k}}{\sqrt{1-p^{2} v_{k}^{2}}}
$$


donde $h_{k}$ corresponde al espesor de la $k$-ésima capa. Entonces, el problema de hallar el rayo isótropo puede plantearse considerando la función

$$
f(p)=p \sum_{k=1}^{N} \frac{h_{k} v_{k}}{\sqrt{1-p^{2} v_{k}^{2}}}-\Delta_{0}
$$

donde $\Delta_{0}$ es la distancia horizontal entre fuente y receptor, y luego hallar $p$ tal que $f(p)=0$. Esto puede resolverse de forma eficiente por medio del método de Newton, de manera iterativa:

$$
p_{i+1}=p_{i}-\frac{f\left(p_{i}\right)}{f^{\prime}\left(p_{i}\right)}
$$

Sin embargo, este planteo se torna inestable cuando $\phi_{1} \approx \pi / 2$. Por este motivo, Yue y Xiao-fei (2005) introducen una nueva variable $q$ que se vincula con $p$ de acuerdo a

$$
p=\frac{q}{v_{M} \sqrt{h_{M}^{2}+q^{2}}} .
$$

Dado un rayo de parámetro $p, q$ corresponde a la distancia horizontal que éste recorre en la capa que presenta mayor velocidad $\left(v_{M}\right)$. De esta forma, la ecuación A.8 se transforma en

$$
F(q)=\Delta(q)-\Delta_{0}
$$

con

$$
\Delta(q)=q \sum_{k=1}^{N} \frac{v_{k} h_{k}}{v_{M} \sqrt{h_{M}^{2}+\left(1-v_{k}^{2} / v_{M}^{2}\right) q^{2}}} .
$$

La ecuación $F(q)=0$ puede resolverse mediante el método de Newton, calculando de manera iterativa:

$$
q_{i+1}=q_{i}-\frac{F(q)}{F^{\prime}(q)}
$$

La función $\Delta(q)$ tiene buen comportamiento y su derivada $d \Delta / d q$ está acotada en todo el rango de posibles ángulos de partida $\phi_{1}$, lo que permite que la solución con el método de Newton sea estable. Además, la convergencia puede acelerarse si se provee una buena estimación inicial de $q$. Para ello, los autores proponen calcular una aproximación inicial $q_{0}$ como se describe a continuación.

Si se evalúa el comportamiento de la función $\Delta(q)$, se tiene que

$$
\Delta(q) \underset{q \rightarrow 0}{\longrightarrow} q \frac{1}{h_{M}} \sum_{k=1}^{N} \frac{v_{k}}{v_{M}} h_{k}=q a,
$$

mientras que

$$
\Delta(q) \underset{q \rightarrow \infty}{\longrightarrow} q+\sum_{k=1, k \neq M}^{N} \frac{v_{k} h_{k}}{v_{M} \sqrt{1-\left(v_{k} / v_{M}\right)^{2}}}=q+b
$$



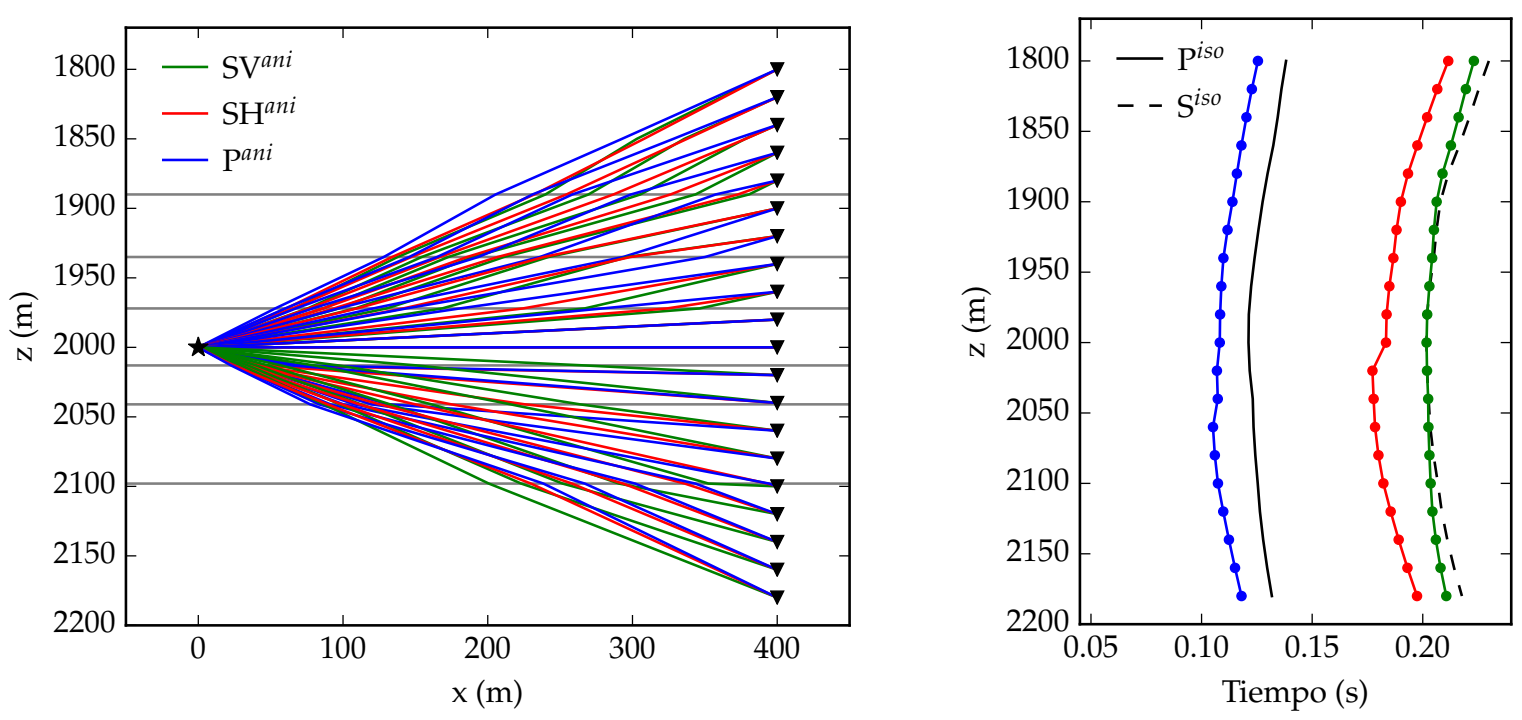

Figura A.4. Izquierda: ejemplo de trazado de rayos para un medio con anisotropía VTI y un arreglo vertical de receptores. Derecha: tiempos de arribo correspondientes a las ondas $\mathrm{P}, \mathrm{SV}$ y $\mathrm{SH}$, y para las ondas $\mathrm{P}$ y $\mathrm{S}$ de un medio isótropo de idénticas velocidades verticales.

La capa $M$ es la de mayor velocidad atravesada por el rayo en su recorrido (independientemente de su posición). Estos límites definen asíntotas de la curva $\Delta(q)$ en 0 y en $\infty$, que se intersectan en el punto

$$
\Delta_{c}=\frac{a b}{a-1}
$$

Finalmente, dada una distancia epicentral $\Delta_{0}$ se puede obtener una aproximación inicial $q_{0}$ como:

$$
q_{0}= \begin{cases}\Delta_{0} / a & \Delta_{0}<\Delta_{c} \\ \Delta_{0}-b & \Delta_{0}>\Delta_{c} .\end{cases}
$$

A modo de ejemplo, en la Figura A.4 se muestran los rayos (izquierda) y los correspondientes tiempos de arribo (derecha) calculados con la metodología descripta en este Apéndice, para el caso de un medio estratificado (7 capas) con anisotropía VTI en el rango débil, y un arreglo vertical de 20 receptores dispuestos con un espaciamiento vertical de $20 \mathrm{~m}$. Con fines comparativos se ilustran, además, los tiempos de viaje de las ondas P y S calculados asumiendo isotropía. 


\section{Apéndice B}

\section{Simulación de registros sintéticos}

En un medio elástico homogéneo, los desplazamientos para campo lejano pueden expresarse como función del tensor momento sísmico (Shearer, 2009):

$$
u_{i(P \mid S)}(\boldsymbol{x}, t)=\left(\frac{1}{4 \pi \rho c^{3}}\right)\left(\frac{1}{r}\right) R_{i j k(P \mid S)} \dot{M}_{j k}\left(t-\frac{r}{c}\right),
$$

donde $u_{i}$ es el desplazamiento registrado en la $i$-ésima componente de un receptor en un momento $t$, en una posición $\boldsymbol{x}$, y $(P \mid S)$ se refiere a ondas compresionales o de corte; $\rho$ es la densidad del medio, $c$ la velocidad de las ondas P o S, y $r$ es la distancia entre la fuente y el receptor. $R_{i j k}$ representa el patrón de radiación definido por el $j k$-ésimo elemento de la derivada del tensor momento $\dot{M}_{j k}$ en la componente $i$-ésima de un receptor, es decir, depende de la posición relativa del receptor y la fuente. Esta expresión permite obtener los desplazamientos que tendrán lugar en un punto lo suficientemente distante de la fuente, para cualquier tensor momento sísmico que represente al mecanismo focal. El patrón de radiación consiste en la distribución espacial de amplitudes alrededor de la fuente. Para una fractura de corte, el patrón de radiación de las ondas $\mathrm{P}$ y $\mathrm{S}$ tiene, en ambos casos, cuatro lóbulos y dos planos nodales en los que no ocurren desplazamientos. En el caso de las ondas P los lóbulos tienen direcciones de desplazamiento alternadas (compresiones y dilataciones). Uno de los planos nodales coincide con el plano de falla y el otro es perpendicular a éste y a la dirección de deslizamiento. Las direcciones de los lóbulos del patrón de radiación asociado a las ondas S, por otro lado, coinciden con las direcciones de deslizamiento y normal a la falla. Los patrones de radiación gobiernan las amplitudes y polaridades de las ondas P y S que se observan en los registros (Udías, 1999). Esta situación puede visualizarse en la Figura B.1, en la que se ha supuesto una fractura en el plano $\left(x_{1}, x_{2}\right)$, con deslizamiento $\Delta U$ en la dirección $x_{1}$. Los desplazamientos son máximos a $45^{\circ}$ de los planos nodales.

En los casos en los que el tensor momento sísmico es variable en el tiempo, es posible representarlo como el producto de un tensor $M_{j k}$ invariante y una función que 

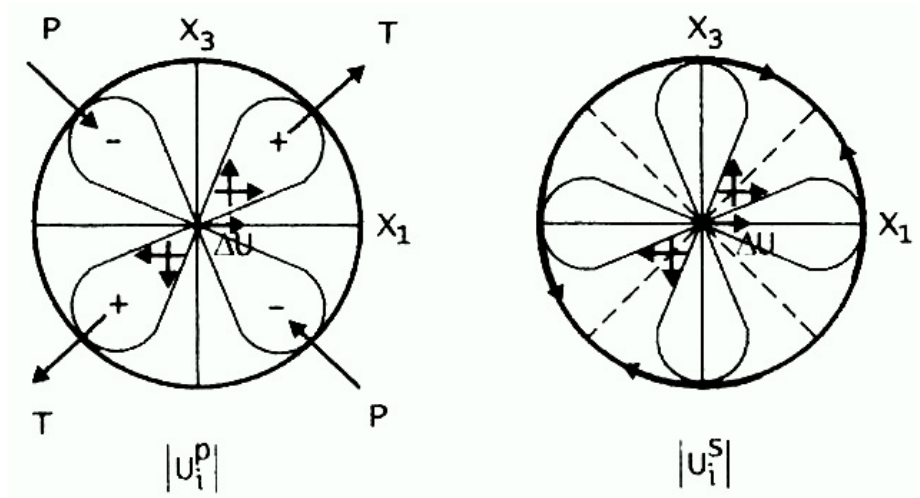

Figura B.1. Patrón de radiación en el plano $\left(x_{1}, x_{3}\right)$ debido a un cizallamiento para las ondas P (izquierda) y S (derecha). Extraído de Udías (1999).

describa la variación en el tiempo, $s(t)$ (Aki y Richards, 2002), de modo que

$$
\dot{M}_{j k}=M_{j k} \frac{d s}{d t}
$$

y, por lo tanto, la ecuación (B.1) queda

$$
u_{i(P \mid S)}(\boldsymbol{x}, t)=\left(\frac{1}{4 \pi \rho c^{3}}\right)\left(\frac{1}{r}\right) R_{i j k(P \mid S)} M_{j k} \frac{d s}{d t}\left(t-\frac{r}{c}\right) .
$$

Cuando se inyecta un material apuntalante en un material rígido se producen aperturas en la zona de infiltración, que modifican a su vez el campo de esfuerzos mas allá de esta región dando lugar a cizallamientos, ayudando de esta manera a incrementar la permeabilidad efectiva del rígido (van der Baan et al., 2013). Esta observación es importante para prever cómo serán los tensores momento a lo largo de la nube de eventos microsísmicos resultantes. Mecanismos de tipo "aperturas" son esperables cerca de las infiltraciones, pero los eventos tipo "doble-cupla" dominan el resto de la región.

La simulación de datos se realiza utilizando la ecuación (B.3). Para el caso en que se quiera simular datos generados por una fuente de tipo "doble-cupla", el tensor momento sísmico toma la forma

$$
M_{j k}=M_{0}\left(l_{j} n_{k}+l_{k} n_{j}\right),
$$

donde $n_{i}$ y $l_{i}$ son las componentes del vector normal al plano de falla y la dirección de deslizamiento respectivamente. Si se modela a la fuente como un desplazamiento en el plano $(x, z)$ en la dirección negativa de $x, n=(0,1,0)$ y $l=(-1,0,0)$. Para la componente temporal se ha supuesto que la señal que se propagó fue una ondícula de Ricker con una frecuencia pico determinada (en los ejemplos de más abajo utilizamos 

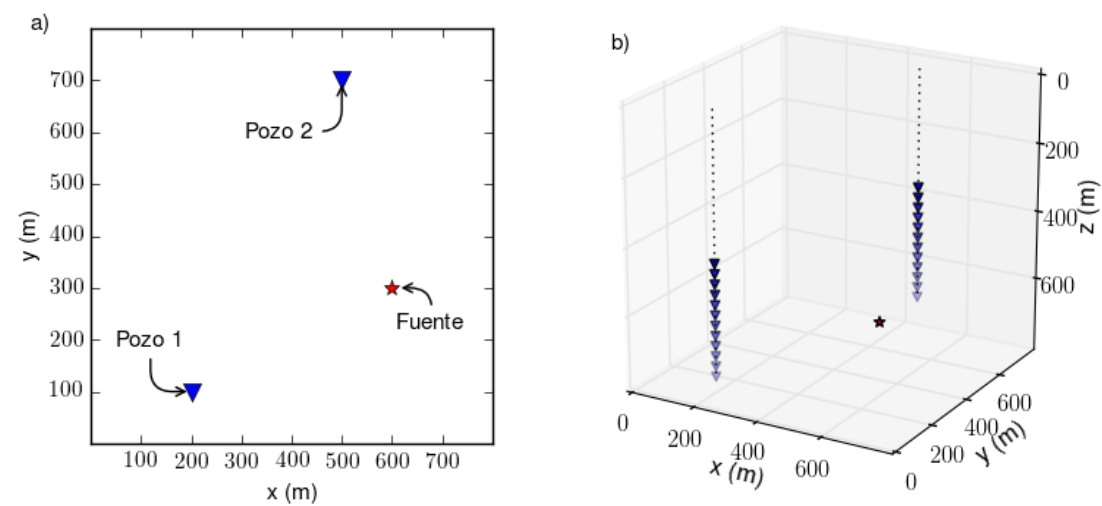

Figura B.2. Geometría de adquisición para el modelo de dos pozos de monitoreo. (a) Vista en planta. (b) Vista en 3D.

un frecuencia pico de $100 \mathrm{~Hz}$ ), o lo que es lo mismo, que la fuente $s(t)$ se comportó como la primitiva de la ondícula de Ricker. Esta última tiene la forma:

$$
r(t)=\left(1-2\left(\pi f_{0} t\right)^{2}\right) e^{-\left(\pi f_{0} t\right)^{2}} .
$$

De esta forma, la señal que esperamos observar en los registros es una ondícula de fase cero, en cuyo máximo en valor absoluto se encuentra el tiempo de arribo de la fase correspondiente. Finalmente se agrega a los datos resultantes ruido obtenido a partir de un generador de números pseudoaleatorios de distribución normal, cuyo ancho de banda es posteriormente limitado a la banda de frecuencias esperable en un registro real.

Como ejemplo, se generaron registros para una situación en la que se tiene dos pozos de monitoreo y una dada fuente, considerando una relación señal-ruido igual a 3 (calculada como el cociente entre las máximas amplitudes de la señal y el ruido), que pueden verse en la Figura B.3. Se consideraron sendos arreglos de 8 receptores tricomponentes con una separación de $30 \mathrm{~m}$. El primero de ellos se encuentra a una profundidad de $350 \mathrm{~m}$ y el último a $560 \mathrm{~m}$. Esta geometría se esquematiza en la Figura B.2.

En la Figura B.3 las trazas 1 a 8 corresponden a la componente $x$ de los receptores, las trazas 9 a 16 a la componente $y$ y las trazas 17 a 24 a la componente $z$. Los registros contienen un total de 350 muestras. El intervalo de muestreo es de $1 \mathrm{~ms}$, por lo que se tiene un tiempo de registración de $350 \mathrm{~ms}$. En ellos se ve claramente que las señales recibidas tienen el aspecto de ondículas de fase cero. Es posible observar, además, que las ondas P y S no siempre son simultáneamente visibles en todas las componentes del arreglo. Esto se debe a las características del patrón de radiación de la fuente simulada, que depende del mecanismo focal. Adicionalmente, aún cuando las señales son visibles en una componente, pueden no serlo en algunas de sus trazas, al estar enmascaradas por el ruido. 

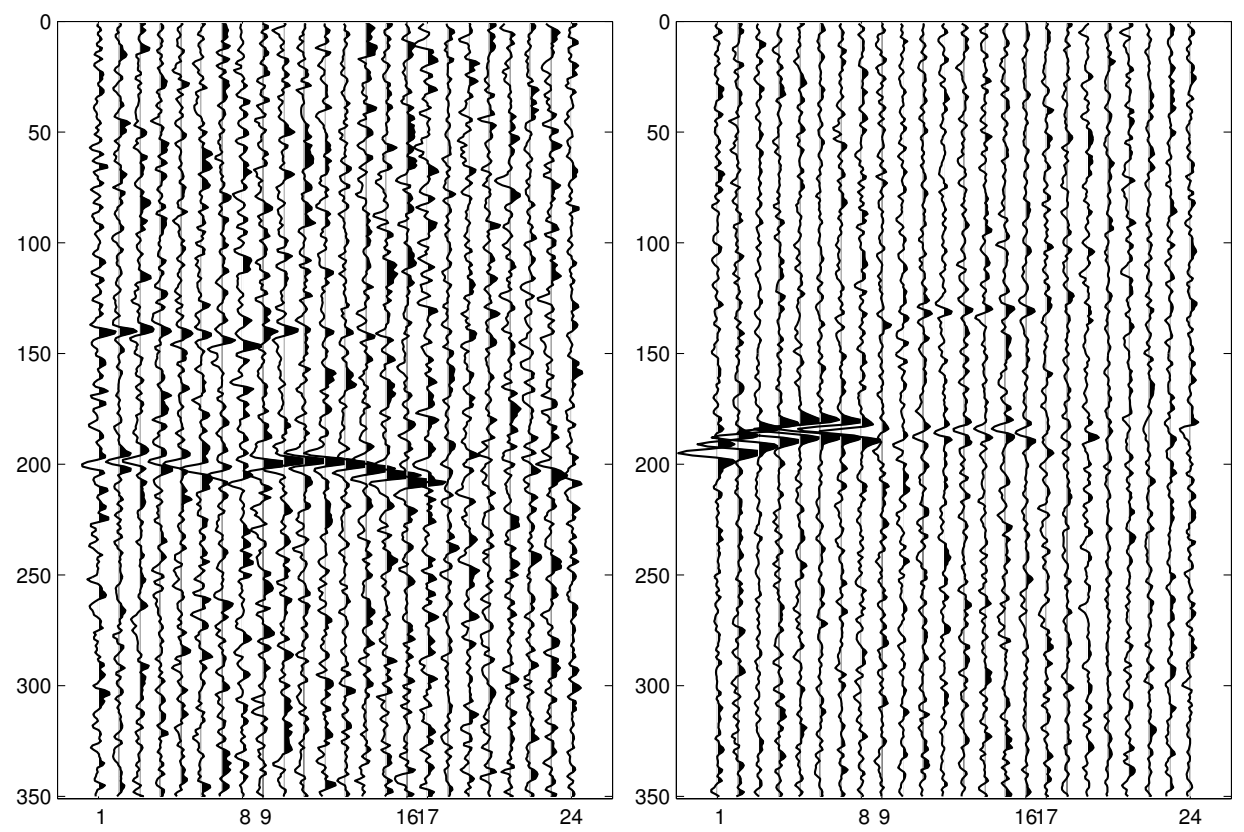

Figura B.3. Registros sintéticos para ambos pozos de monitoreo con $S N R=3$. Las trazas 1 a 8 corresponden a la componente $x, 9$ a 16 a la componente $y$ y 17 a 24 a la componente $z$ del arreglo de receptores. 


\section{Bibliografía}

Abercrombie, R. E., 1995, Earthquake source scaling relationships from -1 to $5 m_{l}$ using seismograms recorded at 2.5-km depth: Journal of Geophysical Research, 100, 24015-24036.

Aki, K., y P. Richards, 2002, Quantitative seismology, 2nd ed.: University Science Books.

Akram, J., y D. W. Eaton, 2016, A review and appraisal of arrival-time picking methods for downhole microseismic data: Geophysics, 81, KS71-KS91.

Alonso, M., A. Civaroli, I. Zabalegui, A. González, y A. Giusiano, 2017, Catálogo de reservorios tight y de baja permeabilidad en la provincia del Neuquén: Technical report, Petrotecnia.

Anderson, P., F. Duennebier, y R. Cessaro, 1987, Ocean borehole horizontal seismic sensor orientation determined from explosive charges: Journal of Geophysical Research, 92, 3573-3579.

Aster, R. C., B. Barchers, y C. H. Thurber, 2005, Parameter estimation and inverse problems: Elsevier Academic Press.

Backus, G. E., 1962, Long-wave elastic anisotropy produced by horizontal layering: Journal of Geophysical Research, 67, 4427-4440.

Baig, A., y T. Urbancic, 2010, Microseismic moment tensors: A path to understanding frac growth: The Leading Edge, 29, 320-324.

Baker, T., R. Granat, y R. Clayton, 2005, Real-time earthquake location using Kirchhoff reconstruction: Bulletin of the Seismological Society of America, 95, 699-707.

Bardainne, T., y E. Gaucher, 2010, Constrained tomography of realistic velocity models in microseismic monitoring using calibration shots: Geophysical Prospecting, 58, $739-753$.

Becquey, M., y M. Dubesset, 1990, Three-component sonde orientation in a deviated well: Geophysics, 55, 1386-1388.

Bentley, R. W., 2002, Global oil \& gas depletion: an overview: Energy Policy, 30, 189-205.

Bercovich, A., y A. Rebossio, 2015, Vaca Muerta: Planeta.

Bjørlykke, K., 2010, Petroleum Geoscience, From Sedimentary Environments to Rock Physics: Springer.

Boatwright, J., 1980, A spectral theory for circular seismic sources: simple estimates of source dimension, dynamic stress drop and radiated energy: Bulletin of the Seismological Society of America, 70, 1-27.

Boëda, E., S. Bonilauri, J. Connan, D. Jarvie, N. Mercier, M. Tobey, H. Valladas, y H. al Sakhel, 2008, New evidence for significant use of bitumen in middle paleolithic technical systems at Umm el Tlel (Syria) around 70.000 bp: Paléorient, 34, 67-83. 
Boore, D. M., y J. Boatwright, 1984, Average body-wave radiation coefficients: Bulletin of the Seismological Society of America, 74, 1615-1621.

Brune, J., 1970, Tectonic stress and seismic shear waves from earthquakes: Journal of Geophysical Research, 75, 4997-5009.

Bulant, P., L. Eisner, I. Pšenčík, y J. Le Calvez, 2007, Importance of borehole deviation surveys for monitoring of hydraulic fracturing treatments: Geophysical Prospecting, 55, 891-899.

Chambers, K., J. Kendall, S. Brandsberg-Dahl, y J. Rueda, 2010, Testing the ability of surface arrays to monitor microseismic activity: Geophysical Prospecting, 58, $821-830$.

Chengzao, J., 2017, Breakthrough and significance of unconventional oil and gas to classical petroleum geology theory: Petroleum Exploration and Development, 44, $1-10$.

Chi, S., y X. Tang, 2006, Stoneley-wave speed modeling in general anisotropic formations: Geophysics, 71, F67-F77.

Cipolla, C., S. Maxwell, y M. Mack, 2012, Engineering guide to the application of microseismic interpretations: Presentado en SPE Hydraulic Fracturing Technology Conference, Proceedings, Society of Petroleum Engineers.

Cipolla, C. L., R. E. Lewis, S. C. Maxwell, y M. G. Mack, 2011, Appraising unconventional resource plays: Separating reservoir quality from completion effectiveness: Presentado en International Petroleum Technology Conference, Proceedings, Society of Petroleum Engineers.

Clerc, M., 2006, Particle swarm optimization: ISTE Ltd.

Corona, W. W., y G. Mavko, 2008, en Predicting Clay Content and Porosity from Gamma-ray and Conductivity Logs: Society of Exploration Geophysicists, 425-433.

Daniel, G., F. Hubans, y A. Rosca, 2013, Estimating magnitude of microseismic events with unknown focal mechanism: Presentado en EAGE 4th Passive Seismic Workshop, Extended Abstracts.

De Meersman, K., J. Kendall, y M. van der Baan, 2009, The 1998 Valhall microseismic data set: An integrated study of relocated sources, seismic multiplets, and s-wave splitting: Geophysics, 74, B183-B195.

DiSiena, J. P., J. E. Gaiser, y D. Corrigan, 1984, Horizontal components and shear wave analysis of three-component VSP data, en Vertical Seismic Profiling, Part B: Advanced concepts: Geophysical Press, 177-235.

Downey, M., 2009, Oil 101: Wooden Table Press LLC.

Drew, J., R. White, F. Tilmann, y J. Tarasewicz, 2013, Coalescence microseismic mapping: Geophysical Journal International, 195, 1773-1785.

Duncan, P. M., y L. Eisner, 2010, Reservoir characterization using surface microseismic monitoring: Geophysics, 75, A139-A146.

Dyer, B., U. Schanz, F. Ladner, M. Häring, y T. Spillman, 2008, Microseismic imaging of a geothermal reservoir stimulation: The Leading Edge, 27, 856-869.

Eaton, D. W., y F. Forouhideh, 2011, Solid angles and the impact of receiver-array geometry on microseismic moment-tensor inversion: Geophysics, 76, WC77-WC85.

EIA, 2013, Technically Recoverable Shale Oil and Shale Gas Resources: An Assessment of 137 Shale Formations in 41 Countries Outside the United States: Technical report, U.S. Energy Information Administration.

— , 2017, International Energy Outlook: Technical report, U.S. Energy Information Administration. 
Eisner, L., P. M. Duncan, W. M. Heigl, y W. R. Keller, 2009a, Uncertainties in passive seismic monitoring: The Leading Edge, 28, 648-655.

Eisner, L., T. Fischer, y J. T. Rutledge, 2009b, Determination of s-wave slowness from a linear array of borehole receivers: Geophysical Journal International, 176, 31-39.

Eisner, L., B. J. Hulsey, P. Duncan, D. Jurick, H. Werner, y W. Keller, 2010, Comparison of surface and borehole locations of induced seismicity: Geophysical Prospecting, 58, 809-820.

Ekström, G., y R. W. Busby, 2008, Measurements of seismometers orientation at USArray transportable array and Backbone stations: Seismological Research Letters, 79, 554-561.

Erwemi, A., J. Walsh, L. Bennett, C. Woerpel, y D. Purcell, 2010, Anisotropic velocity modeling for microseismic processing: Part 3-borehole sonic calibration case study: 80st Annual International Meeting, Expanded Abstracts, Society of Exploration Geophysicists, 508-512.

Eyre, T. S., y M. van der Baan, 2015, Overview of moment-tensor invertion of microseismic events: The Leading Edge, 34, 882-888.

Fairhurst, C., 2016, Fractures and Fracturing: Hydraulic Fracturing in Jointed Rock, en Unconventional Oil and Gas Resources Handbook: Evaluation and Development: Elsevier.

Fernandez-Concheso M., J. E., 2015, Characterizing an unconventional reservoir with conventional seismic data: a case study using seismic inversion for the Vaca Muerta Formation, Neuquén basin, Argentina: Master's thesis, Colorado School of Mines.

Gadano, N., 2006, Historia del petróleo en la argentina: Edhasa.

Gajewski, D., K. Sommer, C. Vanelle, y R. Patzig, 2009, Influence of models on seismic-event localization: Geophysics, 74, WB55-WB61.

Gajewski, D., y E. Tessmer, 2005, Reverse modelling for seismic event characterization: Geophysical Journal International, 163, 276-284.

Grechka, V., y W. M. Heigl, 2017, Microseismic monitoring: Society of Exploration Geophysicists. Geophysical Reference Series, No. 22.

Grechka, V., Z. Li, B. Howell, y V. Vavryčuk, 2017, Single-well moment tensor inversion of tensile microseismic events: 87th Annual International Meeting, Expanded Abstracts, Society of Exploration Geophysicists, 2746-2751.

Greenhalgh, S. A., y L. M. Mason, 1995, Orientation of a downhole triaxial geophone: Geophysics, 60, 1234-1237.

Grigoli, F., S. Cesca, T. Dahm, y L. Krieger, 2012, A complex linear least-squares method to derive relative and absolute orientations of seismic sensors: Geophysical Journal International, 188, 1243-1254.

Gulrajani, S., y K. Nolte, 2000, Fracture Evaluation Using Pressure Diagnostics, en Reservoir Stimulation, 3rd ed.: Wiley.

Han, L., 2010, Microseismic monitoring and hypocenter location: Master's thesis, University of Calgary.

Hanks, T. C., y H. Kanamori, 1979, A moment magnitude scale: Journal of Geophysical Research, 84, 2348-2350.

Häring, M. O., U. Schanz, F. Ladner, y B. Dyer, 2008, Characterisation of the basel 1 enhanced geothermal system: Geothermics, 37, 469-495.

Holditch, S. A., 2013, Unconventional oil and gas resource development - let's do it right: Journal of Unconventional Oil and Gas Resources, 1-2, 2-8. 
Holley, E., U. Zimmer, M. Mayerhofer, y E. Samson, 2010, Integrated Analysis Combining Microseismic Mapping and Fiber-Optic Distributed Temperature Sensing (DTS): Presentado en Canadian Unconventional Resources \& International Petroleum Conference, Proceedings, Society of Petroleum Engineers.

Hongjun, W., M. Feng, T. Xiaoguang, L. Zuodong, Z. Xinshun, W. Zhenzhen, L. Denghua, W. Bo, X. Yinfu, y Y. Liuyan, 2016, Assessment of global unconventional oil and gas resources: Petroleum Exploration and Development.

Huo, Y., W. Zhang, y J. ZhangJoël, 2016, Improve sensor orientation using both drop-ball and microseismic events: SEG Technical Program Expanded Abstracts, Expanded Abstracts, Society of Exploration Geophysicists, 2642-2646.

Ingber, L., 1989, Very fast simulated re-annealing: Journal of Mathematical Computation and Modelling, 12, 967-973.

Jiang, Z., W. Zhang, C. Liang, Y. Wang, H. Liu, y X. Chen, 2016, Basic characteristics and evaluation of shale oil reservoirs: Petroleum Research, 2, 149-163.

Jiao, W., M. Davidson, A. Sena, B. Bankhead, Y. Xia, S. Sil, y C. Zhou, 2014, The matter of size: On the moment magnitude of microseismic events: Geophysics, 79, KS31-KS41.

Jones, G., J.-M. Kendall, y D. Raymer, 2014, Locating microseismic events using borehole data: Geophysical Prospecting, 62, 34-49.

Jones, G., D. Raymer, K. Chambers, y J.-M. Kendall, 2010, Improved microseismic event location by inclusion of a priori dip particle motion: a case study from ekofisk: Geophysical Prospecting, 58, 727-737.

Jupe, A., A. Green, y T. Wallroth, 1992, Induced microseismicity and reservoir growth at the Fjällbacka Hot Dry Rocks Project, Sweden: International Journal of Rock Mechanics and Mining Sciences \& Geomechanics Abstracts.

Jurkevics, A., 1988, Polarization analysis of three-component array data: Bulletin of the Seismological Society of America, 78, 1725-1743.

Kendall, M., S. Maxwell, G. Foulger, L. Eisner, y Z. Lawrence, 2011, Special section. Microseismicity: Beyond dots in a box - Introduction: Geophysics, 76, WC1-WC3.

Kennedy, J., y R. Eberhart, 1995, Particle swarm optimization: Journal of Mathematical Computation and Modelling, IV, 1942-1948.

Kidney, R. L., U. Zimmer, y N. Boroumand, 2010, Impact of distance-dependent location dispersion error on interpretation of microseismic event distribution: The Leading Edge, 29, 284-289.

Krieger, L., y F. Grigoli, 2015, Optimal reorientation of geophysical sensors: A quaternion-based analytical solution: Geophysics, 80, F19-F30.

Lagos, S. R., J. I. Sabbione, y D. R. Velis, 2014, Very fast simulated annealing and particle swarm optimization for microseismic event location: 84th Annual International Meeting, Expanded Abstracts, Society of Exploration Geophysicists, 2188-2192.

Lagos, S. R., y D. R. Velis, 2014, Aplicaciones del análisis de polaridad de ondas a la localización de eventos microsísmicos: Presentado en XXVII Reunión Científica de la Asociación Argentina de Geofísicos y Geodestas.

— , 2017a, Estimación de magnitudes momento de eventos microsísmicos en el dominio de la frecuencia: Presentado en IPSES'17-XXVIII Reunión Científica de la Asociación Argentina de Geofísicos y Geodestas.

- - 2017b, Microseismic moment magnitude estimation: an optimization problem in the frequency domain: Presentado en XVII Reunión de Trabajo en Procesamiento de la Información y Control, RPIC'17. 
, 2018, Microseismic event location using optimization algorithms: An integrated and automated workflow: Journal of Applied Geophysics, 149, 18-24.

- , 2019, A simple energy-based strategy for sensor orientation in borehole microseismic monitoring: The Journal of Geophysics and Engineering (en prensa, doi: 10.1093/jge/gxy007).

Le Calvez, J., R. Klem, L. Bennet, A. Erwemi, M. Craven, y J. Palacio, 2007, RealTime Microseismic Monitoring of Hydraulic Fracture Treatment: A Tool To Improve Completion and Reservoir Management: Presentado en SPE Hydraulic Fracturing Technology Conference, Proceedings, Society of Petroleum Engineers.

Le Calvez, J., M. Williams, y J. Couch, 2013, Tool and velocity model calibration for downhole-based hydraulic fracture monitoring of induced microseismicity: SEG Technical Program Expanded Abstracts, Society of Exploration Geophysicists, 21932195.

Leaney, S., C. Chapman, y X. Yu, 2014, Anisotropic moment tensor inversion, decomposition and visualization: SEG Technical Program Expanded Abstracts 2014, 2250-2255.

Leaney, W. S., 2014, Microseismic source inversion in anisotropic media: PhD thesis, The University of British Columbia.

Li, X., y J. Yuan, 1999, Geophone orientation and coupling in three-component sea-floor data: a case study: Geophysical Prospecting, 47, 995-1013.

Liang, F., M. Sayed, G. Al-Muntasheri, F. F. Chang, y L. Li, 2015, A comprehensive review on proppant technologies: Petroleum, 1-14.

Madariaga, R., 1976, Dynamics of an expanding circular fault: Bulletin of the Seismological Society of America, 66, 639-666.

Marsden, J., y A. Tromba, 1991, Cálculo vectorial, tercera edición: Addison-Wesley Iberoamericana, S.A.

Mata, D., W. Zhou, Y. Zee Maa, y V. Gonzales, 2016, Hydraulic Fracture Treatment, Optimization, and Production Modeling, en Unconventional Oil and Gas Resources Handbook: Evaluation and Development: Elsevier.

Maugeri, L., 2006, The age of oil: The Mithology, History and Future of the World's Most Controversial Resource: Praeger.

Maxwell, S., 2009, Microseismic location uncertainty: CSEG Recorder, 177-188.

,- 2014 , Microseismic imaging of hydraulic fracturing: Improved engineering of unconventional shale reservoirs: Society of Exploration Geophysicists. Distinguished Instructor Series No. 17.

Maxwell, S., L. Bennett, M. Jones, y J. Walsh, 2010a, 420, en Anisotropic velocity modeling for microseismic processing: Part 1-Impact of velocity model uncertainty: SEG, 2130-2134.

Maxwell, S. C., J. Rutledge, R. J. R, y M. Fehler, 2010b, Petroleum reservoir characterization using downhole microseismic monitoring: Geophysics, 75, A129-A137.

Maxwell, S. C., C. Waltman, N. Warpinski, M. Mayerhofer, y N. Boroumand, 2009, Imaging seismic deformation induced by hydraulic fracture complexity: SPE Reservoir \& Engineering, 12, 48-52.

Mayerhofer, M., E. P. Lolon, J. E. Youngblood, y J. R. Heinze, 2006, Integration of Microseismic Fracture Mapping Results With Numerical Fracture Network Production Modeling in the Barnett Shale: Presentado en SPE Annual Technical Conference and Exhibition, Proceedings, Society of Petroleum Engineers. 
Mizuno, T., S. Leaney, y G. Michaud, 2010, Anisotropic velocity model inversion for imaging the microseismic cloud: Presentado en 72nd EAGE Conference and Exhibition, 72nd EAGE Conference and Exhibition incorporating SPE EUROPEC 2010, EAGE.

Nadri, D., S. Joël, A. Bóna, y D. Dewhurst, 2012, Estimation of the anisotropy parameters of transversely isotropic shales with a tilted symmetry axis: Geophysical Journal International, 190, 1197-1203.

Nippress, S., A. Rietbrock, y A. Heath, 2010, Optimized automatic pickers: application to the ANCORP data set: Geophysical Journal International, 181, 911-925.

Pérez, D. O., S. R. Lagos, D. R. Velis, y J. C. Soldo, 2016, Inversion of seismic anisotropic parameters using very fast simulated annealing with application to microseismic event location: Mecánica Computacional, 34, 3351-3367.

— 2017 , Estimation of anisotropic velocity models from microseismic calibration shots: Presentado en IPSES'17-XXVIII Reunión Científica de la Asociación Argentina de Geofísicos y Geodestas.

—_ 2018, Calibrating anisotropic-velocity models using VFSA: Application to Vaca Muerta Formation: SEG Technical Program Expanded Abstracts, 3042-3046.

— , 2019, Calibrating anisotropic velocity models for Vaca Muerta Formation: Journal of Seismic Exploration. (Trabajo aceptado, publicación estimada para mediados de 2019).

Poli, R., J. Kennedy, y T. Blackwell, 2007, Particle swarm optimization: an overview: Swarm Intelligence, 1, 33-57.

Press, W. H., S. A. Teukolsky, W. T. Vetterling, y B. P. Flannery, 1996, Numerical recipes in Fortran 77 and Fortran 90: Cambridge University Press.

Rentsch, S., S. Buske, S. Lüth, y S. Shapiro, 2007, Fast location of seismicity: A migration-type approach with application to hydraulic-fracturing data: Geophysics, 72, S33-S40.

Rider, M., y M. Kennedy, 2011, The geological interpretation of well logs: Rider-French.

Rousseeuw, P. J., y C. Croux, 1993, Alternatives to the median absolute deviation: Journal of the American Statistical Association, 88, 1273-1283.

Rutledge, J. T., y W. S. Phillips, 2003, Hydraulic stimulation of natural fractures as revealed by induced microearthquakes, Carthage Cotton Valley gas field, east Texas: Geophysics, 68, 441-452.

Sabbione, J. I., 2012, Algoritmos matemáticos y computacionales para la detección automática de señales sísmicas: PhD thesis, Facultad de Ciencias Astronómicas y Geofísicas, Universidad Nacional de La Plata, Argentina.

Sabbione, J. I., M. D. Sacchi, y D. R. Velis, 2015, Radon transform-based microseismic event detection and signal-to-noise ratio enhancement: Journal of Applied Geophysics, 113, 51-63.

Sabbione, J. I., y D. R. Velis, 2012, An automatic method for microseismic events detection based on earthquake phase pickers: 82nd Annual International Meeting, Expanded Abstracts, Society of Exploration Geophysicists, 1-5.

- 2 2013, A robust method for microseismic event detection based on automatic phase pickers: Journal of Applied Geophysics, 99, 42-50.

Sayers, C., 2005, Seismic anisotropy of shales: Geophysical Prospecting, 53, 667-676.

Secretaría de Energía, 2018, Argentina Energy Plan -Guidelines-: IAPG Houston. (https://www.argentina.gob.ar/sites/default/files/plan_energetico.pdf).

Selley, R. C., 1998, Elements of Petroleum Geology, Second Edition: Academic Press. 
Sen, M. K., y P. L. Stoffa, 2013, Global optimization methods in geophysical inversion, second edition: Cambridge University Press.

Shaw, R., y S. Srivasta, 2007, Particle swarm optimization: A new tool to invert geophysical data.: Geophysics, 72, 75-83.

Shearer, P. M., 2009, Introduction to Seismology: Cambridge University Press.

Shemeta, J., y P. Anderson, 2010, It's a matter of size: Magnitude and moment estimates for microseismic data: The Leading Edge, 29, 296-302.

Sheriff, R., 2002, Encyclopedic dictionary of applied geophysics, 4rd. ed.: Society of Exploration Geophysicists. Geophysical Reference Series No. 13.

Sheriff, R., y L. Geldart, 1995, Exploration seismology, 2nd. ed.: Cambridge University Press.

Sherlock, D., y K. Dodds, 2003, Geophysical monitoring of subsurface $\mathrm{CO}_{2}$ : Presentado en ASEG 16th Geophysical Conference and Exhibition, Extended Abstracts.

Shi, Y., y R. Eberhart, 1998, A modified particle swarm optimizer: Presentado en Proceedings of 1998 IEEE International Conference on Evolutionary Computation.

Simpson, D. W., 1976, Seismicity changes associated with reservoir loading: Engineering Geology, 10, 123-150.

Sondergeld, C. H., K. E. Newsham, J. T. Comisky, y M. C. Rice, 2010, Petrophysical considerations in evaluating and producing shale gas resources: Presentado en SPE Unconventional Gas Conference, Proceedings, Society of Petroleum Engineers.

Speight, J. G., 2016, Handbook of Hidraulic Fracturing: Wiley.

Stachnik, J., A. Sheehan, D. Zietlow, Z. Yang, J. Collins, y A. Ferris, 2012, Determination of New Zealand ocean bottom seismometer orientation via Rayleigh-wave polarization: Seismological Research Letters, 83, 704-713.

Stork, A., J. Verdon, y J. Kendall, 2014, The robustness of seismic moment and magnitudes estimated using spectral analysis: Geophysical Prospecting, 62, 862-878.

Stow, S. H., y C. Haase, 1986, Subsurface Disposal of Liquid Low-Level Radioactive Wastes at Oak Ridge, Tennessee: Groundwater Monitoring \& Remediation, 6, 49-52.

Szu, H., y R. Hartley, 1987, Fast simulated annealing: Phys. Lett. A., 122, 157-162.

Tarantola, A., 2005, Inverse problem theory and methods for model parameter estimation: SIAM.

Thomsen, L., 1986, Weak elastic anisotropy: Geophysics, 51, 1954-1966.

Udías, A., 1999, Principles of seismology: Cambridge University Press.

van der Baan, M., D. Eaton, y M. Dusseault, 2013, Microseismic monitoring developments in hydraulic fracture stimulation, en Effective and Sustainable Hydraulic Fracturing: Intech.

Van Dok, R. R., N. Tamimi, B. N. Fuller, y K. D. Mahrer, 2016, Do you truly know your geophone's orientation and should you care?: SEG Technical Program Expanded Abstracts, Society of Exploration Geophysicists, 2647-2651.

Velis, D. R., 1998, Application of simulated annealing to some seismic problems: PhD thesis, University of British Columbia, Vancouver, Canada.

— 2007, Statistical segmentation of geophysical log data: Mathematical Geology, 39, 409-417.

Velis, D. R., J. I. Sabbione, y M. D. Sacchi, 2015, Fast and automatic microseismic phasearrival detection and denoising by pattern recognition and reduced-rank filtering: Geophysics, 80, WC25-WC38.

Vera Rodriguez, I., D. Bonar, y M. D. Sacchi, 2012, Microseismic data denoising using a 3C group sparsity constrained time-frequency transform: Geophysics, 77, V21-V29. 
Warpinski, N., 2013, Understanding Hydraulic Fracture Growth, Effectiveness, and Safety Through Microseismic Monitoring, en Effective and Sustainable Hydraulic Fracturing: Intech.

Warpinski, N. R., M. J. Mayerhofer, E. J. Davis, y E. H. Holley, 2014, Integrating Fracture Diagnostics for Improved Microseismic Interpretation and Stimulation Modeling: Presentado en Unconventional Resources Technology Conference, Proceedings, Society of Petroleum Engineers.

Warpinski, N. R., M. J. Mayerhofer, M. C. Vincent, C. L. Cipolla, y E. P. Lolon, 2009, Stimulating Unconventional Reservoirs: Maximizing Network Growth While Optimizing Fracture Conductivity: Journal of Canadian Petroleum Technology, 48, $39-51$.

Waters, G., B. Dean, R. Downie, K. Kerrihard, L. Austbo, y B. McPherson, 2009, Simultaneous Hydraulic Fracturing of Adjacent Horizontal Wells in the Woodford Shale: Presentado en SPE Hydraulic Fracturing Technology Conference, Proceedings, Society of Petroleum Engineers.

Willis, M., A. Tutuncu, y T. Bratton, 2014, A novel approach to upscaling elastic moduli in unconventional reservoirs: Presentado en 48th US Rock Mechanics and Geomechanics Symposium, Proceedings, American Rock Mechanics Association.

Wu, Y., X. Zhao, Z. R.J., H. Wu, V. Vaidya, M. Yang, y J. Qin, 2016, The Application of Microseismic Monitoring in Unconventional Reservoirs, en Unconventional Oil and Gas Resources Handbook: Evaluation and Development: Elsevier.

Yue, T., y C. Xiao-fei, 2005, A rapid and accurate two-point ray tracing method in horizontally layered velocity model: Acta Seismologica Sinica, 18, 154-161.

Zee Maa, Y., 2016, Unconventional resources from exploration to production, en Unconventional Oil and Gas Resources Handbook: Evaluation and Development: Elsevier.

Zeng, X., y G. A. McMechan, 2006, Two methods for determining geophone orientations from VSP data: Geophysics, 71, V87-V97.

Zhou, J., Y. Zeng, T. Jian, B. Zhang, y X. Zhang, 2015, Tiltmeter Hydraulic Fracturing Mapping on a Cluster of Horizontal Wells in a Tight Gas Reservoir: Presentado en SPE/IATMI Asia Pacific Oil \& Gas Conference and Exhibition, Proceedings, Society of Petroleum Engineers.

Zhou, R., L. Huang, J. Rutledge, H. Denli, y H. Zhang, 2009, Double-difference tomography of microseismic data for monitoring carbon sequestration: SEG International Exposition and Annual Meeting, Expanded Abstracts, Society of Exploration Geophysicists, 4064-4068. 